\title{
INDUSTRIAL RISK - AN INDIAN PERSPECTIVE
}

Anandita Sengupta 
Graduation committee:

Chairman/Secretary:

prof.dr.ir. A. Veldkamp University of Twente

Promotor:

Prof.dr.ir. M.F.A.M. van Maarseveen University of Twente

Co-promotors:

Dr. C.J. van Westen University of Twente

Dr. J. Flacke University of Twente

Members:

Prof.dr. B.J.M. Ale

Delft University

Dr. M.D. Christou

Joint Research Centre, EC

Prof.dr. S. Roy

IIT, Bombay, India

Prof.dr. Y. Georgiadou

University of Twente

Prof.dr. J.A. Zevenbergen

University of Twente

ITC dissertation number 297

ITC, P.O. Box 6, 7500 AA Enschede, The Netherlands

ISBN 978-90-365-4277-7

DOI $10.3990 / 9789036542777$

Cover designed by Job Duim

Printed by ITC Printing Department

Copyright (C) 2016 by Anandita Sengupta

TE FACULTY OF GEO-INFORMATION SCIENCE AND EARTH OBSERVATION 


\title{
INDUSTRIAL RISK - AN INDIAN PERSPECTIVE
}

\author{
DISSERTATION
}

to obtain

the degree of doctor at the University of Twente, on the authority of the rector magnificus, prof.dr. T.T.M. Palstra,

on account of the decision of the graduation committee, to be publicly defended

on Thursday 15 December 2016 at 14.45 hrs

by

Anandita Sengupta

born on 30 October 1978

in Kolkata, India 
This thesis is approved by

Prof.dr.ir. M.F.A.M. van Maarseveen (promoter)

Dr. C.J. van Westen (co-promoter)

Dr. J. Flacke (co-promoter) 


\section{Acknowledgements}

The long journey has come to its end. Undertaking this PhD has been a truly life-changing experience for me and it would not have been possible to do without the support and guidance that I received from many people. It is not my own success, rather of all you abetted me in 'bits and pieces' to make this journey complete. I am indebted to all of you.

First and foremost, I would like to convey my sincere and heartfelt gratitude to my co-promoter Cees J van Westen, who has been a constant source of support and inspiration throughout my PhD. Cees, I am thankful to you for always believing in me and for your confidence in my scientific ability even as early as during my Masters. You have always been extremely helpful and particularly understanding about receiving last-minute text to read over the past few months. Thank you for your endless support, continuous encouragement and untiring patience. Words are not enough to convey my profound gratitude to Johannes. Without his constructive criticism and technical advice, this thesis would not have been possible. His thoughtful comments and remarks were very useful and helpful in shaping this thesis in its present form. Cees and Johannes, both of you were my pillars of support without which this thesis might even remain as an unfinished story.

I am grateful to Anne van der Veen for his support and inputs at the initial stage of this research. My sincere thanks also to Martin van Maarseveen, who took the responsibility to act as my promoter without any hesitation at the very last stage of this PhD journey. Thank you Martin for your generous support to complete this journey.

A special mention and thanks to Christiaan Lemmen who helped me with the conceptualization of new techniques, co-authored my papers and took all pain to present our papers at the international forum. Thanks to him for introducing me and my work to his colleagues at Kadaster International, Apeldoorn.

I am extremely thankful to many people at ITC (past and present) who helped me in my studies in one way or the other. I realized that the whole support network behind every researcher is much bigger than one can assume. I am thankful to all faculty members of the PGM and ESA departments. Special thanks to Petra Weber, for helping me with every little problem I have faced since my first day at ITC till the day of my graduation. I am also grateful to the whole team of ITC for the institutional support that I received over these years: especially Paul van Dijk, Loes Colenbrander, John Horn, Marion Pierik, Theresa van den Boogaard, Marie Chantal and Bettine Geerdink. My sincere gratitude is also due to all the library staff to get the 
books and papers that I specially requested for. A special thanks to the ITC Helpdesk, and particularly Aiko Mulder and Gerrit Schuurman for solving innumerable computer related issues even when I was not around at ITC.

I am indebted to the European Commission for providing me the opportunity to have a one-year research traineeship at Major Accident Hazardous Bureau (MAHB) under the Institute for the Protection and Security of the Citizen (IPSC), Joint Research Centre, Italy. My deep appreciation goes out to all officials of the MAHB group with whom I had the opportunity to work: Neil Mitchson, Maureen Heraty Wood, Zsuzsanna Gyenes, Lorenzo van Wijk, Sergio Contini, Masimo Binda, Elisabeth Krausmann and Lucianno Fabbri. They provided a friendly and cooperative atmosphere at work and also useful feedback and insightful comments on my work. A note of thanks to Maria Giuliani and Laurence Campe for helping me with all sort of logistic support during my stay at JRC.

I would also like to convey my sincere thanks to Hans Pasman and Ben Ale for being so generous with their valuable time and insights on my papers. I owe my deepest gratitude to Hans for being my link to the Texas Mary Kay O'Connor Process Safety Centre, United States.

A note of gratitude to Sandip Roy associated with Indian Institute of Technology Bombay, India for his valuable advice and guidance at various stages of my research.

I must acknowledge the administrative support I received from the Haldia Development Authority and the BL\&LRO Sutahata and Haldia Development Block without which it was not possible to conduct the field survey for this research and, albeit indirectly, this thesis.

Thanks to Anil Kumar Gupta and Sreeja S. Nair from the National Institute of Disaster Management (NIDM), Govt. of India for providing me the opportunity to present this research at various national-level workshops and seminars as well as to co-author the national-level training module on chemical disaster management.

On a personal note, my debt of gratitude goes to Debanjan Bandyopadhyay who has mentored me for last ten years and stood beside me in every thick and thin of this PhD journey. He is the person who along with teaching me a great deal about science, also contributed significantly towards overall development of my professional skills. His guidance, patience and encouragement throughout these years are instrumental in its completion. Despite of his very busy schedule, he regularly called me up to find out how things are going on at my side. I will definitely miss the phone call I used to 
receive from him at 9.25 AM sharp. A very special thanks also credits for my other mentor Nilanjan Paul for his support whenever I asked for since my MSc days to till the end of this journey.

My heartfelt thanks goes to my dear friends and fellow PhDs who went through hard times together, cheered me on and supported me through some crucial periods of this journey: Sharon, Nynne, Sanaz, Xuanmei, and Fangyuan. Thank you all. Special thanks to my Indian friends of ITC: Divyani, Maitreyi, Priyasmita, Sejal, Yamini, Saibal(da), Gaurav, Rishi, Tanmoy, Paresh and Pankaj. A note of gratitude also for my fellow PhDs: Anahita, Elnaz, Mitra, Razieh, Khamarrul, Thea, Matthew, Riswan, Haydar, Saad and many others. My special thanks also due to all my JRC-friends and colleagues: Anastasia, Angelika, Alexandra, Joana, Marianthi, Patricia, Simone, Serkan, Gianlughi, Carl, Peter and Hugo.

Most important of all I deeply thank my parents, for their unconditional trust, timely encouragement, and patience over these years. Without their attention and self-sacrifice, pursuing my dream would not have been possible. They deserve my utmost respect and sincere gratitude. A special thanks is reserved for my younger brother Avijit, for his silent support to look after my parents whenever I was away from home. I would also like to express my gratitude to my parents-in-law for their unfailing emotional support.

Finally, a very special thanks goes to my husband, Ashit, for his endless love and encouragement, without whom, I would not have found the inspiration and motivation to complete this journey. Ashit, you should know that your support was worth more than I can express on paper. These past years have not been an easy ride for us and we both learned a lot about life and strengthened our determination and commitment towards each other. Hopefully our tough time is over and so looking forward to the next phase of our lives together.

To them I dedicate this thesis! 


\section{Table of Contents}

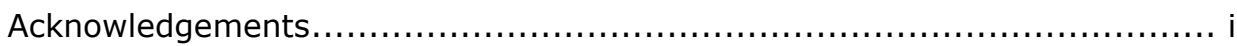

List of abbreviations ............................................................... viii

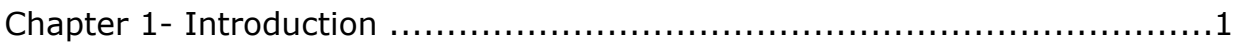

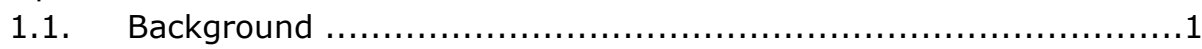

1.1.1. History and development of Bhopal .............................. 1

1.1.2. The aftermath........................................................

1.1.3. Genesis of major accident hazard policy........................... 4

1.2. Research Problem .........................................................

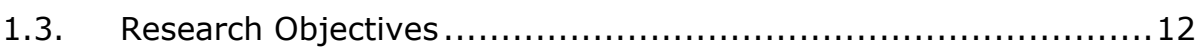

1.4. Research Approach ................................................. 12

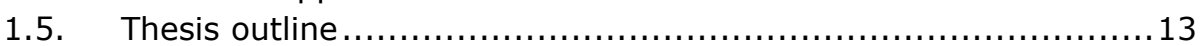

Chapter 2 - Concept of industrial risk management .......................... 15

2.1. Governance of industrial risk ..................................... 15

2.2. Industrial risk management framework ............................. 16

2.3. Process of industrial risk assessment ................................. 19

2.3.1. Hazard (scenario) identification ...................................... 20

2.3.2. Frequency estimation ............................................ 22

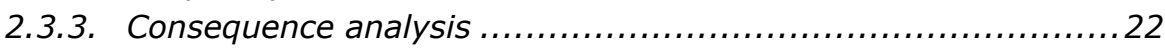

2.3.4. Estimation of Risk.................................................... 24

2.4. Risk-informed Decision Making .......................................... 25

2.4.1. Emergency Preparedness and Response Planning .................25

2.4.2. Land Use Planning .................................................... 26

2.5. Risk Communication....................................................27

Chapter 3 - Industrial risk and land use planning - European experience ....31

3.1. Concept of risk in land use planning ................................... 31

3.2. Relevance of Article 12 of Seveso Directive II ........................ 32

3.3. Review of existing risk assessment approaches used for LUP

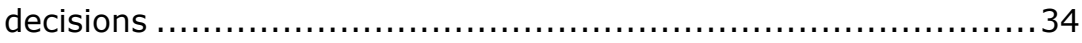

3.3.1. Risk-based or quantitative approach............................ 34

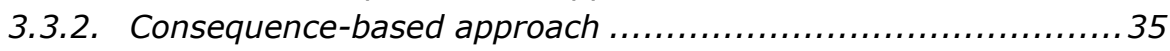

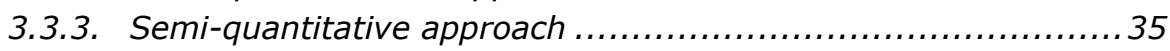

3.3.4. Generic safety distance approach................................ 36

3.4. European practices in implementing Art 12 of Directive II ............36

3.4.1. The Netherlands............................................... 37

3.4.2. United Kingdom ............................................... 38

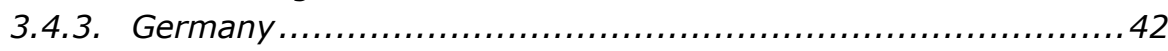

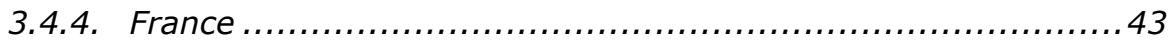

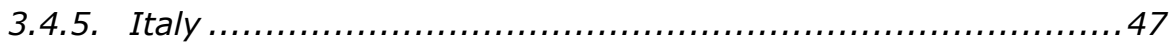

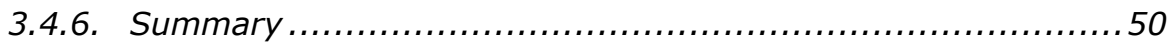

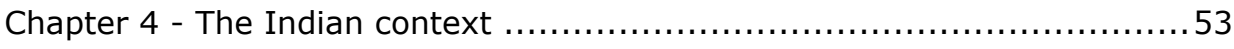

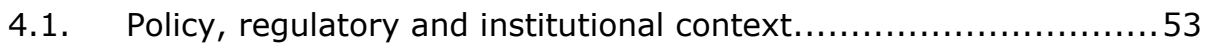

4.1.1. Policy framework ...................................................... 53 


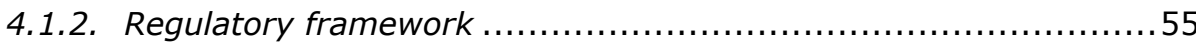

4.1.3. Institutional framework.................................... 59

4.1.4. Summary ..................................................62 62

4.2. Risk assessment procedural context .............................63

4.2.1. Hazard identification .....................................6 63

4.2.2. Scenario selection ...........................................6 63

4.2.3. Accident database ..........................................64 64

4.2.4. Risk analysis................................................ 64

4.2.5. Risk evaluation................................................67 67

4.2.6. Summary ..................................................67 67

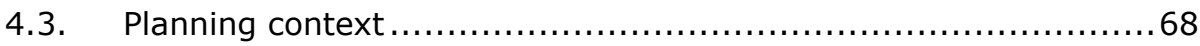

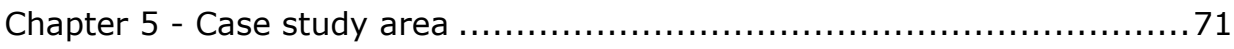

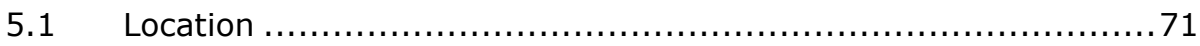

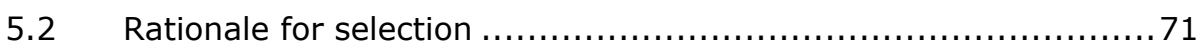

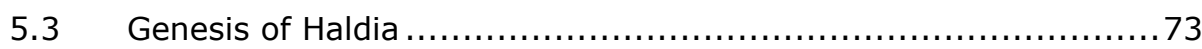

5.4 Administrative structure of Haldia Planning Area.................. 73

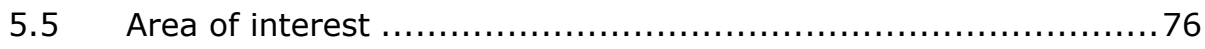

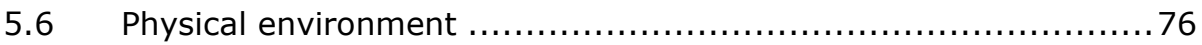

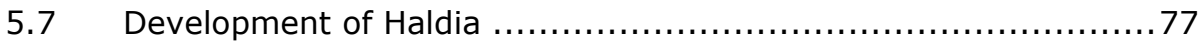

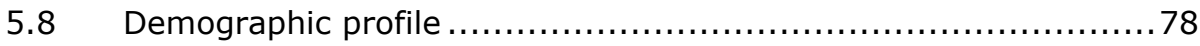

Chapter 6 - Data identification and database preparation $\ldots \ldots \ldots \ldots \ldots \ldots \ldots \ldots 1$

6.1. Hazardous industry and storage-related database $\ldots \ldots \ldots \ldots \ldots \ldots \ldots 1$

6.2. Cadastral-level land use database (map) ......................... 84

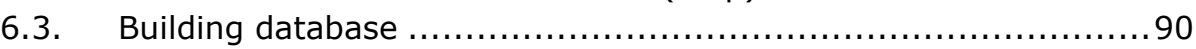

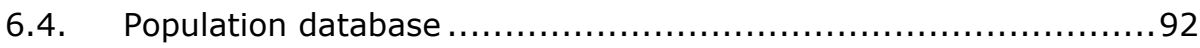

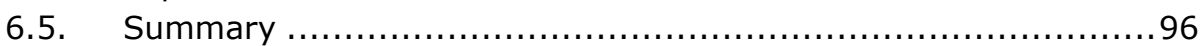

Chapter 7 - Applicability of a simplified QRA-based approach for cumulative

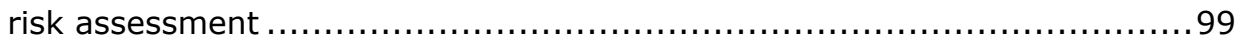

7.1. Introduction .................................................. 99

7.2. Conceptualization .............................................. 100

7.2.1. Scenario selection ......................................... 101

7.2.2. Assigning frequency and probability ............................ 103

7.2.3. Consequence assessment ................................ 104

7.2.4. Risk estimation ............................................. 106

7.3. Cumulative risk maps of Haldia .................................. 107

7.4. Uncertainty analysis ........................................ 109

7.4.1. Scenario Frequency ............................................ 109

7.4.2. Weather condition .......................................... 110

7.4.3. Resolution ............................................... 111

7.5. Discussion ....................................................... 111

Chapter 8- Application of an indicator-based approach for vulnerability

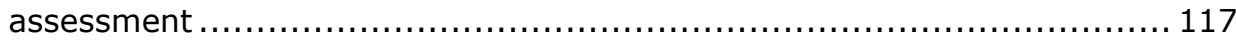

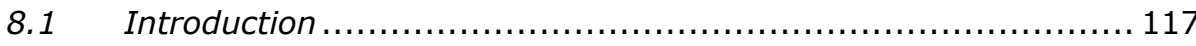

8.2 Conceptualization - Building vulnerability assessment ............ 118 
8.2.1 Identification and selection of building vulnerability indicators 120

8.2.2 Weighting and ranking of indicators .......................... 121

8.2.3 Calculation of effect-specific Relative Vulnerability Index

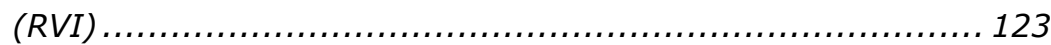

8.3 Building vulnerability assessment of Durgachak area............ 125

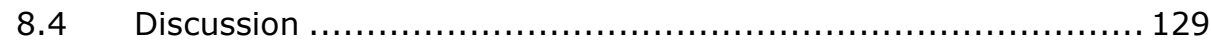

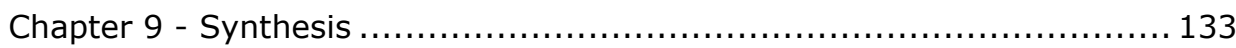

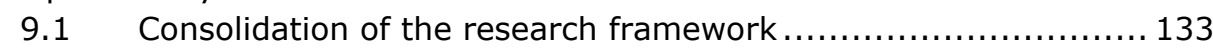

9.2. Setting the context .......................................... 134

9.2.1. Understanding issues pertaining to governance and management of industrial risk in the Indian context............ 134

9.2.2. Rationale to design a methodology for estimating Industrial risk - its use as an indicator for guiding land use planning decisions ................................................ 135

9.3. Identification of the information to estimate risk ................... 136

9.4. Application of a simplified QRA-based approach in the case study area 138

9.5. Application of indicator-based approach for vulnerability assessment in the case study area

9.6. Proposal for a risk-informed land use planning framework....... 139

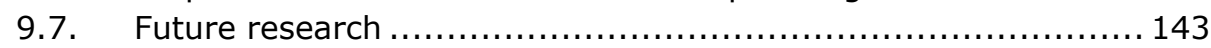

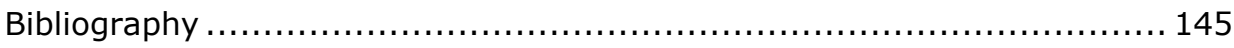

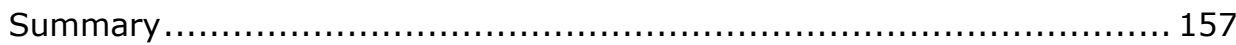

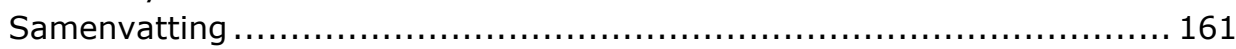

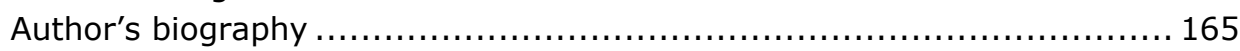

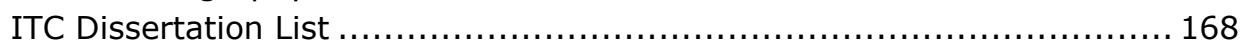




\section{List of abbreviations}

\begin{tabular}{|c|c|}
\hline AIHA & American Industrial Hygiene Association, US \\
\hline ALARA & As Low As Reasonably Achievable \\
\hline ALARP & As Low As Reasonably Practicable \\
\hline ALOHA & Areal Locations Of Hazardous Atmospheres \\
\hline ARAMIS & Accidental Risk Assessment Methodology For IndustrieS \\
\hline BLEVE & Boiling Liquid Expanding Vapour Explosion \\
\hline$C D$ & Community Development (Block) \\
\hline CIMAH & $\begin{array}{l}\text { Control of Industrial Major Accidents Hazard Regulation (1999), } \\
\text { UK }\end{array}$ \\
\hline COMAH & Control of Major Accident Hazards Regulation (2015), UK \\
\hline СРCB & Central Pollution Control Board (Govt. of India) \\
\hline DCDB & Digital Cadastral Database \\
\hline DGFASLI & $\begin{array}{l}\text { Directorate General, Factory Advice Service and Labour } \\
\text { Institutes (India) }\end{array}$ \\
\hline DISH & Directorate of Industrial Safety and Health (India) \\
\hline DLRS & District Land \& Land Reforms \\
\hline DMP & Disaster Management Policy (2006), India \\
\hline DoE & Department of Environment (India) \\
\hline DoLR & Department of Land Records (India) \\
\hline DST & Department of Science and Technology (India) \\
\hline EAC & Environmental Appraisal Committee \\
\hline EIA & Environmental Impact Assessment \\
\hline $\mathrm{EP}$ & Environment (Protection) Act, India \\
\hline EPPRCA & $\begin{array}{l}\text { Emergency Planning, Preparedness and Response to Chemical } \\
\text { Accident Rules (1996), India }\end{array}$ \\
\hline ERDMP & $\begin{array}{l}\text { Emergency Response and Disaster Management Plan Regulations } \\
\text { (2010), India }\end{array}$ \\
\hline ERRIS & Environmental Risk Reporting and Information System \\
\hline EU & European Union \\
\hline EWGLUP & European Working Group on Land Use Planning \\
\hline FRED & Failure Rate and Event Database \\
\hline GCP & Ground Control Point \\
\hline GIS & Geographic Information System \\
\hline GP & Gram Panchayet \\
\hline $\mathrm{GPW}_{3}$ & Gridded Population of the World (version 3) \\
\hline GWR & Geographical Weighted Regression \\
\hline HDA & Haldia Development Authority (local planning authority, Haldia) \\
\hline HSE & Health and Safety Executive (UK) \\
\hline HSM & Hazardous Substances Management \\
\hline HSMD & Hazardous Substance Management Division, MoEFCC (India) \\
\hline HPA & Haldia Planning Area \\
\hline IDLH & Immediately Dangerous for Life and Health \\
\hline
\end{tabular}




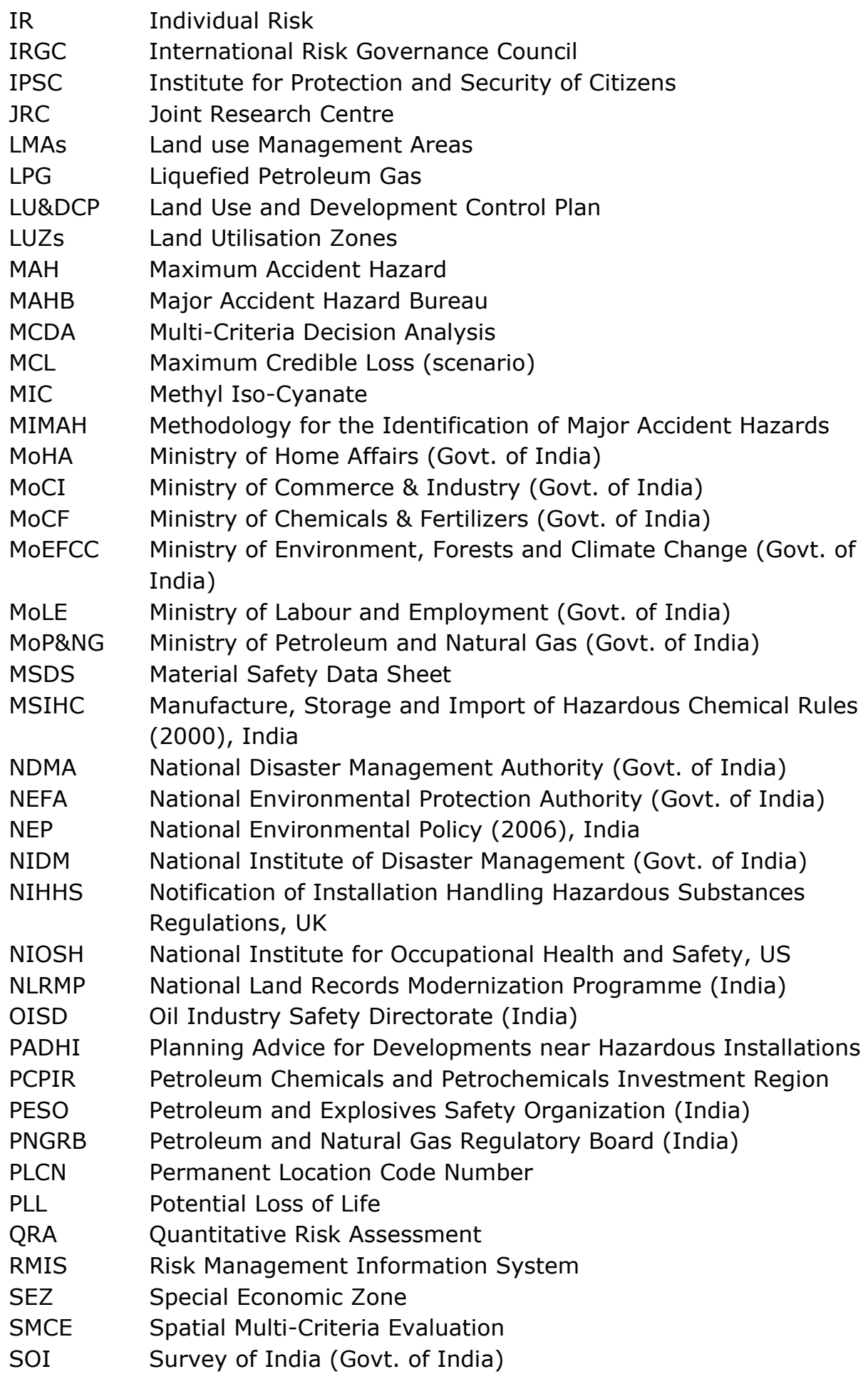




$\begin{array}{ll}\text { SPCB } & \text { State Pollution Control Board (India) } \\ \text { SR } & \text { Societal Risk } \\ \text { ToR } & \text { Terms of Reference } \\ \text { UCIL } & \text { Union Carbide India Limited } \\ \text { UDPFI } & \text { Urban Development Plans Formulation and Implementation } \\ & \text { Guidelines, India } \\ \text { UEL } & \text { Upper Explosive Limit } \\ \text { ULBS } & \text { Urban Local Bodies } \\ \text { UNISDR } & \text { United Nations International Strategy for Disaster Reduction } \\ \text { UT } & \text { Union Territory } \\ \text { UTPCC } & \text { Union Territory Pollution Control Committees } \\ \text { VCE } & \text { Vapour Cloud Explosion } \\ \text { VHR } & \text { Very High Resolution (imagery) }\end{array}$




\section{Chapter 1- Introduction}

This introductory chapter begins with the background of this research, explaining in brief the context of risk informed decision making for planning the uses of land around hazardous installations. Thereafter, subsequent sections discuss the research problem, the objectives and the methodological approaches that have been conceptualized for the purpose of this research.

\subsection{Background}

On the early morning of December $3^{\text {rd }}, 1984$, an accident occurred at the Union Carbide pesticide-manufacturing plant in Bhopal, India triggered the world's worst industrial catastrophe. A leak of 41 metric tons of acutely toxic Methyl Isocyanate (MIC) from a 33 metre long atmospheric vent-line within 90 minutes resulted in exposure of hundreds of thousands of people living in the neighbouring area of about $50 \mathrm{~km}^{2}$ (Lees, 1996; Singh et al., 1987). Within seconds, the lethal substance silently spread towards the shanty towns near the plant, with a population of more than half a million people. It was reported that in the railway colony about $2 \mathrm{~km}$ from the plant, where nearly 10,000 people lived, by the end of the day over 3000 people died and many were injured (Eckerman, 2005; Mannan et al., 2005; Shrivastava, 1995). Although, officially, the government put the immediate death toll at just under 4,000 people, but the unofficial estimates vary from anywhere between 8,000 to 10,000 to much higher numbers with 15,000 to 20,000 premature deaths reportedly occurring in the subsequent two decades (Broughton, 2005). Besides, thousands of people became disabled together with temporary and minor injured cases. In any case, it was a watershed event and qualifies as one of the worst manmade disasters that the world has witnessed to this day (Ayres et al., 1987; Chouhan, 2005).

\subsubsection{History and development of Bhopal}

After the independence of India in 1947, Bhopal became the state capital of Madhya Pradesh. The city started attracting new industries and government institutions and this growth continued throughout 1960s. In the meantime, following the policy initiated by the Indian government to encourage foreign companies to invest in local industry, the Union Carbide India Limited (UCIL) came up in Bhopal because of its central location and access to transport infrastructure. Resultantly, from 50,000 people as a base in the mid-50s, the city grew to 102,000 inhabitants in 1961 up to 670,000 inhabitants in 1981 . However, the rapid growth of Bhopal was not supported by adequate basic services or urban infrastructures; hence the situation led to haphazard urbanisation. Nearly 20 percent of the total population lived in slum colonies within $5 \mathrm{~km}$ of the pesticide plant (areas under red and orange contour lines as shown in Figure 1-1). Due to lack of development restrictions in place, 
many of these colonies encroached up to the site boundaries of the plant. Some of these experienced the direct influence of the gas leak (Sengupta, 2014).

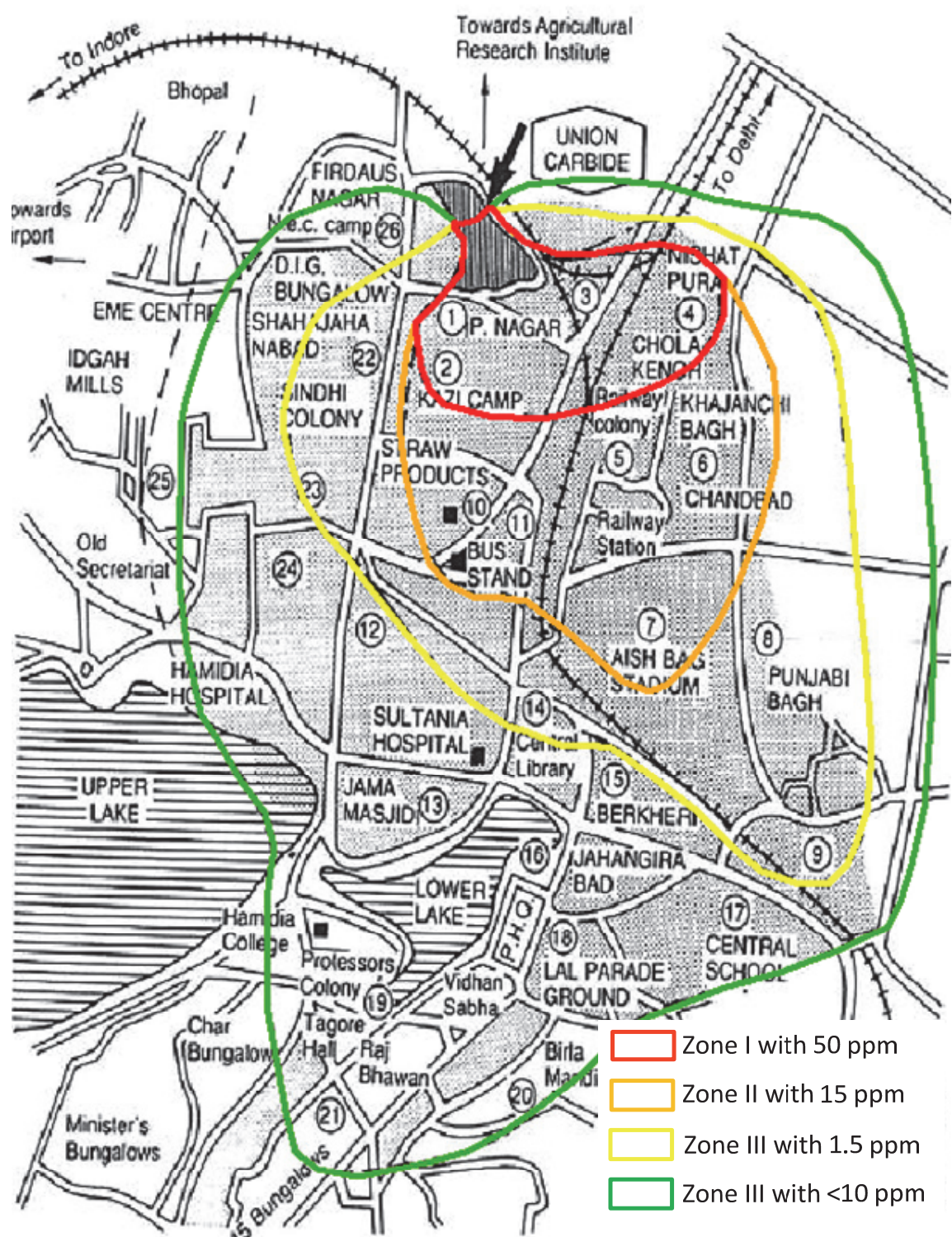

Figure 1-1: The gas affected areas of Bhopal city showing different zones determined on the basis of mortality statistics (Singh et al., 1987) Source: Layout map of the Bhopal city (Gehlawat, 2005)

Referring to the case-histories compiled by Lees (1996), the Bhopal accident was somehow a foreseen disaster. Among many other organisational and 
institutional reasons including lack of adequate information about the storage and handling of hazardous materials, lack of co-ordination between the factory management and the emergency service providers, inadequate warning systems and plant maintenance practices, limited capacity to cope with the crisis and mitigate the damages, etc., the rapid development of these densely populated slums in close proximity of the plant with lacking of minimal infrastructure facilities and hygienic supplies, which all inseparably linked to the developmental process of the area, made the incident worse (Bisarya et al., 2005; Shrivastava, 1995).

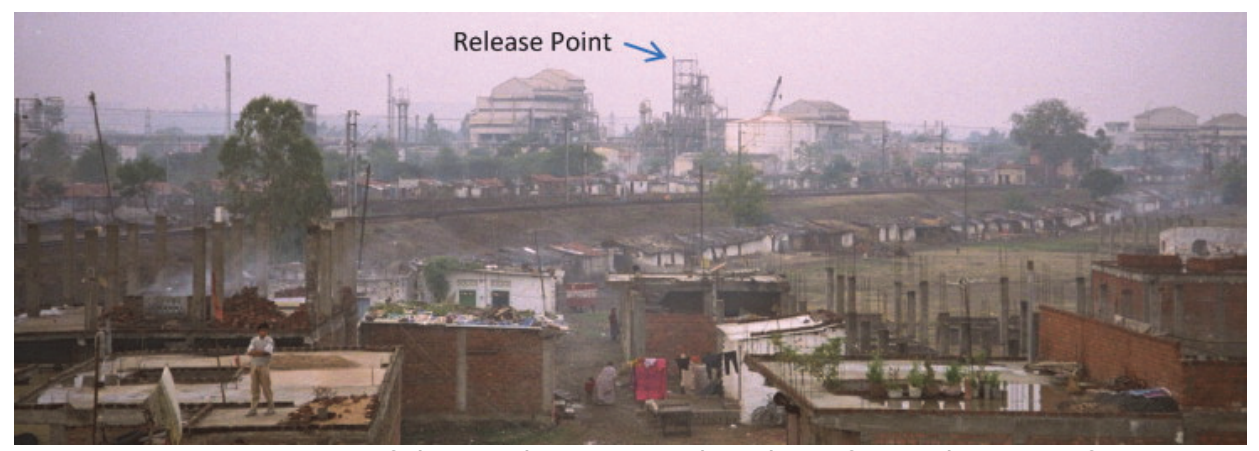

Figure 1-2: View of the accident site in Bhopal city from a house rooftop (Havens et al., 2012)

A large number of studies discussing the dispersion pattern of MIC, the possible role of local meteorological conditions during the accident can be found in the literature (Ayres et al., 1987; Boybeyi et al., 1995; Chouhan, 2005; Eckerman, 2013, 2005; Havens et al., 2012; Limaye, 2014; Sharan et al., 1997; Sharan et al., 2000; Sharan et al., 1995; Singh et al., 1987). Besides, many other attempts made by the academia can also be found highlighting various topics ranging from clinical studies to estimate toxicity, design and manufacturing processes, environmental and regulatory issues etc. (Bowonder et al., 1988; Chouhan, 2005; Gehlawat, 2005; Gupta, 2002; Jasanoff, 1988; Sriramachari, 2004, 2005). However, despite of having a wide range of literature discussing various shortcomings including technical and institutional errors accounted for this devastating accident, not many studies have been placed so far investigating how the rapid unplanned development around the plant contributed significantly to the vast number of fatalities, particularly from the Indian spatial policy and planning context.

\subsubsection{The aftermath}

The Bhopal accident was a wakeup call (Mannan et al., 2005). The immense loss as a result of the incident brought into home a worldwide awareness about such events are to be managed by taking proactive steps in terms of formulating regulations, planning criteria and establishing more stringent 
management control over hazardous industries. Consequently, in view of that, worldwide regulatory agencies were galvanized into bringing more elaborate legislation with regard to siting of and spatial planning around hazardous facilities for limiting the adverse effects of such accident and to reduce the level of risk of surrounding population.

\subsubsection{Genesis of major accident hazard policy}

However, the Bhopal accident was not the first of its kind highlighting the issue of off-site consequences and thereby forced the regulators to set forth major accident regulations. In this regard, Ale (Ale, B.J.M., 1993, 2005a, 1991, 2002b, 2005b) mentioned about two large-scale explosions of ammunition storages in the Netherlands, which are the root cause of formulating the Dutch Major Hazard Policy aiming at protection of the population against major accidents. In the first one, dating back to 1654 , an explosion of the gunpowder tower demolished a large part of the city centre of Delft and fifteen hundred people were killed. After this disaster, the storage of gunpowder was removed outside the city boundaries. Then in 1807,150 years later, a similar type of explosion involving 37,000 pounds of gunpowder destroyed a part of the city Leiden. The van der Werf Park is still there as a witness of the event. The event also caused 150 fatalities; among 50 were children, whose school was demolished by the blast. This explosion led to an imperial decree, concerning the licensing and siting of hazardous establishments. The scope of this imperial decree was then widened and turned into a Royal Ordinance in 1814. In 1875, at the time of the Dutch industrialization, this Royal Ordinance was then turned into the so called Factory Law (Ale, B.J.M., 2005a, 2005b). From then onwards, licensing became part of the Dutch safety system.

Interestingly, the safety regulations in France can also be traced back to the same imperial decree. In France, the first decree on activities with major risks was published in 1810 . The decree was initiated following the huge dust explosion in1794 at Grenelle (France) killing some 1000 people. However, the origin of the modern risk management lies in the industrial accidents after World War II. In 1966, a fire in a storage facility of Liquefied Petroleum Gas (LPG) in Feyzin, France killed 18 and wounded 81. This accident led to reemphasis on design rules for bottom valves on pressure vessels. In the realm of physical planning no actions from the French or the European authorities seemed to have resulted from that accident. 
In next ten years, a number of similar major accidents ${ }^{1}$ occurred worldwide including the Flixborough (UK, 1974); the DSM worksite at Beek (The Netherlands, 1975); Seveso (Italy, 1976); Los Alfaques (Spain, 1978); San Juan Mexico City (Mexico,1984) and many more. All these accidents exhibited that these accident were not unique accidents. Rather it can be understood that independent of the region, the number of such events with significant 'off-site' consequences had increased over time.

Learning from the experiences driven by these major accidents, countries in Europe where industrial developments have long co-existed with densely populated areas, have made significant progress in formulating policies, regulations and planning frameworks to deal with the issue of industrial risk. Formulation of the Seveso Directive (Council Directive 82/501/EEC ${ }^{2}$ ), a comprehensive guidance on prevention of major accidents and limitation of their consequences, by the European Union, is a good example in this regard (Versluis et al., 2010). The Directive was initially formulated in 1986 in light of the significant damages caused by the Seveso accident and accordingly was named after the accident to indicate the importance of major accident as an influential parameter for changing the former legislation (Kirchsteiger, 2002; Mitchison, 1999; Vierendeels et al., 2011).

Since then the Directive has been changed several times to expand the area of application of the legislation and to enhance setting up improved safety management systems driven by the lessons learned from major accidents occurred worldwide. For instance, specific regulations with regard to siting of and spatial planning around hazardous facilities, started to be object of the regulation only after the lessons learned from the Bhopal accident. Consequently, in 1996, the Directive 96/82/EC on the Control of Major Accident Hazards, also known as the Seveso Directive $\mathrm{II}^{3}$, was adopted with a significant re-orientation from a prescriptive-oriented approach to a goaloriented regulatory approach (Porter et al., 1999; Wettig et al., 1998; Wettig et al., 1999). Introduction of Article 12 for land use planning implications around the hazardous installations was one of the key additions of the Directive II. Recently, in 2012, Seveso Directive III (Council Directive

1 According to the Seveso Directive 96/82/EEC, a major accident is "an occurrence such as a major emission, fire, or explosion resulting from uncontrolled developments in the course of the operation of any establishment covered by this Directive, and leading to serious danger to human health and/or the environment, immediate or delayed, inside or outside the establishment, and involving one or more dangerous substances".

2 Council of the European Communities, 1982; Directive 82/501/EEC; Official Journal of the European Union, L230, 05/08/1982, pp. 1-18

3 Council of the European Communities, 1996; Directive 96/82/EC; Official Journal of the European Union, L 10, 14/01/1997, pp. 13-33 
2012/18/EU $)^{4}$ was adopted and as of $1^{\text {st }}$ June 2015the Seveso Directive III came into force. The former Article 12 of the Directive II has been replaced by Article 13 of the Directive III. A brief history of the evolution of the Seveso Directive is presented in Table $1-1$.

Table 1-1: Evolution of the Seveso Directives I, II and III

\begin{tabular}{|c|c|c|c|}
\hline Event & Explanation & Consequences & Resulted in \\
\hline $\begin{array}{l}\text { Seveso, } \\
\text { Italy } 1976\end{array}$ & $\begin{array}{l}\text { Dioxin escape } \\
\text { spread over } \\
\text { countryside }\end{array}$ & $\begin{array}{l}3,000 \text { pets and farm } \\
\text { animals died, } \\
70,000 \text { animals } \\
\text { slaughtered to } \\
\text { prevent dioxins } \\
\text { from entering the } \\
\text { food chain }\end{array}$ & $\begin{array}{l}\text { 82/5001/EEC Seveso } \\
\text { Directive I }\end{array}$ \\
\hline $\begin{array}{l}\text { Bhopal, } \\
\text { India } 1984\end{array}$ & $\begin{array}{l}\text { Leak of Methyl } \\
\text { Isocyanate }\end{array}$ & $\begin{array}{l}\text { Estimates of its } \\
\text { death toll range } \\
\text { from } 4,000 \text { to } \\
20,000 .\end{array}$ & 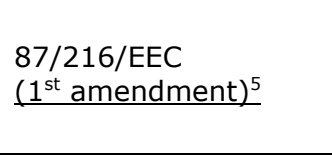 \\
\hline $\begin{array}{l}\text { Sandoz, } \\
\text { Switzerland } 1986\end{array}$ & $\begin{array}{l}\text { Fire in the } \\
\text { storehouse }\end{array}$ & $\begin{array}{l}\text { Tons of toxic } \\
\text { agrochemicals } \\
\text { released into the } \\
\text { Rhine, death of half } \\
\text { a million fish }\end{array}$ & $\begin{array}{l}88 / 610 / \text { EC } \\
{\left(2^{\text {nd }} \text { amendment }\right)^{6}}\end{array}$ \\
\hline \multicolumn{4}{|c|}{$\begin{array}{l}\text { In } 1988 \text {, fundamental review of Directive result in a proposal that would become } \\
96 / 82 / \text { EC - Seveso Directive II }\end{array}$} \\
\hline $\begin{array}{l}\text { Baia Mare, } \\
\text { Romania } 2000\end{array}$ & Cyanide spill & $\begin{array}{l}\text { Untreated cyanide } \\
\text { waste has mixed } \\
\text { with the Danube } \\
\text { river }\end{array}$ & \multirow{3}{*}{$\begin{array}{l}\text { 2003/105/EC } \\
\text { (3 }{ }^{\text {rd }} \text { Amendment) } \\
\end{array}$} \\
\hline $\begin{array}{l}\text { Enschede, The } \\
\text { Netherlands } 2001\end{array}$ & Fireworks accident & $\begin{array}{l}21 \text { people killed and } \\
800 \text { injured }\end{array}$ & \\
\hline $\begin{array}{l}\text { Toulouse, France } \\
2001\end{array}$ & $\begin{array}{l}\text { Explosion at a } \\
\text { fertilizer plant }\end{array}$ & $\begin{array}{l}29 \text { people killed and } \\
\text { injured } 2,500\end{array}$ & \\
\hline \multirow[t]{2}{*}{$\begin{array}{l}\text { In 2008, } \\
\text { F-Seveso Report }\end{array}$} & $\begin{array}{l}\text { Report on } \\
\text { implementation } \\
\text { and effectiveness } \\
\text { of the Directive }\end{array}$ & $\begin{array}{l}\text { Views from } 8 \\
\text { Member } \\
\text { State(industry, CAs, } \\
\text { NGOs) }\end{array}$ & $\begin{array}{l}\text { Proposal for amended } \\
\text { Directive }\end{array}$ \\
\hline & $\begin{array}{l}\text { Changes to the EU } \\
\text { system of } \\
\text { classification of } \\
\text { dangerous } \\
\text { substances }\end{array}$ & $\begin{array}{l}\text { In 2010, EC } \\
\text { published a } \\
\text { proposal for } \\
\text { amended Directive }\end{array}$ & Seveso Directive III \\
\hline
\end{tabular}

${ }^{4}$ Council of the European Communities, 2012; Directive 2012/18/EU; Official Journal of the European Union, L197, 24.07.2012, pp. 1-37

5 Council of the European Communities, 1987; Directive 87/216/EC; Official Journal of the European Union, L 085, 28/03/1987, pp. 0036-0039

${ }^{6}$ Council of the European Communities, 1988; Directive 88/610/EC; Official Journal of the European Union, L 336, 07/12/1988, pp. 0014-0018 
Prevention of industrial accidents in India also has a long tradition that dates back to 1881 with the enactment of the first Factories Act. It is only after the Bhopal accident, that the policy and decision makers realized the true nature and severity of the problems inherently linked with the process of economic development. Against the backdrop of the Bhopal tragedy, the Environment (Protection) Act 1986 (hereafter EP Act) was introduced as an umbrella Act to protect the environment by preventing major accidents. Since then, there has been a gradual evolution of a number of subsidiary regulations in the form of Rules under EP Act 1986 focussing on control and minimization of risk from hazardous installations. Following the provisions made by these regulations, institutional and legal frameworks for management of hazardous substances, enforcement and monitoring of safety and emergency came into place.

Despite of considerable progress that has been made in the post-Bhopal era, even after 30 years of the tragic accident, there is still a lack of a holistic approach in reducing industrial risk and rapid development of industrial areas in densely populated regions to make sure that events like Bhopal are not repeated (Sengupta et al., 2016). A significant number of shortcomings prevail in the existent risk governance framework have already been identified in a review undertaken by a high powered committee set up under the National Disaster Management Authority (NDMA), Govt. of India (NDMA, 2007). The review brought out that there is yet no standardised methodology for risk assessment of hazardous facilities based on which a consistent evaluation of risk at the industrial cluster can be undertaken. Moreover, risk acceptability criteria to be attained is not stipulated through any regulation thus making it difficult for regulators, planners or plant designers to work towards an acceptable goal for safety or a level to which risk has to be reduced through planning interventions. For further details refer Chapter 4 of this thesis. The above mentioned issues thereby provide an opportunity to cast a broad look at the subject of governance of industrial risk in India.

\subsection{Research Problem}

In the last 40 years worldwide there has been an inexorable trend towards industrialization especially in the developing countries like India. The rapid increase in the use of hazardous chemicals in these industries has brought about a significant growth in the number of people whose life could be endangered at any time by an accident involving these chemicals. Indeed the coexistence of hazardous industrial installations with densely populated neighbourhoods is a common occurrence in global south and is responsible for the greater damage to life caused by the industry accidents in these regions (Abbasi et al., 2005). The situation in most developing countries lies within these extremes. India is not an exception in this regard. 
Today the country is one of the emerging economies of the world, and a considerable part of this fast paced growth can be attributed to the economic development model being pursued with an emphasis on industrialization, mainly the chemical industries. The Indian chemical industry stands as the $3^{\text {rd }}$ largest producer in Asia (after China and Japan) and $12^{\text {th }}$ in the world, in terms of volume ${ }^{7}$. Based on its rapid economic performance during the past decade, the country is also identified as one of the highly industrialized countries in the world. As of date there are 1666 Major Accident Hazardous ${ }^{8}$ (MAH) industries in India (NDMA, 2007). And many of these MAH units are often found in clusters to take advantage of common infrastructural facilities and the availability of skilled manpower. An inventory undertaken by the Central Pollution Control Board (CPCB) identified 170 of such industrial clusters housing more than five MAH units across the nation (Figure 1-3). Furthermore, number of such clusters is anticipated to go up significantly either in the form of 'Petroleum Chemicals and Petrochemicals Investment Regions' (PCPIRs) ${ }^{9}$ as conceptualized by the Ministry of Chemicals \& Fertilizers (MoCF), Govt. of India or in the form of 'Special Economic Zones' (SEZs) ${ }^{10}$ proposed by the Ministry of Commerce \& Industry (MoCI), Govt. of India thus to provide further impetus for the growth of chemical industries. The $12^{\text {th }}$ Five Year Plan (2012-2017) envisages that the chemical industry would grow with a projected annual growth rate varying between 11 and 15 percent (Sengupta et al., 2016).

7 CeFIC (2011) The European Chemical Industry Council, The European chemical industry in a worldwide perspective. http://www.cefic.org/Documents/FactsAndFigures/(Offline)\%202011/FF2011 Full \%20Report Chapter/Cefic FF\%20Rapport\%202011.pdf

8 Major Accident Hazards (MAH) installation means the isolated storage and industrial activity at a site handling (including transport through carrier or pipeline) of hazardous chemicals equal to or, in excess of the threshold quantities specified in column 3 of Schedules 2 and 3 respectively in the Manufacture, Storage and Import of Hazardous Chemical (MSIHC) Rules, 1989 under Environmental (Protection) Act, 1986.

9 Petroleum Chemicals and Petrochemicals Investment Regions (PCPIRs): http://cipet.gov.in/pdfs/policy2.pdf

10 Details about SEZ can be found at http://sezindia.nic.in/about-introduction.asp 


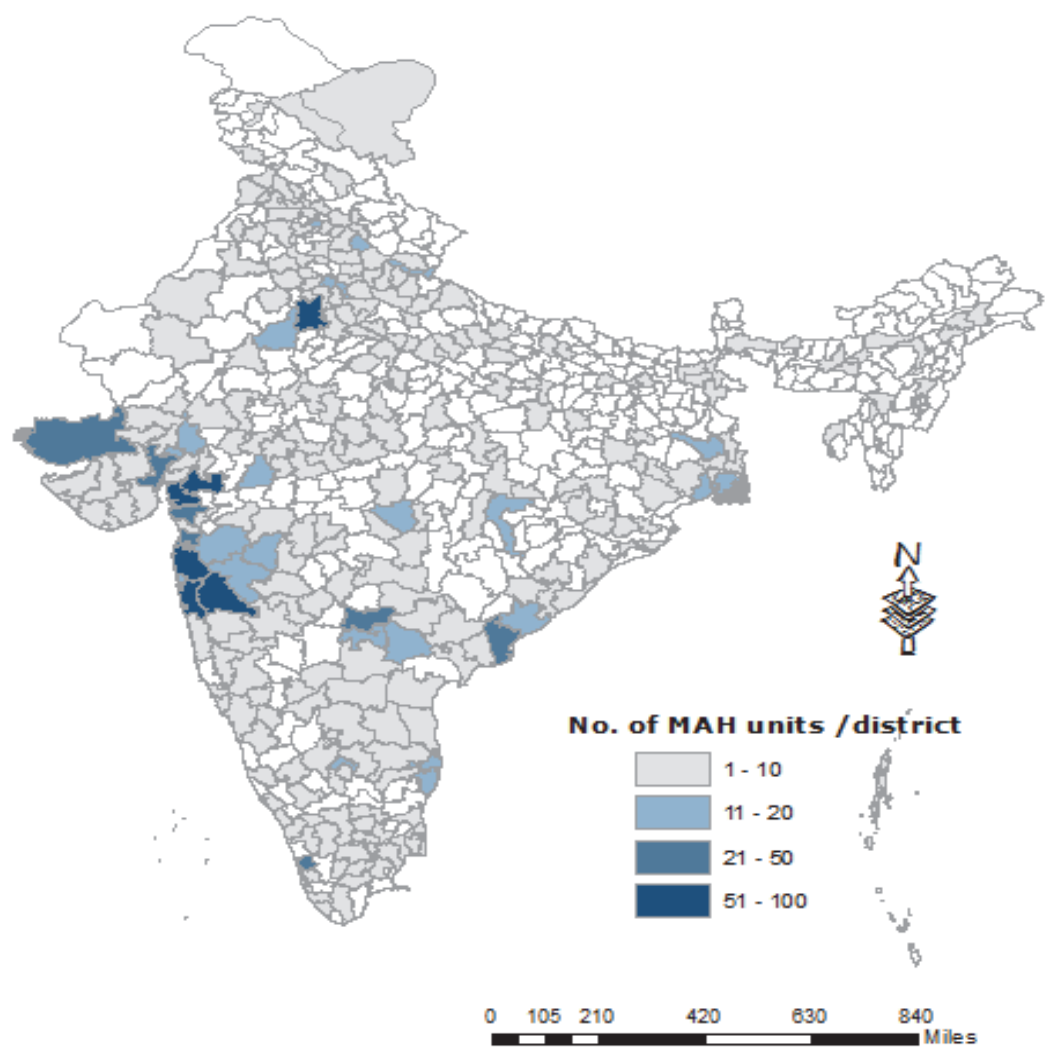

Figure 1-3: District wise location of the MAH industries in India (Sengupta et al., 2013b)

However, there is a flip side of this growth. The pursuance of such rapid industrialization has often led to the growth of polarised industrial-urban centres without adequate infrastructure, appropriate housing facilities, and other basic amenities like transportation, water, health and sanitation etc. In absence of such regulatory requirement for land use restrictions, some of these industrial clusters have not taken risk into account during their development phase. Important to mention here that issues related to the safe siting of hazardous industries although put forward through certain discrete regulatory provisions including the Section $41 \mathrm{~A}$ of the Factories (Amendment) Act of $1987^{11}$ by the Ministry of Labour and Employment (MoLE), Govt. of India, the EIA ${ }^{12}$ Notification of $2006^{13}$ set by the Ministry of Environment Forest\& Climate Change (MoEFCC), Govt. of India, the 'Zoning

${ }^{11}$ Factories (Amendment) Act of 1987:

http://labour.gov.in/upload/uploadfiles/files/ActsandRules/Service and Employme nt/The\%20Factories\%20Act\%2C\%201948.pdf

12 Environmental Impact Assessment

13 EIA Notification of 2006: http://www.envfor.nic.in/legis/env clr.htm 
Atlas for Siting of Industries ${ }^{\prime 14}$ prepared by the CPCB etc.; however none of these provide any specific criteria which can guide land use planning decisions for an industrial cluster. As a result, in continuation with the earlier practice, the level of risk in industrial clusters is increasing considerably. In a nutshell, there is no overarching policy framework either to deal with assessing the risk arising out of such hazardous clusters or to deal with a risk reduction strategy for the areas where the level of risk is already high.

Moreover, acting as engines of industrial and economic growth, these areas often witness a steady influx of population resulting from the migration of people from other part the country to take advantage of jobs and other livelihood opportunities generated by these industries. And in most cases, the concentration of population growth driven by these urban biased industrial developments evolved without adequate infrastructure and basic civic amenities, hence creating harmful living conditions (Shrivastava, 1995). As a result, large number of low-income group people whosoever migrated to this area for job opportunities, do not have any alternative but to settle in areas adjacent to hazardous facilities, thus becoming highly vulnerable to any industrial accidents, of which the Bhopal is an example (de Souza and de Freitas, 1996). de Souza and de Fretias (de Souza Porto et al., 2003) in their research termed this disproportionate increase in level of risk to the people a typical phenomenon of the developing countries, the 'socio-political amplification of risk'.

On the other hand, despite of considerable economic progress in India, the sustainable development of an area is confronted with high population density and huge pressure on land. The country is supporting 17.7 percent of the world's population in 2.3 percent of the total area available on the earth $^{15}$. Consequently, the average area available to a person is only about 1.12 hectares ${ }^{16}$, one of the lowest per capita availabilities of land resources (See Figure 1-4). Resultantly, more and more people now live dangerously close to industries than ever before. Although the regulatory agencies ask the new industries to be sited well away from the populated neighbourhoods, but as soon as a new industry commissioned, commercial activity begins around it and in its wake gradually residential houses and shanties also come. It has been observed that in many places the older industries are functioning in situations where an increasingly dense mix of residential-commercial population thrives right outside the industries' boundary. As a result major

14 Details about Zoning Atlas for Siting of Industries can be found at: http://www.cpcb.nic.in/Env Planning.php

15 The percentage is calculated based on the data accessed from the online publication of the World Bank Report, accessed from http://data.worldbank.org/indicator

161 hectare $=10000$ sq metre 
accidents in the Indian chemical industry almost always take a heavy toll on the life and property of people living or working outside the industry.

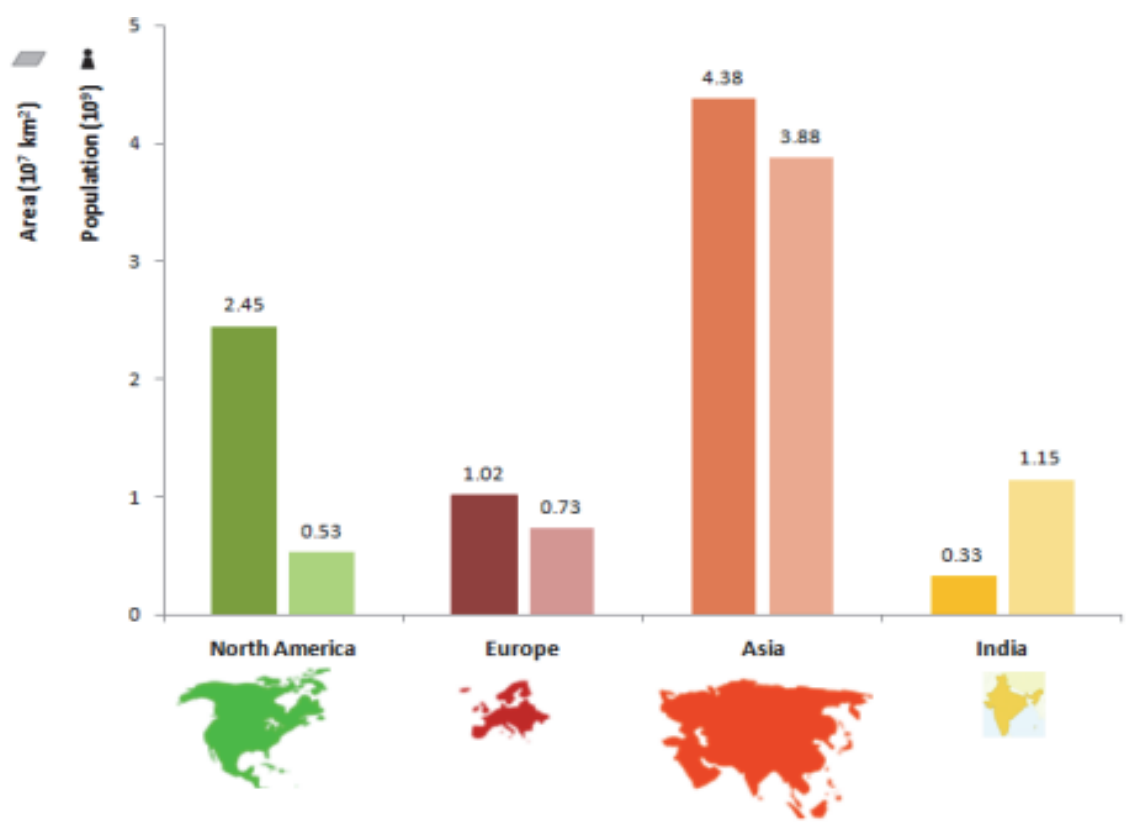

Figure 1-4: Comparison of area to population between continents \& India

But such a situation is not typical of India alone; many industrialized western European countries like the Netherlands faced similar challenges in the past. By far, the Netherlands is the one of the most densely populated (488 people per sq. km) and industrialized countries in Europe, as India in Asia. Secondly, due to its geographical location, available land is very limited in the Netherlands which is also the case for India. Moreover, because of limited land resource in the Netherlands, relatively a large population lives close to one of the largest chemical areas in Europe (Ale, B.J.M., 2005b; Pasman, 2000; Pasman et al., 2014). In spite of encountering similar challenges in the past, the Netherlands has evolved a systematic framework for assessing risk from hazardous industries using quantified method and criteria which then led to the adoption of suitable risk reduction strategies (Pasman et al., 2014). All considered, after 30 years of the tragic accident in Bhopal, the practice which was developed in the Netherlands and other EU Member States, is still missing in India. With this backdrop, this research is focused on identifying the challenges that lie in the way of introducing industrial risk assessment into land use planning decisions for an Indian situation. 


\subsection{Research Objectives}

The purpose of this research was to ascertain how industrial accident risk assessment approaches that have been developed in European Member States can be transferred into an Indian context, as a component for riskinformed decision making? And what contribution can be made by geoinformation technology to support the industrial risk assessment related to hazard footprints, exposed buildings and people and their vulnerability?

In this line, the main objectives as outlined for this research are as follows:

- Outline and critique the Indian regulatory context for assessing the risk of an industrial accident;

- Identify the information required to estimate risk and vulnerability to an industrial accident;

- Analyse how cadastral information can be utilized as a basis for exposure and vulnerability mapping;

- Evaluate the feasibility of applying a QRA-based approach within the existing legislative framework of India;

- Design an indicator-based framework for vulnerability assessment with aid of geo-information techniques.

\subsection{Research Approach}

In order to achieve the objectives of this research, as outlined in the previous section, a four-tier methodical pyramid has been adapted for this research (Figure 1-5).

From the methodological point of view, the top layer of the framework refers to the overall set of principles about governance, information availability and need for risk-informed decision-making in the domain of risk management in India. In the process of conceptualising and developing the methods as a part of this research, an understanding was obtained through review of existing policies, regulations and institutional setups for governance of industrial risk prevailing in India. 


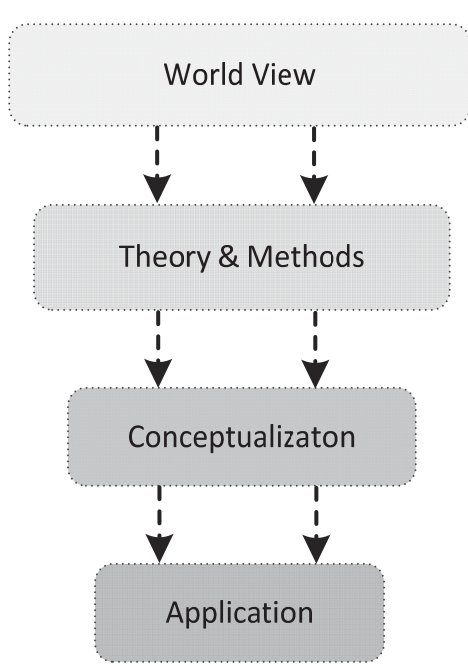

Figure 1-5: Research approach

The second tier in the framework refers to the underlying set of theories and methods on industrial risk assessment, evaluation and it application to planning, as has been developed and applied in Europe. In particular, a review of scientific literature on the regulatory context for managing industrial risk as well as land uses planning as practice in Europe has been undertaken to understand how to adapt such theory and methods to the Indian governance setup for risk management. Important to mention, a good amount of research linking the concepts of risk governance, industrial hazard risk reduction strategy and land use planning has already been undertaken in many EU Member States. However, it appeared that very limited research or literature of such kind has been undertaken in India. From that strand, this research will contribute to the existing body of knowledge, utilising key concepts from existing international literature and taking them forward into an Indian context.

The third methodological step involved conceptualisation of methodologies for risk and vulnerability assessment of an industrial accident for an Indian situation.

The fourth step of the methodology attempts to assess the applicability of the proposed method with reference to a case study area; thereby identifying future alterations (if any) need to be integrated into the proposed framework.

\subsection{Thesis outline}

Following this introductory chapter, the thesis is structured into two parts: a theoretical and an application part. 
- The first part of the thesis presents an overview of risk and safety related issue in context of land use planning decisions, thereby aims to set a context of this research. For the purpose, Chapter 2 provides a brief description of the relevant aspects related to industrial risk governance, different components of risk assessment framework and decision-making. Chapter 3 then reviews various approaches for industrial risk assessment as adopted in the EU Member States to arrive at a risk-informed land use planning decisions. Thereafter, Chapter 4 puts this aspect in an Indian perspective by discussing the prevailing situation with respect to the industrial risk management framework and the land use planning process to identify gaps which need to be bridged to make way for a safer society. This Chapter has common elements with the PhD thesis: Bandyopadhyay, D. (2016), "Information, Decision and Planning Support for Industrial Risk Management in India". Based on this appreciation and learning from the practices as developed and applied in EU Member States, the first part results into the conceptualization of methodologies pertaining to industrial risk and vulnerability assessment for an Indian situation.

- The second part of the thesis demonstrates the application of the proposed methodologies in an Indian situation with reference to a case study area. For that purpose, the case study area, Haldia is introduced in Chapter 5. And Chapter 6 focuses on the focuses on the identification and preparation of the spatial information database necessary for further analysis. Chapter 7 then reviews the applicability of a simplified QRAbased approach for estimating cumulative risk level originating from a cluster of hazardous industries, as practiced in The Netherlands in an Indian context, thus to identify the shortcomings in the existent practice. Subsequently, in Chapter 8, the proposed indicator-based method for assessing the vulnerability of the surrounding area of an industrial cluster, as conceptualized is worked out further for the case study area through the application of GIS.

Then the final chapter 9 provides a synthesis of the key issues in relation to methods and techniques for industrial risk and vulnerability assessment and introduces a proposal for a risk-informed land use planning framework for an Indian situation. 


\section{Chapter 2 - Concept of industrial risk management}

This chapter discusses the concept of industrial risk governance and the main components of the risk assessment framework in context to the research presented in the subsequent chapters.

\subsection{Governance of industrial risk}

The practice of scientific industrial risk assessment started in the late 1960s with the gradual realization that nuclear power plants, chemical industries and other progressive developments in technology are capable of posing substantial risk to humans and the environment, unless dealt with effectively (Löfstedt et al., 2009). Studies involving the social perspective of risk also evolved around the same time and at present, both these disciplines are now widely accepted to complement each other successfully. Social researchers have called for a new reference frame to better understand and treat the complexity associated with risk management in the modern world. This has led to a shift to pursue risk-related decision making through a broader frame of 'risk governance'.

The concept of viewing through the prism of governance is relatively new. On a national scale, governance describes structures and processes for collective decision-making, involving governmental and non-governmental actors (Nye et al., 2000). The term 'risk governance' is also relatively new and has gained popularity in policy studies and risk research thereby instituting a new approach to study the management of risk from a holistic point of view, encompassing the role of all the actors concerned in the process of risk management (van Asselt et al., 2011). Risk governance not only includes the traditional concepts covered in 'risk management' and 'risk analysis', but also accounts for the historical and legal backgrounds, guiding principles, value systems and the perspectives of several stakeholders who have an interest in risk decisions (IRGC, 2005).

According to the International Risk Governance Council (IRGC, 2005) ${ }^{17}$, risk governance includes "the totality of actors, rules, conventions, processes, and mechanisms concerned with how relevant risk information is collected, analysed and communicated and management decisions are taken". This philosophy of risk governance offers a major innovation - it emphasizes on better categorization of risk-related knowledge to guide societal decisions. Once a knowledge base is acquired and made available to risk actors, it can

17 The IRGC was established in Geneva in Switzerland as a global organization for scientists, policy makers and industry and funded by government boards, research councils and companies. 
inform and guide scientific risk analysis through a formal process that links hazard sources with potential consequences and probability of occurrence of the hazard. This can then aid in deciding on whether the risk is acceptable and subsequently drawing up an action plan to reduce it to acceptable levels. In addition to the generic elements of risk, assessment, management and communication, the framework provides equal importance to the contextual aspects which include the knowledge of stakeholders, their (differing) concerns and perceptions about risk and how they interplay as actors. Such an approach can help in the development of a risk governance philosophy and supporting policies that are guided by scientific rationale and result in a consistent and evidence based approach to solving industrial risk problems (Christou et al., 2011a; McIntosh et al., 2011).

\subsection{Industrial risk management framework}

Worldwide, with an overall objective to improve risk governance, there are amplified efforts to mainstream industrial risk considerations into short-term and long-term spatial planning initiatives. Therefore, systematic assessment and evaluation of risk is the key to understanding risk and guide risk treatment and management actions. In order to obtain a better understanding, Table 2-1 provides brief definitions involving key terminologies associated with industrial risk assessment. 
Table 2-1: Terminologies with illustrative examples

\begin{tabular}{|c|c|c|}
\hline Term & Definitions & Illustrative Example \\
\hline $\begin{array}{l}\text { Industrial } \\
\text { Hazard }\end{array}$ & $\begin{array}{l}\text { A chemical or physical condition that } \\
\text { has the potential to cause damage to } \\
\text { people, property or the environment } \\
\text { or some combination of these. }\end{array}$ & $\begin{array}{l}\text { A refrigerated tank } \\
\text { containing } 1000 \text { Metric Ton } \\
\text { of Ammonia }\left(\mathrm{NH}_{3}\right)\end{array}$ \\
\hline $\begin{array}{l}\text { Major Accident } \\
\text { Hazard (MAH) } \\
\text { industry }\end{array}$ & $\begin{array}{l}\text { A facility which stores a hazardous } \\
\text { chemical in excess of a threshold } \\
\text { quantity, as set in regulations. For } \\
\text { India, the threshold quantity is set in } \\
\text { the Schedule of the MSIHC Rules. }\end{array}$ & $\begin{array}{l}\text { A facility storing more than } \\
15 \text { MT of Ammonia }\left(\mathrm{NH}_{3}\right)\end{array}$ \\
\hline $\begin{array}{l}\text { Hazard } \\
\text { Footprint or } \\
\text { Effect Zone }\end{array}$ & $\begin{array}{l}\text { For an incident which produces an } \\
\text { outcome (toxicity, radiation, } \\
\text { overpressure), the area over which } \\
\text { the effect is above a pre-defined level } \\
\text { of concern. }\end{array}$ & $\begin{array}{l}\text { For } \mathrm{NH}_{3} \text {, the area over } \\
\text { which the concentrations } \\
\text { are expected to be more } \\
\text { than the threshold level of } \\
500 \mathrm{ppm}\end{array}$ \\
\hline Consequence & $\begin{array}{l}\text { A measure of the expected negative } \\
\text { outcome from a given incident. }\end{array}$ & $\begin{array}{l}\text { A toxic release of ammonia } \\
\text { resulting in death of } 40 \\
\text { people and injuries to } 60 \\
\text { people }\end{array}$ \\
\hline $\begin{array}{l}\text { Individual Risk } \\
\text { (IR) }\end{array}$ & $\begin{array}{l}\text { The frequency at which an individual } \\
\text { may be expected to sustain a given } \\
\text { level of harm from the realisation of } \\
\text { specific hazards. }\end{array}$ & $\begin{array}{l}\text { The risk of death to an } \\
\text { individual residing in a } \\
\text { certain area of interest } \\
\text { being } 1 \text { in } 10,000 \text { in a year }\end{array}$ \\
\hline $\begin{array}{l}\text { Societal Risk } \\
\text { (SR) }\end{array}$ & $\begin{array}{l}\text { The relationship between the } \\
\text { frequency and the number of people } \\
\text { suffering from a specified level of } \\
\text { harm in a given population from the } \\
\text { realisation of specific hazards. }\end{array}$ & $\begin{array}{l}\text { A probable loss of } 20 \text { lives / } \\
\text { year for the population in } 1 \\
\mathrm{~km}^{2} \text { of an area of interest }\end{array}$ \\
\hline
\end{tabular}

The risk assessment process, which lies at the heart of risk management, comprises of systematic steps to identify, analyse and evaluate the existing industrial risk and generally lead to a representation of risk. One of the less common ways is to spatially represent risk through a 'risk map' wherein the prevailing risk can be compared to acceptable risk criteria linked to potential hazard sources and vulnerabilities present in an area. In simple term, risk assessment is the objective or scientific part of the framework whereas risk management is the subjective or political part.

Based on output of the risk assessment, the risk treatment phase involves the selection and adoption of risk mitigation measures that aim to reduce residual risk to levels that are acceptable to society (Versluis et al., 2010). The key risk mitigation methods include improvement of plant safety, formulation of emergency preparedness and response plans, adoption of offsite safeguard measures and incorporating risk as a factor for land use planning in industrial areas. The selection of a risk treatment or mitigation option usually involves the balancing of costs and efforts of implementation 
against perceived benefits with regard to protection of citizens and the environment.

It must be noted though that recent trends in decision making involving risk issues indicate a paradigm shift from technocratic approaches involving objective assessments undertaken by experts towards participatory frameworks (Eduljee, 2000; Renn, 2006). In 1996, based on a review of practice, the National Research Council of the United States proposed a shift from an earlier objectivity-oriented approach. The authors of the report stress the necessity of making risk-related decision making an inclusive and participatory process and incorporate the perspectives and knowledge of interested and affected parties through effective stakeholder engagement through all the phases of the process to understand the risks (Stern et al., 1996). The approach therefore articulates the requirement for integrating analytical reasoning with deliberation and interpretation through a participative process involving stakeholders, providing for acceptance of risk decisions within a socio-political framework (Renn, 1999).

In addition, two other aspects are also important:

- communication of risk to build on a proper perception of risk amongst stakeholders is important so that their views and concerns can be identified and incorporated in the decision making process; and

- the monitoring and review mechanisms which evaluates whether the risk treatment measures are being able to effectively able to reduce risk to desired levels and provide feedback to the entire process.

Figure 2-1 depicts a simplified hierarchical structure of the risk management framework for industrial risk, depicting different components and their interrelation within the framework. 


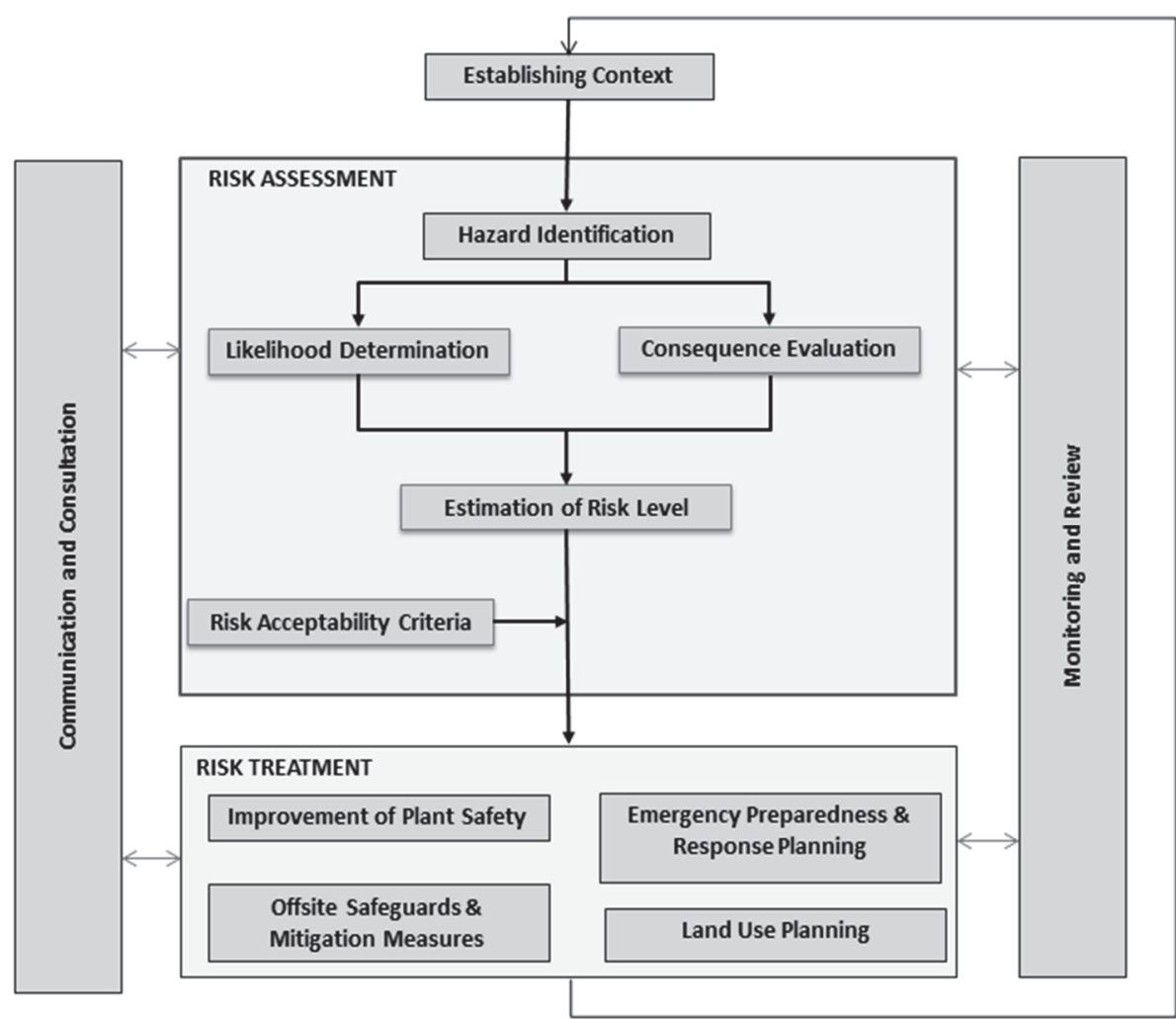

Figure 2-1: Simplified representation of risk management framework

\subsection{Process of industrial risk assessment}

From methodological point of view, risk assessment procedure includes risk analysis and risk evaluation. In particularly in risk analysis step, hazards are identified and estimated by systematic use of available information; whereas, in risk evaluation step, evaluation of the level of risk is carried and decided whether acceptable risk has been achieved or not (Christou, et al., 2006b). The evaluation of resulted risk requires risk acceptance criteria - which is used as a basis for decisions about acceptable risk (Christou, et al., 2011b). In other words, risk assessment is the process of risk analysis and evaluation of the significance of the results. From this perspective, the risk assessment process can be viewed as concentrating on five basic questions in relation with risk analysis and risk evaluation, as summarized in Table 2-2. 
Table 2-1: Elements of risk assessment

\begin{tabular}{|c|c|c|}
\hline \multirow{5}{*}{$\begin{array}{l}\text { Risk } \\
\text { assessment }\end{array}$} & \multirow{4}{*}{$\begin{array}{l}\text { Risk } \\
\text { analysis }\end{array}$} & $\begin{array}{l}\text { What can go wrong? } \\
\text { Potential accidents and the ways they could come } \\
\text { about are identified }\end{array}$ \\
\hline & & $\begin{array}{l}\text { How often? } \\
\text { Probability of their occurrence is estimated }\end{array}$ \\
\hline & & $\begin{array}{l}\text { What are the consequences? } \\
\text { Potential consequences of the accidents are estimated }\end{array}$ \\
\hline & & $\begin{array}{l}\text { What are the risks? } \\
\text { Risks are identified in terms of their level by using the } \\
\text { above analyses, and their significance assessed; and } \\
\text { compared with established criteria }\end{array}$ \\
\hline & $\begin{array}{l}\text { Risk } \\
\text { evaluation }\end{array}$ & $\begin{array}{l}\text { So What? } \\
\text { Risk management actions are carried out } \\
\text { Demonstration of resulting risk and evaluation with } \\
\text { established tolerability criteria (identification of } \\
\text { mitigation measures, acceptance of result, } \\
\text { modification or abandoning) }\end{array}$ \\
\hline
\end{tabular}

Several approaches exist for assessing risk originating from hazardous industries and storages and they vary from purely quantitative to semiquantitative and qualitative. Among others, methods for Quantitative Risk Assessment (QRA) based practices have evolved as an established practice amongst the scientific risk community to quantify a value of risk, based on the hazard potential of industries and the potential for damage to population present in the neighbourhood (Lees, 1996; Christou et al., 2011). However, several aspects like the availability of dependable data, identification of accident scenarios, risk calculation models and risk acceptance criteria continue to be researched and debated in many countries of the world (Fabbri et al., 2009; Salvi et al., 2006).

Different elements of the QRA method have evolved over time and are considered to be based on sound scientific knowledge in the risk assessment practice (Lees, 1996; Baesi et al., 2013; Pasman et al., 2014). In order to obtain a better understanding, it is required to recognize the different elements of the QRA method and their inter-relation within the risk assessment framework. In the following sections these different components of a QRA method are discussed.

\subsubsection{Hazard (scenario) identification}

This step involves attaining an understanding of the hazards, including the location, type of storage involved and the hazardous property of the 
chemicals. It also refers to the characterisation of the risk associated with hazardous storage(Ale, B.J.M., 2002b).

For scenario identification, generally, a two phase process is followed. The relationship between the two is represented by a 'bow-tie' model. First is a 'fault tree' that leads up to the stage where a 'Loss of containment' or 'Top event' can occur. Second, an 'event tree' considers the sequences of events following the loss of containment (Christou, M.D. et al., 2011b).In this regard, the definition of a 'scenario' must be clarified. In principal, the whole bow tie, since the beginning (i.e. initiating event) to the end (casualties or injuries etc.) is an accident scenario. For example, the corrosion as an initiating event leads to a pipe leak (i.e. LOC) ends up in pool fire (i.e. dangerous phenomenon) and additional consequences (e.g. casualties or injured people) is considered to be as an accident scenario. Likewise, another accident scenario could be the corrosion as initiating event leads to a pipe catastrophic rupture which ends up in VCE and death of people. Figure 2-2 illustrates an example of the scenario trees for LPG storage leaks from a pressurized above ground storage tank through a logical sequence of steps from: storage-critical event-dangerous phenomena-effects.

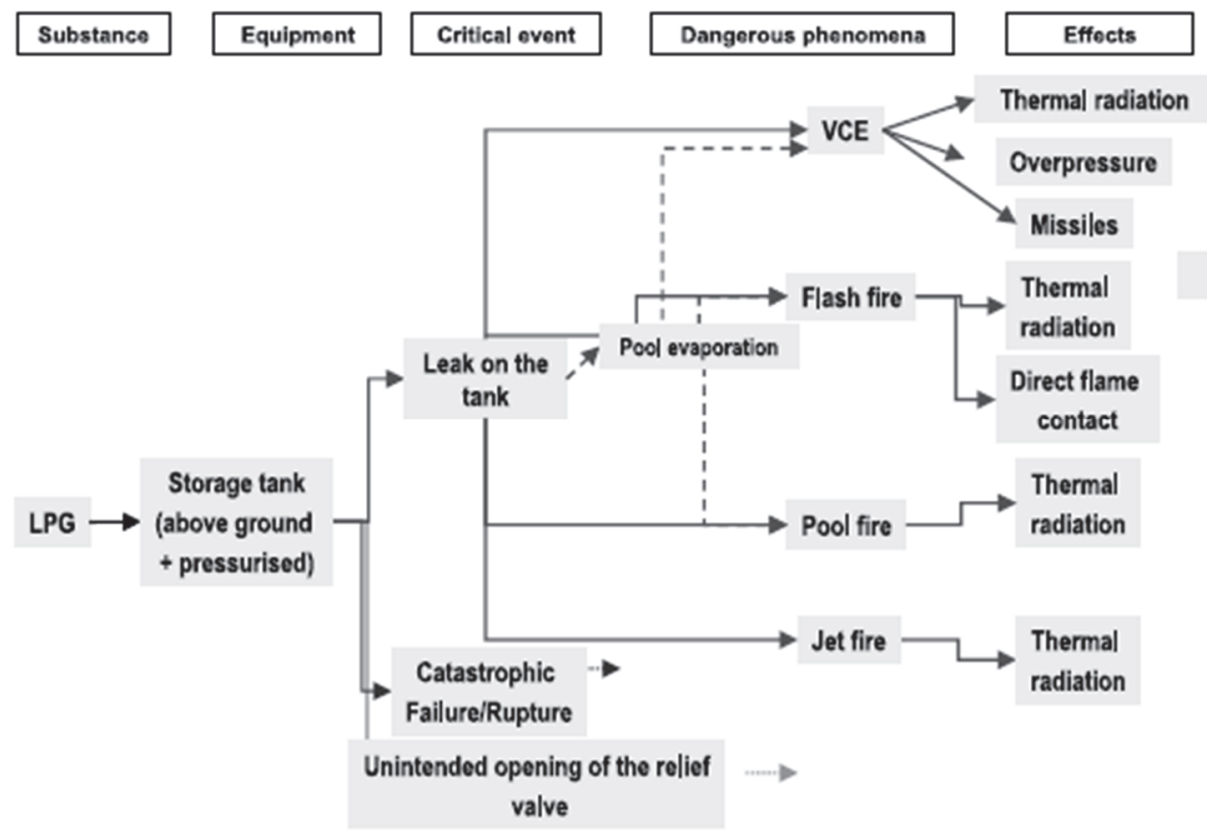

Figure 2-2: An example of a scenario tree for LPG storage tank leaks Source: (Christou et al., 2011b) 


\subsubsection{Frequency estimation}

Once the possible hazard scenarios and the type of negative outcome are identified, the scenario frequency is determined based on the failure frequency of the initiating event and the probability of intermediate events. The frequency of a scenario specifies the number of probable occurrences of that scenario in a period of time and is generally taken from failure frequency databases and literature prepared after analysing historical data of previous incidents (Uijt de Haag, et al., 2005a). The probability of an intermediate event varies from 0 to 1 indicating the possibility of occurrence of that event (Baesi et al., 2013). The following example in Figure 2-3 shows how the estimation of frequencies can be made for four possible accident outcomes (Jet Fire, Flash Fire, VCE, Tank BLEVE, Road Tanker BLEVE) that may originate from the Full Bore rupture of a pipe through which highly inflammable Propane gas is being loaded from a Storage Tank to a Road Tanker (Casal, 2008).

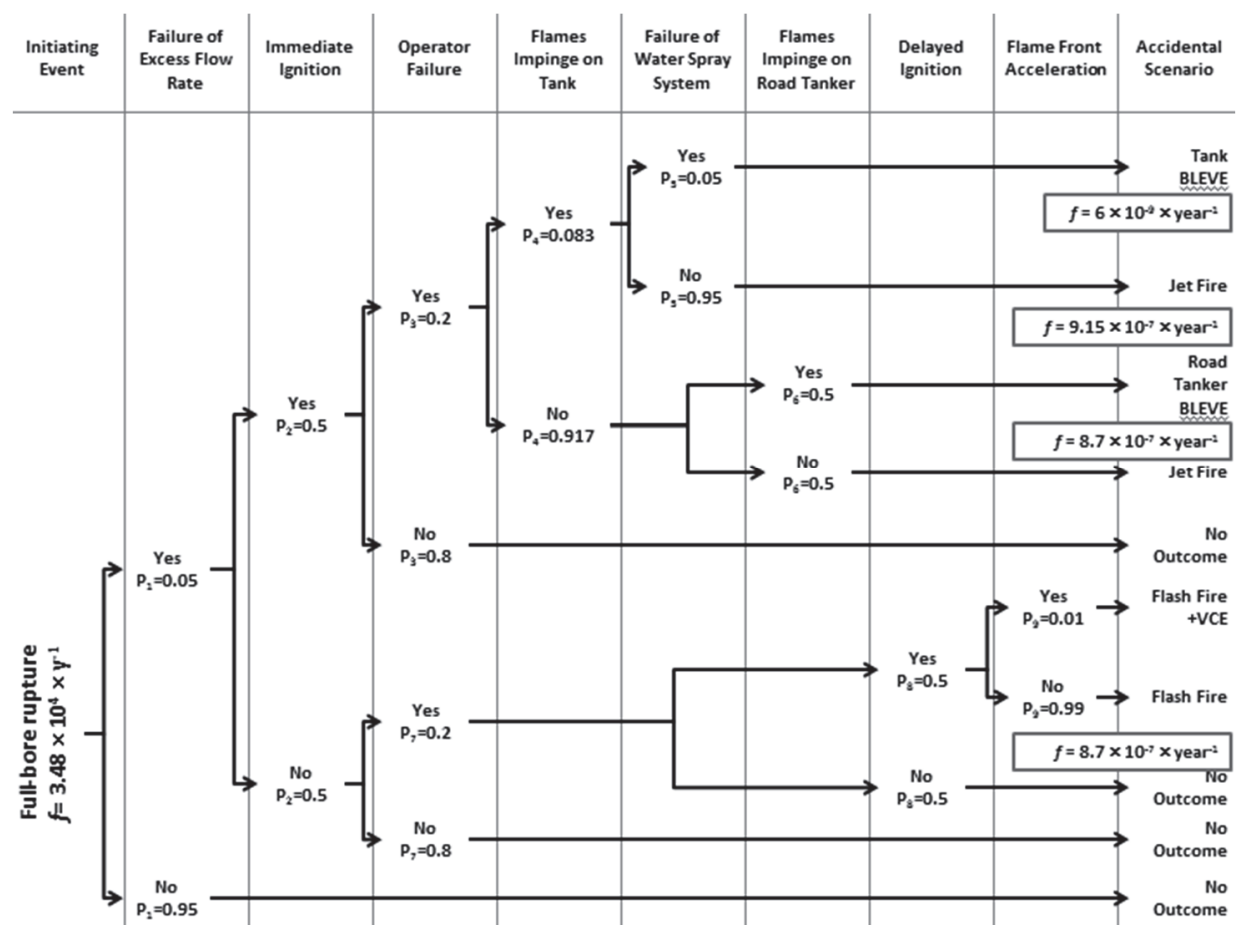

Figure 2-3: An example of accident scenarios and frequency for full bore rupture of propane pipeline. Source: Casal (2008)

\subsubsection{Consequence analysis}

The consequence assessment involves determining the impact of an event in terms of physical extent and severity(Lees, 1996). The physical extent of an accident scenario usually involves the calculation of the effect-distance (i.e. 
maximum distance with certain intensity) from the source within which people might get affected. The severity of an event is expressed as a level of harm to people, mostly in the form of a fatality or level of injury.

Typically, once accident scenarios have been established through the process of hazard identification, mathematical algorithms are then used as a part of a consequence analysis to estimate the physical effect that may be caused and the potential impact it may have in terms of injuries or fatalities, damage to property or damage to the environment. The physical phenomenon involved in an accident being considered (mainly, toxic release, fire or explosion) is dependent on the nature and type of hazardous chemicals and specific information on hazardous storages located within fixed installations. The effect of an accidental event is also influenced by factors extrinsic to the hazard source like meteorological conditions and the presence of physical features in the affected zone, which can act as barriers and reduce the impact of the physical spread to the hazard.

Once the modelling of physical effects (i.e. thermal radiation, overpressure wave, dispersion of toxic substances) is predicted, generally as a function of a distance from the hazard source, then consequences of these accidents is determined based on specific end-points:

- For toxic release, it is the concentration of the gas in air in parts per million (ppm);

- For thermal radiation, it is radiant energy flux measured in Kilowatt per square meter $\left(\mathrm{KW} / \mathrm{m}^{2}\right)$;

- For explosion, it is the overpressure in pounds per square inch (psi).

In order to estimate such consequences of an accident on humans, a function relating the magnitude of the impact is required. Customarily, two types of models are used to estimate the effect of radiation, overpressure and toxic release on people. For quantitative risk assessment purposes, the method used to assess such impact on people is based on Probit functions (i.e. mathematical value between the dose or the exposure and the fraction of people that might get killed). Important to mention, several algorithms have been discussed extensively in the literature, See (AIChE/CCPS, 2000; Pe, 2005; Uijt de Haag, et al., 2005b).

In other cases the analysis is concluded by the assessment of the concentration field compared to threshold limits (i.e., a limit on a measurable quantity representing a certain potential effect, established or formally accepted by a regulatory body)(Ale, B.J.M., 2002b; Fabbri et al., 2009). For example, for toxic releases, the level of concern for an airborne gas is expressed as a specified concentration over a set time period and for a defined population group set up by government agencies and professional organisations. It can be expressed as the three tier Emergency Response 
Planning Guidelines (ERPG) levels of concern published by the American Industrial Hygiene Association (AIHA) (American Industrial Hygiene Association) or the Immediately Dangerous to Life or Health (IDLH) levels defined by the US National Institute for Occupational Health and Safety (NIOSH). They provide exposure concentrations to airborne contaminants that is likely to cause death or immediate or delayed permanent adverse health effects or prevent escape from such an environment.

\subsubsection{Estimation of Risk}

Finally, the risk estimate is derived by multiplying the consequence of the event and the probability of occurrence. The risk is represented in the form of metrics like individual and societal risk (Jonkman et al., 2003).

Individual (or location-based) Risk (IR) is the probability at which an individual may be expected to sustain a given level of harm from the realization of specified hazards (Engineers, 1992). In simple terms it measures as the probability that an (unprotected) person dies in one year as a consequence of an accident with hazardous substances and is expressed as a frequency (per year).Principally, the IR estimation takes into account an annual frequency of occurrence of a reference damage (e.g. fatalities) in any area for a person present 24 hours/day and 365days/year without protection and possibility of being sheltered or evacuated. Graphically IR can be represented as a set of risk contours around a hazardous installation.

Societal Risk (SR), another risk measure of the QRA approach, is the relationship between frequency and the number of people suffering from a specified level of harm in a given population from the realization of specified hazards (Engineers, 1992). Therefore, if no people are present around the hazardous activity, SR is zero whereas IR may be quite high (Bottelberghs, $2000 \mathrm{~b})$. It is represented through a societal risk ( $F, N)$ plot showing cumulative complementary frequency distribution where the absolute probability $\mathrm{F}$ for an accident with more than $\mathrm{N}$ lethal victims is plotted against group size N (Ale, B.J.M., 2002b; Bottelberghs, 2000b). The risk measures are illustrated in Figure 2-4. 

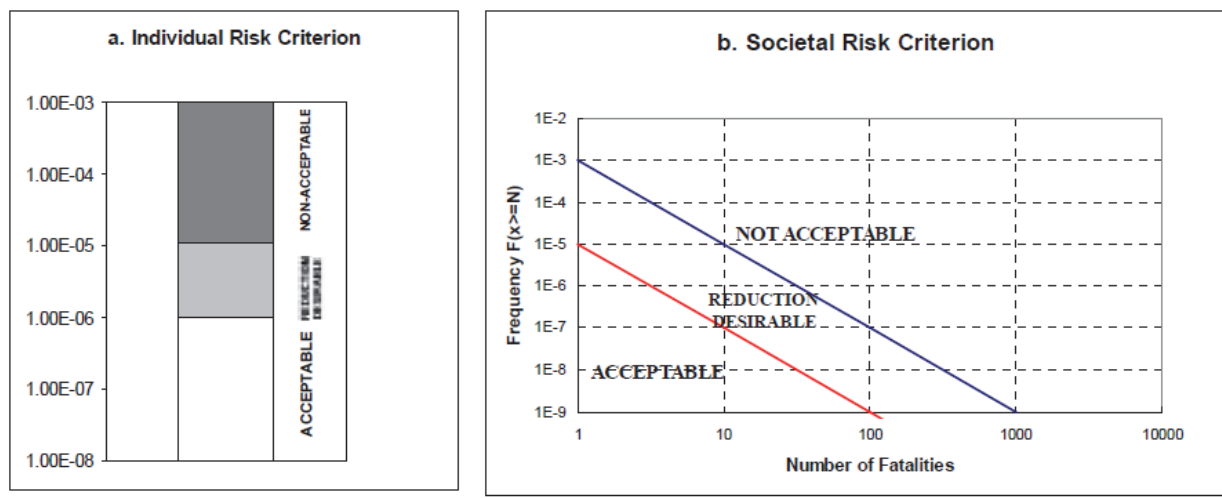

Figure 2-4: Examples of Risk Acceptability Criteria for (a) Individual and (b) Societal Risk measures in the Netherlands Source: (Christou et al., 2011)

The outcome of a QRA based risk assessment is often a risk map and Vamanu, 2004). As both hazard and vulnerability have a strong spatial dimension, risk is mostly displayed in maps showing the distribution of risk which together with the risk-related attributes form the basis for risk evaluation (Büchele et al., 2006; Carpignano et al., 2009; Lahr et al., 2010; Tyagunov et al., 2006). Presented through paper or electronic means, risk maps can play an important role in ensuring that the results of risk assessment are communicated to all actors involved in the risk assessment process or in some way are affected by risk related decision making (Basta et al., 2007; Moen and Ale, 1998). For industrial risk, the traditional method of risk mapping is based on quantitative techniques (Cozzani et al., 2006). This requires understanding of many aspects such as potential accident scenarios, probability of occurrences, and impacts like fire, explosion or toxic releases. The computation of a risk metric like individual or societal risk lead to visualization on a map of the concerned area, assisted by software tools (Spadoni et al., 2000; Uijt de Haag, , 2013). In several developed countries, preparation of risk maps for the major types of hazards (such as industrial hazards) is mandatory according to policy or regulatory frameworks. This will be worked out in the next chapter with illustrations from several European countries.

\subsection{Risk-informed Decision Making}

\subsubsection{Emergency Preparedness and Response Planning}

The practice of industrial risk management deals with short-term strategies and plans that can help the administration and communities at risk to prepare for and respond effectively to major accidents originating from hazardous facilities. Effective management of emergencies requires careful planning, preparedness and response in order to be able to reduce damage, 
rescue victims, and ensure quick return to normalcy (FEMA, 1997). In the perspective of industrial risk, this would mean accidents like a toxic release, fire or explosion originating from a hazardous industry or a transportation accident involving a hazardous chemical. Emergency management deals with short-term preparedness and response strategies as well as long-term mitigation plans that can help the administration and communities deal with an emergency (Alexander, 2002).

Literature on emergency management identify following four key phases:

Mitigation: pre-disaster efforts directed at reducing the effect of a probable industrial event on human life and personal property;

Preparedness: actions taken prior to a disaster event that enables disaster management units to appropriately respond to the hazard;

Response: actions taken immediately prior to, during, and after, the accidental event that assists in reducing human and property losses as well as actions taken to aid in the post-disaster recovery effort;

Recovery: actions and measures that facilitate the return of social and economic activities to an acceptable standard (Haddow et al., 2013).

The task of managing industrial emergencies is complex. Experience has shown that they often develop very rapidly, with factors that may change rapidly over time (e.g. weather conditions, traffic volumes, etc.). They are often difficult to predict and require multiple actors to work in coordination to arrive quickly at decisions to protect the community and the environment (Georgiadou et al., 2007; Sorensen et al., 2004). In addition, judgments during an emergency are often tentative, imprecise and approximate due to incomplete information, and the inherent complexity and uncertainty of a rapidly evolving decision environment, where a mistake can lead to immensely adverse consequences on life and property (Levy et al., 2007). Such dynamic and time-sensitive requirements require emergency managers to efficient use up-to-date information from several heterogeneous and multidisciplinary sources in order to be able to make correct decisions. The decision-making requirements are most critical when an accident situation evolves, accompanied by uncertainty and rapidly changing information. A delay in reaching a decision may lead to higher loss of lives and/or damage to property.

\subsubsection{Land Use Planning}

Significant damages caused by industrial accidents like Bhopal and Mexico City is related to inappropriate land use near highly hazardous facilities. In most of these cases, either the siting of an industrial facility was made 
without taking into consideration proximity to existing settlements or demographic pressure led to the migration of population around the hazardous industry later. This point to ineffective land use planning or regulatory restrictions leading to an increase of risk in industrial areas. Consequently, judicious planning of land use around hazardous facilities or deciding on the siting of new hazardous facilities is internationally accepted to be an important risk reduction or mitigation measure and have been implemented through directives and legal instruments.

The implementation of the Seveso Directive, providing regulatory guidance on risk-based land use planning, amongst European Member States, is a good example in this regard. A review of such country-level procedures and practices show considerable diversity in terms of methods for identification of risk scenarios, probability of failures leading to accidents, consequence models used for risk calculation and criteria for risk acceptability depending on the perception of the prevailing safety situation, country level regulatory approach towards risk assessment (Pasman et al., 2014). This will be worked out in the next chapter with illustrations from several European countries.

\subsection{Risk Communication}

A related but equally important front in risk governance concerns the availability of risk information, communication between concerned parties and awareness amongst stakeholders. Risk governance emphasizes the importance of effectively exchanging risk information in order to enable stakeholders and civil society to understand the results from the risk assessment process and the justifications for decisions taken based on this information, guiding them to make informed choices about risk (Renn, 1999). The IRGC risk governance model also considers risk information and communication as a central element of integrated framework for risk management (IRGC, 2005).

General principles formulated through international and regional conventions have recognised that citizens have a right to know about their environmental and risk related issues in their neighbourhood, express their concerns and be party in decision making in order to enhance the quality and the implementation of such decisions (UNCED, 1992; UNECE, 1998). The Hyogo Framework for Action 2005-2015 stressed the use of knowledge, innovation and education to build a culture of safety and resilience from risk at all levels of governance. An important cornerstone of this strategy is the provision of information on disaster risks and appropriate protective action to citizens exposed to risk and the strengthening of information networks and dialogue amongst risk experts, managers and planners (ISDR, 2005). The strategy laid considerable emphasis on the development of national information 
sharing systems to capture relevant knowledge on disaster risk reduction and dissemination to risk actors and citizens. This has recently been carried forward through the Sendai Framework for Disaster Risk Reduction 2015 2030 (UN, 2015).

The success of regulatory approaches for industrial risk management depends to a considerable extent on the availability of up-to-date and valid information on hazards, dangerous substances, and vulnerabilities existing in the surroundings of hazardous installations. International agreements like the Aarhus Convention oblige public authorities to allow public access to environmental information and provide opportunities for participation in the decision making process (UNECE, 1998). In Europe, the Seveso Directive (82/501/EC \& 88/610/EC) stresses the exchange of information between governments, industry and the public and requires Member States to actively inform the public likely to be affected by potential industrial accidents about the nature of the risk and the best way to act in the event of an accident (EU, 2012). However, there is also a strong debate on how much, what hazard and risk information should be shared with the public, and the level of acceptance to share such information varies with the regulatory style prevailing in individual countries (Wynne et al., 1991 154).

Initially, the risk communication mandate for hazardous industries revolved around the view of 'need to know' where information could be passively conveyed to the community on aspects like emergency action. However, with an evolving paradigm for a more active communication of risk information, the communities have increasingly voiced support for a 'right to know' about sources of hazards and prevailing risk as also participation in risk related decision making. This led to the strengthening of public information provision in many regulations proposing adoption of active methods for supply of information and led to the evolution of a broader relationship between government, industry and the public for handling risk problems (Walker et al., 2000). The public is increasingly not ready to accept the legitimacy of decisions involving environmental or hazard related issues, particularly those pertaining to regulatory decision making that depend on scientific evidence to underpin or justify such decisions. There is an increasing interest in deliberative approaches to environmental risk related issues that seek to encourage the involvement of stakeholders in the public decision making process at the local level (Owens, 2000; Spash, 2001). Consequently, the need for proactively sharing of information related to hazards is also becoming the norm as compared to the reactive stance that was maintained by hazardous industries previously, citing concerns of security or of alarming the neighbouring community (Gouldson, 2004). It is expected that with time, the adoption of such approaches will lead to the emergence of new 
governance paradigms, which would be more inclusive i.e. involve transparent sharing of information and participation for decision-making. 


\section{Chapter 3 - Industrial risk and land use planning - European experience}

This objective of this chapter is to give a summary of the development of major accident legislation, the Seveso II Directive, and legal background relevant to major accidents in the EU.

\subsection{Concept of risk in land use planning}

Over the years, with the evolution of human society, decisions on the uses of land have changed. Earlier land use changes often occurred following separate decisions taken by individuals, while at present the changes are often taken place by the process of planning. Land use planning has become frequent because of the changing needs and pressures including competing uses for the same land. The principal function of land use planning (LUP) is to guide decisions on uses of land in such a way that the resources of the environment can set to the most beneficial use for man, and at the same time conserving them for future.

The concept of land use planning has changed gradually over time. Traditionally, the term depicted efficient uses of land while now it is considered to be a multi-dimensional process, having a 'spatial' aspect in it, describing the amalgamation of natural environment and its use by humans. Thus the term 'spatial planning' came into picture. In simple words, spatial planning is a process of decision making by weighing social, ecological and economic demands of a society for a balanced development (Christou et al., 2006a). At the same time, land use planning has become increasingly complex. The principles of sustainable development confront land planners with a paradox of two apparently contradictory objectives: nature conservation and economic development (van Lier, 1998). Consequently, the NIMBY(Not In My Back Yard) or LULU (Locally Unwanted Land-Use) controversies became more relevant to illustrate the difficulties that often arise when a development project significantly modifies its surrounding environment (Shrivastava, 1995; Walker, 2000).

From this viewpoint, problems associated with planning the land uses around hazardous installations originate from the fact that under certain condition an industrial facility is able to cause accidents with off-site consequences. Accidents like Bhopal and Mexico tragically demonstrated how inappropriate uses of land near highly hazardous facilities resulted into large scale damage in the surroundings. In most of the cases, it has been observed that either the siting of an industrial facility was made without taking into consideration proximity to existing settlements or demographic pressure led to the migration of population around the hazardous industry later. Hence, this 
ineffective land use planning or regulatory restrictions could lead to an increase of risk in industrial areas. Early studies conducted in the industrial areas of Netherlands, have concluded with the requirement to formulate riskinformed decision criteria for land use planning purpose (COVO, 1982). Consequently, judicious planning of land use around hazardous facilities or deciding on the siting of new hazardous facilities is internationally accepted to be an important risk reduction or mitigation measure for managing risk that may arise from development of industrial areas and have been implemented through directives and legal instruments (ISDR, 2004).Learning the lessons from these accidents and many others, the International Strategy for Disaster Risk Reduction (ISDR) therefore prioritises land use (spatial) planning as one of the key instruments for disaster risk reduction in hazard prone areas, in particular for areas which are highly populated or are witnessing fast urbanisation (ISDR, 2005). As a part of this focus and more recently the Sendai Framework for Disaster Risk Reduction ${ }^{18}$ encourages the development and upgrading of methods and tools to guide risk reduction strategies and risk sensitive spatial planning. The concept of risk-based planning is also encouraged by the UNISDR ${ }^{19}$ by highlighting the role of land use plans to control or prevent development in extreme risk areas, and to mitigate risk in existing developments.

In this regard, many countries have developed legal instruments that take into account risk acceptability criteria in spatial planning, for the management of industrial risks originating from hazardous installations and transportation of hazardous substances. In continental Europe, where hazardous installations are often located in areas having high population densities, the Seveso II Directive requires that the consequences of industrial accidents be taken into account. This is done through appropriate land use policies and controls when dealing with the planning of new industrial facilities, undertaking modifications to land use around existing ones and new residential developments in the vicinity of hazardous establishments (Porter et al., 1999; Versluis et al., 2010).

\subsection{Relevance of Article 12 of Seveso Directive II}

Twenty years after the accident at Seveso in Northern Italy, in which a large rural area was polluted by a dioxin release, the Seveso II Directive formalized the need of 'bridging the gap' between two traditionally independent disciplines: risk assessment and land use planning (Horlick-Jones, 1998).

18 United Nations (2015): Sendai Framework for Disaster Risk Reduction, United Nations, Geneva pp. 2015-2030 http://www.unisdr.org/files/43291 sendaiframeworkfordrren.pdf

19 UNISDR(2013): Proposed Elements for Consideration in the post-2015 Framework for Disaster Risk Reduction;

http://www.preventionweb.net/files/35888 srsgelements.pdf 
Considering 'risk' as the central element in the decision making process regarding land use planning, is the main contribution of the Seveso II Directive. Within the scope of the Directive II, in particular, Article 12 requires that the objectives of preventing major accidents and limiting their consequences be taken into account by the Member States in their land use policies and/or other relevant policies (Basta et al., 2008; Christou et al., 1999b). It recognises that planning policies can be directed towards the need, in the long term, to maintain appropriate distances between establishments covered by the Directive and residential areas, areas of public use and areas of particular natural sensitivity or interest. In case of existing establishments planning shall recognize the need for additional technical measures so as not to increase the risks to people.

The relevant part of the Article 12 read as follows:

"...Member States shall ensure that the objectives of preventing major accidents and limiting the consequences of such accidents are taken into account in their land-use policies and/or other relevant policies. They shall pursue those objectives through controls on:

a) Siting of new establishments,

b) Modifications to existing establishments,

c) New developments such as transport links, locations frequented by the public and residential areas in the vicinity of existing establishments, where the siting or developments are such as to increase the risk or consequences of a major accident."

"...Member States shall ensure that land use planning and other relevant policies and the procedures for implementing those policies take account of the need....to maintain appropriate distances between establishments covered by this Directive and residential areas...."

In spite of this common objective, the Directive does not stipulate a specific form on how the objectives of Article 12 shall be achieved. It was (and is) left to the Member States how this rather generic concept is to be implemented in their national legislation. Accordingly, many Member States have formulated their preferred approaches for assessing risk levels of the hazardous facilities to guide the planning decisions around a hazardous establishments that complies with the requirements of Article 12 (Hauptmanns, 2005; Christou et al., 2006b; Cozzani et al., 2006; Basta et al., 2008; Kontic et al., 2009; Pey et al., 2009; Sebos et al., 2010; Taveau, 2010). The procedures, methodologies and criteria developed by each country reflect its safety culture and attitude towards risk, in accordance with their respective political, cultural, technical, legal and societal backgrounds. 


\subsection{Review of existing risk assessment approaches used for LUP decisions}

As defined in several comparative studies and EU surveys (Christou. et al., 1999a; Christou et al., 1999b; Cozzani et al., 2006) from the methodological point of view, the approaches followed for risk-based LUP decisions amongst the Member States can be divided in the following four categories:

a) Risk-based (quantitative) approach;

b) Consequence-based (effect-based) approach with implicit consideration of frequencies;

c) Semi-quantitative approach; and

d) Deterministic / Generic safety distances approach

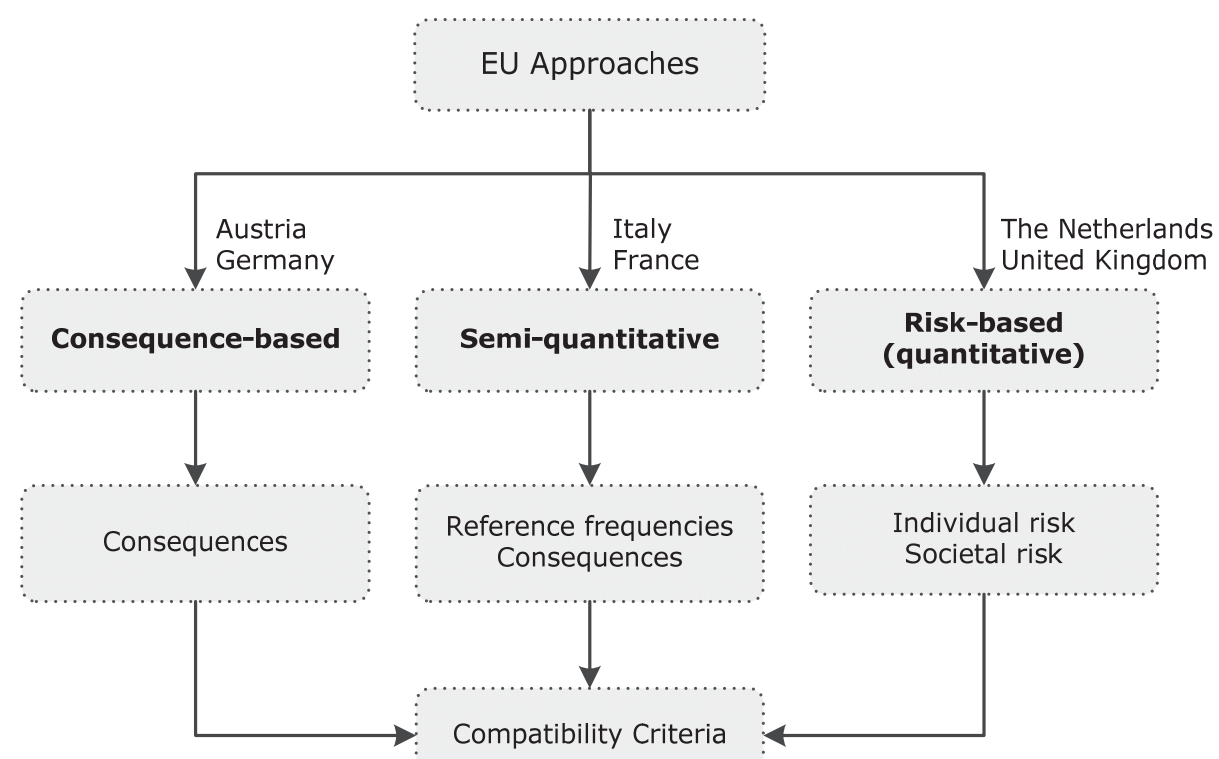

Figure 3-1: Overview of risk assessment approaches for LUP as practiced in the Member States

\subsubsection{Risk-based or quantitative approach}

The risk-based approach (also known as probabilistic approach)is characterized by a final decision based on a numerical risk figure. For reasons of practicability the form of a single figure is preferred, although a strictly mathematical calculation would require a measure of uncertainty of the final number. The underlying approach is probabilistic, i.e. based on a definition of risk as a numerical definition of effects and frequencies of accident events. In brief, the risk-based approach focuses on the assessment of both probabilities of occurrence and the possible consequences of accident 
scenarios. The results are then quantified in terms of individual risk and societal risk and criteria to assess the risk to which the public is exposed.

The approach is followed in the Netherlands and in the United Kingdom; however with different criteria and practical details. In the Netherlands an accident resulting in individual risks higher than $10^{-6}$ is considered unacceptable; whereas in UK, three zones are determined, for toxic releases corresponding to $10^{-5}, 10^{-6}$ and $3 \times 10^{-7}$ levels of individual risk of receiving a dangerous dose or worse, and within each zones the types of developments allowed are then specified accordingly.

\subsubsection{Consequence-based approach}

Another category used in Land Use Planning is the consequence-based approach focuses on the assessment of the consequences of a number of reference scenarios obtained from a quantitative risk assessment study. Damage threshold values for physical effects (i.e. overpressure, thermal radiation, toxic concentration) of an accident scenario are determined with respect to undesired consequences of fatalities, irreversible effects, reversible effects, etc. Differing from the risk-oriented approach, this approach requires a limited number of decisions. This approach is however extensively criticised since it is based on the subjective choice of reference scenarios by expert personnel. Moreover, this selection is made considering historic data and qualitative information which have previously been obtained in the hazard identification process.

Important to mention is that the main difference between risk-based and consequence-based approaches lies in the way how frequencies of an accident event are used within the evaluation. Moreover, the risk-based approach (also known as probabilistic approach) seeks to picture the real situation as much as possible in a more dynamic form. Whereas, the consequence-oriented approach depicts a homogenous situation which covers all deviations (thus adding a safety factor to the statistic results). The probabilistic approach is more ambitious and requires more data input and related efforts.

\subsubsection{Semi-quantitative approach}

The semi-quantitative approach is a hybrid approach which splits the main elements (i.e. likelihood and consequences) into two different choices of description, qualitative or quantitative. In this approach, estimation of frequency of occurrence of an event represents the qualitative aspect whereas evaluation of consequence is the quantitative aspect. Finally, risk is thereby determined by means of a matrix combining a qualitative occurrence axis with a quantitative consequence measure. Except for splitting up in the 
first step of the decision scheme, the data requirements are the same as in the case of the other methods. A comparison of semi-quantitative and quantitative approaches is shown in Figure 3-2. This approach is used in Italy and France.

\subsubsection{Generic safety distance approach}

The deterministic approach is very simple as it is based on safety distances whose length depends on the type of dangerous substances that can potentially be involved in an accident. The determination and use of "generic" safety distances is based on the type of activity rather than on a detailed analysis of the risks. These safety distances are based on the concept of separation zones, and usually depend on the type of industrial activity and on the quantity of and type of hazardous chemical. These distances are defined on the basis of experience and on the evaluation of similar past accidents. Practically, this is a 'zero risk' approach, which is conceptually close to the concept of traditional land use planning framework.

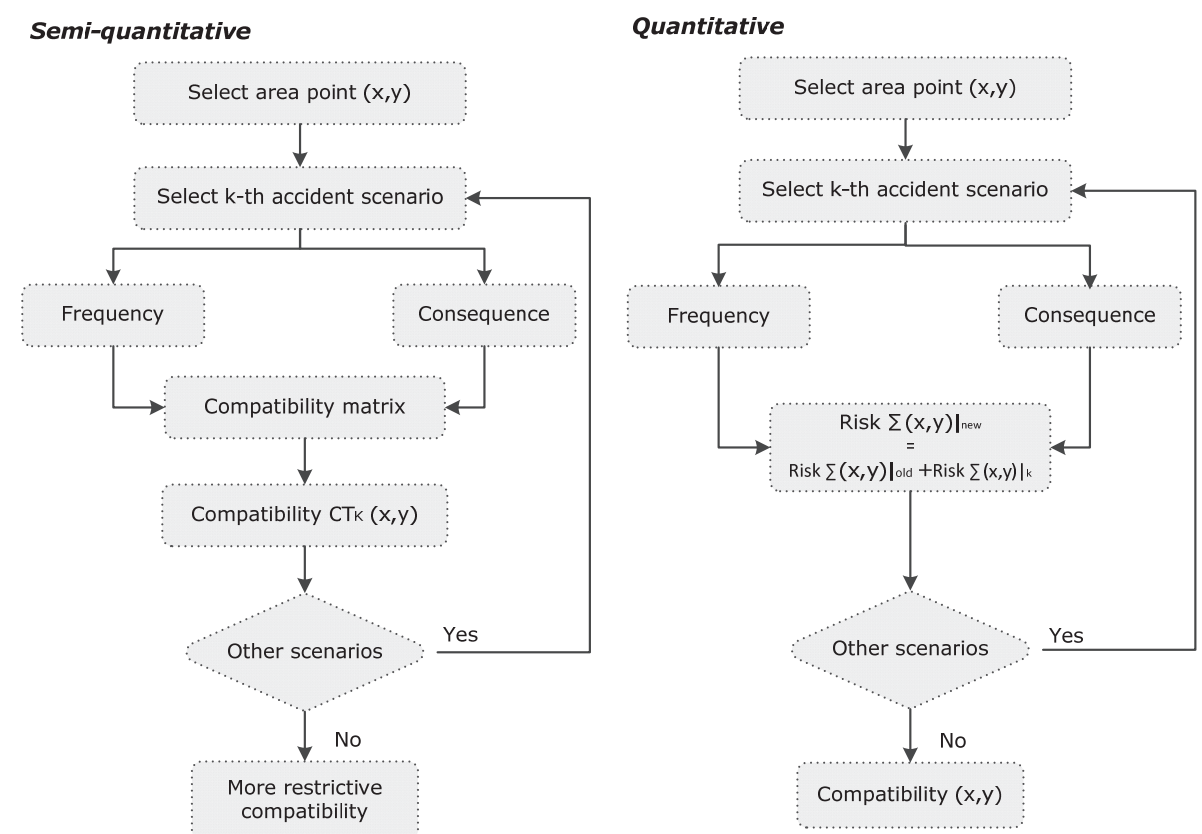

Figure 3-2: Comparison of semi-quantitative and quantitative approaches

\subsection{European practices in implementing Art 12 of Directive II}

In this section, the country-level approaches for implementing the Article12 of the Directive II from The Netherlands, United Kingdom, German, France, and Italy are discussed. 


\subsubsection{The Netherlands}

The Kingdom of the Netherlands, the most densely populated European country, has developed its safety regulation since the ' 80 's, when the increase of the use of LPG became evident together with the connected storage problems. Extensive studies on LPG led to the development of quantitative assessment procedures and, in the light of the scarcity of land, to the development of sophisticated quantitative criteria for the evaluation of risk acceptability based on the likelihood of occurrence of the events. A riskbased approach had been used for the optimization of the flood defences of the low-lying Netherlands prior to its application in land-use planning with respect to industrial safety. Divided in Provinces and Municipalities, the country is well known for being an under-sea level territory for a main part of their extension. Due to the presence of the main industries and commercial harbours; it is also the most populated. Consequently, safety matters in The Netherlands are instinctively connected with flood risks, and the probabilistic approach developed for their management in the '70 has led to the current safety culture addressed.

The assessment of risk from hazardous installations in the Netherlands is guided by the External Safety Policy and traces its origins to the 1970's when the Rijnmond risk assessment study was commissioned to formulate safety goals and then relate them with land use planning guidelines (BRZO, 1999; COVO, 1982). The Dutch risk assessment practice is hinged on the use of QRA methods to determine risk, which is then compared to criteria's for individual risk (IR) and societal risk (SR). The QRA process requires the adoption of a standard process as stipulated in the BEVI Manual for RA resulting in the estimation of a numerical value for risk (Uijt de Haag, 2013). For populated areas, the Dutch Ministry of Housing, Spatial planning and Environment (VROM) has set the standard IR $<10^{-6}$ (per year) and the spatial disposition of IR is generally represented with iso-risk contours overlaid on a geographic map of the establishment and its vicinity (Bottelberghs, 2000b). In addition, the SR criterion is also taken into account in order to plan for any new development in an area, where risk sources are present. 

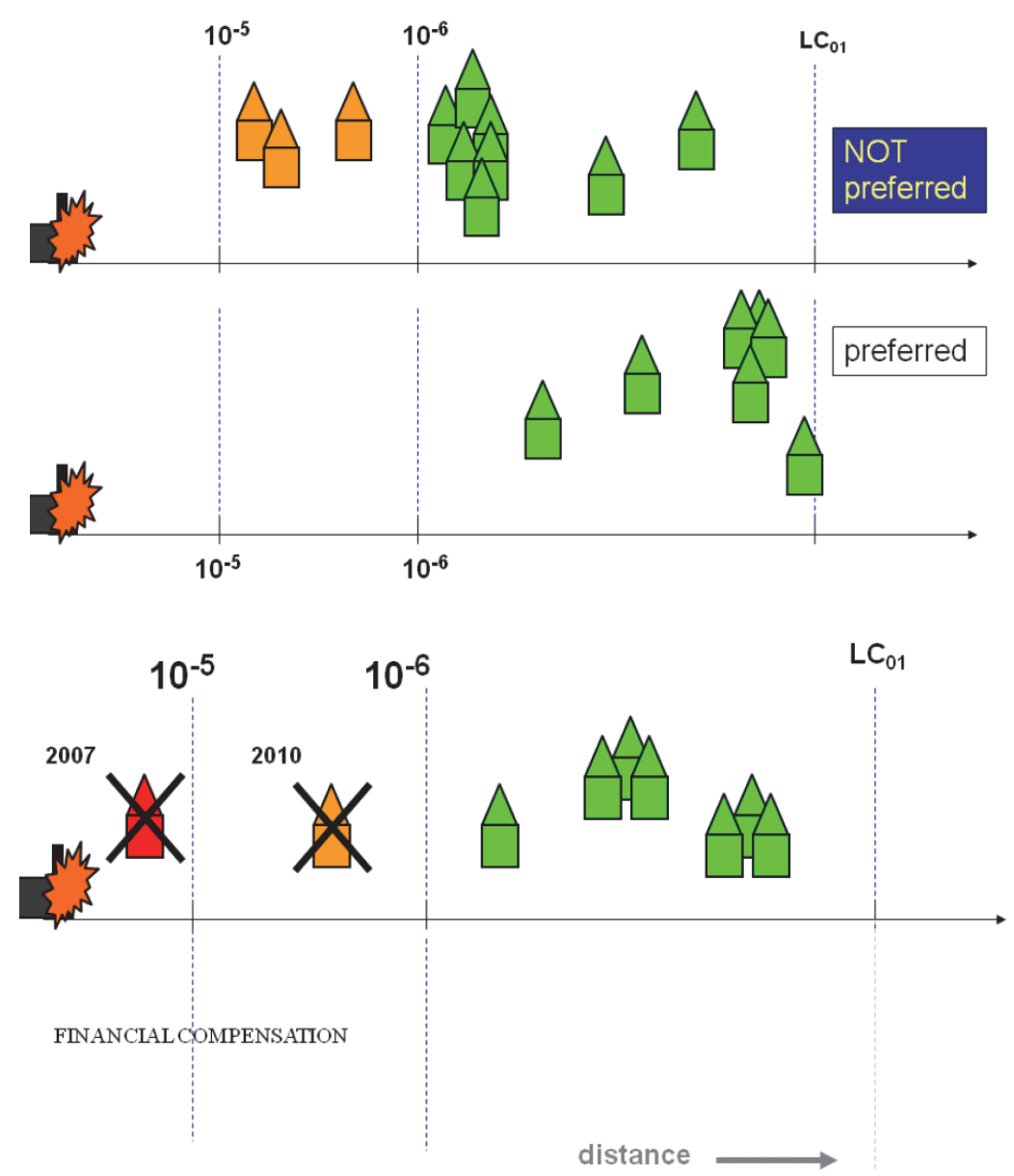

Figure 3-3: Spatial planning criteria for new developments (above) and for the existing situation (below)

The Dutch legislation defines the thresholds for the individual risk and sets the target for the societal one. The value prescribed for the individual (location-based) risk of $10^{-6}$ is legally binding for vulnerable objects (e.g., hospitals, residential areas, schools); while a target value of $10^{-5}$ applies to less vulnerable objects (e.g., buildings, hotels, restaurants, shops). However, for societal risk, the evaluations are carried out case-by-case but no limiting values are in place. Nevertheless, legislation requires the Municipalities to document how the societal one is taken into account in their planning decisions.

\subsubsection{United Kingdom}

The United Kingdom has one of the longest European traditions with respect to external safety policies. A safety culture has been created and supported 
since the 70's by one of the best-known European safety institutions, the Health and Safety Executive (in Northern Ireland, the HSE of Northern Ireland).Differently than the Netherlands, the UK relies on HSE -the centralized competent authority for safety-concerned issues. The Agency is considered as the institutional link between risk assessment and land use planning procedures, because each planning evaluation in UK's risky areas is carried out following the technical advices furnished by HSE to Local Planning Authorities (LPAs). In particular, HSE advices the LPAs on the hazardous substances consent (i.e. installation and/or modification of the Seveso establishments) as well as on the compatibility of proposed developments within pre-existing dangerous areas. This second advice is carried out by personnel of the local offices of the HID and supported by a system known as Planning Advice for Developments near Hazardous Installations (PADHI ${ }^{20}$. Traditionally, the cooperation among the LPAs and the HSE is effective, and even if applying the advices is not obligatory, LPAs usually recognizes HSE as the appropriate body to assess their plans for health and safety concerns.

With respect to licensing procedure and prescribed risk assessment methods legal references are: the Notification of Installation Handling Hazardous Substances Regulations (NIHHS) and/or the Control of Industrial Major Accidents Hazard Regulation (CIMAH) ${ }^{21} 1999$; and for land use planning in the surroundings of chemical sites is regulated by the Planning (Hazardous Substances) Act $1990^{22}$ and the Planning (Hazardous Substances) Regulations $1992^{23}$, as amended by the Control of Major Accident Hazards (COMAH) Regulations 1999, which recently were replaced by the COMAH Regulations 2015 in accordance with the Seveso Directive III (Walker, 1995; Walker et al., 2000b).

Risk analysis is the basis of the procedure of land use planning in the surroundings of plants carried out by the HSE. The method in use to assess the risk is addressed depending on the specific scenario and substances: for advising related to toxic releases the approach is the risk-based while in the case of thermal radiation and explosions the method is based on the consequence-oriented approach ${ }^{24}$. In the first case, the zoning system is

20 PADHI Methodology, Retrieved from: http://www.hse.gov.uk/landuseplanning/padhi.pdf

21 Source:Risk Criteria for land use planning in the vicinity of major industrial hazards, The Health and Safe Executive, www.hse.co.uk

22 Each of these Acts has been amended by the Planning and Compensation Act 1991.

23 COMAH regulations: http://www.legislation.gov.uk/uksi/2015/483/pdfs/uksi 20150483 en.pdf

24 This difference is based on the characteristic of the explosions and thermal radiation to present a sharp decline at a specific distance, where specific thermal radiation or overpressure is achieved. 
based on the probability to receive at least a dangerous dose ${ }^{25}$; in the second one, the zoning is based on the receipt of prescribed thermal dose units. The criteria used to determine the likelihood of incurring these effects are both the individual and the societal risk. As in the Netherlands, both the individual and the societal risk are LUP criteria ${ }^{26}$. The societal risk is not numerically assessed and compared with numerical risk criteria. The concept refers to the presence of high-density populated areas and/or specific vulnerable targets (hospitals, schools, elderly, children, etc.), has to be considered in order to integrate the judgment resulting from the individual risk criteria. Hence, SR assessment is an integration of the individual risk estimation with population data. Interestingly, this approach to the definition of societal risk for modelling major accident scenarios involves a major attention for the vulnerability of the population of a given area.

The HSE standard method has several well-developed tools for evaluating both. But with respect to the complex concept of 'societal risk' it has been adopted a 'judgmental approach' to evaluate a risky situation in its particular aspects, by integrating the result of the individual risk figure with additional population data. For the purpose, a system known as Planning Advice for Developments near Hazardous Installations (PADHI) came into force in 2002 in order to facilitate the advising process in terms of 'ADVICE AGAINST' or 'DON'T ADVICE AGAINST' by combining the result of the individual risk and territorial data (i.e. type of targets, proposed developments' sensitivity level and population). For each plant in fact, HSE establishes the so-called 'consultation zones'. Within these zones both the risk-based and the consequence-based approaches are used, mostly depending on the substances involved. However, when a development is proposed within the 'consultation zones', a full assessment is performed. The scope of this successive accurate analysis is the individualization of the 'consulting zones', more or less compatible with the presence of more or less vulnerable urban populations. However, in either case the HSE advice is required for any planning decision.

In this regard, another aspect of the analysis that supports the external safety objective is, in fact, what can be defined as 'vulnerability analysis' where population, buildings and infrastructures (generally the targets) are

25 Dangerous dose is defined as a dose which related effects lead to a substantial fraction requires medical attention; some people are seriously injured, requiring prolonged treatment; any highly susceptible people might be killed.

26 The two concepts are largely used in both UK and Dutch practice; however a difference exists between the two. In the UK societal risk evaluations no thresholds apply for LUP purposes, whereas, in The Netherlands, recent developments have also indicated target values for societal risk 
classified using specific indicators ${ }^{27}$, four classes of decreasing vulnerability (i.e. A, B, C, D) are determined. Therefore, the deriving evaluation of compatibility can be seen as the match among the three variables of frequency, damage and vulnerability. The HSE advice is delivered to LPAs in the form of risk-map, where the three inner, middle and outer iso-risk areas are represented on the relative cartographic base. Generally, the criteria used to assess the risk's acceptability are those defined in the report of the Advisory Committee on Major Hazards as the so called "protection concept". In a simple form, the advice provided to the Planning Authorities is based on the standard criteria and methodology; three zone hazard/risk maps (Figure 3-4) and a matrix approach (Figure 3-5) to the zones and to the classification of types of developments allow ready access to HSE methodology by planners. The clarity of the advice from HSE and the transparency of the information given are the main drivers for the wide acceptance of them by the side of Planning Authorities (Walker et al., 2000a).

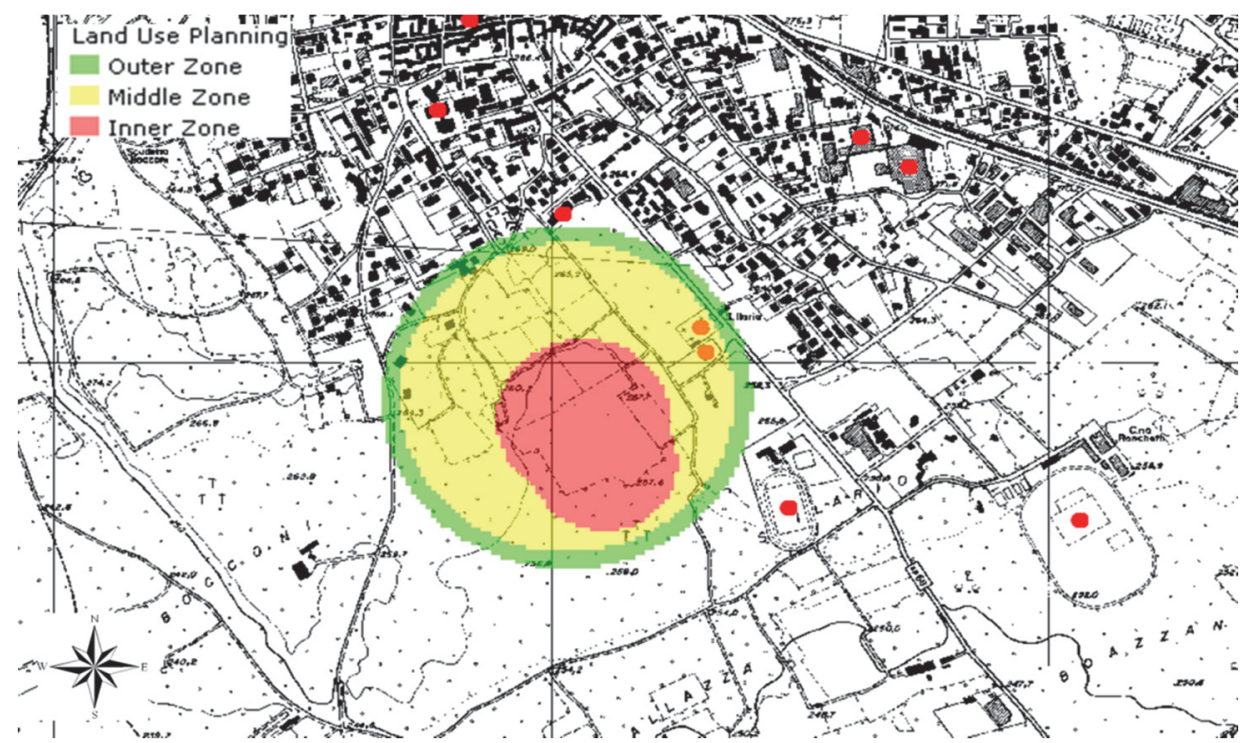

Figure 3-4: An example of consolation zones around a hazardous installation

\footnotetext{
${ }^{27}$ Among them, and with respect to population, the class of age, the daily permanence inside the buildings, the structural characteristic of them, etc. are important one
} 


\begin{tabular}{cc|lccc}
\hline \multicolumn{2}{c}{ Examples of developments } & $\begin{array}{l}\text { Outer } \\
\text { zone }\end{array}$ & $\begin{array}{c}\text { Middle } \\
\text { zone }\end{array}$ & Inner zone \\
\hline & 1 & $\begin{array}{l}\text { Industrial establishments, } \\
\text { parking areas }\end{array}$ & DAA & DAA & DAA \\
& $\begin{array}{l}\text { Residential areas } \\
\text { Vulnerable population }\end{array}$ & DAA & DAA & AA \\
\hline & $\begin{array}{l}\text { Highly vulnerable facilities } \\
\text { (e.g., Stadium, hospitals) }\end{array}$ & DAA & AA & AA \\
\hline
\end{tabular}

DAA: HSE does not Advise Against development

AA: HSE does Advise Against development

Figure 3-5: Decision matrix

\subsubsection{Germany}

Germany is a federal country consisting of States or Länder. The relationship between the national, federal and the states is regulated within the "Basic Law". Land use planning in Germany is regulated within a number of statutes at federal and state level including the Raumordnungsgesetz (ROG) and the Baugesetzbuch (BauGB).

Land use planning connected to risk is regulated more at the state and municipal level. In particular, the municipalities are responsible for the more detailed planning. For zoning, the designation of the use of particular areas must be "appropriate", i.e. industrial areas may not border directly on residential areas, moreover they should be separated by a suitable other type of use such as green-belt, commercial zone, etc. In 2005, the Guidance SFK/TAA-GS- $191^{28}$ on recommendations for separation distances between establishments under the German Major accidents Ordinance (StörfallVerordnung) and areas requiring protection within the framework of land use planning was published jointly by the erstwhile German Hazardous Incidents Commission (SFK/TAA) and the German Technical Committee for Plant Safety $(\mathrm{SFK} / \mathrm{TAA})^{29}$.

The separation distance recommendations are only related to people as the subject to be protected, they are not suitable for the assessment of current mixed situations (existing buildings), for the licensing procedure under BImSchG or as the basis for the external emergency planning. On reaching or exceeding the recommended separation distances, generally it assumed that the effects of a major accident within an establishment, based on the assumptions made, will not lead to a serious hazard as defined in the German

28 SFK/TAA-GS-1: http://www.kas-bmu.de/publikationen/sfk gb/sfk-taa-gs-1k-en.pdf

29 Since November 2005, the SFK and TAA merged together to form the Commission on Process Safety (KAS). 
Major Accident Ordinance for the population. The method generally used in Germany is of the consequence-based type instead of the probabilistic risk assessment as carried out in the Netherlands and the UK. However, in exceptional cases, probabilistic assessment with certain conventions, as preselected scenarios or a case-by-case approach (e.g. for existing situations) are applied. The general used consequence-based approach refers to preselected worst credible or representative scenarios. In any case, the evaluation of the safety distance with respect to the worst credible scenario is based on: the maximum permitted amount of substance, its temperature and pressure; as well as the vulnerability of the surrounding environment.

Regarding the effects, the criteria adopted to define the compatibility are:

- Injuries or fatalities of a large number of people;

- Material damage;

- Individual/societal risk (only in exceptional cases).

The SFK/TAA-Recommendations for the endpoints (Table 3-1) should be considered as target criteria. However, the application is left to the individual State and the executive authorities at regional and local level, which, where justified, may adopt other values.

\begin{tabular}{ll}
\multicolumn{2}{l}{ Table 3-1: Endpoint values adopted in Germany } \\
\hline Effects & Endpoint values \\
\hline Toxic & ERPG $2 / 3$ \\
Thermal radiation & $1.6 \mathrm{~kW} / \mathrm{m}^{2}$ \\
Overpressure & $0.1 \mathrm{bar}$ \\
\hline
\end{tabular}

The tolerability of risks under the German Major Accident Ordinance is governed by the concept that "establishments may only carry out their hazardous activities if they are able to demonstrate that hazardous effects from an accident may be reasonably excluded". This is based on technical regulation and expert judgment. This does not however preclude all and every single accident.

\subsubsection{France}

France has a 200 years history in risk prevention regulations related to dangerous facilities. Between 1780 and 1800 , polluting factories were moved out of Paris and a Napoleon decree established three classes of dangerous activities. This 1810 decree can be considered as the first regulation addressing risk prevention and enforcing the concept of safety distances. The land and use planning aspect following the Seveso II Directive mainly took place in France within the framework of the law of December 13, 2000 
that makes it mandatory for local authorities to account for industrial risk in their LUP documents.

However, the French land use planning regulations were deeply modified in 2003 following the Toulouse accident in September 2001 (31 fatalities, 3000 injured and damage estimated at $€ 3$ billion). Consequently, a new law on the prevention of technological and natural risks and to the compensation for damages was adopted in July 2003 (Salvi et al., 2005). The new law of 2003 (law no. 2003-699) introduces an important innovation into the process of technological risks prevention to improve the efficiency of future construction and to deal with existing situation of concern (Cahen, 2006).

In particular, the new regulation set three requirements:

- Harmonization of risk analysis approaches;

- Integration of the risk-based and consequence-based approaches;

- Corrective actions on existing/developing urbanization and controls on future LUP in the proximity of hazardous establishments

Following the 2003law and the regulatory developments with respect to the safety report risk assessment, the Circular of May 42007 has been issued to deal with new aspects (especially the probability parameter): technological risk information (Porter à Connaissance) and land use planning around classified installations. It is stated that this information document should include two parts:

- A first part dealing with the hazards (aléas) ${ }^{30}$

- A second part dealing with LUP recommendations based on the aléas levels.

Moreover, in addition to LUP tools the Code de I'Urbanismeenables the Mayor to refuse a building permit if he judges that the "constructions, with respect to their location or dimension, are of such a type as to put public safety or health into jeopardy". Finally, the Prefect could use two strongly effective tools:

- The "Project of General Interest" (Projetd'IntérêtGénéral- PIG). The PIG enables the Prefect to override the decision concerning the land-use in risky areas if the latter has not been taken into account enough; and,

- The land use restriction around top-tier hazardous establishment (Authorization avec Servitudes).

30 Aléa is a French term defined as "probability that a dangerous phenomenon creates effects of a given intensity and over a determined period of time at a given point of the territory used to decide LUP decisions". 
Accordingly, to satisfy these requirements, the Technological Risk Prevention Plans (PPRT) ${ }^{31}$ were introduced as a new instrument to develop LUP policies and for configuration of the urbanization around top-tier hazardous plants with a long-term view. The aim of the PPRT Plans is to limit the exposure of the population to the consequences of major accidents.

Along with this, the French Ministry of the Environment also issued 'General Principles for the Elaboration of Safety Reports' guidelines in order to facilitate and standardize the process of elaboration of safety reports. In the safety report, the hazardous phenomena and associated major accidents are characterised according to three parameters: probability, intensity and gravity of effects (Lenoble et al., 2011).

PPRT employs representative scenarios by taking into account the probability, intensity, and gravity of effects. In this regards, the French major accident risk regulation refers to a range of endpoint values to calculate intensity of the accidents based on possible effects of a dangerous phenomenon (Basta et al., 2008). A representative range of endpoint values and a gravity scale imposed with five categories depending on the intensity (effect threshold) and on the number of exposed people is illustrated in Table 3-2and Table 3-3 respectively (Salvi et al., 2005; Taveau, 2010).

Table 3-2: Range of endpoints values adopted in France

\begin{tabular}{|c|c|c|c|c|}
\hline \multirow[b]{2}{*}{ Effects } & \multicolumn{4}{|c|}{ Range of endpoints values } \\
\hline & $\begin{array}{l}\text { Significant lethal } \\
\text { effect threshold }\end{array}$ & $\begin{array}{l}\text { Lethal effect } \\
\text { threshold }\end{array}$ & $\begin{array}{r}\text { Irreve } \\
\text { th }\end{array}$ & $\begin{array}{l}\text { ible effect } \\
\text { shold }\end{array}$ \\
\hline $\begin{array}{l}\text { Toxic release } \\
\text { (individual risk) }\end{array}$ & $\mathrm{SEL}^{32} 5 \%$ & SEL $1 \%$ & & $E I^{33}$ \\
\hline $\begin{array}{l}\text { Fire } \\
\text { (Thermal } \\
\text { radiation) }\end{array}$ & $8 \mathrm{~kW} / \mathrm{m}^{2}$ & $5 \mathrm{~kW} / \mathrm{m}^{2}$ & & $\mathrm{~W} / \mathrm{m}^{2}$ \\
\hline $\begin{array}{l}\text { Explosion } \\
\text { (Overpressure) }\end{array}$ & 200 mbar & 140 mbar & $\begin{array}{l}50 \\
\text { mbar }\end{array}$ & $\begin{array}{l}\text { Indirect } \\
20 \text { mbar }\end{array}$ \\
\hline
\end{tabular}

\footnotetext{
31 Technological risk prevention plan (PPRT) acting together to control risks by Ministry of Ecology and Sustainable Development (2013). Retrieved from http://www.paca.developpementdurable.gouv.fr/IMG/pdf/Plaquette PPRT english cle07855c.pdf

$32 \mathrm{SEL}$ is a French acronym for significant lethal effects

33 SEIis a French acronym for irreversible lethal effects
} 
Table 3-3: Gravity scale

\begin{tabular}{llll}
\hline Gravity level & $\begin{array}{l}\text { Significant lethal } \\
\text { effect threshold }\end{array}$ & $\begin{array}{l}\text { Lethal effect } \\
\text { threshold }\end{array}$ & $\begin{array}{l}\text { Irreversible effect } \\
\text { threshold }\end{array}$ \\
\hline Disastrous & $>10$ & $>100$ & $>1000$ \\
Catastrophic & 1 to 10 & 100 to 1000 & 100 to 1000 \\
Major & 1 & 100 to 1000 & 10 to 100 \\
Serious & 0 & 1 & 1 to 10 \\
Moderate & 0 & 0 & $<1$ \\
\hline
\end{tabular}

Once the major accidents have been characterized according to probability class and gravity scales, the local state representative (Préfet) makes a decision using a risk acceptability matrix for assessing the societal acceptability of the risk generated by the hazardous industry (Figure3-6). The input data are the probabilities of major accidents, effect thresholds and the number of people potentially exposed to their consequences. Important to mention, based on the past events, probability is also categorized in five classes from A ( $>10^{-2} /$ year) to $\mathrm{E}\left(<10^{-5} /\right.$ year $)$.

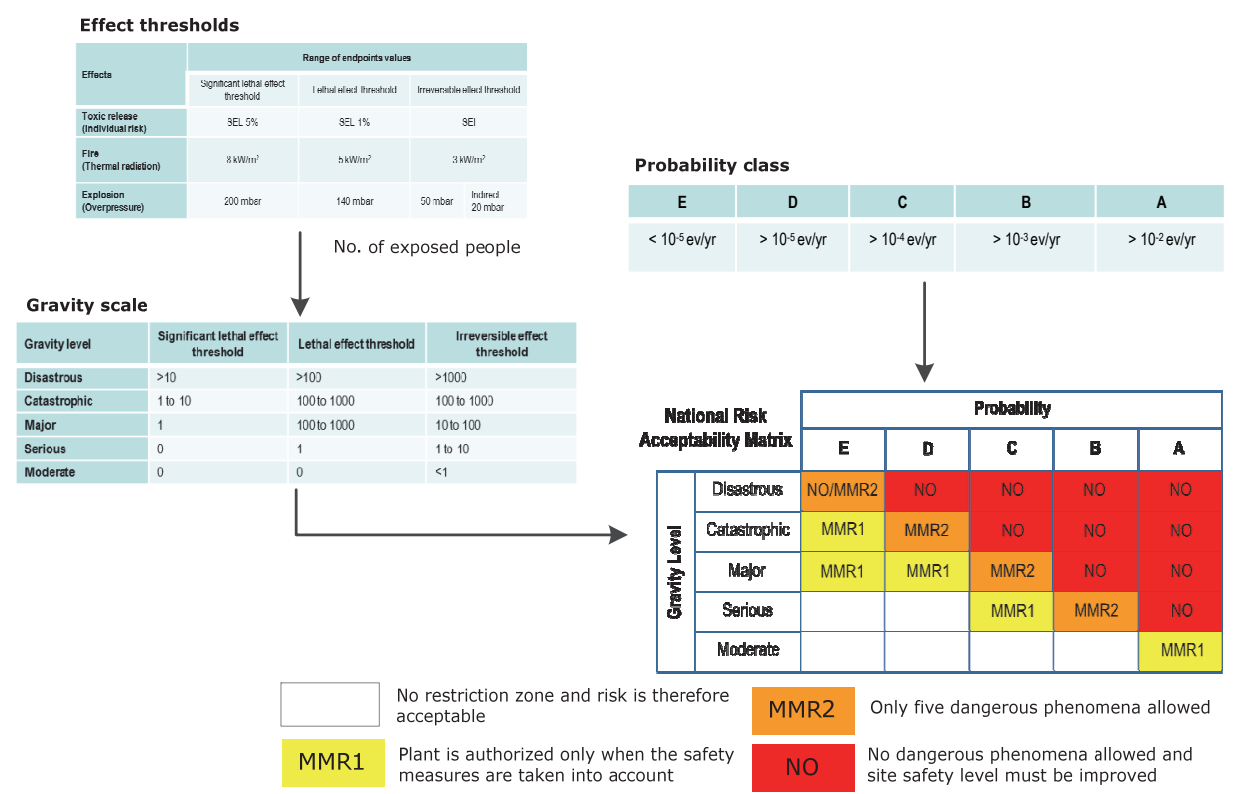

Figure 3-6: A simplified risk matrix and its input data: effects thresholds, gravity and probabilities

Accordingly, zoning principles related to the aléa levels (i.e. combination of intensity and cumulative probability) are set out in the national PPRT guide (Figure 3-7). The PPRT plans are carried out on a local level under the coordination and responsibility of governor, following a public consultation. 


\begin{tabular}{|c|c|c|c|c|c|c|c|c|c|c|}
\hline \multirow{2}{*}{$\begin{array}{c}\begin{array}{c}\text { Maximum effects } \\
\text { on population at } \\
\text { a given point }\end{array} \\
\begin{array}{c}\text { Cumulative } \\
\text { probability } \\
\text { distribution of } \\
\text { dangerous } \\
\text { phenomena at a } \\
\text { given point }\end{array} \\
\end{array}$} & \multicolumn{3}{|c|}{$5 \%$ lethal effects } & \multicolumn{3}{|c|}{$1 \%$ lethal effects } & \multicolumn{3}{|c|}{ Irreversible effects } & \multirow{2}{*}{$\begin{array}{c}\text { Indirect effects } \\
\text { All }\end{array}$} \\
\hline & $>D$ & $5 E$ to $D$ & $<5 \mathrm{E}$ & $>D$ & $5 E$ to $D$ & $<5 E$ & $>D$ & $5 E$ to $D$ & $<5 E$ & \\
\hline Aléa & $\begin{array}{l}\text { ery High } \\
\text { ()) } \mathrm{VH}+\end{array}$ & $\begin{array}{l}\text { Very High } \\
\text { VH }\end{array}$ & & & $\begin{array}{c}\text { High } \\
\mathrm{H}\end{array}$ & & & $\begin{array}{c}\text { Medium } \\
\mathrm{M}\end{array}$ & & Low \\
\hline
\end{tabular}

Figure 3-7: Territorial compatibility assessment through aléa mapping

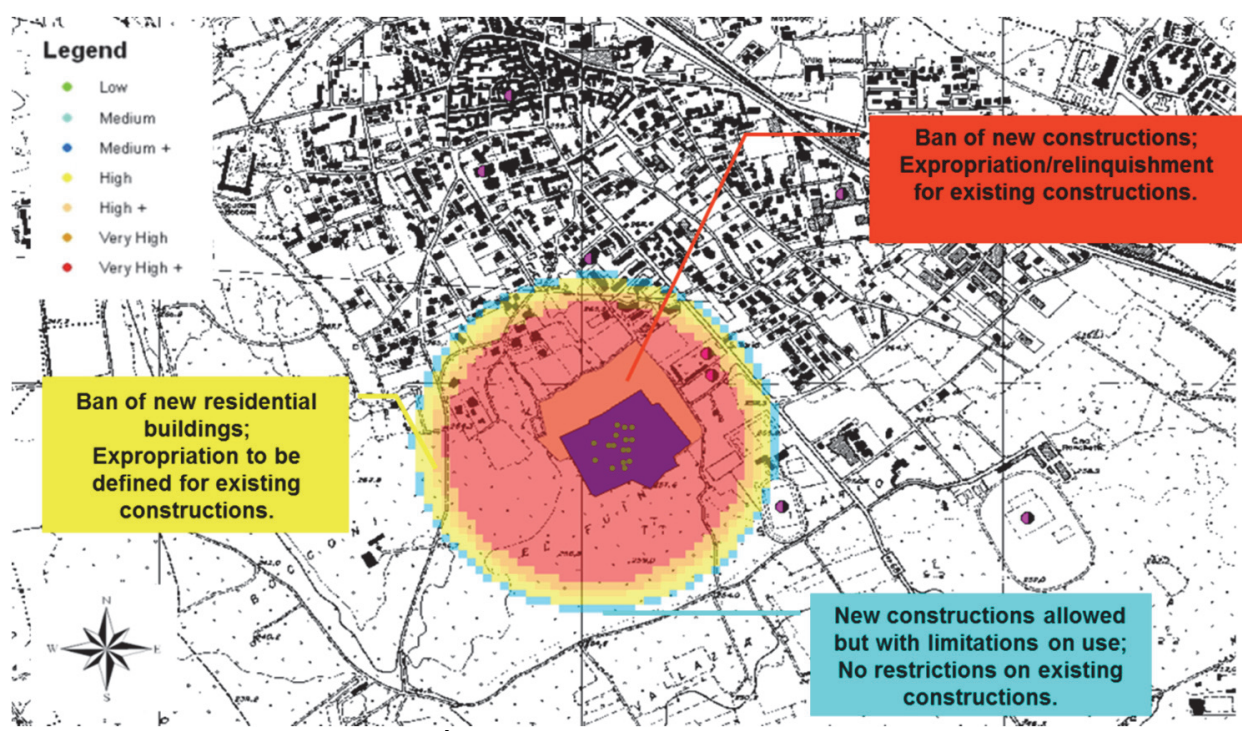

Figure 3-8: An example of Aléa mapping for an establishment in case of toxic release and thermal radiation scenarios

\subsubsection{Italy}

Historically structured as a Central-State government, the Republic of Italy is characterized by huge differences from northern to southern regions as well as from mainland, mountains areas and its numbers of islands. Due to this heterogeneous background, the decentralization process established since the ' 90 's has increasingly powered the responsibilities of the local-level institutions, represented by the 20 Regions along with their Provinces and Municipalities. Consequently, these three political entities have the central role for what concern environmental \& territorial governance, and for other matters including civil protection, natural resources protection and (local) economic development.

Within this process, each region has the power to implement national laws having direct implication on the issues as protection of the environment, control of major-accident hazards, safety, health, etc. As a consequence, in 
Italy the Seveso II Directive has been implemented not only by the legislative decree n. 334/99 (law of first level) and by the Ministerial Decree 9 May 2001(law of second level), that dictate the national criteria for Land Use Planning, but also by regional legislation. Accordingly, municipality seeks technical advice from the Regional Technical Committee ${ }^{34}$, before giving a building permit in one of the cases of the Article 12 of the 96/82/EC Directive.

Concerning the implementation of the Seveso Directive, the National reference is the Legislative Decree 334/99.In particular, the Article 14 defining the need of the "control of urbanization", implemented by the Law Decree 9 Maggio 2001, which can then translated in "Minimal Safety requirements for the urban and territorial planning in the areas subject to major accident risks". The implementation of the DM 9 Maggio 2001 within the land use planning regulation is summarized in Table 3-4.

Table 3-4: Competency of various levels of government for risk and spatial planning in the Italian framework

\begin{tabular}{|c|c|c|}
\hline Level & Risk related & Planning related \\
\hline Central Govt. & $\begin{array}{l}\text { Transposes the Seveso II } \\
\text { Directive with the emanation of } \\
\text { the LGS Decree } 334 / 99, \text { which } \\
\text { LUP regulation is defined with the } \\
\text { DM 9Maggio } 2001\end{array}$ & $\begin{array}{l}\text { National Urban Law, defining } \\
\text { principles and objectives of } \\
\text { National interest. The Law is } \\
\text { compulsory to implement for all } \\
\text { the } 20 \text { Regions }\end{array}$ \\
\hline Regions & $\begin{array}{l}\text { Adopt the National legislation } \\
\text { into } \\
\text { regional law; ensure the } \\
\text { enforcement of the procedure } \\
\text { and } \\
\text { the assignment of responsibilities }\end{array}$ & $\begin{array}{l}\text { Defining the Regional Plan, } \\
\text { the planning objectives for } \\
\text { Provinces and Municipalities } \\
\text { and the discipline for regional } \\
\text { competence are as (specific per } \\
\text { region) }\end{array}$ \\
\hline Provinces & $\begin{array}{l}\text { Within the territorial plans, } \\
\text { define the area "object of specific } \\
\text { regulation"; provide principles for } \\
\text { urban plans }\end{array}$ & $\begin{array}{l}\text { Define the territorial plan, } \\
\text { where protected areas, } \\
\text { transportation } \\
\text { route, etc. need to be } \\
\text { disciplined; give } \\
\text { principles for urban plans }\end{array}$ \\
\hline Municipalities & $\begin{array}{l}\text { Defining the technical paper on } \\
\text { LUP in which the risk deriving } \\
\text { from the establishments and the } \\
\text { vulnerable elements are } \\
\text { represented in a common and } \\
\text { easy-reading cartographic base. } \\
\text { Land uses are then disciplined on } \\
\text { the base of this document }\end{array}$ & $\begin{array}{l}\text { Define the urban plan on the } \\
\text { base of the directives of } \\
\text { Province and Region and assign } \\
\text { property rights, regulating all } \\
\text { the local competence goods. } \\
\text { The plan is subject to } \\
\text { consultation with the public } \\
\text { after its official publication }\end{array}$ \\
\hline
\end{tabular}

34 Regional Technical Committees are the technical authorities regarding hazardous industries at the regional level, composed of members of the Regional Fire Departments, National Authority for Prevention and safety at work (ISPESL) and of other local authorities, such as the Regional Agency for Environmental protection (ARPA). 
Within this framework, and in order to insert the industrial risk evaluation within the territorial planning practice, the Ministry of Infrastructure has developed a specific programme ${ }^{35}$ for technical assistance to the authorities dealing with the implementation of the DM 9 Maggio 2001.

Different regulations are in place for LPG and all other substances classified as dangerous. For LPG storages and toxic or flammable liquids storages specific national decrees have been issued, and a soft deterministic-based risk assessment methodology is in use. The methodology integrates probabilistic elements, through the application of an index method which defines the likelihood of an accident scenario. Each accidental situation is considered case-by-case, and impact areas are identified using defined threshold values. Whereas, concerning the other dangerous substances, a semi-quantitative approach is used to assess both the frequencies of the expected events and the deriving effects. In doing so, the regulation refers to the National legislation on dangerous substances, the Legislative Decree 334/99. The land-use decision is based on the specific requirements of the DM 9 Maggio 2001, where the categories of frequencies and effects are combined with 6categories of vulnerability, as presented in Table 3-5.Based on this matrix, the compatible location of the vulnerable targets, classified in decreasing vulnerable categories from $A$ to $F$, is then estimated.

Table 3-5: Compatibility matrix of the Italian DM 9 Maggio 2001

\begin{tabular}{ccccc}
\hline \multirow{2}{*}{$\begin{array}{c}\text { Frequency } \\
\text { (classes) }\end{array}$} & \multicolumn{4}{c}{ Estimated damage (Effect categories) } \\
\cline { 2 - 5 } & $\begin{array}{c}\text { Elevated } \\
\text { mortality }\end{array}$ & Mortality & $\begin{array}{c}\text { Irreversible } \\
\text { damage }\end{array}$ & $\begin{array}{c}\text { Reversible } \\
\text { damage }\end{array}$ \\
\hline$<10^{-6}$ & DEF & CDEF & BCDEF & ABCDEF \\
$10^{-4}$ to $10^{-6}$ & $\mathrm{EF}$ & $\mathrm{DEF}$ & $\mathrm{CDEF}$ & $\mathrm{BCDEF}$ \\
$10^{-3}$ to $10^{-4}$ & $\mathrm{~F}$ & $\mathrm{EF}$ & $\mathrm{DEF}$ & $\mathrm{CDEF}$ \\
$>10^{-3}$ & $\mathrm{~F}$ & $\mathrm{~F}$ & $\mathrm{EF}$ & $\mathrm{DEF}$ \\
\hline
\end{tabular}

The threshold values used for lethality, initial lethality, irreversible injuries, reversible injuries and damages due to thermal radiation, overpressure or toxic release, are mentioned in Table 3-6. Both for LPG storages and dangerous substances, these thresholds values are legally binding and on no case it can be exceeded.

${ }^{35}$ Refer to http://www.infrastrutturetrasporti.it/sites/seveso2/pages/sev page 05. htm 
Table 3-6: Endpoint values adopted in the Italian regulation

\begin{tabular}{lccccc}
\hline Scenario & $\begin{array}{c}\text { High } \\
\text { lethality }\end{array}$ & $\begin{array}{c}\text { Initial } \\
\text { lethality }\end{array}$ & $\begin{array}{c}\text { Irreversible } \\
\text { injuries }\end{array}$ & $\begin{array}{c}\text { Reversible } \\
\text { injuries }\end{array}$ & Damages \\
\hline Fire & $12.5 \mathrm{~kW} / \mathrm{m}^{2}$ & $7 \mathrm{~kW} / \mathrm{m}^{2}$ & $5 \mathrm{~kW} / \mathrm{m}^{2}$ & $3 \mathrm{~kW} / \mathrm{m}^{2}$ & $12.5 \mathrm{~kW} / \mathrm{m}^{2}$ \\
$\begin{array}{l}\text { BLEVE/ } \\
\text { Fireball }\end{array}$ & $\begin{array}{c}\text { Fireball } \\
\text { radius }\end{array}$ & $350 \mathrm{~kJ} / \mathrm{m}^{2}$ & $200 \mathrm{~kJ} / \mathrm{m}^{2}$ & $200 \mathrm{~kJ} / \mathrm{m}^{2}$ & $200-800 \mathrm{~m}$ \\
Flash fire & $\mathrm{LFL}$ & $1 / 2 \mathrm{LFL}$ & -- & -- & -- \\
VCE & $0.3 \mathrm{bar}$ & $0.14 \mathrm{bar}$ & 0.07 bar & $0.03 \mathrm{bar}$ & $0.3 \mathrm{bar}$ \\
$\begin{array}{l}\text { Toxic } \\
\text { release }\end{array}$ & LC50 & -- & IDLH & -- & -- \\
\hline
\end{tabular}

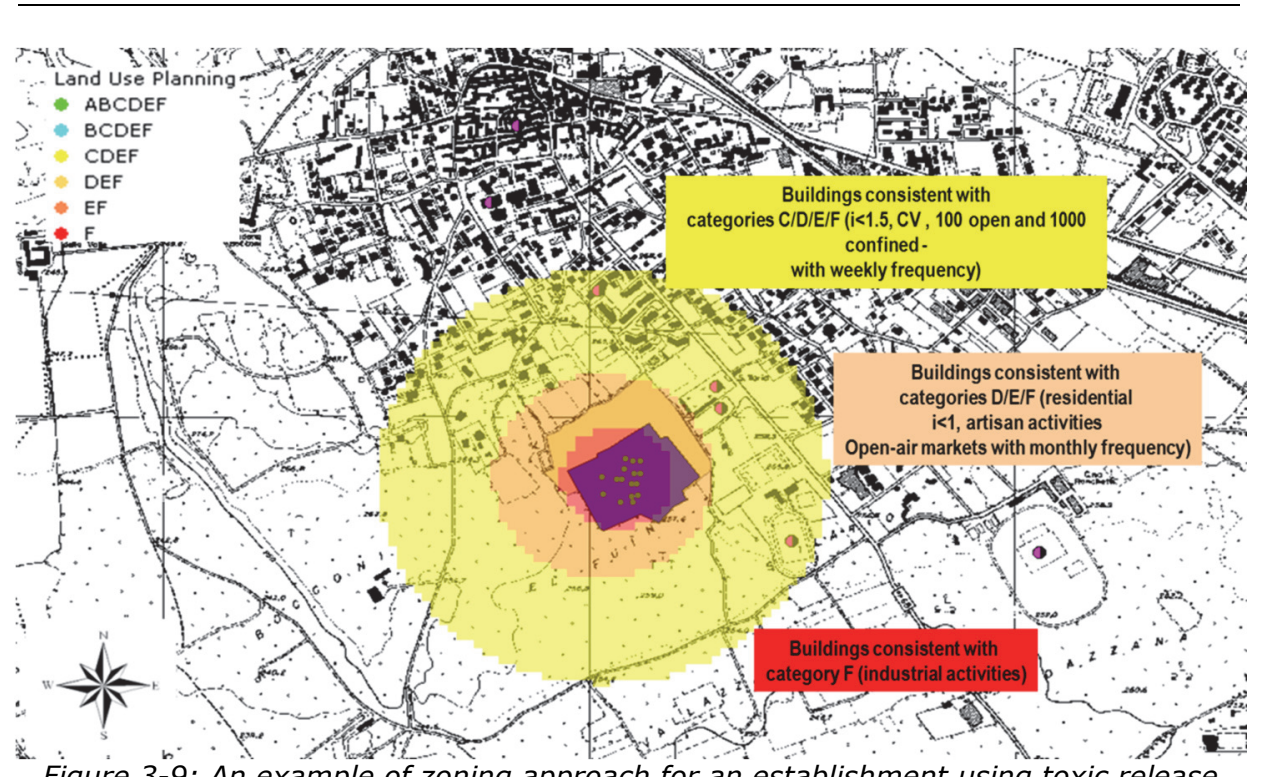

Figure 3-9: An example of zoning approach for an establishment using toxic release and thermal radiation scenarios

\subsubsection{Summary}

After reviewing the various approaches in European countries it can be concluded that there are significant differences in acceptance criteria and methods of implementing Article 12. Although the choice between the orientations is influenced by the policy and territorial context of regulations, there are some common elements in the respective frameworks (e.g., risk criteria, vulnerable objects etc.).

To summarize the approaches:

- In the Netherlands, quantitative risk acceptance criteria apply to both existing and new situations. These criteria examine both location-based (individual) risk and societal risk. 
- The UK approach employs a criteria based on location-based (individual) risk of a new development in the vicinity of an existing plant. These criteria define limits on the number of people who may be exposed to particular levels of risk, thus giving partial consideration to societal risk.

- Germany follows a deterministic approach; accident scenarios are selected based on a technical description of releases and relation to the surroundings. It does not consider accidents larger than the reference scenarios. Generic safety distances requirements are regarded as risk acceptance criteria.

- France follows a hybrid method that approximates a quantitative risk analysis. However, some qualitative aspects have been retained namely; frequency assessment, fixed end-point values, various types of consequences frequencies are calculated separately and the effects of wind direction and speed are not considered.

- Italy also follows a hybrid approach, which takes into account criteria that incorporate frequencies as a mitigation factor for the damage zones, but it does not necessitate the calculation of the individual and societal risk

It can be concluded that it is the underlying scope and not the result of land use planning evaluations that appears to determine the adoption of one of the methods. Here, the demographic variable and different national legislative contexts may be determinant factors. In this perspective, the choice between the orientations confirms to be influenced by the political and territorial context of regulations rather than by mere methodological considerations. The implementation of the Article12 in the above discussed Member States is summarized in Table 3-7. 
Table 3-7: Summary of the implementation of the Article12

\begin{tabular}{|c|c|c|c|}
\hline & $\begin{array}{l}\text { Modification of existing } \\
\text { establishments }\end{array}$ & $\begin{array}{l}\text { Siting of new } \\
\text { establishments }\end{array}$ & $\begin{array}{l}\text { New developments } \\
\text { surroundings existing } \\
\text { establishments }\end{array}$ \\
\hline $\mathrm{NL}$ & $\begin{array}{l}\text { Competent Authority } \\
\text { (CA) requires a full } \\
\text { QRA assessing the new } \\
\text { level of risk; } \\
\text { Municipalities } \\
\text { are to be informed on } \\
\text { the new situation for } \\
\text { LUP concerns }\end{array}$ & $\begin{array}{l}\text { Licensing procedure } \\
\text { for environmental } \\
\text { impacts and full QRA } \\
\text { are required }\end{array}$ & $\begin{array}{l}\text { LUP regulation } \\
\text { (according to the } \\
\text { requirements of the } \\
\text { External Safety Decree) } \\
\text { has to fulfil individual } \\
\text { risk endpoints for all } \\
\text { new developments }\end{array}$ \\
\hline UK & $\begin{array}{l}\text { A legal requirement for } \\
\text { an establishment is to } \\
\text { notify to the Hazardous } \\
\text { Substances } \\
\text { Authority of any } \\
\text { intended material } \\
\text { change. Modifications } \\
\text { are assessed by the CA } \\
\text { and are agreed to only } \\
\text { if there is no } \\
\text { substantial increase in } \\
\text { risk to surrounding } \\
\text { population. Additional } \\
\text { technical measures are } \\
\text { sometimes required }\end{array}$ & $\begin{array}{l}\text { Permit procedure for } \\
\text { building new } \\
\text { establishments } \\
\text { submitted to the local } \\
\text { authorities and } \\
\text { forwarded to the HSE } \\
\text { for the risk analysis } \\
\text { and the definition of } \\
\text { the consulting zones }\end{array}$ & $\begin{array}{l}\text { All applications for } \\
\text { developments have to } \\
\text { be notified to the CA. } \\
\text { HSE plays the role of the } \\
\text { advising authority with } \\
\text { respect to the Local } \\
\text { Planning issues. }\end{array}$ \\
\hline D & $\begin{array}{l}\text { Licensing procedure } \\
\text { (German Federal } \\
\text { Pollution Control Act } \\
\text { and German } \\
\text { Major Accidents } \\
\text { Ordinance } \\
\text { (Störfall-Verordnung); } \\
\text { inspections carried out } \\
\text { by the authorities }\end{array}$ & $\begin{array}{l}\text { The Raumplanungand } \\
\text { the Bauleitplanungare } \\
\text { the legal instruments } \\
\text { of land use regulation } \\
\text { in which new } \\
\text { establishments are } \\
\text { regulated }\end{array}$ & $\begin{array}{l}\text { Rules are included into } \\
\text { land use plan }\end{array}$ \\
\hline $\mathrm{FR}$ & $\begin{array}{l}\text { Safety Report revision; } \\
\text { when associated to the } \\
\text { Permitting System, this } \\
\text { measure also } \\
\text { guarantee the lack of } \\
\text { increase of the risk or } \\
\text { consequences }\end{array}$ & $\begin{array}{l}\text { Instruction of Safety } \\
\text { Report (art L512-1 of } \\
\text { code de } \\
\text { l'environnement); } \\
\text { Constraint } \\
\text { with compensation by } \\
\text { the industrial included } \\
\text { into land use plan } \\
\end{array}$ & $\begin{array}{l}\text { Rules are included into } \\
\text { land use plan; the } \\
\text { mayor delivers a } \\
\text { building permit, } \\
\text { while a control by the } \\
\text { state is carried out }\end{array}$ \\
\hline IT & $\begin{array}{l}\text { Inspections carried out } \\
\text { by the authorities and } \\
\text { check of the licensing } \\
\text { procedure }\end{array}$ & $\begin{array}{l}\text { Licensing procedure } \\
\text { and urban plan } \\
\text { regulation; minimal } \\
\text { safety requirements } \\
\text { regulated by the DM } 9 \\
\text { Maggio } 2001\end{array}$ & $\begin{array}{l}\text { Rules are included into } \\
\text { land use plan }\end{array}$ \\
\hline
\end{tabular}




\section{Chapter 4 - The Indian context}

This chapter focuses on the governance of industrial risk in India, and critically appraises the regulatory, institutional and procedural framework for assessing industrial risks in order to be able to identify gaps and provide likely solutions which can bridge these gaps and make way for a safer society in India ${ }^{36}$.

\subsection{Policy, regulatory and institutional context}

The risk assessment practice in a country perspective is strongly driven by the regulatory and institutional setup. Thereby to comprehend the current state-of-the art of risk assessment practice of India, it is important to discuss the existing policy, regulatory and institutional framework first.

\subsubsection{Policy framework}

Traditionally, the policy framework of the Government of India has focused on policy formulation from a sectoral perspective. Typical examples are economic policy statements, transportation policy, rural development policy etc., which are supported by different national and state level plans and programs. The need for policies in the front of environmental protection and resource consumption was only felt around the early nineties. Accordingly, the 'National Conservation Strategy and Policy Statement on Environment and Development and Policy Statement for Abatement of Pollution' ${ }^{\prime 37}$ was formulated by the Ministry of Environment, Forest \& Climate Change (MoEFCC), Govt. of India, in 1992. This policy outlines some fundamental principles to balance economic growth with sustainable development goals in line with the mandate of the Rio Summit 1992. However, the scope of the policy was considered to be too broad and not providing any specific direction on how such goals were to be attained. As a result the policy has minimum impact on improving environmental governance. Moreover, in spite of the Bhopal disaster having occurred, the policy did not mention or show any direction to be adopted for attaining effective management of industrial risks. Subsequently, when the need for a common ground policy was felt to cover all environmental issues, the 'National Environmental Policy' (NEP) ${ }^{38}$ was

\footnotetext{
${ }^{36} \mathrm{An}$ excerpt of this chapter is published as "An evaluation of risk assessment framework for industrial accidents in India" in Journal of Loss Prevention in the Process Industries (2015), which has been co-authored as a part of this thesis.

${ }^{37}$ National Conservation Strategy and Policy Statement on Environment and Development and Policy Statement for Abatement of Pollution: http://www.moef.gov.in/sites/default/files/introduction-csps.pdf

${ }^{38}$ National Environmental Policy: http://www.moef.gov.in/sites/default/files/introduction-nep2006e.pdf
} 
formulated in 2006. But, again the NEP does not provide enough emphasis on management of industrial risks either.

The NEP also followed similar trends like its precursors and lacks specific focus or direction on several aspects. Many of the principles stated in the policy essentially read like a listing of global best intentions rather than being directed at specific issues which are compatible with existing impact level conditions in the country, characterized by degradation of environment and high risk levels that prevail in many industrial areas which are also listed as pollution hotspots (Chatterjee, 2009). In spite of the fact that specific emphasis was provided to the adoption of the 'precautionary principle', it's jurisdiction however appears to be more from the point of environmental protection rather than the aspect of industrial risk. Further detailing with the concept, the principle goes on to mention that "where there are credible threats of serious or irreversible damage to key environmental resources, lack of full scientific certainty shall not be used as a reason for postponing cost-effective measures to prevent environmental degradation". But, for a country like India witnessing rapid developmental pressures resulting from fast paced economic growth, implementing development plans based on the precautionary principle can be extremely challenging. First, in a realistic sense, without any specific guidance, it is difficult to ascertain what presents a 'credible threat' especially when the concept of risk is intrinsically linked to the probability of occurrence; wherein design principles in industries generally take into account that an accident with high damage potential has lesser probability of occurrence. Second, application of such an approach in industrial towns which house large clusters of chemical industries would essentially make these industrial areas infeasible and lead to prohibition for any further industrialization.

It needs to be mentioned that a Disaster Management Policy (DMP) ${ }^{39}$ has been formulated more recently in 2009 by NDMA. Though the DMP introduces policy thrust to reduce risk from various kinds of hazards or to create a mechanism that assists in minimizing damages, but yet again, there is no added focus or strategy for managing the risks that may arise in MAH industrial clusters. The policy overall aims at promoting a culture of prevention, preparedness and resilience at all levels through knowledge, innovation and education; mainstreaming disaster risk management into the developmental planning process; establishing institutional and techno-legal frameworks to create an enabling regulatory environment and a compliance regime; ensuring efficient mechanism for identification, assessment and monitoring of disaster risks; developing contemporary forecasting and early

${ }^{39}$ Disaster Management Policy:

http://www.ndma.gov.in/images/guidelines/national-dm-policy2009.pdf 
warning systems backed by responsive and reliable communication with information technology support; ensuring efficient response and relief with a caring approach towards the needs of the vulnerable sections of the society; as well as undertaking reconstruction as an opportunity to build disaster resilient structures and habitat for ensuring safer living.

\subsubsection{Regulatory framework}

The regulatory mechanism plays an important role in risk governance. Worldwide, several regulatory styles have been practiced by nations in how risk regulations have evolved and are implemented. The contemporary style for regulating risk from hazardous installations was based on a prescriptive 'command and control' based approach which focused on licensing and monitoring based control of hazardous installations. However, appreciating the complexities involved in regulating risk originating from hazardous industries, and learning from the experiences of the Bhopal disaster in early 1980 's, many countries initiated a review of their regulatory system for regulating risk. In comparison, the Indian regulatory system still continues to mainly be based on the paradigm of 'command and control' that is based on regulatory permitting with overt emphasis on inspections and monitoring to monitor regulatory conformance.

After being a part to the Stockholm Convention, the Govt. of India formulated several environmental regulations starting with the Water Act of 1974. Additional impetus to broaden the portfolio of regulations to cover issues like industrial hazards and risks was prompted primarily by the Bhopal disaster of 1984. However, the regulatory framework on chemical safety can be traced back to chemical class-specific regulations like the Explosives Act, 1884; the Petroleum Act, 1934; the Factories Act, 1948, the Inflammable Substances Act, 1952; the Insecticide Act, 1968 and Static \& Mobile Pressure Vessels Rules, 1981, etc. The focus of these pre-Bhopal regulations was mainly limited to on-site safety of the workers; whereas legal system to regulate offsite emergency, safe storage and transportation of hazardous materials hardly existed (NDMA, 2007).

Learning the lessons from the Bhopal accident made it imperative for the government to create an overarching legislative framework, the Environment (Protection) Act of 1986. It should be mentioned that prior to the Bhopal incident, the Factories Act of 1948 was the major Indian law that dealt with worker's welfare and health. After the promulgation of the EP Act, additional impetus was put forward to further broaden the regulatory framework (or portfolio of regulations) to encompass issues like industrial hazards and risks caused by chemicals and wastes, which were earlier not considered to be a priority. Drawing the powers conferred by the EP Act, a comprehensive set of regulations in the form of rules focussing on the management of hazardous 
substances, was enacted. The key rules in this context are the Manufacture, Storage, Import of Hazardous Chemicals Rules (MSIHC) notified in 1989 (amended in 1994 and 2000); and the Emergency Planning, Preparedness and Response to Chemical Accidents (EPPRCA) Rules in 1996 (amended 1994 and 2000). Besides, the Hazardous Waste (Management \& Handling) Rules of 1989, (amended in 2000 and 2003); the EIA Notification of 2006; the BioMedical Waste (Management and Handling) Rules of 1989; the National Environment Appellate Authority Act of 1997; the Manufacture, Use, Import, Export and Storage of Hazardous Micro-Organism or Genetically Manipulated Organisms or Cells rules of 1989 etc. are the other rules notified under EP Act (1986) for hazardous installations.

Drawn up on the model of the COMAH regulations of the UK, the MSIHC Rules were notified in 1989 under the powers conferred by the EP Act to widen the scope and provide for a few additional requirements. The principle objectives of the rules are the prevention of major accidents arising from industrial activities, the limitation of the effects of such accidents both on man and on the environment and the harmonization of various control measures and agencies to prevent and limit major accidents. As per provisions of the rules, industries storing or handling more than a certain threshold of hazardous chemicals (as mentioned in the Schedules of the Rules) are categorised as Major Accident Hazard (MAH) industries. The MAH industries have to fulfil a number of obligations in order to ensure that they are in control of hazards and risks that may originate from the facility and ensuring the public is informed about suitable safety measures to be adopted in case of an accident. Following are the key requirements:

- Take necessary precautions to prevent major accidents and limit their consequences to humans and the environment;

- Bring, major accidents involving the release of major emissions, fire or explosion linked with a hazardous chemical that has the potential cause substantial loss of life and property or adverse impact on the environment, to the notice of concerned authorities;

- Prepare safety reports on that industrial activity and submit them to competent authorities;

- Prepare an on-site emergency plan;

- Inform the public about the accidents that might occur and the do's and don'ts in case of particular accidents;

Provide assistance in the preparation of an off-site emergency plan in accordance with guidelines provided.

Keeping in view the vastness and the highly populated nature of the country and multiplicity of authorities, another scheme for the control of hazardous and toxic chemicals with three levels of controls, were prescribed for the 
industries. Accordingly, the EPPRCA Rules was notified in 1996, as a complement of the MSIHC Rules envisaging a four-tier crisis management system of the country involving the Central Crisis Group, the State Crisis Group, the District Crisis Group and the Local Crisis Group to manage emergencies arising out of industrial operations. Effectively, the EPPRCA Rules thus provides statutory backup for setting up of Crisis Groups at various levels to ensure the management of risk arising out of MAH industries across the country.

In advance of the MSIHC and EPPRCA rules, the Factories (Amendment) Act came into force with effect from $1^{\text {st }}$ January 1987 which introduced special provisions on hazardous industrial activities in the backdrop of the Bhopal Gas tragedy and the Supreme Court's judgment in the Shriram gas leak case. The Act was amended to establish safeguards for the use of hazardous substances by facilities. The amending Act has conferred vast powers on the Factory Inspectors with the objective of implementing the safety provisions of the Act. In conjunction with the Factories Act of 1948, most of other acts of the pre-Bhopal era were amended to strengthen the safety and disaster prevention related provisions. In addition, provisions of existing regulations like the Factories Act and Rules, the Petroleum Act and Rules, the Explosive Act and subsidiary rules that were concerned with regulating safety performance of industrial operations and plants involving hazardous operations or handling of the hazardous chemicals and explosives were also strengthened. 
Table 4-1: Important changes in legislation in post Bhopal era

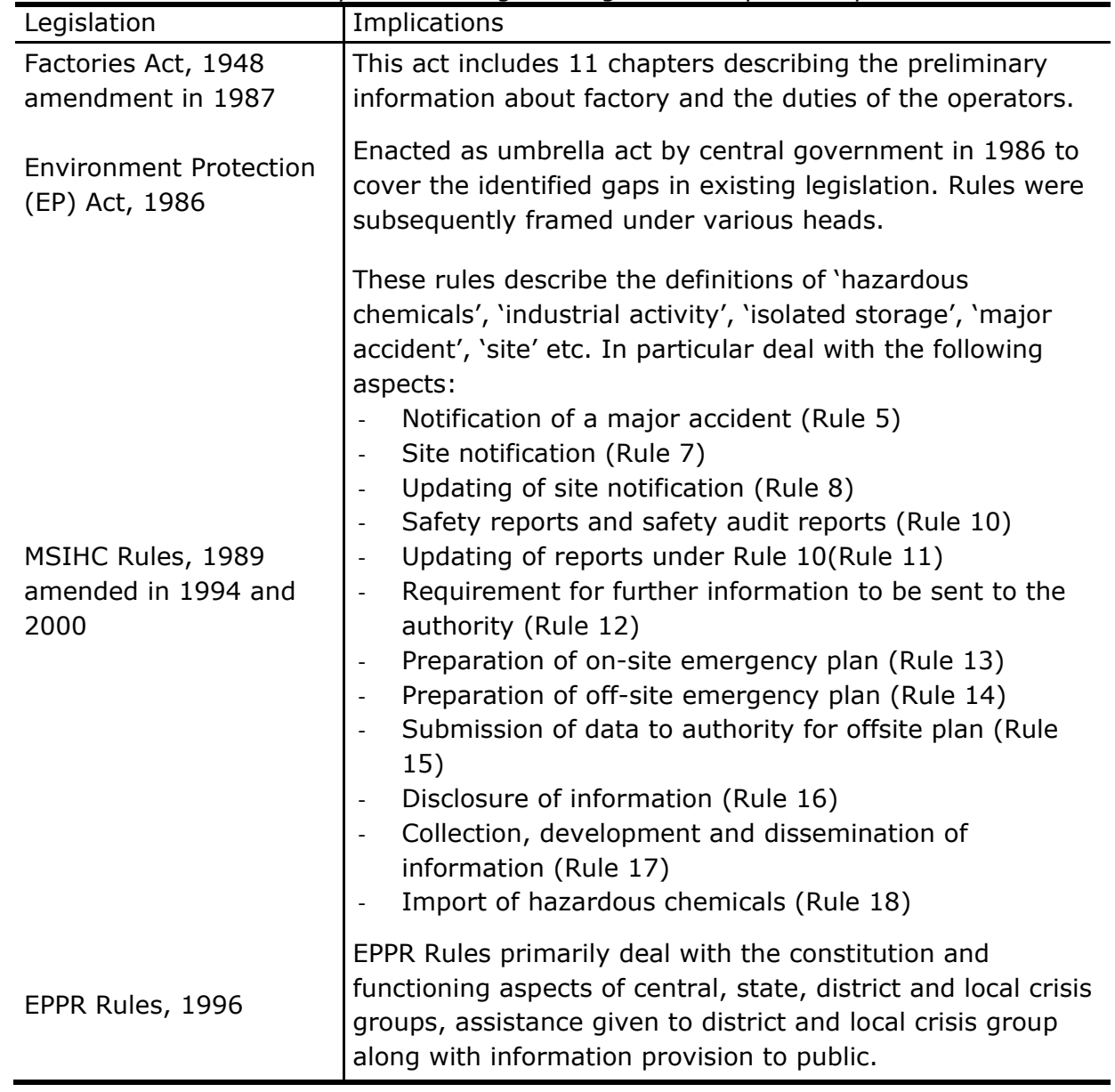

Other regulations like the Standards and Guidelines complied by the OISD ${ }^{40}$ provide industry-specific criteria with regard to operational procedures, maintenance of safety distances between storages and safeguards for processes and equipment's. The Petroleum and Natural Gas Regulatory Board (PNGRB) ${ }^{41}$ also promulgated the Codes of Practices for Emergency Response and Disaster Management Plan (ERDMP) Regulations of $2010^{42}$ for petroleum and natural gas industries. The Codes stipulates that all

${ }^{40}$ Oil Industry Safety Directorate (OISD) is a technical directorate under the Ministry of Petroleum and Natural Gas (MoP\&NG) that formulates and coordinates the implementation of a series of self-regulatory measures aimed at enhancing the safety in the oil \& gas industry in India.

OISD standard: http://oisd.nic.in/pdf/oisdstddraft244.pdf

${ }^{41}$ PNGRB was constituted under The Petroleum and Natural Gas Regulatory Board Act, 2006 (NO. 19 OF 2006) notified via Gazette Notification dated 31st March, 2006.

${ }^{42}$ ERDMP Regulations of 2010: 
such industries would carry out a systematic risk assessment to identify potential failures, calculate a combination of potential consequence and probability, evaluate the risk based on maximum tolerable risk criteria, and adopt measures to keep the risk ALARP principal. The overall regulatory framework is schematically represented in Figure 4-1.

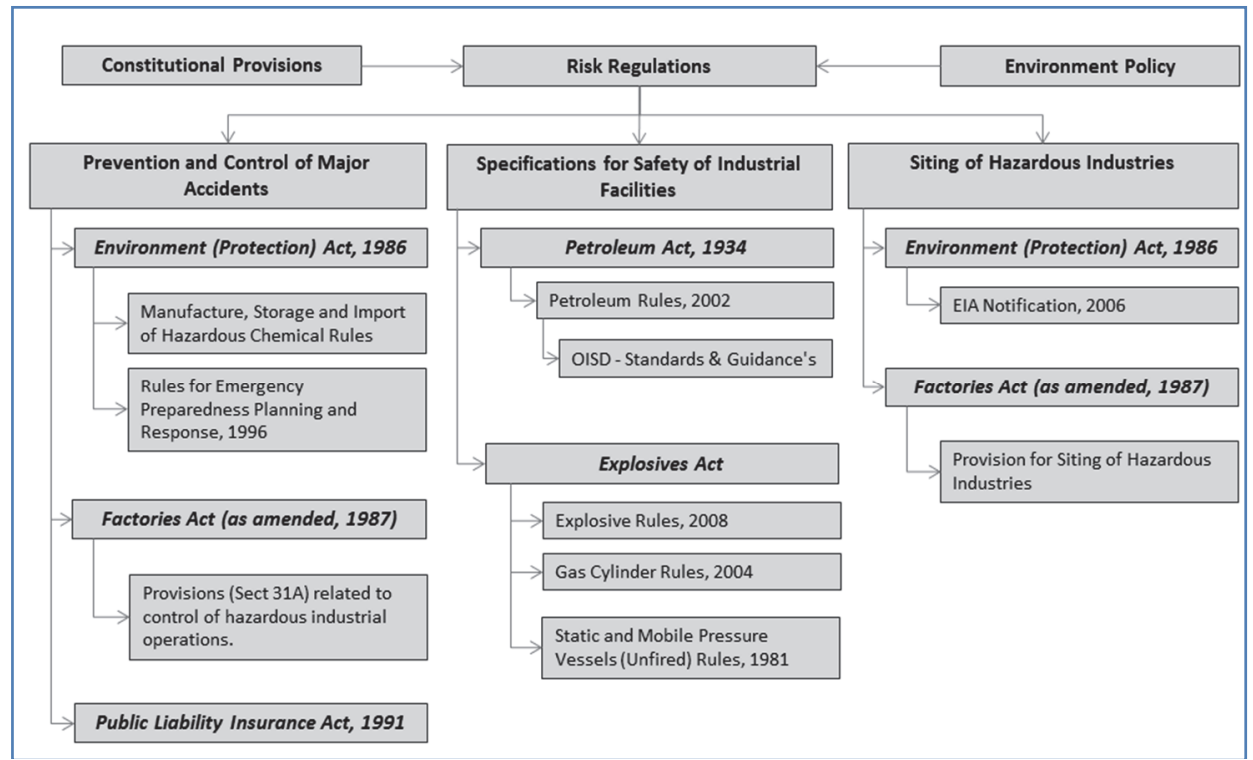

Figure 4-1: Regulatory Framework for industrial risk management in India

\subsubsection{Institutional framework}

An institutional framework for providing technical support services at various levels is the key requirement for sustaining proper development and implementation of the risk management. The existing institutional set-up of India for industrial risk assessment and/or management is a two-tier system. The responsibility for control and management of risk from hazardous industries is dispersed amongst multiple organizations, which come under the ambit of several line-ministries and authorities both at central and state level.

At the federal level, the MoEFCC is acting as the nodal ministry for instituting and implementing the regulatory framework. This is because in India the whole gamut of laws for hazardous chemicals is formulated under the EP Act, 1986 (Gupta, 2006). Within the Ministry, the Hazardous Substances Management Division (HSMD) is the nodal point within the Ministry for management of chemical emergencies and hazardous substances. The main

http://www.pngrb.gov.in/pdf/public-notice/Draft Structure-CGD-

IMS REV 23april.pdf 
objective of the Division is to promote safe management and use of hazardous chemicals and wastes, thus to avoid damage to health and environment. The Division also acts as the nodal point for the implementation of the International Conventions viz. the Basel Convention, the Rotterdam Convention, the Stockholm Convention, and the Minamata Convention.

Other federal agencies, also responsible for enacting and monitor compliance of the regulations are:

- the Central Pollution Control Board43 (CPCB) under MoEFCC;

- the Directorate General, Factory Advice Service and Labour Institutes (DGFASLI) ${ }^{44}$ and the Directorate of Industrial Safety and Health (DISH) under the Ministry of Labour and Employment (MoLE);

- the Petroleum and Explosives Safety Organization (PESO) ${ }^{45}$ under the Ministry of Commerce and Industry (MoC\&I); and

- the National Disaster Management Authority (NDMA) under the Ministry of Home Affairs (MHA).

Similarly, at the state level, such responsibilities and roles are primarily led by either the State Pollution Control Boards (SPCBs) or the Union Territory Pollution Control Committees (UTPCCs) under the state Dept. of Environment (DoE) and by the Inspectorate of Factories to implement the Factories Act and Factories Amendment Act. In nutshell, the power for regulating and enforcing the laws and rules pertaining to industrial risk management is dispersed between many organizations at central and state levels. The overall institutional framework is schematically represented in Figure 4-2.

\footnotetext{
${ }^{43}$ CPCB: http://cpcb.nic.in/

${ }^{44}$ DGFASLI: http://dgfasli.nic.in/

${ }^{45}$ PESO: http://peso.gov.in/index.aspx
} 


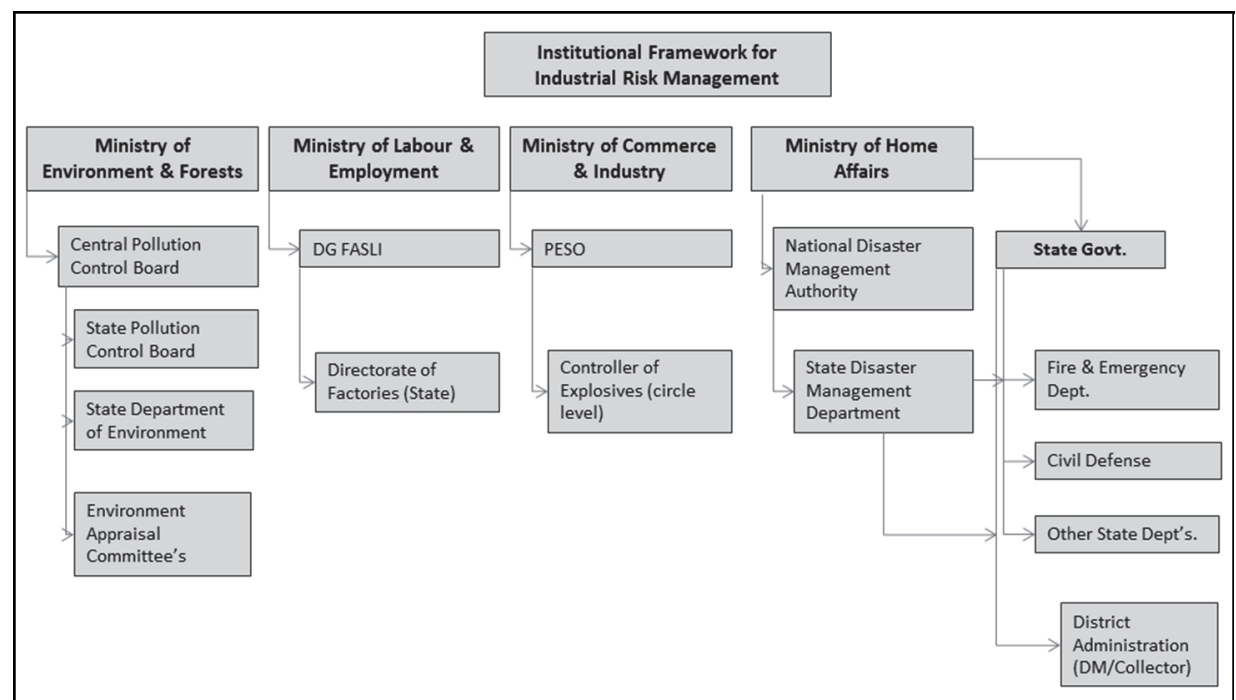

Figure 4-2: Institutional framework for industrial risk management in India

There are several weaknesses in the existing institutional framework:

- First, there is an absence of an independent regulatory body (other than the competent authority) to assess the overall effectiveness of the system.

- Second, there is no structured and clear hierarchy to comprehend the institutional mechanism as well as the role of individual organizations.

- Third, the multiplicity of institutions to deal with permitting, reporting and inspection for industrial risk aggravate the compliance problem. With the number of institutions at different levels, there is often a lack of both horizontal and vertical coordination between the agencies. In the vertical chain, there is more a tendency of central and state level agencies to get into a conflict.

- Fourth, there has been a lack of adequate institutional capacity at both the nodal (MoEFCC and CPCBs) and implementation level (SPCBs and others) to match the demand for compliance services as a result of a steady increase in the numbers of the regulated community and the complexity of environmental issues that are being encountered.

Several reviews undertaken by different agencies have strongly recommended strengthening of existing institutions and certain recommendations proposing setting up a new National Environmental Protection Authority (NEPA $)^{46}$ along with the appropriate regional authorities. The absence of adequate powers with the MoEFCC or the CPCB to sanction

${ }^{46}$ National Environmental Protection Authority (NEFA):

http://www.envfor.nic.in/mef/NEPA\%20-\%20Discussion\%20Paper.pdf 
the state level projects often makes it possible that the state agencies can dilute certain requirements, if it is seen as an impediment to the development of the state. This has often been the case, when permissions are given at the State level to several hazardous industries to be sited in close proximity in a prospective industrial area without considering cumulative impacts or risks to the population or the environment. At the horizontal level, the lack of a common database of information on the regulated community often result in duplicate efforts which result in industries to fill in multiple forms to meet the permitting requirements.

\subsubsection{Summary}

From the above discussion, it can be summarized that risks arising from the hazardous industries can be minimized through a more comprehensive or effective risk management framework. Therefore, an overarching framework in accordance to the existing legislation needs to be institutionalized to support any decision making process. In the view of policy framework, at this time, there is no specific policy thrust to reduce risk or minimize damages, if a sever accident unfolds and the only option available to the government is to regulate various aspects related to it.

On regulatory front, in spite of having a comprehensive set of regulations, one of the key weaknesses of the Indian regulatory regime is its inability to keep pace with the rapid economic development and respond to the problems resulting from the process of intense industrialization and urbanization in the last two decades. Operating mostly in the responsive mode, the regulatory system is often unable to pre-empt future or upcoming problems and the issue of management of industrial risk appears to be one of them. Even though there is general acceptance that the compliance of industries to risk regulation is unsatisfactory, however nothing significant has been done to bring about a shift in the regulatory approach, since the formulation of the EP Act in 1986.In addition to this, the regulated authority also encountered with the multiplicity of regulations with similar scope. For example, following the provisions of MSIHC regulations, hazardous industries require reporting to be done both to the Factories Inspectorate and the State Pollution Control Boards, as both are designated competent authorities as per Schedule 5 of the regulation. The resulting complexity in regard often acts as an obstacle. In a nutshell, the existing situation of having industrial safety under this Act in itself is a misfit in compare to the USA, UK or Europe.

From institutional framework perspective, it can be noted that with an inadequate institutional framework, government agencies and regulatory bodies have been severely constrained in implementing most of the regulations. Consequentially, many industries default on providing right and timely information on risks present within a $\mathrm{MAH}$ installation while on the 
other hand, the government is yet to set up and make operational Crisis Groups who can coordinate effective response in a contingency situation. The local emergency control centres are also handicapped with lack of proper information resources. Added to the problem, is the unavailability of competent technical personnel in controlling positions in the central and state regulatory agencies. As a result the decisions are not made based on the facts or any proper technical analysis. Moreover, the government officials generally trained in traditional administrative roles, are usually overwhelmed by the scale of a high consequence accident that would never occurred before.

\subsection{Risk assessment procedural context}

Risk assessment, in the broad sense, involves a structured procedure that evaluates qualitatively or quantitatively the level of risk that is imposed by a hazardous facility. It plays an important role in the risk governance framework by assisting decision makers to prioritize safety management within the facility and also take appropriate preventive and mitigation measures to safeguard the community living in the vicinity of such a facility from a potential accident. In this section, the procedural framework for industrial risk assessment as practice in India is analysed in order to identify weaknesses prevails in the existing practice and consequently uncertainty leads towards the decision.

\subsubsection{Hazard identification}

Conventionally, hazard identification is the first step in the risk assessment process. The identification of hazardous installations, the volume and nature of hazardous chemicals that they store, are the key elements of the hazard identification process. In India, industries dealing with hazardous chemicals equal to or in excess of the threshold quantities as specified in the Schedules 2 and 3 of the MSIHC Rules, 1989 are categorized as MAH units. According to the regulatory requirement, the MAH units are obliged to report on their respective hazard potentials on a periodic basis. However, in most cases those reports are not available digitally and retained with different competent authorities. This result in a lack of accessible and valid information on a common platform which can further be used for emergency response and/or risk mitigation.

\subsubsection{Scenario selection}

Selection of reference scenarios for risk analysis constitutes an important component and on which the results can vary considerably. In India, the only guidance in this regard is provided in the method delineated by MoEFCC for undertaking cluster-level hazard analysis (ERM, 2002). The guidance mentions that analysis of consequence for storage of hazardous chemical is 
undertaken taking into account maximum loss scenario that considers catastrophic vessel failure. It also goes on to mention the weather conditions that are to be considered for generating the scenario. As there is no formal laid down risk assessment process, which takes into account the probability of an event to arrive at a measure of risk caused by a hazardous facility, no further guidance on scenario selection for risk analysis is provided in any regulations or regulatory guidance document. There is often no consistency in terms of generation of scenarios for probable or worst case accidents thus leading to widely varying results for the same risk scenario pointing out towards a gap in the assessment practice.

\subsubsection{Accident database}

An accident database and information captured in it can provide vital learning towards preventing future accidents and leading to corrective action being taken at a facility of concern. Understanding that, some recent efforts have been initiated to establish accident databases. In order to ensure that such databases can be accessed by relevant actors' intent on submitting or retrieving data, in recent years there is trend towards developing internet based solutions.

In India, at present there is no such accident database available for frequency assessment (NDMA, 2007). The MoEFCC being the nodal agency is in the process of building a web-based accident information system with the objective of integrating accident reporting formats prescribed by several regulatory authorities such as the $\mathrm{CPCB}$, Inspectorate of Factories and the Controller of Explosives. It is designed as a centralized database in order to facilitate effective communication of accident information between the competent authorities and the parties concerned and to ensure access to accident reports from a single domain. However, though the project was commenced in 2009, the system is yet to be made operational. The DGFASLI and the NIDM has also initiated similar initiatives for recording accidents at MAH installations. However, in absence of a proper institutional mechanism to supervise, coordinate and guide accident reporting by actors concerned, none of these initiatives can be considered to be successful at this time.

\subsubsection{Risk analysis}

There is a variety of methods that have been developed to analyse risk originating from hazardous facilities, ranging from the strictly quantitative one which tries to assign a numerical value for risk to more subjective ones which try and evaluate risk through a semi-quantitative risk matrix. Various countries have formulated their preferred methods for risk assessment of the hazardous facilities, based on availability of data, credible risk models and accounting for management practices followed in industries. However, in 
India, at this time there is not prescribed standard methodology for risk assessment of hazardous facilities based on which an evaluation of risk emanating from them can be rated and based on which risk reduction strategies for a region formulated. Though regulations like the Factories Act and the MSICHR Rules focus on undertaking risk evaluation and report them to regulatory authorities, the absence of guidance on a standardized method to be followed and any risk benchmark or criteria to be attained makes it impossible for regulators, planners or plant designers to work to a certain level of safety. In addition, facility level safety assessments which are commissioned by industries and undertaken by consultants are seldom shared with the regulatory agencies, if they bring forward any significant deficiencies in either technology or safety management practices of the facility. As a result, the agencies have to depend on the mandated 'safety audit' report which again is not carried out by an independent agency and thus is often biased towards the industry making an objective evaluation of risk impossible.

The risk analysis process in India is functional in any of the following three forms:

First, all industries which fall under the categories regarded as having high potential to pollute the environment and exceeding certain minimal thresholds, qualify for an Environmental Impact Assessment (EIA) study based on which it has to acquire an Environmental Clearance (EC). The EIA study involves scoping process wherein the designated Environmental Appraisal Committee reviews preliminary information on the project and prescribes a Terms of Reference (ToR) for the study. If the industry is hazardous in nature, it is expected that the EAC would include a risk assessment study as a part of the overall EIA study.

Second, operational industries which meet the criteria requirements and as a result are categorized as MAH industries and storing hazardous chemical beyond specified thresholds, have to undertake a facility level risk assessment. And according to the MSIHC Rules, are required to submit the results documented in a Safety Report (as per Rule 10) and an onsite emergency plan (as per Rule 13) to the Competent Authority. Regulatory provisions under Schedule 8 of the MSIHC Rules prescribe that the safety report should include a preliminary hazard analysis based on the identification of the type of possible accidents along with an evaluation of systems elements, resulting hazards and relevant safety components; and a hazard assessment based on hazard identification, ascertaining the cause of major accidents, assessment of hazards based on their frequency and potential consequence, safety systems and accident history. 
Third, there is a provision to undertake an area level risk assessment as a part of the pocket wise hazard analysis program initiated by the MoEFCC during the 8th plan in order to enable district authorities to effectively manage off-site technological emergencies. After the preparation of the report, they are evaluation by core group of experts appointed by the MoEFCC, workshops are organized in the respective clusters and based on common understanding, recommendations for on-site and offsite emergency plans, improvement of safety management practice in industries are to be taken up and are to be followed by monitoring by the agencies concerned.

However, there is no unified philosophy or principle which governs any of these risk assessment processes that may result in the characterization of risk based on certain acceptable criteria. Though, on one side the absence of such standardization provides considerable flexibility to the respective players to make decisions on the approach to be adopted for risk assessment, on the other the absence of guidance on a standardized method to be followed and any risk benchmark or criteria to be attained makes it impossible for regulators, planners or plant designers to work to a certain level of safety.

On the EIA front, though the regulation provides an option for scoping a risk assessment into the EIA study, but the appraisal committee primarily constitutes of members (who focus on different environmental and socioeconomic impacts that can be caused by a proposed facility) often do not have the expertise or the scientific knowledge to propose a standardized risk assessment study. This lack of understanding is clearly evident in the guidance manuals that are made available by the MoEFCC for scoping EIA study. For example, the guidance manual that deals with EIA of isolated storage facilities for chemicals or petroleum refineries in which risk aspects should logically be provided additional emphasis in an EIA, instead provides only generic guidance on the formulation of safety, disaster and emergency management plans without specifying any clear approach for undertaking a systematic risk assessment of the proposed facility based on a standardized approach.

A review of hazard analysis reports of 53 industrial clusters undertaken in 2001 by the MoEFCC brought out a number of striking gaps in these reports based on information provided by the industry and a safety audit(ERM, 2002). The report indicated that consequence analysis calculations for many of the hazardous chemicals (including explosive, flammable and highly toxic chemicals such as pesticides) has not been undertaken, which may affect the overall output of the study, and there was often inconsistency in terms of generation of scenarios for probable or worst case accidents leading to widely varying results for the same risk scenario pointing out towards a gap in the 
assessment practice being followed by different consultants. Significantly, even though the gaps were pointed out couple of years' back, but till date the government has not initiated any study for formulating a standard guidance for area-level risk assessment, like the ones carried out in Rijnmond area (The Netherlands), Canvey Island (UK) and Ravenna area (Italy) etc., during the 1970's (Christou, et al., 1999a; Roodbol, 1984). The focus of those studies was mainly to formulate safety goals and then relate them with land use planning guidelines (Amendola et al., 1995). The concern and awareness of the authorities on taking major accident hazards into account in LUP has clearly been expressed in these early attempts to establish risk tolerability criteria and in the performance of a number of area risk studies.

\subsubsection{Risk evaluation}

The next step in the risk assessment process is the evaluation of assessed risks for an activity to determine whether the risks are acceptable to regulators and society at large. In the absence of any clearly laid down risk philosophy or standard criteria, there are measureable levels of risk which can be considered to be acceptable. Understanding that it may be difficult for a single risk level to be applicable to the entire country as diverse as India, it is expected that a set of guiding criteria or a framework to lay out a logical basis or a range of risk measure against which the results of the risk assessment can be evaluated. Without this, the assessment of a hazardous industries performance towards attainment of safety goals becomes arbitrary and subjective. It is also difficult to compare or arrive at a summation of risk originating from multiple hazardous units, carry out an industry wise apportionment of risk or arrive at a measure of cumulative area level risk in an industrial area. In practice, therefore, most industries would undertake a consequence analysis study based on certain benchmarked hazard end-points for toxic gas concentrations, overpressure or radiation levels and present the footprints as an output of the risk assessment process. Neither are there any subjective engineering good practice principles like ALARA or ALARP been espoused in any policy, regulations or guidance based on which risk mitigation measures can be planned, implemented and monitored.

\subsubsection{Summary}

In nutshell, 30 years since Bhopal following deficits are still there in the risk assessment framework for industrial accidents in India:

- Lack of harmonized or standard risk analysis methodology;

- Lack of standardization to use for QRA (e.g., weather condition, threshold limit);

- No standard damage criteria (i.e. fixed endpoints or Probit endpoints);

- Non-uniformity in the structure of the on-site and off-site plan; 
- Lack in the procedure for conduct of safety audit and safety report preparation;

- Lack of cumulative risk assessment practice for industrial clusters;

- For safety audit many department for the same location are involved;

- No place to report accidents that occur during commissioning and decommissioning of plants;

- The testing of on-site emergency plans every six months is a statutory requirement. A large number of units conduct mock drills shop-floor wise or cover only a few components, while the requirement is for the installation as a whole;

- A yearly mock drill of district off-site emergency plans is essential and mandated. However, very few full-scale drills of district off-site emergency plans are being conducted in the country, and even those are not conducted as per the norms.

\subsection{Planning context}

Presently, there is lack of comprehensive and integrated land use planning in India, which enables rationale and optimal land utilisation. There is also no single approach currently being followed across the country. Various sectors at central level such as urban, rural, industrial, transport, mining, agriculture etc. follow their own approaches. The Constitution (Seventy-fourth Amendment) Act, 1992 provides for District Planning and Metropolitan Area Planning that consolidates plans of both Panchayets and municipalities having regard to spatial (land use) planning. District plans are prepared at a lower scale and currently do not cover spatial (land), environmental or urban concerns. For urban development areas a land use control development plan (LUD\&CP) is prepared and updated, as per the requirements of the respective state-level Town and Country Planning Acts; however, implementation of the local zoning and land use restrictions, have been quite ineffective in most of such planned area.

The recently formulated Draft National Land Utilisation Policy ${ }^{47}$ in 2013 by Dept. of Land Resources under the Ministry of Rural Development (GoI:MoRD)aims to provide a framework for land use planning and management, recognising the economic, developmental, social and environmental needs that are catered to by the rational and sustainable use of land. According to this draft policy, all land in the country will be classified into Land Utilisation Zones (LUZs) and to undergo land use planning for one or more objectives like rural areas, agricultural areas, industrial areas, etc. Further, for the purpose of land management, LUZs are to be divided into

${ }^{47}$ Draft National Land Utilisation Policy: http://dolr.nic.in/dolr/downloads/PDFs/Draft\%20National\%20Land\%20Utilisation\% 20Policy\%20(July\%202013).pdf 
various Land use Management Areas (LMAs) to ensure protection, regulation, control and guided development. The planning process in these LUZs is expected to be guided by the newly drafted Urban Development Plans Formulation and Implementation (UDPFI) Guidelines ${ }^{48}$ which recommends the adoption of a tiered planning process comprising of preparation of a perspective plan followed by development plans and annual plans (MoUAE, 1996). Besides, several initiatives have been prepared for a large number of urban local bodies like Comprehensive Development Plans and Draft Development Plans with provision for proactive involvement of the public in the planning process and in the discussion of planning alternatives and schemes.

In order to ensure proper siting of newly planned industries taking into account environmental considerations, a project called the "Zoning Atlas for Siting of Industries" has been implemented through the Central Pollution Control Board (CPCB) - the apex pollution control authority in the country (Punihani et al., 2002). The project lays down a methodology of preparing thematic maps at district level factoring aspects like prevailing air, water and ground water quality and undertaking multi-criteria based sensitivity analysis for assessing suitability for new industries at a district level. Using a standard methodology, zoning atlas maps for several districts in the country have been prepared and are available as hardcopies from the CPCB. However, the Zoning Atlas methodology did not incorporate risks in the siting analysis. Also, the use of Zoning Atlases for planning of new industrial areas has been inadequate and the tools and methods drafted as a part of the Atlas have not so far been mainstreamed with the planning process or adopted by planning authorities at the state or district levels.

A good case in a point, for to pin down the siting problem, is the emergence of more than 100 industrial clusters in India which houses a significant portion of the country's hazardous industries. When some of the first hazardous industries came up in these clusters, in areas demarcated for industrial development as a part of a centralised planning process, there was little local population and therefore, low risk to society in the eventuality of an industrial accident. However, as these industrial areas expanded and new industries came up, they witnessed a rapid in-migration of people cohabiting beside hazardous industries, made possible by weak land use controls and leading to a significant amplification of risk (de Souza Porto et al., 1996). While creating sufficient separation distances between such facilities and residential areas could have provided for a straightforward resolution of the problem, such decisions were difficult to implement in rapidly urbanising areas where land availability was constrained. Consequently, on one side,

${ }^{48}$ UDPFI Guidelines:http://www.mpurban.gov.in/Pdf/URDPFIGuidelinesVol IDraft 1.pdf 
land-use planners had to account for the safety of surrounding population in an industrial area while on the other they have to consider options to exploit land in the best possible manner accounting for socio-economic considerations like employment opportunities, benefits to the local community from operation of an industry and objectives for area level industrial development (Gupta, 2002). As a result, often desire for short term and tangible developmental gains has often prevailed over notions of anticipated safety benefits to communities in the long run.

In brief, it can be concluded that regulatory provisions for control of industrial risk have seldom been taken into account in land use planning and in the design or the adoption of community-level preventive measures for risk reduction in India (NDMA, 2007). Several regulations like provisions of the Environment Protection Act, the EIA Notification and the Factories Act, along with associated Rules and codes of practice have been formulated to provide directions for safe siting of industries. However, there has also been no attempt to interlink the technocratic approach adopted for risk analysis, predominantly through the setting of appropriate safety distances or zoning restrictions, with the land use planning practice adopted by developmental agencies and urban local bodies (ULBs).As a result, within this planners faced with pressures to use land for productive purposes are often not aware of such land use restrictions or without having a stringent restriction imposed by the competent regulator, are not been able to justify the exclusion of privately owned or public land from future development. 


\section{Chapter 5 - Case study area}

This chapter presents an overview of the case-study. Case selection is one of the important steps in the design and data collection process. In order to do so the chapter describes the case study area including its location, its evolution as an emerging industrial town, the development of the area in terms of progressive changes in land use pattern, and its impact on demographic profile and economic setup over the time. The industrial town Haldia, one of the emerging industrial destinations as well as the biggest ports in the Eastern India was selected as case study of this research.

\subsection{Location}

The city of Haldia, including the existing industrial base, is located 56 nautical miles ${ }^{49}$ downstream of the legendary port of Calcutta, the Gateway of Eastern India, at the southern tip of the state of West Bengal. The extension of Haldia (township) lies between $22^{\circ} 03^{\prime} 44^{\prime \prime} \mathrm{N}$ to $22^{\circ} 04^{\prime} 53^{\prime \prime} \mathrm{N}$ latitude and $88^{\circ} 07^{\prime} 53^{\prime \prime} \mathrm{E}$ to $88^{\circ} 09^{\prime} 03^{\prime \prime E}$ longitude. Situated in the lower Gangetic plain or deltaic reaches of river Bhagirathi, this port and industrial town is located at distance of 125 $\mathrm{km}$ south-west of Kolkata and $50 \mathrm{~km}$ from the Bay of Bengal at the confluence of river Hooghly and Haldi in East Medinipur district (Figure 5-1).

\subsection{Rationale for selection}

Haldia was selected as case study of this research because of the following key considerations. The first relates to its importance of the industrial town as one of the largest petro-chemical hubs of India supported by a port complex and other infrastructural facilities. Presently there are 42 industrial units, of which 20 are identified as MAH industries. Apart from that the area has also declared as the PCPIR of West Bengal. Hence in the last few decades, the town is poised for rapid urbanization and industrial development. However, due to the lack of proper and updated development plan in place to meet the need for its rapid industrialization, most of these industrial units along the River Hooghly are juxtaposed with residential areas with a total population of 200,331 persons (according to the Census 2011) ${ }^{50}$, including a large area with informal settlements lying in close vicinity of the hazardous industries. On the other hand, these development activities also generate in-migration of people to the Haldia industrial town. As the demographic profile of the area considers, the region becomes one of the most densely populated regions in India, having an average population density of 904 persons per $\mathrm{km}^{2}$ as per Census 2011. Resultantly, with the surge in the number of hazardous industries which are coming up and the

491 nautical mile $=1.37$ miles

${ }^{50}$ http://www.census2011.co.in/census/city/252-haldia.html 
gradual in-migration of people, the level of risk originating from industries, are expected to rise further in Haldia.

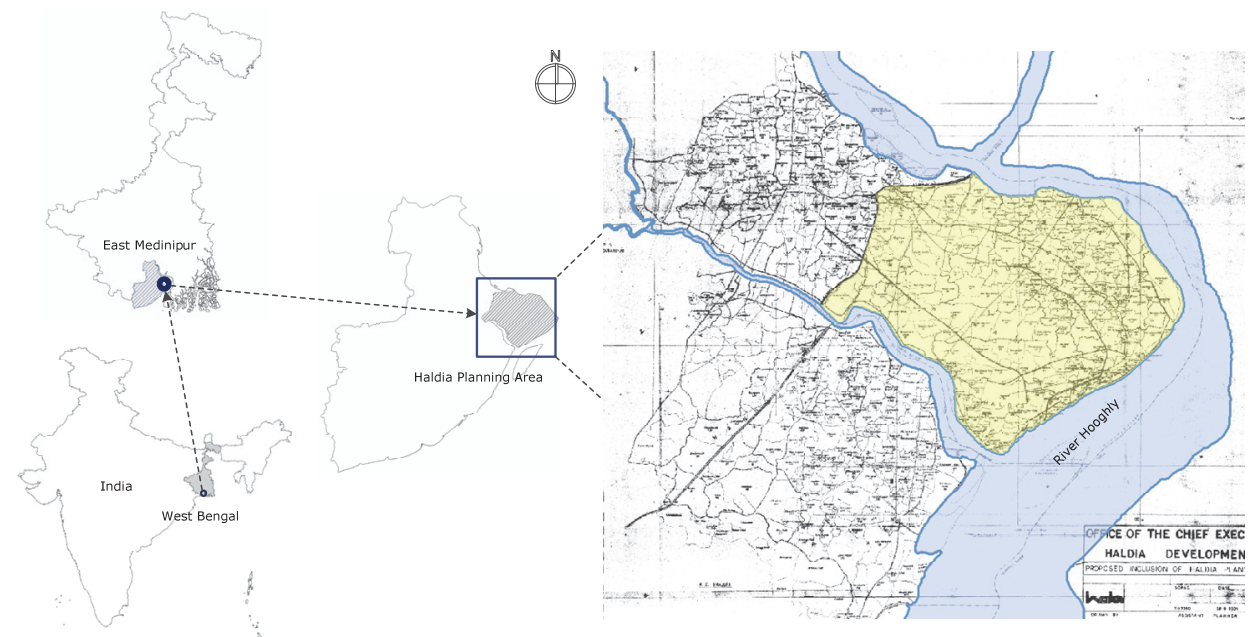

Figure 5-1: Location map of Haldia, West Bengal, India

But, till date, potential risks arising out of these hazardous industries have never been factored into the land use planning decisions or the overall development of the region. In particular, no effort has been made to maintain any exclusion or separation distance between residential areas or informal habitations from the hazardous industries. As a result, densely populated areas often co-exist with hazardous industries, hence resulting in very high degree of vulnerability of the residents. Having said this, in order to get a clear view of the nature and dynamics of the urbanization and industrial process, which is typical in other industrial towns of India, the town of Haldia has been selected as a case study area.

The second reason relates to the familiarity of the area including planning and institutional setting as well as the spatial configuration of prevailing risks as acquired during the implementation of the 'Environmental Risk Reporting and Information System (ERRIS)' project (Bandyopadhyay et al., 2008), which is a precursor to this research.

In addition, the Development Authority of the area was also supportive of this research. Being the nodal agency for physical planning, the Development Authority of Haldia took an initiative during 2010-2012 to prepare and update the Land Use and Development Control Plan (hereafter LU\&DCP) for the old Planning Area in a GIS platform, the first of its kind in West Bengal. As a part of this initiative, the researchers (including the author of this PhD thesis) from the Faculty of Geo-information Science \& Earth Observation, University of Twente, were invited to extend their expertise in the preparation of a 
seamless digital cadastral-level land use map of the area, the base map for LU\&DCP to monitor and control rapid industrial and commercial development as well as new growth centres.

\subsection{Genesis of Haldia}

In the context of gradual deterioration in the navigability of the river Hooghly and consequent limitations of handling large vessels at the Calcutta (Kolkata) Port, the idea of establishing an ancillary port at Haldia was born during late1950's. Accordingly, the port of Haldia brought in its wake in the mid 60's as a potential port-based urban-industrial centre through establishment of large industries in and around it. In 1965, the Planning Commission, the apex planning body of Govt. of India, approved Haldia as a major port and related industrial urban activities. This decision was then followed up with setting up of an oil refinery, a fertilizer complex and a township.

The emergence of Haldia apparently opened up visions of creating a growth centre in relatively backward region in the state of West Bengal as well as to encourage industrial depolarization in the region. To further strengthen the prospect of industrial development in Haldia, the Govt. of West Bengal in 1972 declared Haldia as a growth centre along with seven other towns in the State. Gradually, Haldia began to be identified as not merely a subsidiary port of Calcutta to supplement its facilities, but also as new seaway to the prosperity of the entire eastern India. This entitled the perspective for setting up the Haldia Development Authority $(\mathrm{HDA})^{51}$, the statutory authority for accelerating the further development of Haldia area. Then the Development Authority came under the preview of the T\&CP Act, $1979^{52}$ for defining the planning area under section 9(1) of the said $\mathrm{Act}^{53}$. Another statutory body, the Haldia Municipality (erstwhile Notified Authority) came up subsequently in accordance to the Bengal Municipal Act of 1932, to look after the urban phenomena.

\subsection{Administrative structure of Haldia Planning Area}

The Haldia Planning Area (hereafter HPA) used to cover an area of 326.85 $\mathrm{km}^{2}$ including 259 mouzas (i.e. revenue village) and Municipal area of 109 $\mathrm{km}^{2}$. The delineation of HPA was unique, as encircled by the rivers in three sides while Hijli Tidal canal delineate the northern boundary (see Figure 5-2).

The area outside the Municipal boundary identified as rural area constituted of three Community Development (CD) Blocks, namely Sutahata, Haldia

51 vide Gazette Notification No.7061-T\&CP/IC-24/76 dated 30.11.1977

52 West Bengal Town and Country (Development and Planning) Act of 1979

53 vide Gazette Notification No.1874-T\&CP/IR-6/80 dated 17.03.1980 
(erstwhile known as Sutahata-II) and part of Mahishadal. Altogether, these CD Blocks cover 14 Gram Panchayets (GP) and 147 mouzas. The hierarchical composition of the rural area under HPA is illustrated in Table 5-1. In recent time, the planning area became $761 \mathrm{~km}^{2}$ by adding another $434 \mathrm{~km}^{2}$ to the old planning area. The extended planning area contains in total 476 mouzas of Mahishadal, Sutahata, Haldia, Nandigram I, Nandigram II and part of Nandakumar Block (See Figure 5-3).

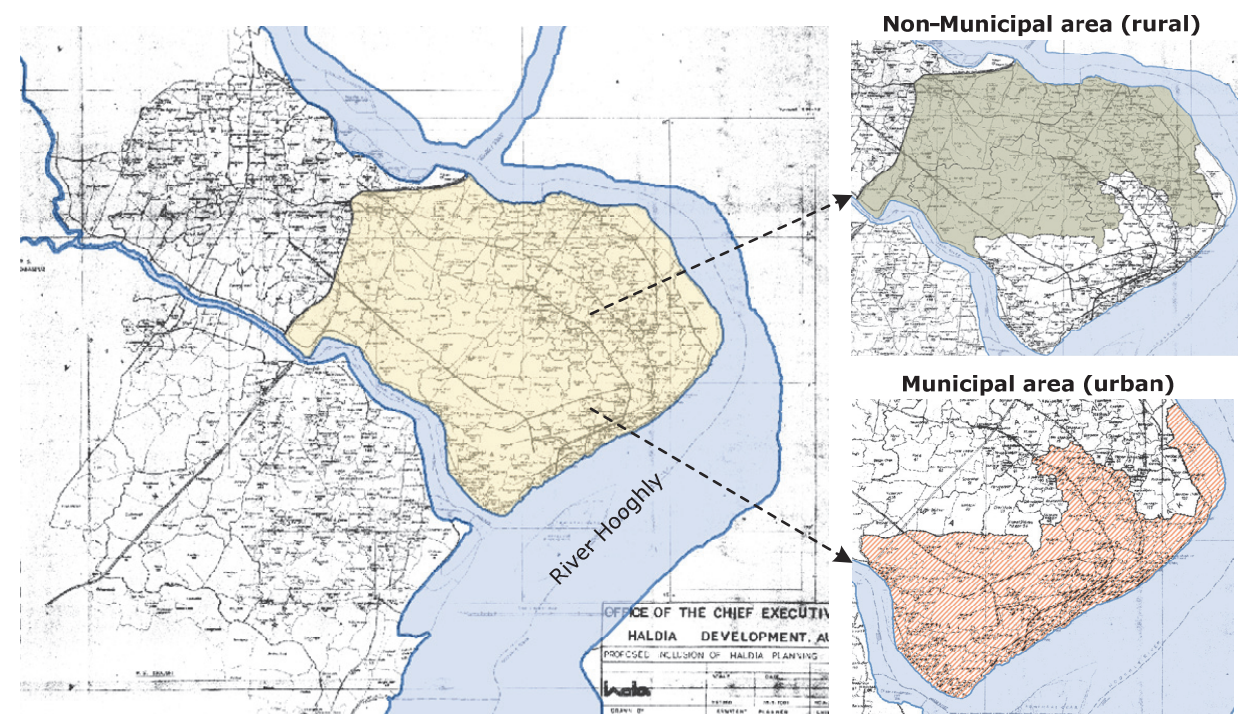

Figure 5-2: Administrative structure of old Planning Area

Table 5-1: Hierarchical composition of non-municipal area: Block-GP-Mouza

\begin{tabular}{|c|c|c|}
\hline Block & Gram Panchayet (GP) \\
\hline & 6 & 81 \\
\hline Sutahata & 4 & 23 \\
\hline Haldia & 7 & (including 13 part) \\
\hline Mahishadal & 6 & 83 \\
\hline
\end{tabular}




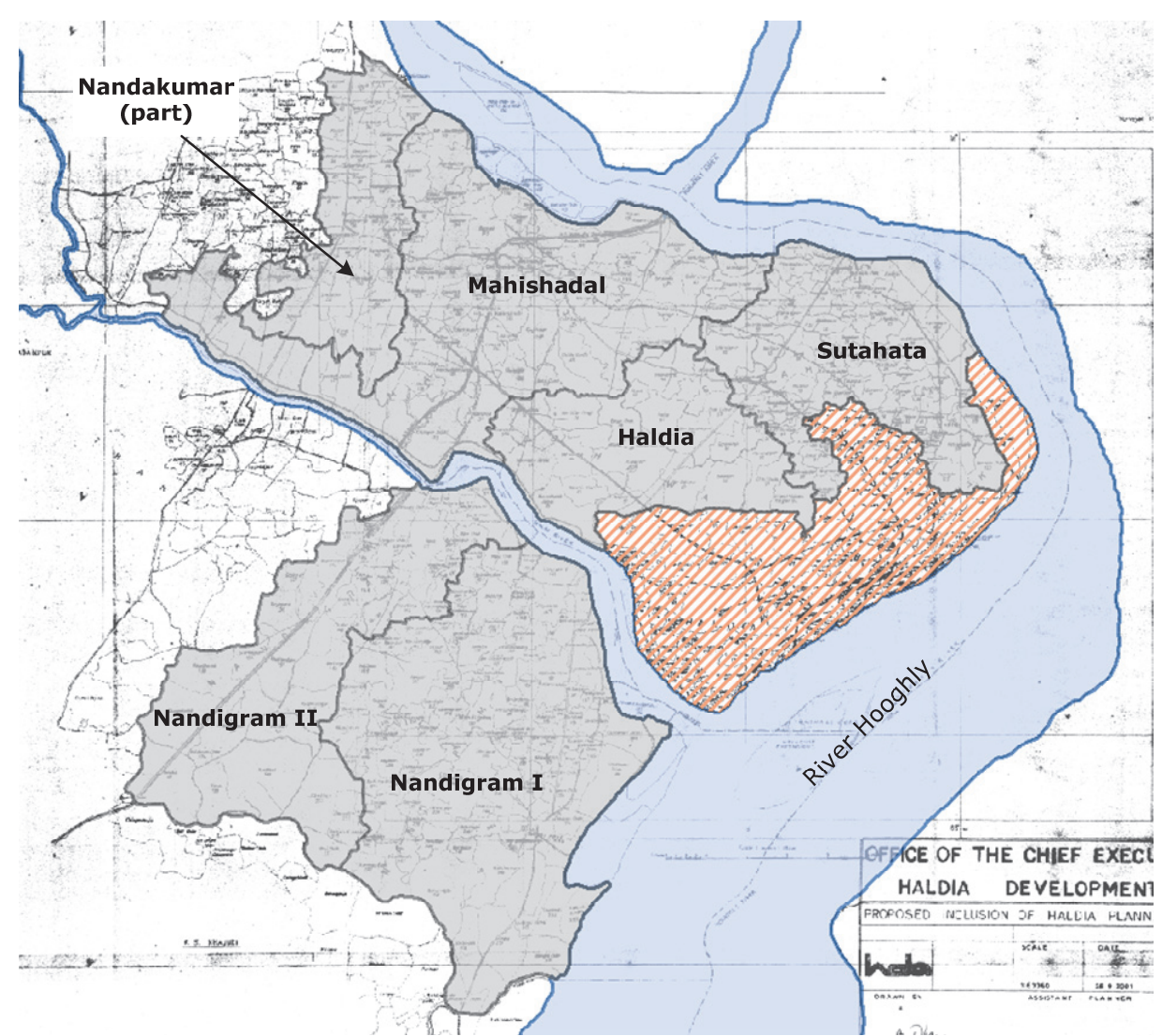

Figure 5-3: Administrative structure of extended planning area of Haldia

Table 5-2: Administrative composition of extended HPA

\begin{tabular}{|c|c|c|c|}
\hline \multicolumn{2}{|c|}{ Area under extended HPA } & No. of mouzas & Total area $\left(\mathrm{km}^{2}\right)$ \\
\hline \multicolumn{2}{|c|}{ Municipal area } & 113 & 109.0 \\
\hline \multicolumn{4}{|c|}{ Non-municipal area } \\
\hline \multirow{6}{*}{$\begin{array}{l}\text { ㄴ. } \\
\frac{\mathrm{O}}{\infty}\end{array}$} & Sutahata & 82 & 78.95 \\
\hline & Haldia & 24 & 59.61 \\
\hline & Mahishadal & 76 & 135.20 \\
\hline & Nandigram I & 99 & 169.63 \\
\hline & Nandigram II & 41 & 105.25 \\
\hline & Nandakumar (part) & 41 & 103.62 \\
\hline \multicolumn{2}{|c|}{ Total } & 476 & 761.26 \\
\hline
\end{tabular}

Source: Haldia Development Authority, Annual Report 2010-2011 


\subsection{Area of interest}

For this research, the area of interest is however limited only to the old Planning area. In particular, analysis was carried out at three different levels: old planning area at regional level, municipal area at local level and part of the Durgachak residential area at building level (see Figure 5-4).

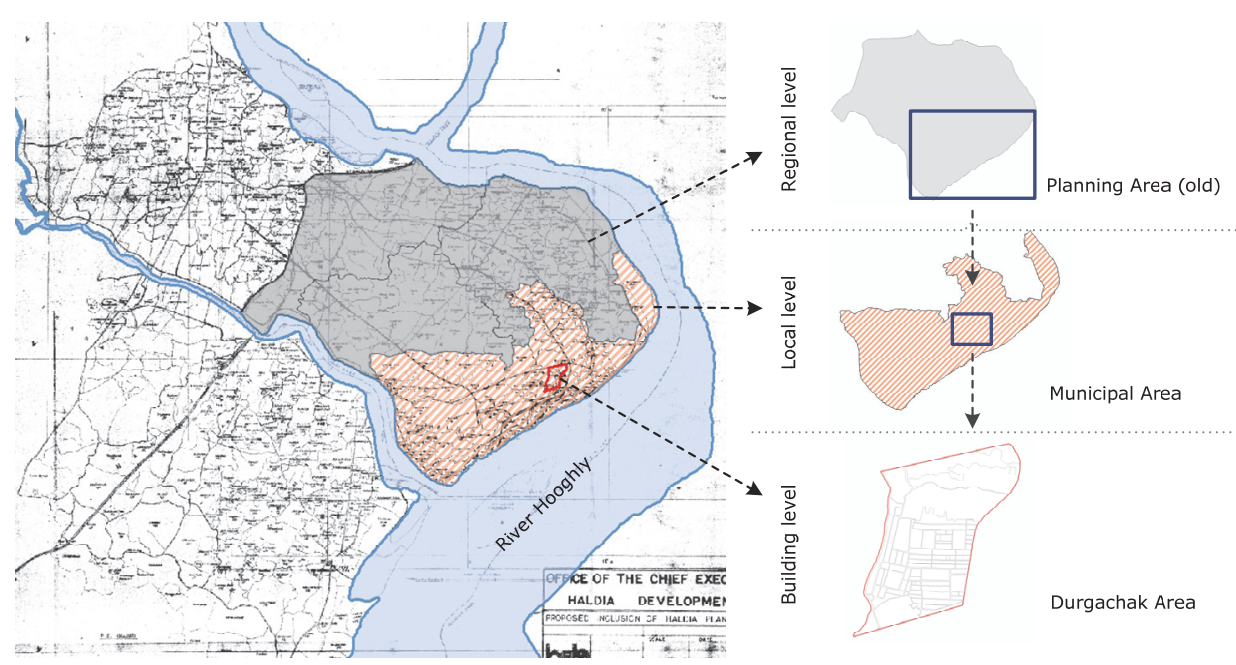

Figure 5-4: Area of interest at different level (scale)

\subsection{Physical environment}

From the physiographic nature, the town Haldia is situated in lower Gangetic plain region. The land in this region is flat with negligible height of 7 to 11 feet above mean sea level. The ground surface slope is from NW to SE. The region has certain flood prone areas which get flooded during the rains when waters from the upstream dams on these rivers are released. The area possesses alluvial soil.

The region forms part of an estuary with two large rivers meeting the sea. As they are in an estuarine condition, these rivers are heavily influenced by tidal forces. In the southern part of the region, the Hooghly and the Haldi, due to their proximity to the sea; have high saline content, thus decreases the fertility of the area. These saline areas are used for mono-crop cultivation and also as brick kilns that use the clay rich silt deposited by the rivers. However the northern areas are extremely fertile. These fertile lands have more than one crop with a rich potential for horticulture and floriculture. Besides, a lot of silt carried by these rivers along with them leads to constant formation and erosion of lands mass and shifting of the banks hence make any development along this river edge very uncertain. As a result, most of 
these river edges have high embankments to protect internal land masses and settlements along the bank.

From the meteorological position, the region is located in tropical monsoon climatic area. The maximum temperature goes up to $33^{\circ} \mathrm{C}$ during the summer time whereas the minimum temperature remains $20^{\circ} \mathrm{C}$ in the winter. The variation in the diurnal range of temperature is not very high which results in humid conditions. The total rainfall that this region receives averages around $1490 \mathrm{~mm}$ per year and the relative humidity fluctuates between 60 to 80 percent.

\subsection{Development of Haldia}

Until middle of the sixties, Haldia was predominantly a backward agricultural area with very weak transportation linkages. Following the decision of setting up of a major port at Haldia in 1959, the process of transformation of the environment of Haldia as the node of chemical industries in Eastern India was started. Since then with commissioning of the port along with the construction of an oil jetty in 1960s, many chemical industries including the Indian Oil Corporation, Hindustan Fertilizer Corporation, Hindustan Liver, Eureka Chemicals, Petrochemical Complex, etc. came into scene in the mid70s followed by the establishment of high profile industrial development like Mitsubishi in late 1990s. Later, other medium-sized chemical industries also came into operation. At present the town has developed into a large industrial cluster with more than $20 \mathrm{MAH}$ units and about 40 other industries. With this rapid industrial development, land use pattern of the predominantly rural area has change considerably in the last decades (See Figure 5-5).
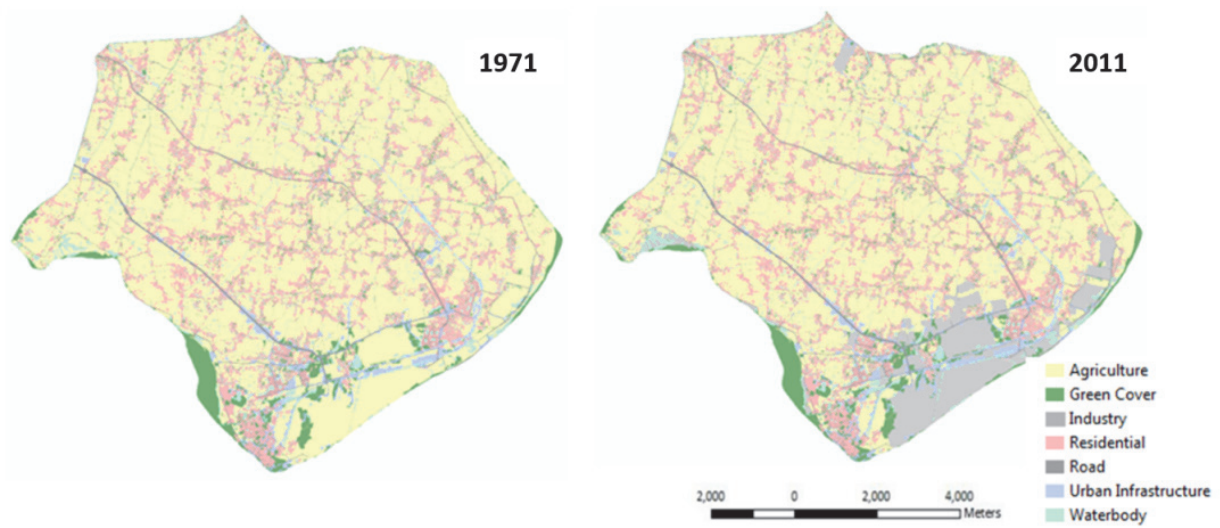

Figure 5-5: Land use changes in Haldia from 1971 to 2011 
Table 5-3: Decadal changes of land use pattern of HPA between 1971 \& 2011

\begin{tabular}{|l|c|c|c|c|c|}
\hline \multirow{2}{*}{ Land use } & \multicolumn{2}{|c|}{1970} & \multicolumn{2}{c|}{2011} & \multirow{2}{*}{ Difference } \\
\cline { 2 - 5 } & Area $\mathrm{Km}^{2}$ & Area \% & Area $\mathrm{Km}^{2}$ & Area \% & \\
\hline Agriculture & 190.26 & 62.19 & 163.97 & 53.59 & -8.60 \\
\hline Green Cover & 20.34 & 6.65 & 17.12 & 5.60 & -1.05 \\
\hline Industrial & 13.45 & 4.40 & 25.66 & 8.39 & +3.99 \\
\hline Residential & 50.98 & 16.66 & 62.45 & 20.41 & +3.75 \\
\hline Road & 8.67 & 2.83 & 12.04 & 3.93 & +1.10 \\
\hline $\begin{array}{l}\text { Urban } \\
\text { infrastructure }\end{array}$ & 5.23 & 1.71 & 7.75 & 2.53 & -0.82 \\
\hline Water body & 16.99 & 5.55 & 16.99 & 5.55 & 0.00 \\
\hline Total & 305.92 & 100.0 & 305.98 & 100.0 & 0.00 \\
\hline
\end{tabular}

Source: Haldia Development Authority

Along with changes in land use pattern, there has been a considerable change in the occupational structure of the inhabitants and still continuing with time. Agriculture used to be the predominant occupation of the region, but after the establishment of the port and the industries, a major step put also forward towards the development of the area.

\subsection{Demographic profile}

Demographic profile of an area is the best indicator to realize the rate and process of urbanization. It does not only indicate demographic growth and distribution over space and time, also includes the economic perspective of the demographic structure. With rapid industrialization, the population of HPA has grown from 0.17 million in 1961 to 0.62 million in 2011 . Similarly, the level of urbanization in HPA has increased from less than 2 percent to around 36 percent in the last 50 years, and it is further projected to increase to more than 50 percent by 2016 . Being one of the fast growing industrial complexes, Haldia has experienced above 5 percent annual growth of population and 6 percent annual growth of workers of West Bengal during 1991 to 2001 - the era of liberalization, privatization and globalization. Thus, development of the Haldia urban complex has been accelerated. 

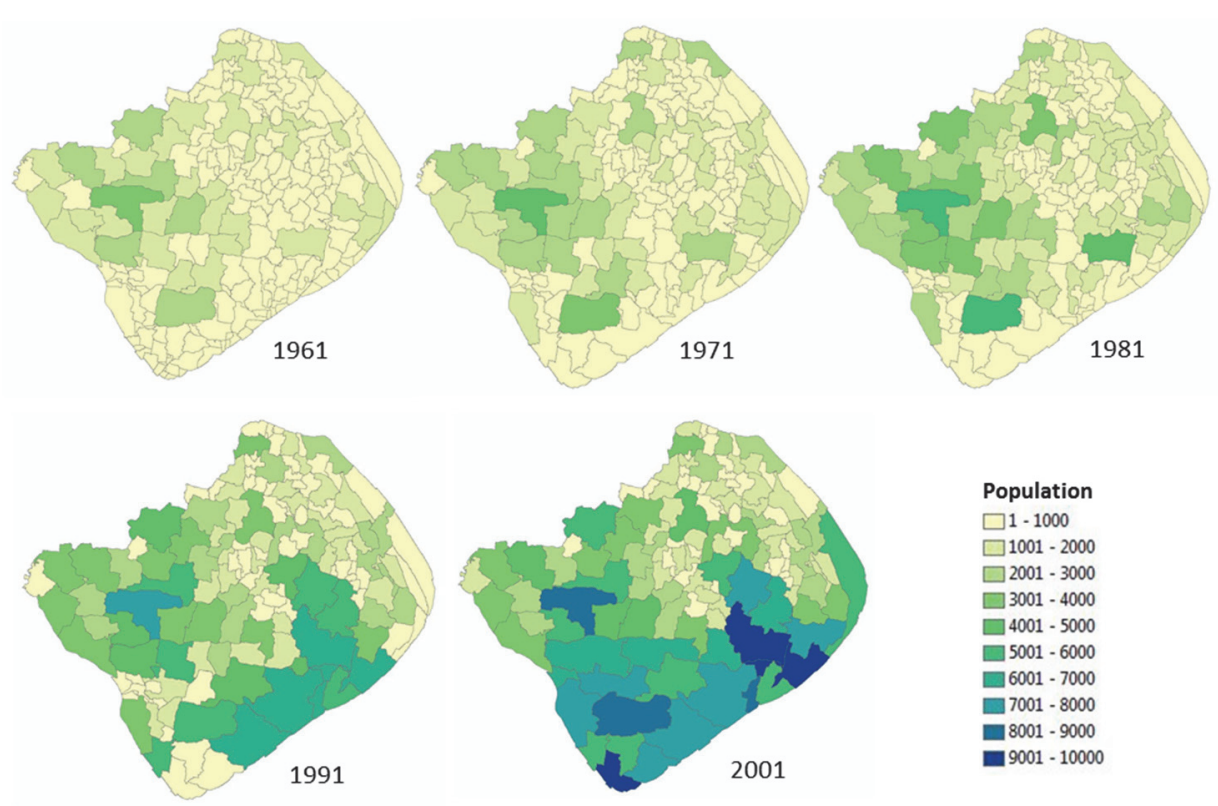

$$
\begin{aligned}
& \text { Population } \\
& \square 1-1000 \\
& \square 1001-2000 \\
& \square 2001-3000 \\
& \square 3001-4000 \\
& \square 4001-5000 \\
& \square 5001-6000 \\
& \square 6001-7000 \\
& \square 7001-8000 \\
& \square 8001-9000 \\
& \square 9001-10000
\end{aligned}
$$

Figure 5-6: Decadal growth of population per Census tract (1961-2001) ${ }^{54}$

54 Census data for 2011 is yet not published officially. 


\section{Chapter 6 - Data identification and database preparation}

The lack of appropriate hazard and risk information amongst relevant stakeholders can be a key factor causing higher than expected damages from an industrial catastrophe, as demonstrated in many historical cases like Bhopal, Mexico City, Toulouse and Enschede (Ayres et al., 1987; de Freitas et al., 2001; Jasanoff, 1988; Porto et al., 1996). These incidences have shown that limited information has resulted in: lack of awareness on potential hazards amongst communities vulnerable to industrial risk; inadequate emergency preparedness plans amongst administrators; inappropriate land use plans in the vicinity of highly hazardous industries, thereby resulting in significantly higher damages to life and property in case of a disaster.

The development of area level risk scenarios requires considerable amount of information to be consolidated from several sources: location of the hazard source, nature of chemicals stored, physical construction details of storage containers, conditions of storage (pressure, temperature),potential ignition sources, likelihood of an accidental event and nature and typology of the accidental event and its potential consequences. In addition, also required is environmental information including data on meteorological parameters like average wind speed and wind directions, stability class; data on vulnerability including population density and existing community level safeguards like barriers; data on land use in the surrounding area, preferably cadastral level.

However, in most cases, so also for Haldia, such datasets are not readily available. Consequently to get the information on industrial risk in Haldia, the real world objects representing hazards and vulnerabilities were converted into data and thereafter systematically stored in the GIS database. Such databases include a combination of locational data of the real world objects and their attributes. Different databases related to hazardous industry, cadastre-level land use, building, population etc., prepared for the purpose are described in the following sections with reference to the case study area, Haldia.

\subsection{Hazardous industry and storage-related database}

A significant component of industrial accident risk analysis comprises the data on accident scenario originating either from the fixed installations or from the non-fixed installations, such as pipelines, mobile sources like trucks, railways etc. used for transporting the hazardous chemicals. Therefore, identification and characterisation of the hazardous source using a planned exercise in collaboration with the industries, is considered to be the first step 
in the risk assessment process. Figure 6-1 shows different aspects of data that would need to be accounted for the hazard identification process.

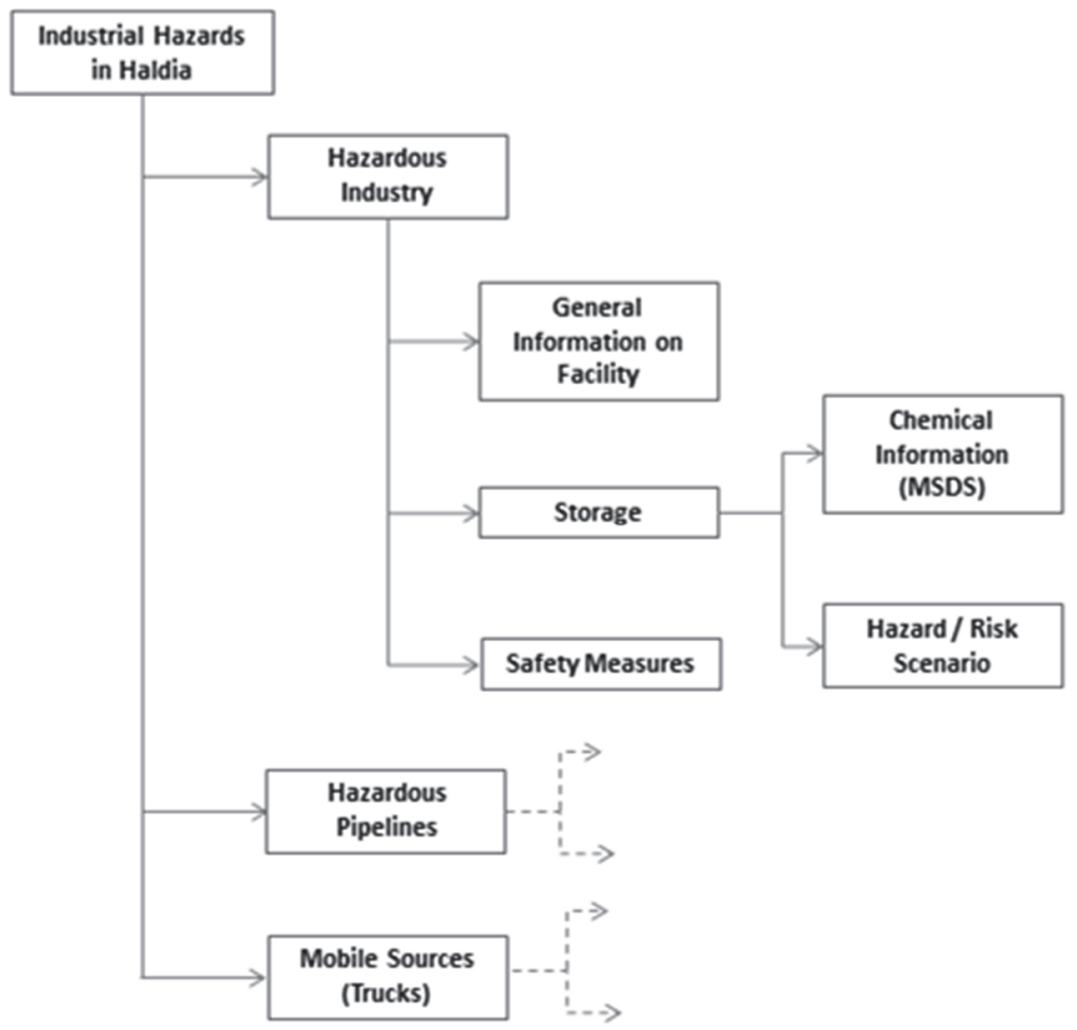

Figure 6-1: Identifying and characterising hazards in Haldia

The information about the facility pertains to understanding geographical extent of the facility, the main process the industry is running, number of employees, the layout, knowing information about the key contacts who need to be in the network of risk related planning, etc. The storage of hazardous chemicals needs to be geo-located accurately so that the origin of a particular hazard can be traced. In addition, the physical characteristics and the conditions storages and the inherent safety considerations that are designed to prevent an accident from happening needs to be documented as they have a crucial bearing on the nature of hazard event that can be triggered from storage. Also important is the properties of the hazardous chemical involved as it physical and chemical properties with significantly influence the degree of damage an accidental release or an event like a fire or explosion involving it may cause. Such information is normally available for all hazardous chemicals in a Material Safety Data Sheet (MSDS). 
In addition, the physical characteristics (type of tank, material of construction, thickness, etc.) the condition of storages (under normal temperature and pressure, pressurized, cryogenic, etc.) and the inherent safety considerations that are designed to prevent an accident from happening (leak alarm systems, water curtains, secondary storage, etc.) needs to be documented as they have a crucial bearing on the nature of hazard event that can be triggered from a storage.

In India, an effort to consolidate such industry-level information was first made through the ERRIS project which was implemented in the industrial towns of Haldia and Durgapur in the State of West Bengal in 2006. The project was recognised as a key technical initiative by the National Guidelines for Chemical Disaster Management (Bandyopadhyay et al., 2013; NDMA, 2007). The system has subsequently been upgraded to a more versatile platform called the 'Risk Management Information System (RMIS)' which is capable of storing spatial and related attribute data of industries, including their hazardous chemical storage facilities, the nature of the chemicals stored or handled, the nature of the process details, site maps (Bandyopadhyay et al., 2011; Sengupta et al., 2011). Important to mention in this research mobile or non-fixed sources were not taken into account.

Table 6-1: Data requirement to industrial risk assessment

\begin{tabular}{|l|l|l|}
\hline Data requirement & Importance & \multicolumn{1}{c|}{ Source } \\
\hline Location & $\begin{array}{l}\text { To identify the origin of } \\
\text { the accident scenario } \\
\text { To model the scenario } \\
\text { footprint hence to } \\
\text { understand the degree } \\
\text { of damage }\end{array}$ & $\begin{array}{l}\text { Facility-level } \\
\text { questionnaire } \\
\text { survey } \\
\text { conducted } \\
\text { (ERRIS } \\
\text { project) }\end{array}$ \\
\hline $\begin{array}{l}\text { Details of storage containers } \\
\text { parameters }\end{array} \quad \begin{array}{l}\text { Wind speed } \\
\text { Wind directions } \\
\text { Stability class }\end{array}$ & $\begin{array}{l}\text { To predict the } \\
\text { consequence of an } \\
\text { scenario }\end{array}$ & \\
\hline
\end{tabular}




\subsection{Cadastral-level land use database (map) ${ }^{55}$}

Long term risk reduction strategies provide considerable focus on controlling or influencing uses of land around sources of natural or industrial hazards as a risk prevention and mitigation measure (ISDR, 2004). Hence, cadastre information in the form of parcel-level land use map of an industrial area under consideration is another important requisite in order to understand how certain land uses and the property they characterise may be impacted by industrial accidents. Accordingly, the planners and the decision makers can adopt policies and plans involving zoning and rehabilitation in order to control or reduce risks associated with a particular land use, e.g., a cluster of hazardous industries, thereby to attain sustainable development of the area.

Internationally there has been a lot of movement to create the multi-purpose land cadastre systems that are centred on a Digital Cadastral Database (DCDB) in the last couple of decades. These DCDBs provide land parcel-level information in a referenced spatial framework to multiple user groups. Several well established data models are used for structuring data in such cadastral information systems so that serve several land administration related functions, including spatial planning. However, India has remained away from such developments and is yet to reach a position of competence. The existing land administration system of the country is a British legacy considering the village as an administrative unit. Since independence, a few exceptions apart, no significant efforts have been made to revise or update these colonial cadastral maps and registers. As a result, the colonial cadastral maps and land records available today are mostly outdated and do not always reflect the realities on the ground either in relation to ownership or plot boundaries. Nevertheless, updating of the maps on paper and related registers is anticipated to be very cumbersome for several reasons. First, in the conventional setup that prevails in India, cadastral maps and land records are maintained separately in different organizations. In this case, updating of plot boundaries changed by mutation and modification of other title information, takes a long time. Second, the cadastral maps used to prepare

${ }^{55}$ This section is abstracted from the following published publications, as a part of this thesis:

i. Sengupta, et al. (2015). Constructing a seamless digital cadastral database using colonial cadastral maps and VHR imagery - An Indian perspective. Survey Review. DOI: $10.1179 / 1752270615 Y .0000000003$.

ii. Sengupta, et al. (2013). Potential use of LADM in cadastral data management in India; Proceedings of the 5th Land Administration Domain Model (LADM) workshop, 24-25 ${ }^{\text {th }}$ September 2013, Kuala Lumpur, Malaysia; pp. 311-328. ISBN: 978-8792853-06-6.

iii. Sengupta, et al. (2012). Constructing a cadastral database using colonial cadastral maps and satellite imagery: An Indian perspective; International Federation of Surveyors (FIG), International Office of Cadastre and Land Records (OICRF). ISBN: 978-87-92853-00-4. 
are on low quality paper or cloth, are subject to various kinds of degrading factors. Hence in most cases, maps are in poor physical condition and torn due to lack of timely substitution. Finally, the maintenance of an infrastructure to continue with this earlier practice also involves an extremely high cost. All these factors together reinforce the case for a digital (seamless) cadastral database with up to date information for India.

In this regard, very recently, the Dept. of Land Records (DoLR) under the Ministry of Rural Development, Govt. of India, has taken an initiative for the digitization and updating of existing paper-based maps through the 'National Land Records Modernization Programme(NLRMP)'.Major components of this programme comprise computerisation of all land records including mutations, digitisation of maps, integration of textual and spatial data, survey/resurvey and updating the records, generation of original cadastral records wherever necessary, computerisation of registration and its integration with the land records maintenance system. However, yet till date, application of this guideline has not been carried out for a large area as there is no country wide cadastral data model that had been formulated. In addition, certain discrepancies pertaining to the digitisation of scanned maps were also observed. Because of these shortcomings, a methodology to construct a seamless DCDB for an extended area using $\mathrm{VHR}^{56}$ satellite imagery, first of its kind in India, was formulated by adapting the NLRMP technical manual in accordance to the geodetic framework of India (Sengupta, 2015 \#985). Thereby, the dataset could easily be integrated with the other spatial datasets that can allow spatial planning and other land use control functions. Important to mention, the methodology has been conceptualized as a part of the broad research framework as illustrated in Figure 6-2, where the usability of these colonial cadastral maps as an acceptable basis for spatial planning is investigated (Sengupta et al., 2012, 2013a). In particular, the proposed methodology focuses only on the 'spatial' aspects of the conversion of colonial cadastral maps to create a seamless DCDB based on the satellite imagery. The methodology is summarized in the Figure 6-3.

\footnotetext{
${ }^{56}$ Very High Resolution
} 


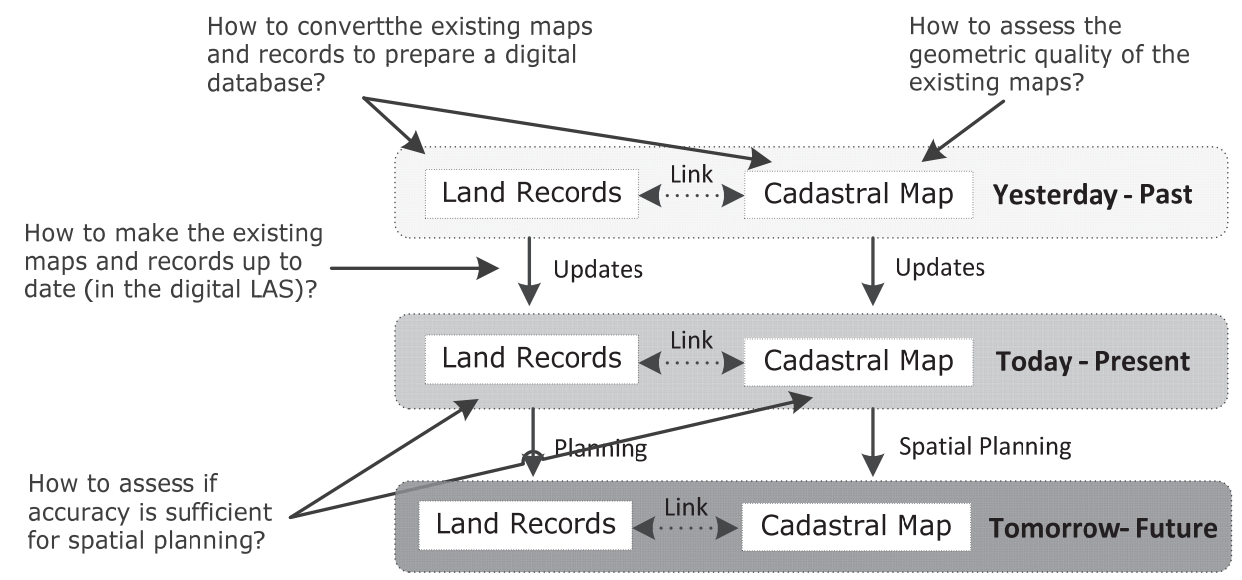

Figure 6-2: Research framework for quality upgrading of land administration for spatial planning (Sengupta et al., 2012, 2013a)

Following the proposed methodology, a seamless cadastre-level land use map was prepared for the old Planning area. For the purpose, a Geo-Eye1 (pansharpened) image with 0.45 meters pixel size, 310 colonial paper-based cadastral maps or sheets (also known as mouza maps) covering the area were used with limited on-site survey observation carried out in early 2012. Important to mention here many of these maps were prepared in mid-50, and later been updated in different time periods. A detailed history of the cadastral maps of the area is presented in Table 6-2. Each of such maps at a scale of 1:3960 graphically depicts the individual plot (locally known as 'dag') with respective plot number. An example of a cadastral map available for the area is shown in Figure 6-4. 


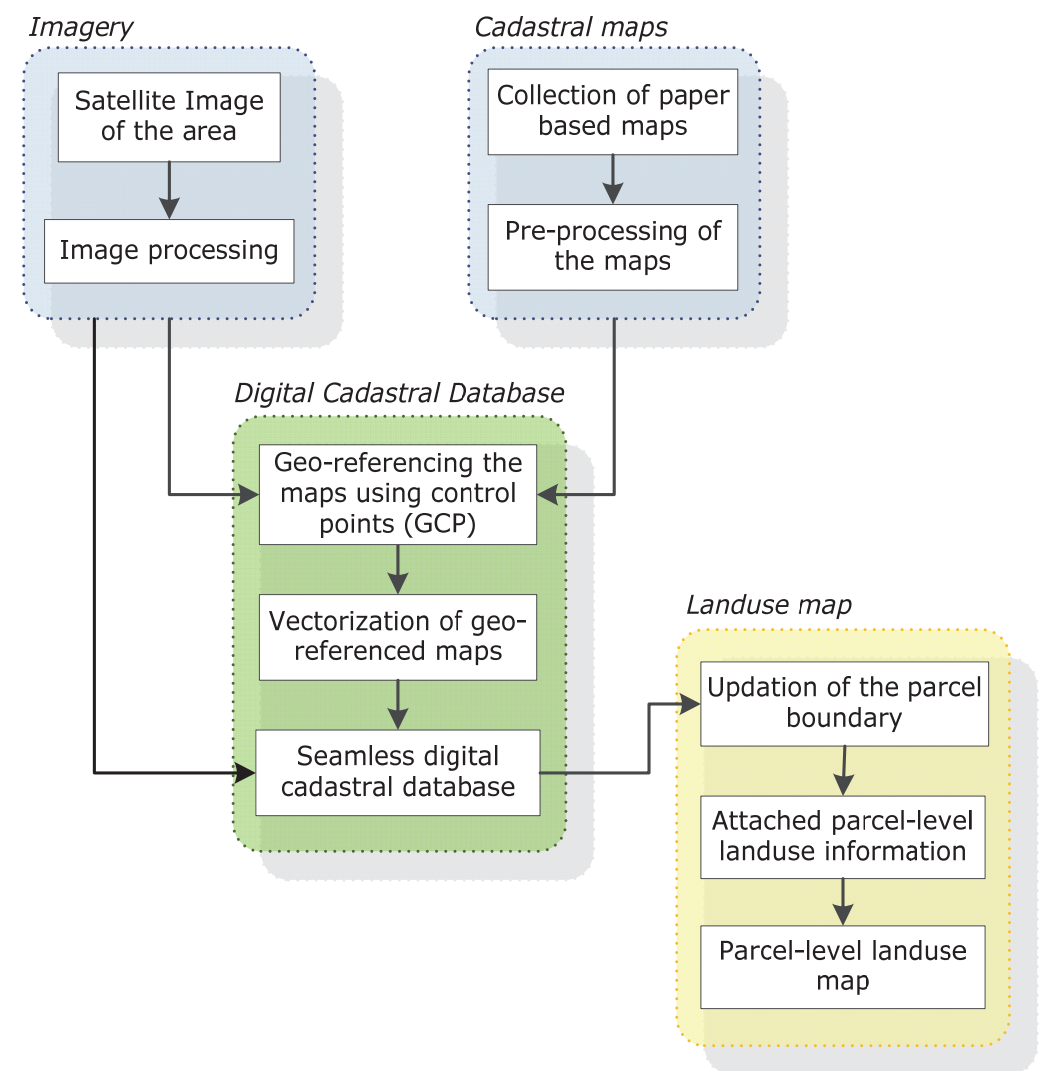

Figure 6-3: Proposed methodology for constructing a DCDB and thereafter a parcellevel land use map using colonial maps and satellite imagery

After scanning the paper-based cadastral maps as collected from the local District Land \& Land Reforms (DLRS) office, under Govt. of West Bengal; individual sheets were first geo-rectified with respect to the VHR satellite imagery of the area. For each map, 10 to 15 identical points both on imagery and scanned cadastral maps were used as 'Ground Control Points (GCPs)' to define the coordinate location. In addition, few GCPs were also taken along the map boundary by matching the edge of the individual mouza, thus to set the adjacent mouza accurately. Subsequently, these geo-rectified scanned cadastral maps were vectorised or digitized on-screen in a GIS platform. In doing so, first the boundary of each mouza map was digitized in a polygon layer with respect to its neighbouring map. In this regard, important to mention certain cartographic adjustments were made to solve the traditional problem of non-fitting cadastral map boundaries. As mentioned earlier, the paper-based cadastral maps available for the area are mostly of pre-1920s surveyed and 1950s mapped. 


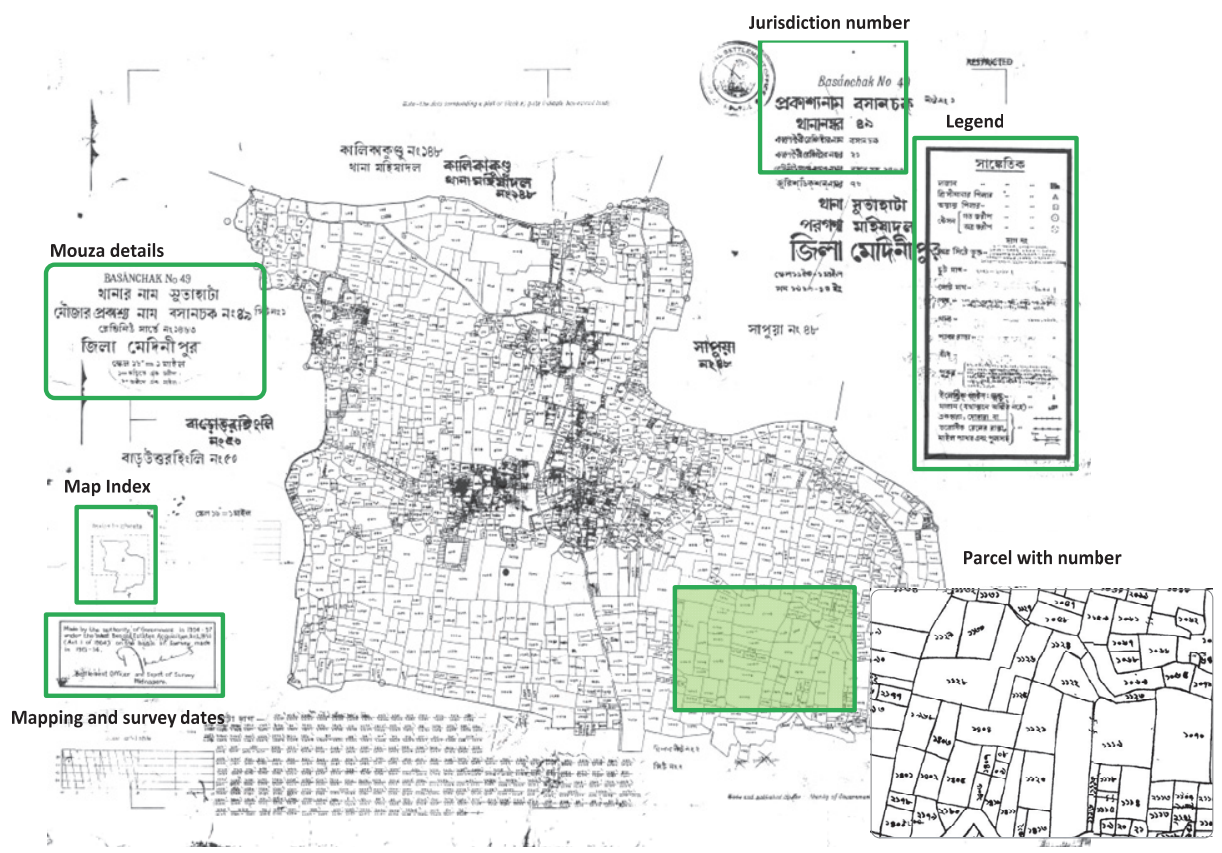

Figure 6-4: An example of a cadastral map available for old Planning area (Sengupta, 2015)

Table 6-2: History of cadastral maps of old Planning Area

\begin{tabular}{lccc|c|ccc}
\hline & \multicolumn{3}{c}{ Surveyed } & Mapped & \multicolumn{3}{c}{ Revised } \\
\cline { 2 - 8 } No. of & $1913-$ & $1915-$ & $1933-$ & $1954-57$ & $1979-$ & $1980-$ & $1996-$ \\
sheets & 14 & 16 & 34 & & 91 & 95 & 2000 \\
\cline { 2 - 8 } & 70 & 18 & 158 & 258 & 2 & 4 & 2 \\
\hline
\end{tabular}

Customarily, these maps were used to prepare manually as island maps following a systematic mapping system. However, in many cases, it has been observed that the boundaries of adjacent mouzas don't fit with each other precisely; either they are overlapping each other or leave a gap in between. Besides, depending on the size and shape, one single mouza is sometimes sub-divided in a number of separate sheets. And in such cases, the divisions among these individual sheets are often not clear. Nevertheless, such errors in geometry of the analog maps lead to a subsequent lack of accuracy while using as base map for preparing a seamless digital cadastral map; hence it was required to resolve these errors. For example, gaps and overlaps between the original paper maps were eliminated by matching the edge of the 2 , in exceptional cases 3 or 4 , neighbouring maps. Also special care was taken for small parcels along the boundary while doing the edge matching. On the other hand, in case of a common canal, the boundary was digitized by following the mid-way of the canal. Finally, individual parcels within each 
mouza map were digitized accordingly as separate polygon layer, taking the adjusted boundary layer as base. Then, all the individual parcel layers were merged to make a seamless parcel layer covering the entire area. And, topology was built for the layer to check any gaps in between the parcels or overlaying on each other. With the advent of GIS techniques, this map was then overlaid on the VHR satellite imagery to update the details of the parcel. Figure 6-4 showing different steps involved in preparation of seamless cadastral-level land use map for the old Planning area.
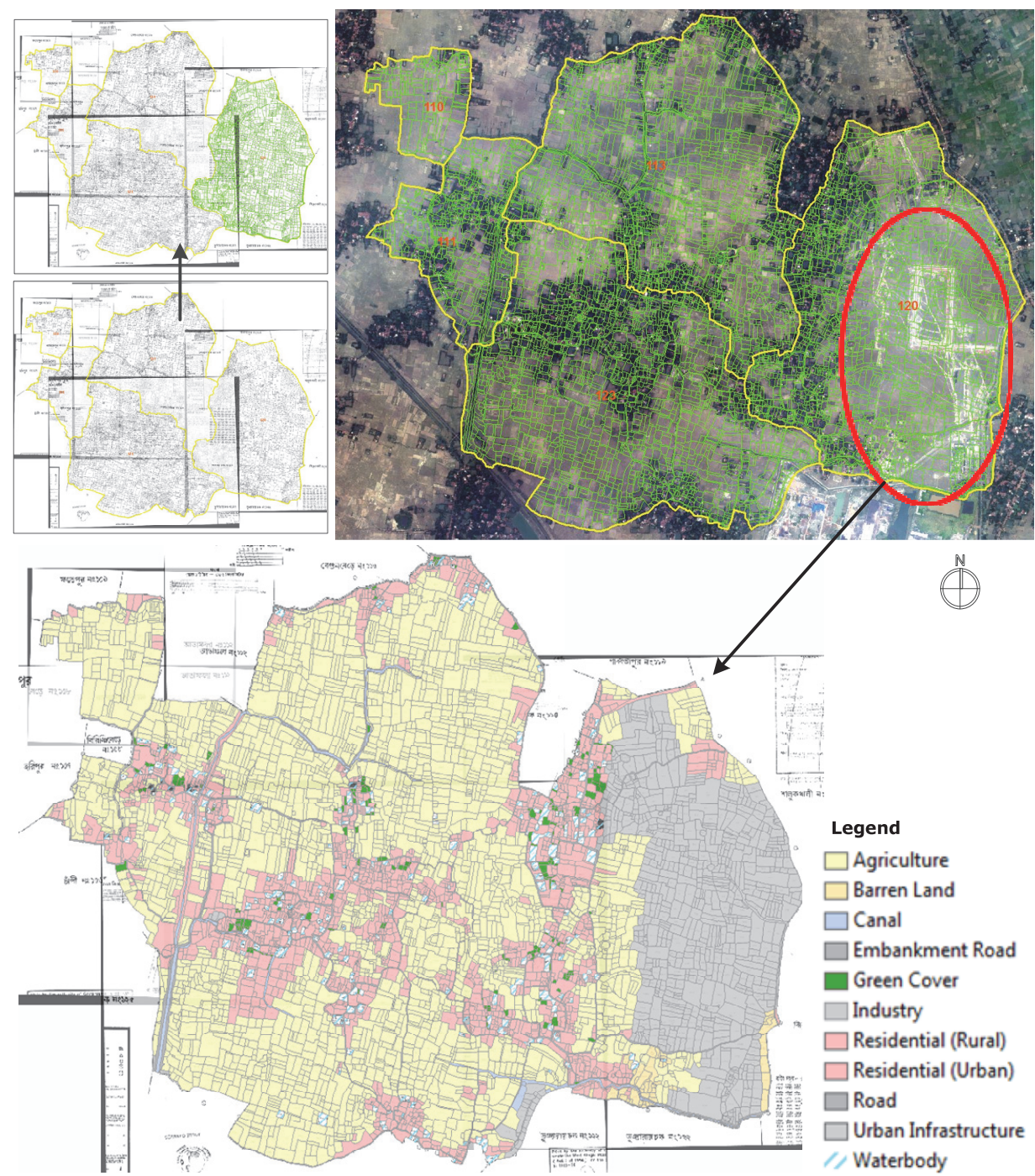

Figure 6-5: Digitization of individual parcel from the geo-rectified cadastral map (above-left); overlaying digitized seamless parcel layer on the VHR satellite imagery to update the parcel boundary and parcel-level land use (above-right); an example of the parcel-level land use map (below) 
From Figure 6-5, it can be noted that area under red circle, has undergone major changes as new industry is coming up, hence resulting in significant changes in the plot boundaries (locally known as 'aal') as well as land use pattern.

\subsection{Building database}

Buildings in hazard prone areas that house population represent an important element-at-risk. And the behaviour of buildings when impacted by an accident event will determine the safety of its inhabitants; hence it is important to be able to capture data on buildings that will help in assessing the adverse impacts on a building caused by an event (Blong, 2003). This aspect is important especially for a country like India, where urban areas have wide variability in building types and construction methods from informal hutments to high rise buildings made of concrete. Therefore, data on buildings would crucial to estimate vulnerability of the general population. Consequently, a proper understanding of vulnerability of the built environment on an individual basis can provide the base for preparedness and mitigation strategies, such as retrofitting of vulnerable buildings which in turn can reduce the loss of life and economic costs.

In case of an industrial accident involving release of toxic gas, fire or explosion, regardless of the distance from the hazardous industry, not every building within the same exposure zone is equally vulnerable as it depends on its structural characteristics, including type of construction, roof material, height, air-infiltration capacity, etc. However unlike natural hazard, the contribution of a particular characteristic towards the overall vulnerability of a building, also changes depending on the nature or type of the accident. For instance, the type of roof material is of more important characteristics as far as fire or explosion events are concerned, because if a building with thatched roof catches fire then it can easily be spread to the neighbouring buildings with the same type of roof material. Whereas in case of release of toxic gases, it would be the infiltration capacity of the building characterized by the number of openings such as windows or doors, which in turn determine the vulnerability of the inhabitants. Thus it can be understood that depending on its structural condition, a particular building either may completely or partially damaged or experience some distortion in response to an accident scenario.

In addition to the building characteristics, the surroundings of a building play an important role by offering protection from different physical effects of an accident. For example, spacing between individual buildings is an important factor for preventing it from pounding damage in case of a fire. In such cases, buildings characterized by kuchha construction and thatched roof, 
closely spaced with other buildings with more or less same characteristics, then it could be spread to the neighbouring buildings more easily and rapidly. However, their location in close vicinity of water body may reduce their vulnerability as well. On the other hand, in case of an explosion, height of the neighbouring buildings should not be ignored, where a smaller building might get protected from the blast of an explosion, if a taller building is standing in between the smaller building and the explosion site, so-called shadow-effect. Hence it can be seen that the surrounding of a particular building has a significant positive or negative effect on the vulnerability of that building and therefore have to be considered in another way.

However, in most cases and also for Haldia, such detailed information for was not readily available. Instead, a building-level survey was conducted in heterogeneous residential areas of the Durgachak area (Refer Figure 5-3) for collecting such building data. The survey was carried out into two phases. In the reconnaissance phase, the problems in and around the study area were analysed and accordingly the strategy for the detailed-level survey was perceived. This included specifying the information to be collected and approach to be followed for quantification purpose. Identification of individual buildings on field within the study area also carried out in this phase. It is important to mention that as such no systematic address scheme exists in this area. Even within a single plot two or more buildings were often observed, thus created the difficulty to identify individual building separately. To overcome with this problem, before the data collection phase, individual buildings were first identified on large printouts of the VHR satellite imagery and cross checked with the plot boundary map (Figure 6-6). Accordingly a unique identifier comprises of respective ward, block and plot number, assigned to each building for identification purpose. The second phase of the survey was dealt with cross-checking of the building footprint map as prepared, followed by data collection for individual building about construction characteristics, occupancy type along with their indoor population details at different time period using a structured questionnaire designed for the purpose.

For data collection purpose, a sampling strategy based on the occupancy type of the buildings was adopted. The choice of this classification was made given the fact occupancy type of buildings provide a real time scenario that allows to estimate the number of people per building in different time periods in accordance to its functional use. Here, importance was mainly given to the residential buildings as well as the buildings with commercial shops in their ground floor while other floors are used mainly for residential purpose. During the reconnaissance survey, 1300 such buildings were accordingly identified. A group of 3 people spend around 45 man-days for collecting the data of these buildings using the questionnaire. During the survey, data of 
each individual building was entered in an excel sheet. Later, the excel sheet was attached as attribute table of building footprint map to create a building inventory of 1300 buildings to quantify the consequence of an accident scenario- an integral part of risk assessment framework.
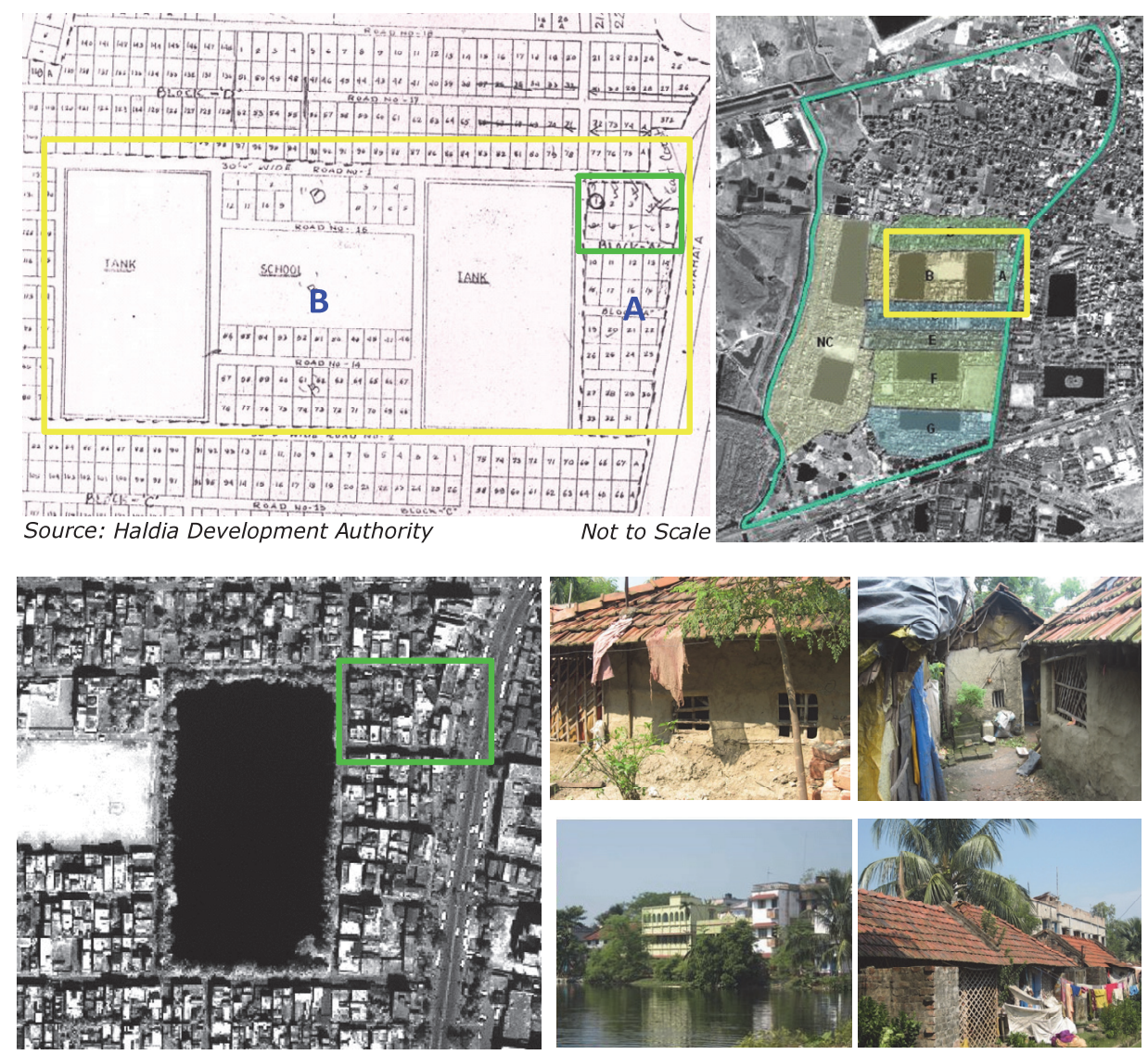

Figure 6-6: Plot boundary map of residential blocks (Above); identification of individual buildings on VHR imagery (Below-left) and photos of some typical buildings as observed in the field (Below-right)

\subsection{Population database}

An estimate of population size and its spatial distribution is another crucial aspect need to be considered for risk-informed planning decisions. For instance, in an emergency planning scenario, availability of population data assists in estimating the number of people vulnerable to an accident, whereas, for longer term planning, population data is fundamental concept to calculate levels of societal risk in an area of concern. Therefore, a better understanding of the spatial pattern of population distribution will lead to more effective risk management policies. A number of criteria need to be 
considered for formulation of a population datasets that could be integrated and manipulated to provide the necessary information to decision makers. It is important that population data sets should have wide geographical coverage and be of sufficiently fine resolution to be able to provide an estimation of risk or vulnerability. It should be able to account for diurnal changes in population as also mobility aspects in the target population-people going to work, markets, etc. and societal risk calculations need to factor this range of possible locations and vulnerability.

Table 6-3: Summary of building database generated for two blocks

\begin{tabular}{|c|c|c|c|}
\hline Category & & Block C & Block E \\
\hline \multirow{4}{*}{ Roof material } & Thatched ( $\left.\mathrm{R}_{\mathrm{f} 1}\right)$ & 0 & 0 \\
\hline & Tiles ( $\left.\operatorname{Rf}_{2}\right)$ & 51 & 39 \\
\hline & Asbestos ( $\left.\mathrm{R}_{\mathrm{f} 3}\right)$ & 6 & 7 \\
\hline & Concrete $\left(\mathrm{Rf}_{\mathrm{f} 4}\right)$ & 131 & 62 \\
\hline \multirow{4}{*}{ Construction type } & $\begin{array}{l}\text { Kuchha/Mud } \\
\left(C_{t 1}\right)\end{array}$ & 12 & 5 \\
\hline & Thatched $\left(\mathrm{C}_{\mathrm{t} 2}\right)$ & 0 & 0 \\
\hline & Brick ( $\left.C_{t 3}\right)$ & 45 & 41 \\
\hline & Concrete $\left(\mathrm{C}_{\mathrm{t} 4}\right)$ & 131 & 62 \\
\hline \multirow{4}{*}{ Number of floors } & Four $\left(F_{n 1}\right)$ & 5 & 0 \\
\hline & Three $\left(F_{n 2}\right)$ & 41 & 12 \\
\hline & Two & 67 & 42 \\
\hline & One $\left(F_{n 3}\right)$ & 75 & 54 \\
\hline \multirow{3}{*}{ Infiltration capacity $\left(\mathrm{I}_{\mathrm{c}}\right)$} & High $\left(I_{c 1}\right)$ & 44 & 34 \\
\hline & Medium ( $\left.\mathrm{I}_{\mathrm{c} 2}\right)$ & 102 & 54 \\
\hline & Low $\left(\mathrm{I}_{\mathrm{c} 3}\right)$ & $x x$ & $x x$ \\
\hline
\end{tabular}

Several methods have been formulated for disaggregation of population data to higher resolution than Census tract units (Su et al., 2010). They utilise techniques like areal interpolation, Geographical Weighted Regression (GWR) and geo-statistical modelling (Flowerdew et al., 1992; Fotheringham et al., 1998). A reasonably successful and used method of dasymetric interpolation can be devised by combining the areal weighting method with an additional step of filtering the data using ancillary data like land cover obtained from VHR imagery and other data like road buffer zones. Using such methods, several such databases with worldwide coverage make the data available through publicly available databases or as map services. The Gridded Population of the World, version $3\left(\mathrm{GPW}_{3}\right)$ provides spatially disaggregated population on a world-wide geo-referenced framework as a map service and as vector files that is compatible with data sets from social, economic and earth science fields. The gridded data set which provides data on grid of 
about $5 \mathrm{~km}$ is constructed from national or sub-national input units by assorting geopolitical spatial units worldwide (SEDAC, 2005). The LANDSCAN dataset has been compiled on a grid system with a resolution of 30 " and has census data redistributed accounting for a likelihood coefficient determined based on factors such as land cover, proximity to roads, slope, night time lights etc. and is valuable for the purpose of emergency response (Bhaduri et al., 2007b).

In India, Census is the major source for population distribution information. Data is usually available as aggregated in Census tract (which is known as enumeration block) which can be classified either as village units (i.e. mouza) or urban units (i.e. wards) with respective Permanent Location Code Number (PLCN). Such datasets are published in every 10 years, comprising of total no. of population, male and female population, sex, age etc. However, the Census database do not provide information about the spatial distribution of population within a particular census tract; hence, cannot be used for some planning or management issues at either at regional or local level that may require very detailed population distribution to yield meaningful results. For instance, in case of local level risk and accident modelling, it might need to estimate the number of people in a smaller area within a certain tract, or an area that includes only part of that tract and part of other tract. Moreover, currently no other dataset is also available for the study area which can provide such information. Accordingly, a database was prepared by areal interpolation of the Census data based on cadastral-level land use map as prepared (See Section 6.3) following the methodology as depicted in Figure 6-6.

In order to do so, the residential plots were first extracted from the cadastral-level land use map of the area as a separate polygon layer in a GIS environment. Subsequently, the 'residential plot layer' was intersected with the 'census tract unit layer' (using the centroid function) to assign the identification code to each plot. Consequently, the aggregated population of that particular Census tract as per the official record was re-distributed into those residential plots which are falling within its boundary, using an areametric method to reveal the spatial population distribution across the tract (Figure 6-7). In particular, following expression was used to estimate the no. of people at each residential plot:

$H P i=\left(\begin{array}{c}C P \\ \sum_{k=1}^{n} H A k\end{array}\right) \cdot H A i$

$\mathrm{HPi} \quad$ Population of the census tract $i$

$C P \quad$ Census tract population

HA Total residential plot area in the census tract 
$H A i \quad$ Residential plot area of $i$

$k \quad$ Summation index

$n \quad$ No. of residential plot falling within the same census tract

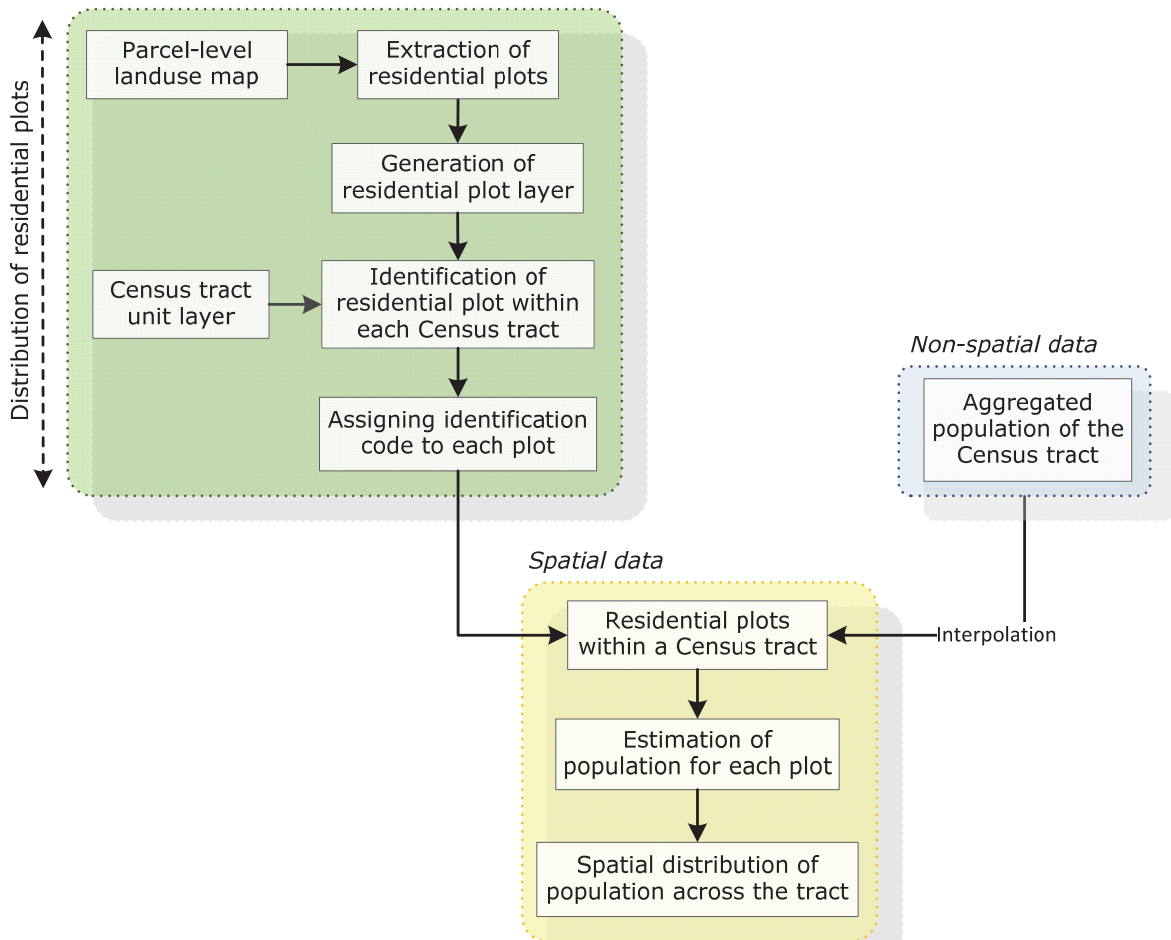

Figure 6-7: Methodology for mapping the population distribution spatially

Consequently, the no. of people per residential plot was interpolated at a vector mesh that represented the study area as a grid of equally sized square cells of $100 \times 100 \mathrm{~m}$ size. Figure 6-8 showing different steps involved in interpolating the census population into residential plot and thereafter at the grid level for the old Planning area. 


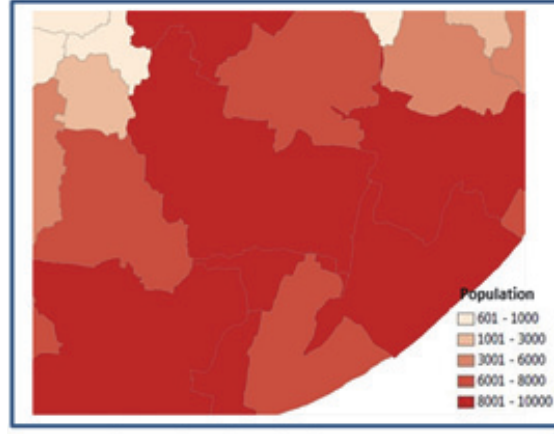

Census Tract Population

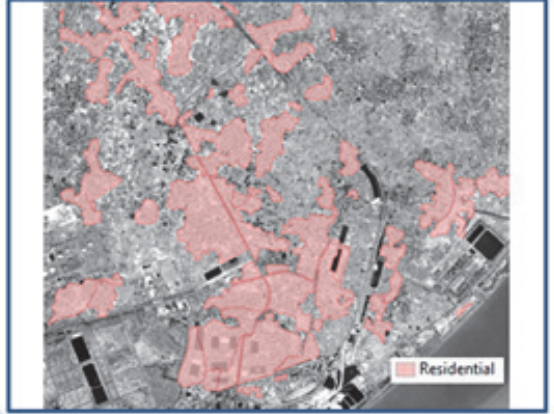

Habitated areas identified from satellite imagery

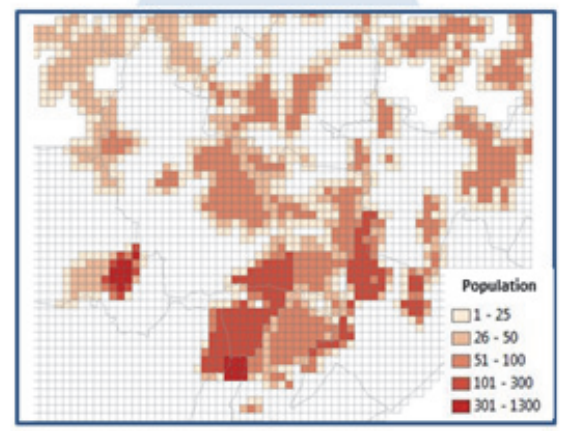

Interpolated population in $100 \times 100$ m grid

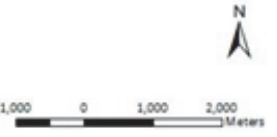

Figure 6-8: Interpolated population at $100 \times 100 \mathrm{~m}$ grid showing number of people per unit area

\subsection{Summary}

This chapter identified the information relevant for risk and vulnerability assessment of an industrial hazard. Among different datasets, the industrydatabase used in this research was developed basically as a part of the ERRIS Project. Regarding the cadastral-level land use, an innovative and cost-effective method to construct a seamless digital cadastral database using the colonial paper-based cadastral maps, was introduced. The digital cadastral database was prepared according to the mapping standard of the country, so that it can be used with other datasets and updated in short-time span. For building-level information, a detail survey was conducted. The questionnaire designed and approach for collecting the information of individual buildings also included in this chapter. Based on the collected information, the method of creating building inventory for consequence assessment is also discussed in this chapter. The use of these databases will be discussed in the following chapters. 
Table 6-4: Summary of different data layers as prepared

\begin{tabular}{lll}
\hline Theme & Spatial data & Description \\
\hline \multirow{2}{*}{ Industry } & $\begin{array}{l}\text { Location } \\
\text { Storage location }\end{array}$ & $\begin{array}{l}\text { Details of the hazardous storages and } \\
\text { stored chemicals }\end{array}$ \\
\cline { 2 - 3 } Land use & $\begin{array}{l}\text { Parcel-level land use } \\
\text { for planning area }\end{array}$ & $\begin{array}{l}\text { Land use classified into different } \\
\text { categories; viz. agriculture, barren } \\
\text { land, canal, embankment road, green } \\
\text { cover, industry, residential (rural \& } \\
\text { urban), river, riverbed, road, urban } \\
\text { infrastructure and water body }\end{array}$ \\
\cline { 2 - 3 } Building & Building footprint & $\begin{array}{l}\text { Building construction type, other } \\
\text { vulnerability related details, timed- } \\
\text { average population }\end{array}$ \\
\cline { 2 - 3 } Population & Population per grid & $\begin{array}{l}\text { Habitation with interpolated } \\
\text { population and population } \\
\text { density/hectare }\end{array}$ \\
\cline { 2 - 3 } & &
\end{tabular}




\section{Chapter 7 - Applicability of a simplified QRA- based approach for cumulative risk assessment}

This chapter examines the possibility of applying a QRA-based approach, as used in European countries, for risk assessment to guide land use planning decisions, in an Indian situation. For the purpose, a simplified QRA-based approach has been adapted for estimating cumulative measures of individual and societal risk level for an industrial cluster. Testing the applicability of the proposed methodology through the analysis of some reference plants located in the study area, the chapter also underlines the difficulties that an analyst has to face to determine confident risk maps as a basis for planning the uses of land, due to deficiencies in the Indian legislation and the lack of guidelines ${ }^{57}$.

\subsection{Introduction}

Evaluation and implementation of risk reduction measures for industrial risk varies considerably in different EU Member States depending on the citizen's perception of the prevailing safety situation, the regulatory approach towards risk assessment and the available methods and tools for handling the problem (Christou and Mattarelli, 2000; Pasman et al., 2014). A review of such country-level practices shows considerable diversity in terms of methods for identification of risk scenarios, probability of failures leading to accidents, consequence models used for risk calculation, and criteria for risk acceptability (Christou et al., 2011b; Pey et al., 2009).For example, in the Netherlands, use of QRA-based methods are preferred in order to determine risk and compare it to standard risk criteria which then guides land use planning decisions in the vicinity of hazardous installations (Ale, 2005b; Bottelberghs, 2000b; BRZO, 1999).

On the contrary, in India despite of also having high population density and limited land resources, like in the Netherlands, estimation of the cumulative risks originating from a cluster of hazardous industries has seldom being undertaken with the intent of implementing risk reduction and land use planning measures. This gap has been attributed to the lack of a standardised and consistent methodology for risk assessment, absence of consistent risk evaluation criteria and the lack of linkage of industry level risk assessment to the planning process (NDMA, 2007).

57 This chapter is based on the publication: Sengupta, A., Bandyopadhyay, D., Roy, S., van Westen, C.J. and van der Veen, A. (2016) Challenges for introducing risk assessment into land use planning decisions in an Indian context. In: Journal of Loss Prevention in the Process Industries, 42 (2016), pp. 14-26. 
From this perspective, the key objective of this chapter is to evaluate the feasibility of applying a simplified QRA-based methodology for estimating cumulative measures of individual and societal risk, and to investigate how LUP decision making process can be supported and informed by 'risk maps'. The investigation is carried out through the analysis of some reference plants located in the case study area, to generate cumulative risk maps of the area.

\subsection{Conceptualization}

In India, with an increasing number of hazardous industries operating within large industrial clusters juxtaposing densely populated areas, it is expected that the level of industrial risks would continue to increase. Risk actors are often confronted with conflicting interests when judging the suitability of future development proposals and implement measures to reduce industrial risk. In this setting, adoption of a scientific and standardised approach for estimation of cumulative risk, along with an understanding of risk contributions from individual hazardous industries can provide a strong foundation for evaluating future development proposals (e.g. industry, residential and commercial) and measures for risk reduction for an industrial town (Christou et al., 2000).

However, the aggregation of risk from several hazard sources is quite complex. For example, the industrial area of Haldia has more than a hundred hazard sources, and such an assessment can be a complicated issue. Hence, adoption of a scenario-based approach could assist regulators and planners to understand the present risk state and evaluate probable future states that may emerge as a result of implementation of alternative strategies for industrial and residential development (Mahmoud et al., 2009). Based on the identified scenario, a systematic QRA-based approach for risk assessment can calculate risks from each identified hazard source and aggregate them over the target area and finally display this through a risk map to guide risk reduction decisions (Ale, 2002a; Bottelberghs, 2000a). In view of that, a QRA-based approach has been adapted to an Indian condition to estimate the cumulative risk from a limited number of identified hazard sources and to assess the degree of effectiveness of such risk measures for guiding the land use planning decisions of the area due to lack of availability of criteria and guidelines.

The adoption of a standardised methodology for risk assessment is central to providing scientifically sound results for QRA-guided land use decision making that is robust and convincing to stakeholders.. The main principles of the methodology should include: consistency of outcomes, which will broadly be the same in similar conditions; proportionality of risk decisions with regard to risk reduction and planning restrictions; and transparency in the decision making process (Christou et al., 2006a; Christou et al., 2011b). As there is 
yet no standardised risk assessment procedure laid down through regulatory provisions, this investigation provides the opportunity to develop a methodology which can be used by risk actors for guiding planning decisions. The scenario-oriented QRA based framework for risk assessment that was utilised is outlined in Figure 7-1. The steps involved are discussed in the following sections with reference to the case study area, Haldia.

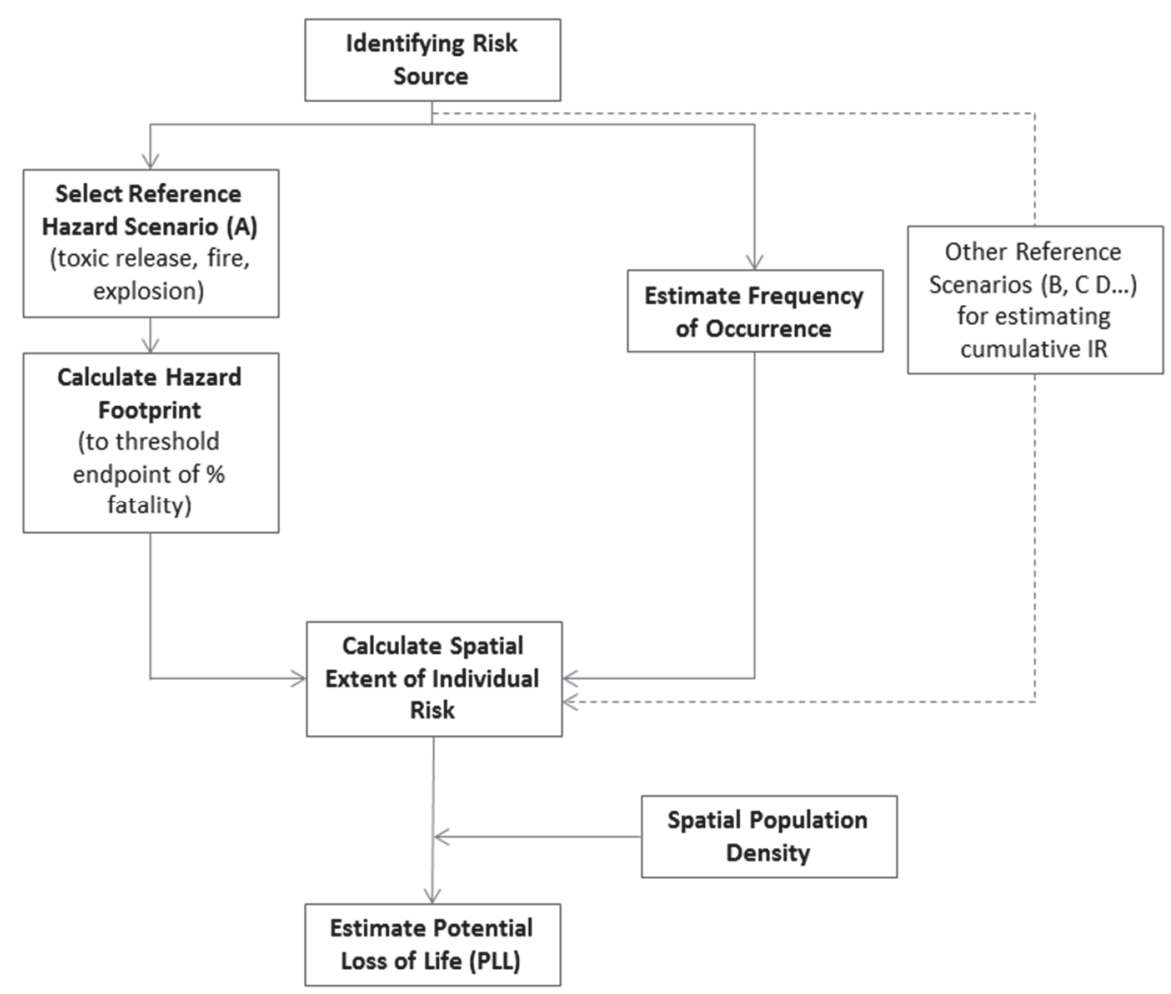

Figure 7-1: QRA framework for risk estimation

\subsubsection{Scenario selection}

In simple terms, an accident scenario is one of many specific situations that might evolve at the end of an accident sequence, e.g., the development of a toxic cloud in a given direction. Due to the large number of factors involved (hazardous substances, their properties, processes, presence of safety barriers, etc.) a large number of potential accident scenarios can occur.

To demonstrate the practical applicability of a QRA-based method, eight accident scenarios of Vapour Cloud Explosion (VCE), Boiling Liquid Expanding Vapour Explosion (BLEVE) and toxic release events, were considered for the analysis as 'reference scenarios'. The scenarios originating from different hazardous industries located in the study area (Figure 7-2), were selected 
with an inherent assumption of having the potential of causing Maximum Credible Loss (MCL) (Khan et al., 2002) as identified on the basis of facility level risk assessment (Table 7-1). For each scenario, possible release types were identified, for example pipe rupture, formation of holes in pressurized vessels, major or catastrophic failure etc. which can cause loss of life in the surroundings. To ensure that the method remains workable, a number of credible accident scenarios per industry, was selected which could lead to potential offsite consequences.

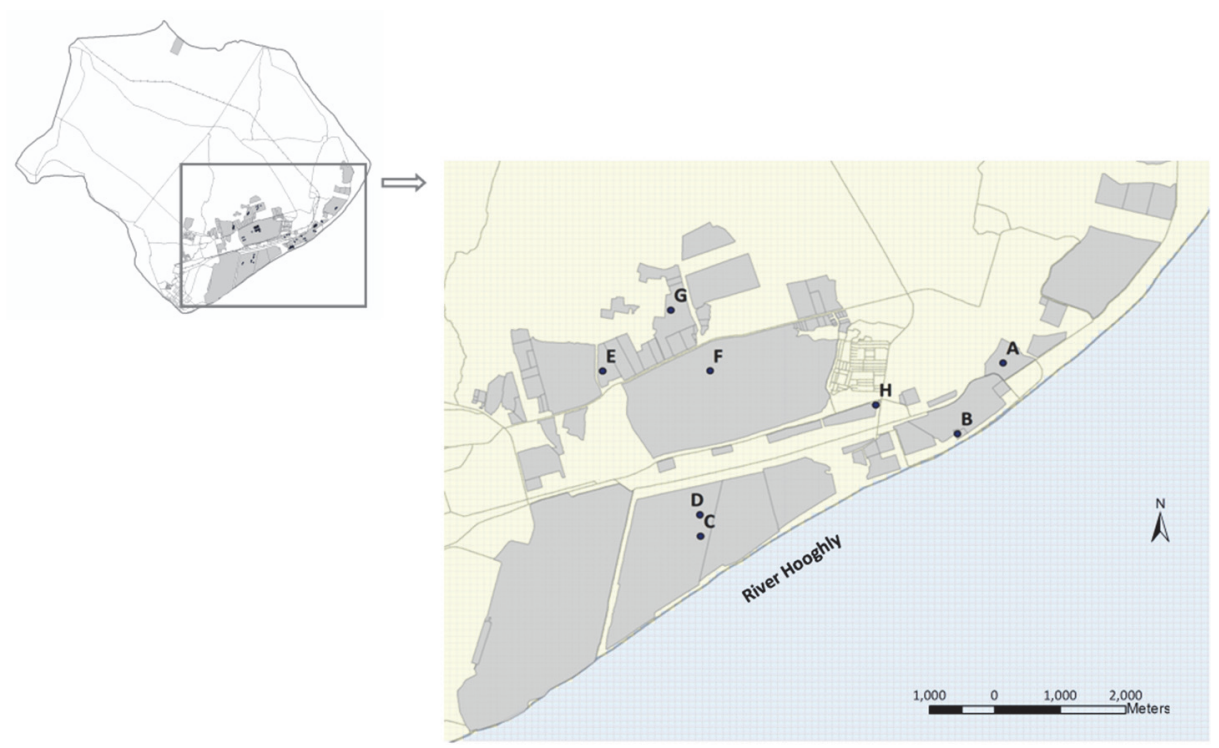

Figure7-2: Location of the storages used for reference scenarios

Table 7-1: List of selected scenarios

\begin{tabular}{|c|c|c|c|c|c|}
\hline $\begin{array}{l}\text { Scenario } \\
\text { ID }\end{array}$ & Installation & Containment & $\begin{array}{l}\text { Frequency } \\
\left(y^{-1}\right)\end{array}$ & $\begin{array}{l}\text { Total } \\
\text { Capacity }\end{array}$ & $\begin{array}{l}\text { Scenario } \\
\text { Description }\end{array}$ \\
\hline A & $\begin{array}{l}\text { Atmospheric } \\
\text { tank single } \\
\text { walled }\end{array}$ & $\begin{array}{l}\text { Motor Spirit or } \\
\text { Gasoline } \\
\text { (highly } \\
\text { flammable } \\
\text { liquid) }\end{array}$ & 5. $10^{-658}$ & $4200 \mathrm{MT}$ & $\begin{array}{l}\text { Catastrophic } \\
\text { failure leading to } \\
\text { a formation of } \\
\text { vapour cloud } \\
\text { which is ignited } \\
\text { resulting in VCE } \\
\text { involving } 1200 \\
\text { MT }\end{array}$ \\
\hline B & $\begin{array}{l}\text { Double } \\
\text { walled } \\
\text { dome roof }\end{array}$ & $\begin{array}{l}\text { Ammonia } \\
\text { (liquefied } \\
\text { toxic gas) }\end{array}$ & 4. $10^{-4} 59$ & $\begin{array}{l}10000 \\
\text { MT }\end{array}$ & $\begin{array}{l}\text { Release of toxic } \\
\text { vapour involving } \\
50 \text { MT of }\end{array}$ \\
\hline
\end{tabular}

58 Derived from historical data by Glossop (HSE internal report: RAS/01/06); pp. 9

59 Documented in a HSE internal report (RAS/00/10) by J. Gould; pp. 14 


\begin{tabular}{|c|c|c|c|c|c|}
\hline $\begin{array}{l}\text { Scenario } \\
\text { ID }\end{array}$ & Installation & Containment & $\begin{array}{l}\text { Frequency } \\
\left(y^{-1}\right)\end{array}$ & $\begin{array}{l}\text { Total } \\
\text { Capacity }\end{array}$ & $\begin{array}{l}\text { Scenario } \\
\text { Description }\end{array}$ \\
\hline & $\operatorname{tank}$ & & & & $\begin{array}{l}\text { Ammonia from } \\
20 \text { meters height }\end{array}$ \\
\hline C & $\begin{array}{l}\text { Atmospheric } \\
\text { tank single } \\
\text { walled }\end{array}$ & $\begin{array}{l}\text { Motor Spirit or } \\
\text { Gasoline } \\
\text { (highly } \\
\text { flammable } \\
\text { liquid) }\end{array}$ & $2.5 \cdot 10^{-31}$ & $\begin{array}{l}24150 \\
\text { MT }\end{array}$ & $\begin{array}{l}\text { Minor failure } \\
\text { leading to } \\
\text { formation of } \\
\text { vapour cloud } \\
\text { which is ignited } \\
\text { resulting in VCE } \\
\text { involving } 100 \mathrm{MT}\end{array}$ \\
\hline D & Tonner & $\begin{array}{l}\text { Chlorine } \\
\text { (liquefied } \\
\text { toxic gas) }\end{array}$ & 4. $10^{-6} 60$ & $1 \mathrm{MT}$ & $\begin{array}{l}\text { Cylinder } \\
\text { undergoes } \\
\text { catastrophic } \\
\text { rupture releasing } \\
1 \mathrm{MT} \text { Chlorine } \\
\text { into atmosphere }\end{array}$ \\
\hline$E$ & $\begin{array}{l}\text { Atmospheric } \\
\text { tank }\end{array}$ & $\begin{array}{l}\text { Motor Spirit or } \\
\text { Gasoline } \\
\text { (highly } \\
\text { flammable } \\
\text { liquid) }\end{array}$ & 1. $10^{-41}$ & & $\begin{array}{l}\text { Major failure } \\
\text { involving } 400 \text { MT } \\
\text { of Motor Sprit }\end{array}$ \\
\hline $\mathrm{F}$ & LPG bullet & $\begin{array}{l}\text { Propane } \\
\text { (liquefied } \\
\text { flammable } \\
\text { gas) }\end{array}$ & 5. $10^{-661}$ & $160 \mathrm{MT}$ & $\begin{array}{l}\text { A release of } 80 \\
\text { MT of Propane } \\
\text { as vapour cloud, } \\
\text { finds a source of } \\
\text { ignition and } \\
\text { explodes }\end{array}$ \\
\hline G & $\begin{array}{l}\text { Horton } \\
\text { Sphere }\end{array}$ & Butane & 9. $10^{-7} 62$ & 915 MT & $\begin{array}{l}\text { Tank engulfed } \\
\text { into fire and } \\
\text { resulting in } \\
\text { BLEVE or fireball }\end{array}$ \\
\hline $\mathrm{H}$ & LPG bullet & Butane (LPG) & 1. $10^{-54}$ & $30 \mathrm{MT}$ & $\begin{array}{l}\text { BLEVE involving } \\
25 \mathrm{MT} \text { of LPG }\end{array}$ \\
\hline
\end{tabular}

\subsubsection{Assigning frequency and probability}

Once the possible scenarios are selected, the next step in QRA requires the estimation of their frequencies. However a review of several industry-specific risk assessment reports of MAH units in Haldia showed a complete absence of any estimate of failures that could result in a major accident with potential offsite consequences. Even at a broader level, no such failure frequency

\footnotetext{
${ }^{60}$ Reported in the Major Hazard Assessment Unit Handbook; pp. 23

${ }^{61}$ Documented in a HSE internal report (RAS/06/04) by Keeley and Prinja; pp. 33

${ }^{62}$ Proposed by M. Selway, 1988; pp. 26
} 
statistics exist in India. As an alternative, the available generic failurefrequency databases like the so-called TNO's Purple Book, HSE's Failure Rate and Event Database (FRED) etc. (Casal, 2008) have been used. The assigned frequency of the above mentioned scenarios from the available HSE's Failure Rate and Event Database is presented in Table 6-1. However, generic failure frequency data is not proposed as an alternative to estimating industryspecific failure frequency through the use of system reliability techniques, in particular fault tree analysis.

Additionally, in contemporary QRA methodology, the potential incidents for which data are available from failure-frequency databases are further analysed for conditional probabilities of a range of possible accident sequences which include accident initiation, loss of containment and finally the outcome of the accident. However, in the present research, the probability of an accident sequence has been considered equal to the probability the initiating event i.e. no mitigation measures were considered as a conservative assumption due to the lack of information.

\subsubsection{Consequence assessment}

The physical effects of the selected reference scenarios were analysed using ALOHA ${ }^{63}$, one of the standard and widely accepted tools known to calculate conservative effect distances. The choice of ALOHA has been made taking into account the low level of complexity and manageable input requirements of the software. For calculating the effect distance of each scenario, data about the hazardous facilities, e.g. chemical substances, storage condition etc., as obtained from the industry database (See Section 6.1) and the most frequently occurring atmospheric condition of an average wind speed of 3.0 $\mathrm{m} / \mathrm{s}, 35^{\circ} \mathrm{C}$ temperature and stability class of $D$ as input parameters, were used.

Followed by the effect-distance calculation, the severity of the accident scenarios was estimated in terms of fatalities that might happen due to effects of thermal radiation, overpressure wave or concentration of toxic substances (Ale, 2002b; Fabbri et al., 2009). Accordingly, the damage potential in terms of physical effects was estimated based on threshold values as derived from Probit functions. Probit functions are commonly used to estimate the number or percentage of fatalities to population exposed to the physical effects of any accident, assuming that the relationship between the logarithmic value of the dose and mortality can be described with a cumulative normal distribution (Casal, 2008). The details of the Probit functions that have been used to calculate the endpoints as distances from

63 ALOHA (Areal Locations Of Hazardous Atmospheres): http://www.epa.gov/ceppo/cameo/index.htm 
the hazard source location are presented in the Table 7-2. The reference damage assumed was the death of a non-protected person. It must be noted that no specific studies have been undertaken till date to calculate Probit values for potential damages in an Indian perspective.

Table 7-2: Probit values for calculation of physical impacts

\begin{tabular}{|c|c|c|c|}
\hline \multicolumn{2}{|l|}{ Effects } & Probit Equation & Dose \\
\hline \multicolumn{2}{|c|}{ Thermal Radiation ${ }^{64}$} & $Y=-14.9+2.56 \ln (D)$ & $D=I^{1.33} t_{\mathrm{e}}$ \\
\hline \multicolumn{2}{|l|}{ Overpressure 65} & $Y=1.47+1.37 \ln (D)$ & $D=P_{\mathrm{s}}$ \\
\hline Tovir roleaco66 & Chlorine & $Y=-5.3+0.5 \ln (D)$ & $D=C^{2.75} t_{e}$ \\
\hline roxic iemease & Ammonia & $Y=-9.82+0.71 \ln (D)$ & $D=C^{2} t_{\mathrm{e}}$ \\
\hline
\end{tabular}

Where:

$Y \quad$ Probit value corresponding to the probability for fatality;

I Radiation intensity $\left(\mathrm{kW} / \mathrm{m}^{2}\right)$

$P_{\mathrm{s}} \quad$ Peak static overpressure (psi)

C Toxic concentration $\left(\mathrm{mg} / \mathrm{m}^{3}\right)$

$T_{\mathrm{e}} \quad$ Exposure time (minutes)

The calculated threshold values for each reference scenario for different levels of fatality mentioned above are shown in Table 7-3. Using a GIS technique, the estimated effect-distances were calculated for 1, 5, 10, 20 and $50 \%$ fatality as shown in Figure $7-3$ were then overlaid on the map of the area concerned to visualize the spatial spread of the scenario impact in terms of fatality. The effect-distances were mapped with respect to the storage associated with the identified accident scenario as the point of origin (i.e. storage).

Table 7-3: Threshold values for each event type

\begin{tabular}{lcccc}
\hline $\begin{array}{c}\text { Probability } \\
\text { of fatality }\end{array}$ & $\begin{array}{c}\text { Radiation }\left(\mathrm{kW} / \mathrm{m}^{2}\right) \\
\text { Butane }\end{array}$ & $\begin{array}{c}\text { Overpressure } \\
(\mathrm{psi})\end{array}$ & \multicolumn{2}{c}{ Toxic Release $\left(\mathrm{mg} / \mathrm{m}^{3}\right)$} \\
\hline 1 & 65.00 & 120.00 & 8000 & 18000 \\
0.5 & 26.50 & 13.10 & 870 & 4000 \\
0.2 & 20.78 & 7.15 & 470 & 2525 \\
0.1 & 18.25 & 5.20 & 340 & 2030 \\
0.05 & 16.42 & 3.95 & 260 & 1680 \\
0.01 & 13.42 & 2.40 & 160 & 1200 \\
\hline
\end{tabular}

64 Lees 1996; AIChE 1999

65 HSE Guidebook

66L ees 1996; AIChE 1999; CPR 1999 


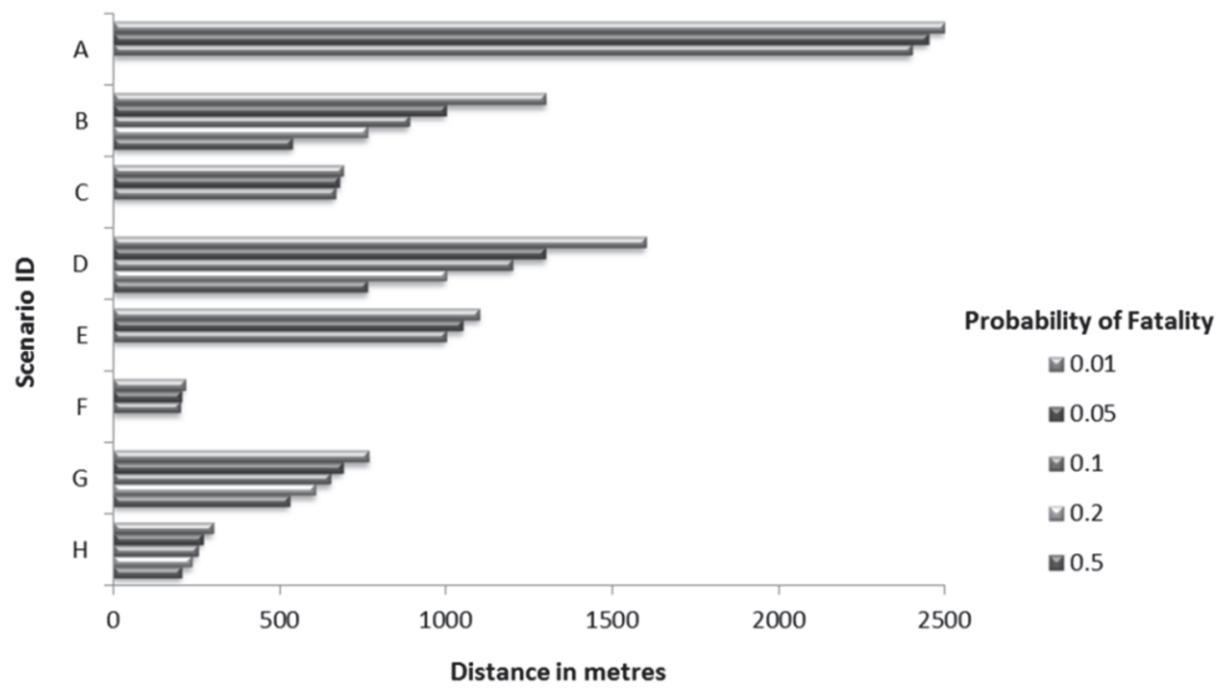

Figure 7-3: Effect-distances of the reference scenarios

\subsubsection{Risk estimation}

Finally, risk was estimated by combining the frequency with the consequences per hazard scenario. As risk to the people concerned, two indices were used: individual risk and societal risk (Bottelberghs, 2000b).

In order to generate individual-risk contours, it was required to estimate the effect of all individual scenarios at each location. Accordingly, risk resulting from each reference scenario was estimated combining frequency of the initiating event (i.e. incident), conditional probability of the scenario (i.e. sequence) and the corresponding probability of fatality (i.e. Probit). In particular, the following expression was used to estimate IR at a given location for a particular accident scenario.

$\operatorname{IR}(x, y, i)=\left[f_{i}, P F_{i}\right]=\left[\left(f_{\text {incident } i .} P\right.\right.$ sequence $\left.\left.i\right) \cdot P F_{i}\right]$

Where:

- $\operatorname{IR}_{(x, y, i)}$ is the individual risk at the geographical location $(x, y)$ for a particular reference scenario $i$;

- $\quad f_{i}$ is the frequency of occurrence of the accident scenario $i\left(y^{-1}\right)$;

- $\quad \mathrm{PF}_{\mathrm{i}}$ is the probability of fatality that the accident scenario $i$ will result at location $(x, y)$.

The resulting overall IR at that particular location $(x, y)$ was then calculated as the sum of the individual IR's corresponding to each reference scenario. 
$\operatorname{IR}_{(x, y)}=\sum \operatorname{IR}(x, y, i)$

- $\operatorname{IR}(x, y)$ is the overall IR at the geographical location $(x, y)$ for all reference scenarios

It is important to mention that all events considered had radial effects, except for the scenarios involving toxic release which were considered as a directional footprint with its spread distributed in a sector of 22.5 degrees, using a wind direction probability of 0.125 taking any of 8 principal wind directions.

A number of measures can be found in the literature to estimate or express the societal risk (Jonkman et al., 2003; Laheji et al., 2000). Among them, the PLL measure was chosen in this research as it allows spatial display of the risk to society by combining the damage potential with population density estimates. In particular, the following expression as adapted from the literature was used to estimate SR in terms of Potential Loss of Life (PLL) (Jonkman et al., 2003).

$\operatorname{PLL}(x, y)=[\operatorname{IR}(x, y) \cdot N P(x, y)]$

Where:

- $\operatorname{PLL}(x, y)$ is the Potential Loss of Life at a geographical location $(x, y)$;

- $\operatorname{IR}(x, y)$ is the individual risk at location $(x, y)$; and

- $N P(x, y)$ is the number of people at a geographical location $(x, y)$.

However, to be able to estimate PLL across a spatial grid, it is necessary to have a high-resolution spatial population database for the area. This is not readily available for the study area. In order to do so, the area was divided into a series of grid cells measuring $100 \times 100 \mathrm{~m}$ 's. The number of people per grid cell was estimated by interpolating the census population data (available per administrative unit) to the spatial spread of residential areas using a dasymetric approach (Bhaduri et al., 2007a) . It is expected that the results would be helpful for planners and other decision makers to understand the severity of existing risk level and accordingly identify the areas where risk reduction measures should be adopted. It is important to mention here that the societal risk estimation is conservative since it considers all people to be unsheltered and always present at their residences.

\subsection{Cumulative risk maps of Haldia}

The methodology presented in the previous section was applied in a subset comprising of about $100 \mathrm{~km}^{2}$ of the larger Haldia Planning Area to estimate the existing cumulative risk to people in the vicinity of the hazardous 
industries. Figure 7-4 shows iso-risk contours depicting the probability of an unprotected individual being killed in the vicinity of such industries per year. Finally, the societal risk in terms of the number of probable fatalities that may be caused in an area was estimated using a PLL function by combining the IR with the number of persons residing in each cell of the grid. The societal risk (unit being no. of people in each grid who can suffer fatalities/year) is presented in Figure 7-5.

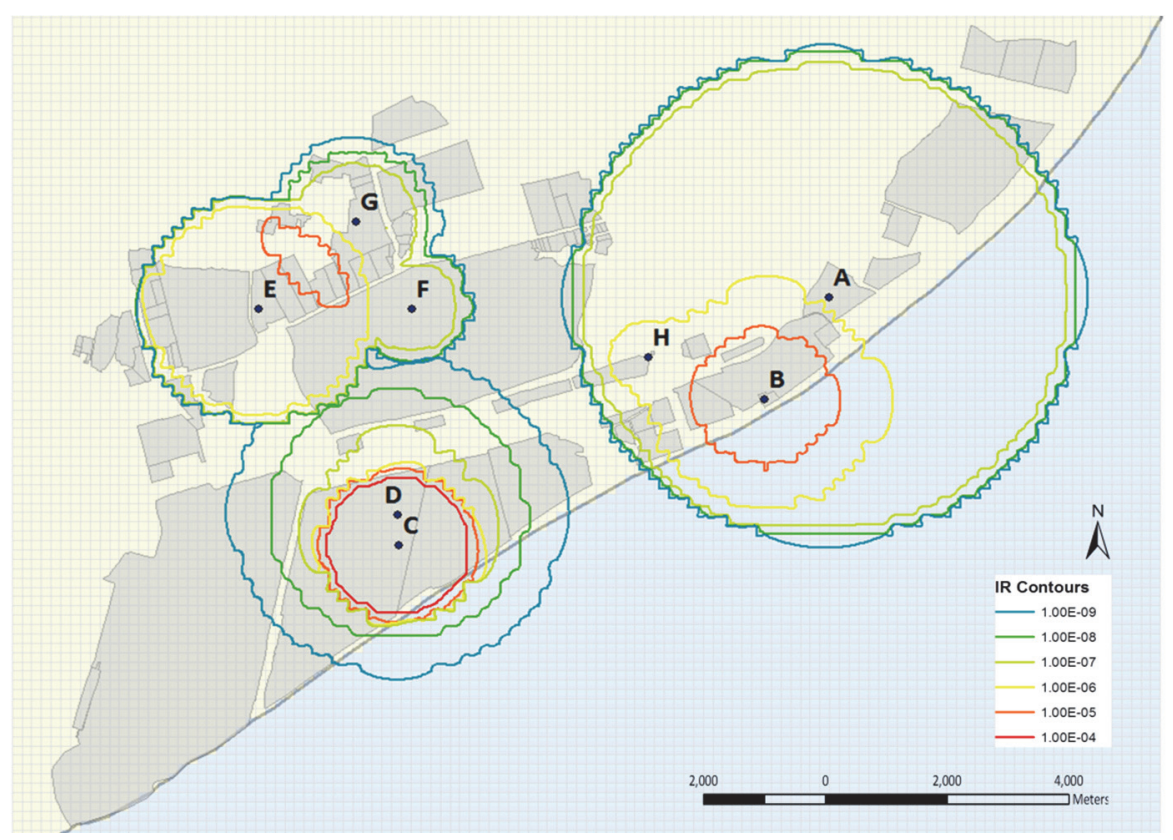

Figure 7-4: Individual risk-Iso-risk contours 


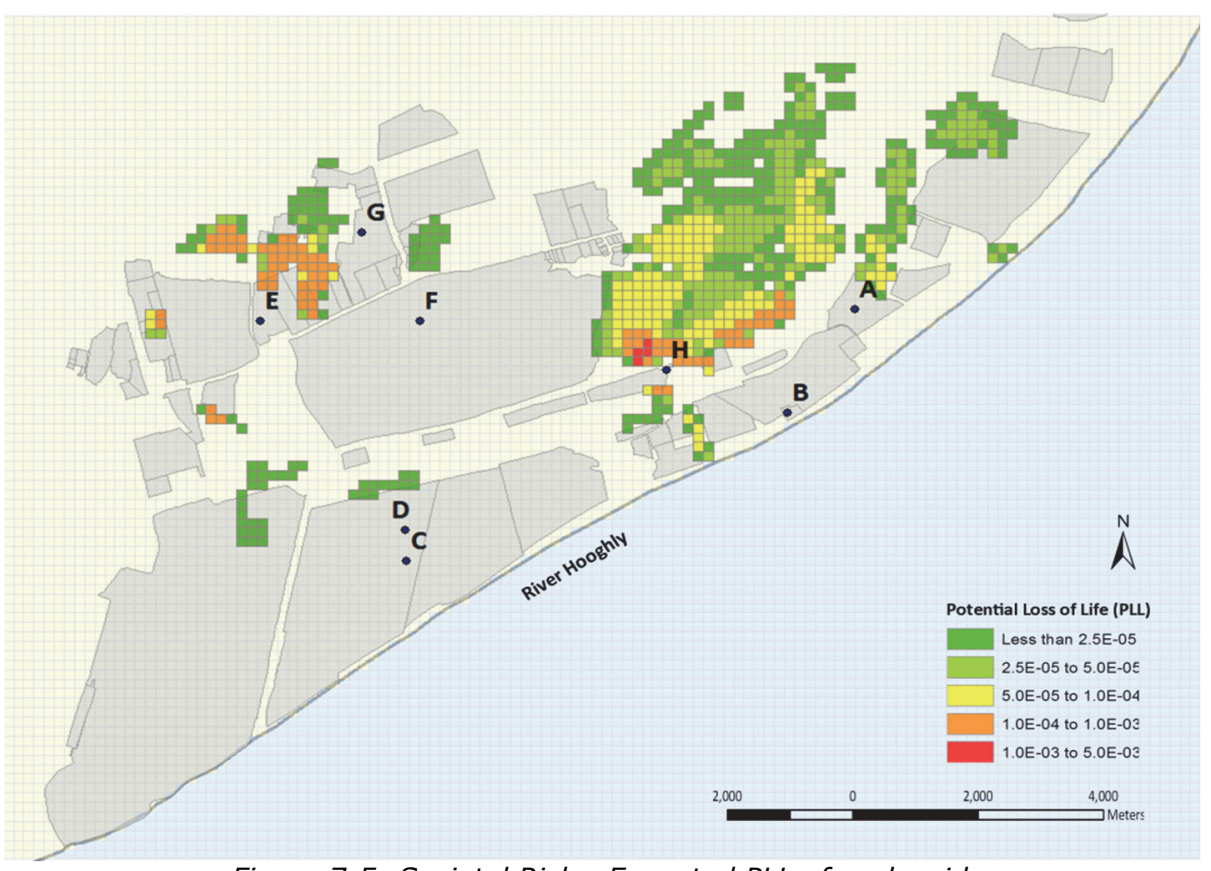

Figure 7-5: Societal Risk - Expected PLL of each grid

\subsection{Uncertainty analysis}

The methodology was based on a QRA approach, as applied in European countries. However, for applying this method in an Indian situation, several assumptions had to be made. These included the selection of a limited number of scenarios based on a pre-set criterion, estimation of the frequency of initiation events, the probability of sequences leading to the accident scenario, and the Probit coefficient. The reliability of the results presented in the previous section, is dependent on these assumptions. To evaluate the validity of these assumptions, an uncertainty analysis was carried out for the key variables (Amendola et al., 1992). These variables were analysed to stimulate discussion between risk assessment professionals and planners who may intend to apply this methodology.

\subsubsection{Scenario Frequency}

For the performance of a consistent QRA, it is essential to determine event frequencies as realistic as possible. Alternatively, over or under-estimation of these values can lead to an error of more than one order of magnitude in the calculation of risk. Generally, the estimation of failure frequency for QRA is done based on data obtained either from different research projects, historical analysis of accidents or by expert judgment, which are documented in the generic failure-frequency databases. Likewise, frequency of each scenario was estimated based on an international generic failure database. 
However, whether these levels of failure frequency will be viable for Indian MAH installations has to be discussed and agreed upon, since frequency of accidents in India might be different from those in the Western European countries because of factors like enforcement of the regulations on maintenance, replacement, safety management etc. Hence, the alteration of risk contribution from different scenarios has been studied, based on the variation of scenario frequencies. A comparison between estimated frequency based on HSE's database as compared to considering a common frequency, indicative of tolerable risk and assumed to be $1 \times 10^{-4}$ in this case, for all scenarios is presented in Table 7-4.

\begin{tabular}{lll} 
Table 7-4: Contributions of the reference scenarios to the PLL estimation (\%) \\
\cline { 2 - 3 } Scenario ID & $\begin{array}{l}\text { Estimated Frequency } \\
\text { (as per HSE) }\end{array}$ & $\begin{array}{l}\text { Assumed common } \\
\text { Frequency }\left(1 \times 10^{-4}\right)\end{array}$ \\
\hline A & 39.72 & 75.08 \\
B & 9.17 & 0.22 \\
C & 0.00 & 0.00 \\
D & 0.25 & 0.59 \\
E & 28.52 & 2.70 \\
F & 0.00 & 0.00 \\
G & 0.43 & 4.58 \\
H & 21.90 & 16.83 \\
\hline
\end{tabular}

From Table 6-4, it is evident that further research needs to be carried out to establish frequencies of the initiating events and probabilities of possible sequences which may result in different accident outcomes and consequently spatial distribution of risk levels.

\subsubsection{Weather condition}

The results of consequence predictions can vary to a significant extent based on input weather factors like wind speed, direction, stability class etc. (Marx et al., 2009). The variability in individual risk levels, when using actual wind direction data recorded at a weather station compared to an assumed equal probability wind direction averaged across eight wind directions, is shown in Figure 7-6. 


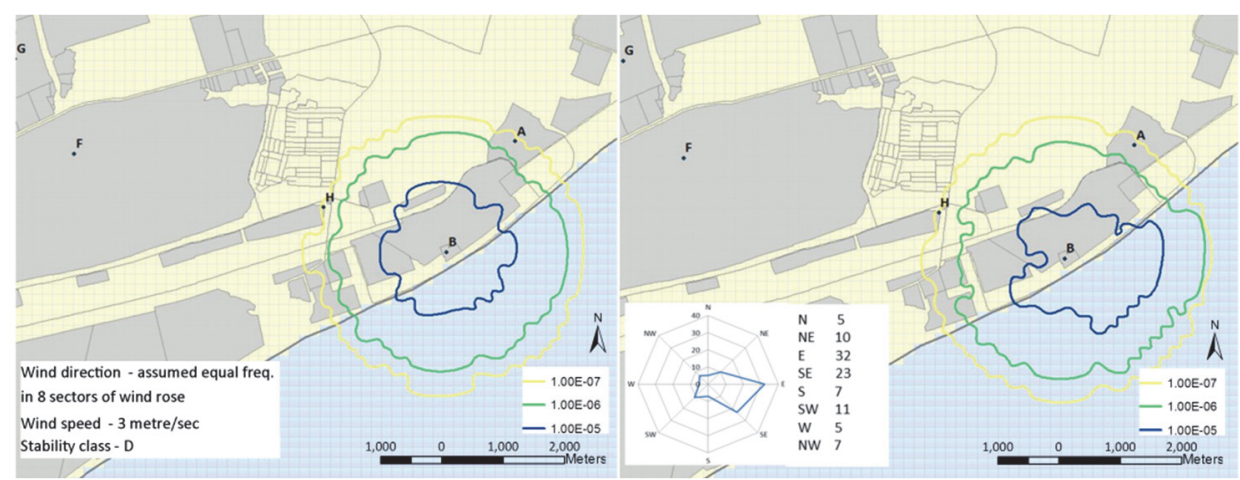

Figure 7-6: Variation in IR levels accounting for wind direction probability based on assumed weather data (left); and from wind rose (right)

\subsubsection{Resolution}

The societal risk results are also sensitive to the defined grid size and the level of detail, at which land use is captured for population interpolation. Given the fact, the methodology was also tested at a smaller grid size of 50 by $50 \mathrm{~m}$, and a comparison of the societal risk levels between the $100 \times 100$ $\mathrm{m}$ and the $50 \times 50 \mathrm{~m}$ grids is shown in Figure 7-7.

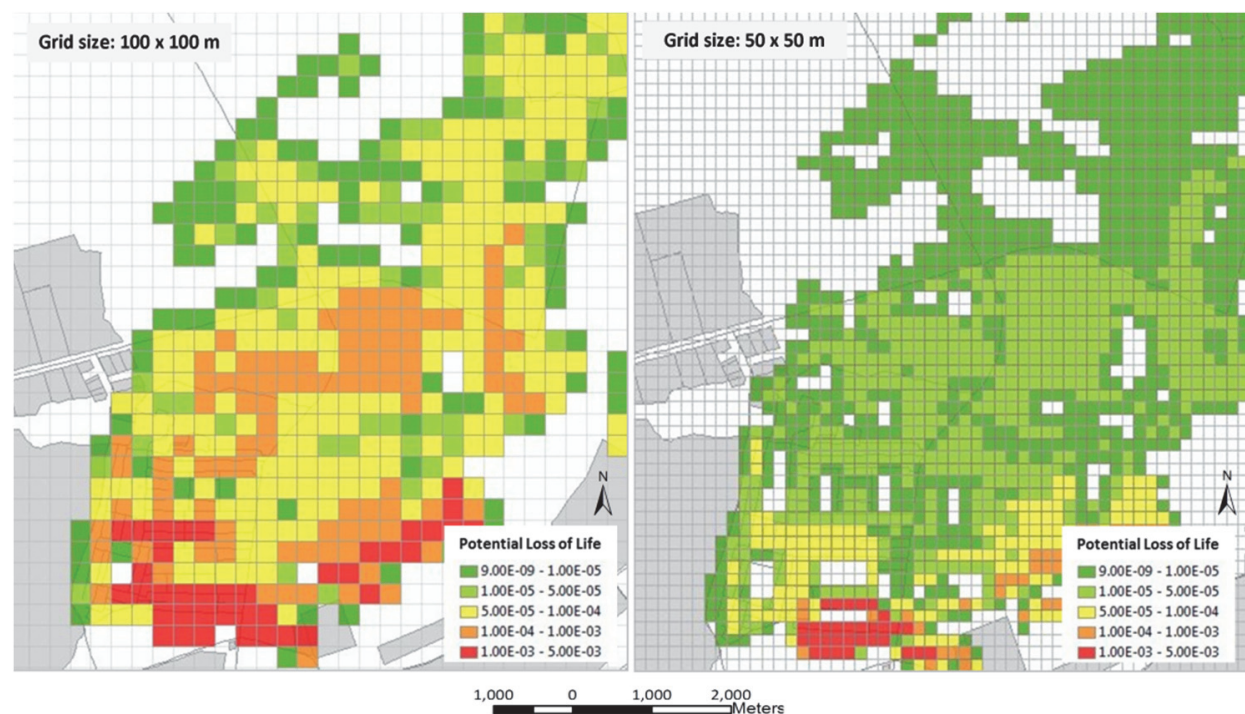

Figure 7-7: Changes in the level of societal risk at different resolution

\subsection{Discussion}

The study presented here shows that a simplified methodology based on the contemporary QRA approach can be applied for estimating the spatial extent of risk originating from a number of hazardous facilities using a selected number of reference scenarios. However, the output of the investigation 
revealed several important concerns requiring further research and discussion.

The first important issue is the selection of scenarios that have to be accounted for in order to arrive at a decision of the scenarios with an offsiteimpact. The experts of the European Working Group on Land-use Planning (EWGLUP) have indicated that for the purpose of risk-informed land use planning, accident scenarios have to be selected based on their frequency of occurrence and the severity of their consequences (Christou et al., 2006b).However, in India the risk analysis presently undertaken by the MAH industries is based on the MCL scenarios representing the probable scenario that can cause maximum offsite consequences only. However, no clear criteria or limits are yet formulated for identifying such scenarios at the national level (NDMA, 2007). The choice of MCL scenarios is dependent on the methodology adopted for facility level risk assessment, based on a number of assumptions made during the analysis and then presented through a safety report, which will bring in inherent uncertainties in QRA studies involving multiple facilities. Hence, there is a need for a methodology giving consistent rules to identify and select accident scenarios, and their control in risk analysis which would enable a cumulative risk assessment study. Otherwise the results may convey a wrong picture.

Second is the accuracy or trustworthiness of the scenarios and the resulting risk estimation. It has been noted that alteration of any modelling assumptions or variables may exhibit substantial variations in the size of the impact area and thereby the consequences from similar scenarios (See Table 7-4). Therefore to arrive at a harmonized result, recommended parameters and other input variables (like threshold values for effect-distance calculation, Probit equations etc.) to estimate the consequence of an accident scenario, need to be formulated in order to generate consistent risk scenarios prevailing in an industrial area.

The next important issue is the number of scenarios that have to be accounted for in order to arrive at a decision. In this research only eight 'reference scenarios' were used. However, from a probabilistic point of view, there could be numerous release scenarios associated with a particular storage of hazardous chemicals, in an industrial area like Haldia which could have major consequences for the residential areas located in between. Therefore selection of accident scenario would have a significant bearing on the decision for risk reduction or land use planning. In this regard, several studies like ARAMIS, and MIMAH have been undertaken in Europe to standardise and set the reference criteria for their selection (Delvosalle et al., 2005; Delvosalle et al., 2006a; Delvosalle et al., 2006b; Kontic et al., 2006; Salvi et al., 2006; Fabbri et al., 2009; Tugnoli et al., 2013).In India, 
however, criteria still need to be formulated for the selection of the reference scenarios to assess the existing level of risk. Moreover, the selection of the number of scenarios is also critical as the total individual risk is calculated by adding up the values of the individual scenarios. Ideally all possible scenarios should be taken to arrive at a correct IR value; but that may mean considering $1000 \mathrm{~s}$ of scenarios. So for practical purposes, the scenarios to be considered have to be restricted using certain limiting criteria. In this study, individual risk was estimated taking eight scenarios, which may lead to an underestimation of the existing risk levels. Nevertheless, the results can be used to analyse areas where the risk level, using these eight scenarios, already surpasses international risk acceptability levels.

A specific risk acceptability criterion is not yet defined in India; hence an attempt has been made to compare the results with the Dutch criteria used for land use planning decision. It has been observed that the application of these criteria might be difficult in India as it would result in too much unacceptable area for land use planning decisions. Thus further research is required for establishing risk acceptability criteria for India in accordance to the societal background and existing regulatory framework.

Regarding risk-informed land use planning, as mentioned earlier, European countries have formulated different risk assessment approaches (See Chapter 3). From a methodological point of view, for a given hazardous installation, the consequence-based approach shows the consequence area for lethal effects and serious injuries resulting from the reference scenarios assessed, whereas the risk-based approach shows an area within which there is a given probability of a specified level of harm resulting from the large number of possible accident scenarios (Christou et al., 2000). Therefore proposing a risk-based approach, in comparison to a consequence-based approach, the proposed methodology assigns due weight to the issue of optimal use of land resources for planning purposes in India. The proposal for a consequencebased approach would result in too costly spatial claims. For this purpose, both approaches were tested in the study area (Figure 7-8) and percentages of the total area affected as well the percentage of affected area under different land use category were compared in Table 7-5 and 7-6. It is evident that a risk-based approach results in stricter land use planning. 


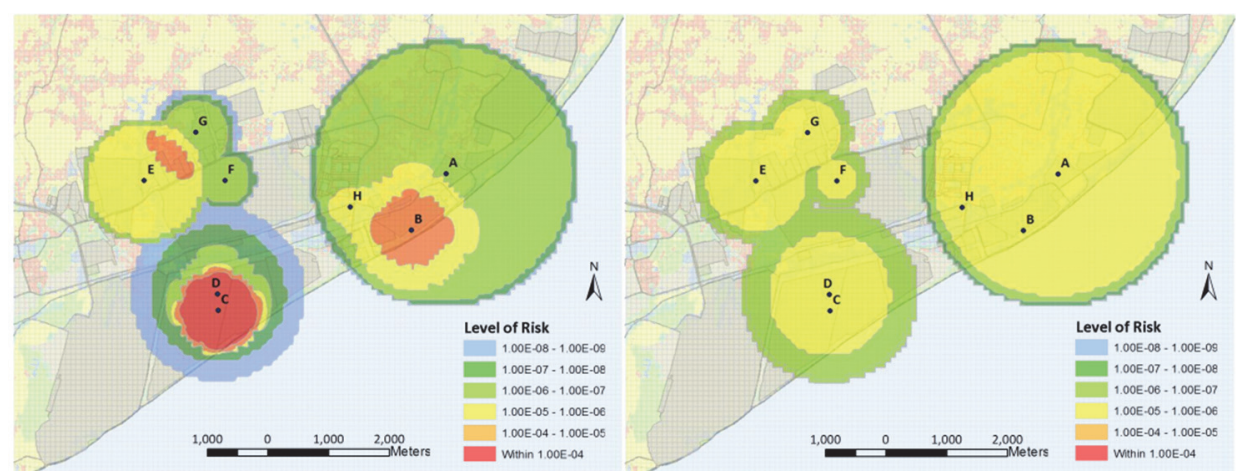

Figure 7-8: Application of risk-based approach (left) and consequence-based approach (right) to the study area

A host of analytical approaches have been formulated and used by risk analysts to predict potential damage, in terms of injury or fatality, from an accident involving a toxic release, fire or explosion in a hazardous installation. Regulatory authorities have varying opinions on the outcome of consequence modelling. Some agencies like the Environment Protection Agency in the US, stress the use of simple consequence modelling equations for prediction of worst case damage distances to specific end-points whereas other agencies, like RIVM in the Netherlands or the HSE in the UK, prescribe the use of specific tools like SAFETI and RISKAT respectively, to be applied based on certain requirements and boundary conditions (Ale, 2005b; Pasman, 2011). Several independent evaluations undertaken pointed out the need for benchmarks and prescribed calculation methods for undertaking such risk analysis. Therefore adapting such methods would lead to a reliable and standardized estimate of risk or for judging the severity of consequences which could subsequently be summed up to arriving at a measure of cumulative risk.

Table 7-5: Comparison of area-affected (sq. km) in consequence-based and risk-based approaches

\begin{tabular}{lcccc}
\hline $\begin{array}{l}\text { Iso-risk } \\
\text { contour } \\
\text { value }\end{array}$ & \multicolumn{2}{c}{ Risk-based approach } & \multicolumn{2}{c}{ Consequence-based approach } \\
\cline { 2 - 5 } & Area & $(\%)$ & Area & (\%) \\
\hline Within $10^{-4}$ & 1.67 & 5.92 & 0.00 & 0.00 \\
$10^{-4}$ to $10^{-5}$ & 1.84 & 6.53 & 0.00 & 0.00 \\
$10^{-5}$ to $10^{-6}$ & 5.48 & 19.44 & 20.60 & 72.51 \\
$10^{-6}$ to $10^{-7}$ & 12.70 & 45.05 & 5.66 & 19.92 \\
$10^{-7}$ to $10^{-8}$ & 3.58 & 12.70 & 1.83 & 6.44 \\
$10^{-8}$ to $10^{-9}$ & 2.92 & 10.36 & 0.32 & 1.13 \\
\hline
\end{tabular}


Table 7-6: Percentage of affected area under different land use categories in both approaches (Agri. = agriculture, Ind = Industrial, Res = residential)

\begin{tabular}{cccccccccc}
\hline $\begin{array}{c}\text { Iso-risk } \\
\text { contour } \\
\text { value }\end{array}$ & \multicolumn{3}{c}{ Risk-based approach } & \multicolumn{3}{c}{ Consequence-based approach } \\
\cline { 2 - 9 } & Agri & Green & Ind & Res & Agr & Green & Ind & Res \\
\hline Within $10^{-4}$ & 0.00 & 0.00 & 5.93 & 0.00 & 0.00 & 0.00 & 0.00 & 0.00 \\
$10^{-4}$ to $10^{-5}$ & 0.25 & 0.50 & 4.18 & 0.46 & 0.00 & 0.00 & 0.00 & 0.00 \\
$10^{-5}$ to $10^{-6}$ & 3.00 & 2.11 & 7.29 & 2.32 & 10.07 & 4.29 & 30.21 & 12.96 \\
$10^{-6}$ to $10^{-7}$ & 8.46 & 1.82 & 13.43 & 11.4 & 0.25 & 1.50 & 10.75 & 1.93 \\
$10^{-7}$ to $10^{-8}$ & 5.75 & 0.93 & 2.07 & 0.93 & 1.36 & 0.43 & 2.79 & 1.00 \\
$10^{-8}$ to $10^{-9}$ & 0.82 & 0.86 & 6.07 & 0.93 & 0.21 & 0.07 & 0.46 & 0.21 \\
\hline
\end{tabular}

Another key aspect of the methodology presented for estimation of risk measures in a spatial context is that no complex or proprietary software tool has been used in realizing the method. The proposed approach takes advantage of using simple GIS functions and the ALOHA model, one of the known and accepted effect models by the regulatory and industrial communities. Therefore, the methodology aligns with the accepted framework set by many countries, like the Netherlands that risk analysis should not be a preserve of risk analysts, but a decision maker or planner should be able to apply the same after receiving a basic training. For fast growing industrial areas, land use planners can thus easily consider various risk scenarios and spatially overlay them on the present land use in order to allocate future land for future industrial and residential development. The work carried out by Bandyopadhyay $(2008,2016)$ in the development of a decision and planning support tool for industrial risk management in India, is an important contribution in this respect.

The present approach also applied a novel method to estimate PLL based on a grid-basis population data derived from the Census data using a dasymetric interpolation technique. Generally, for risk estimation purpose, ward-level population as extracted from the Census database is used without considering the exact location of population. However, often this leads to a wrong picture; hence interpolated population database into a 100×100 meter grid was used in order to get a fair estimation of number of people who might be affected. Nevertheless, it is important to mention here that grid-wise population data used is just cumulative of all people including the sensitive people as well residing in that grid. 


\section{Chapter 8- Application of an indicator-based approach for vulnerability assessment}

This chapter demonstrates the application of a methodological framework to assess the vulnerability of the human communities adjacent to the hazardous industries, in an Indian context. For the purpose, a specific methodology was developed based on a set of indicators and a multi-criteria evaluation method to obtain a semi quantitative estimate of vulnerability illustrated with an example of the case study area. Furthermore, a methodological framework for inclusion of this vulnerability assessment in land use planning decisions in an industrial cluster has also been proposed.

\subsection{Introduction}

The assessment of potential risk of industrial accidents is an important concern for population, industries and/or decision makers. And in order to take the right decisions, stakeholders must base their analysis on the knowledge of potential hazards, but also on intrinsic vulnerabilities concerning the surrounding population and territory, with the aim to have a pertinent representation of the risk not only based on hazards. However, following the traditional QRA approach, as outlined in the previous chapter, the assessment of potential risk is carried out based on a detailed description of scenarios, assessment of the likelihood as well as its consequence (Tixier, 2002). And this is generally done by modelling many scenarios, in which variations in population and building factors are not taken into account. Consequently, the outcome of such estimation doesn't take into account the variation in degree of vulnerability. This is a very crucial aspect for a country like India where a large number of low-income group people live in close proximity of hazardous industrial facilities, to take the advantage of jobs and other livelihood opportunities generated by these industries. In such cases, the continual growth of residential areas without adequate infrastructure and other basic amenities like transportation, water, health and sanitation etc., increase the vulnerability of the areas to accidents. In order to safeguard such vulnerable communities, it is therefore vitally important to understand the impact of an accident scenario on these areas and thereby their degree of vulnerability.

Based on this appreciation, the objective of this chapter is to conceptualise a systematic approach for assessing the vulnerability of an area exposed to potential industrial hazards, reflecting the specific situation of India. The proposed approach for vulnerability assessment is mainly to complement the traditional hazard-based approach for consequence assessment. The proposed approach would thereby allow the authorities to take into account vulnerability of an area as a self-consistent variable while making any 
decision. The methodology is illustrated with an example of the case study area, using the information and dataset prepared for the purpose.

\subsection{Conceptualization - Building vulnerability assessment ${ }^{67}$}

The aspect of assessing the vulnerability of individual buildings in response to an industrial accident is of great importance for an Indian situation, where the urban areas in the vicinity of hazardous industries characterized by different building types ranging from informal hutments to buildings made of concrete. In such urban areas, depending on the construction characteristics, the vulnerability of individual buildings varies significantly which in turn determine the number of people at risk. From this standpoint, it is therefore important to understand the potential impacts of different physical effects of an accident scenario on the built environment.

In case of an industrial accident, regardless the distance from hazardous industries, not every building within the same exposure zone is equally vulnerable. For instance, a two storied building with large number of openings (windows, doors, etc.) is more vulnerable as far as toxic release event is concerned; whereas the same building might not be that much vulnerable in case of a fire or explosion event. Thus it can be understood that depending on its structural condition a particular building may be either completely or partially damaged or experience some distortion in response to different physical effects of an accident scenario. In this regard, a number of studies discussing the role of some typical building characteristics in reducing or increasing vulnerability of the building and their use for the development of vulnerability curves corresponding to different construction types, in response to natural hazards, e.g., earthquake, landslide, tsunami, flood, etc., can be found in the literature (e.g. Calvi et al., 2006; Birkmann, 2006, 2007).However, after reviewing existing studies regarding industrial risk and vulnerability assessment it was found that few studies have been carried out so far on vulnerability assessment for industrial accidents in India.

This chapter proposes a conceptual model that allows coherent assessment of building vulnerability in response to fire, explosion and release of toxic gas events. For quantification purposes, a set of measureable attributes related to building construction characteristics and its surroundings were identified. Depending on the nature of the physical effect of an accident scenario, each attribute contributes in varying degrees to the overall vulnerability of a building and these attributes can be seen as indicators to measure the potential impact of an accident scenario on a building. Accordingly, relative

67 Based on this section a publication entitled "An indicator-based framework for building vulnerability assessment to industrial accidents" is under preparation. 
ranks and weights were assigned to assign to those selected attributes based on expert judgment in accordance to their relevance and importance with respect to different physical effects. Finally, a multi-criteria evaluation technique was adopted to combine these ranks and weights, to calculate the effect-specific Relative Vulnerability Index (RVI) of individual buildings. The main steps of the proposed methodology are shown in Figure 8-1.

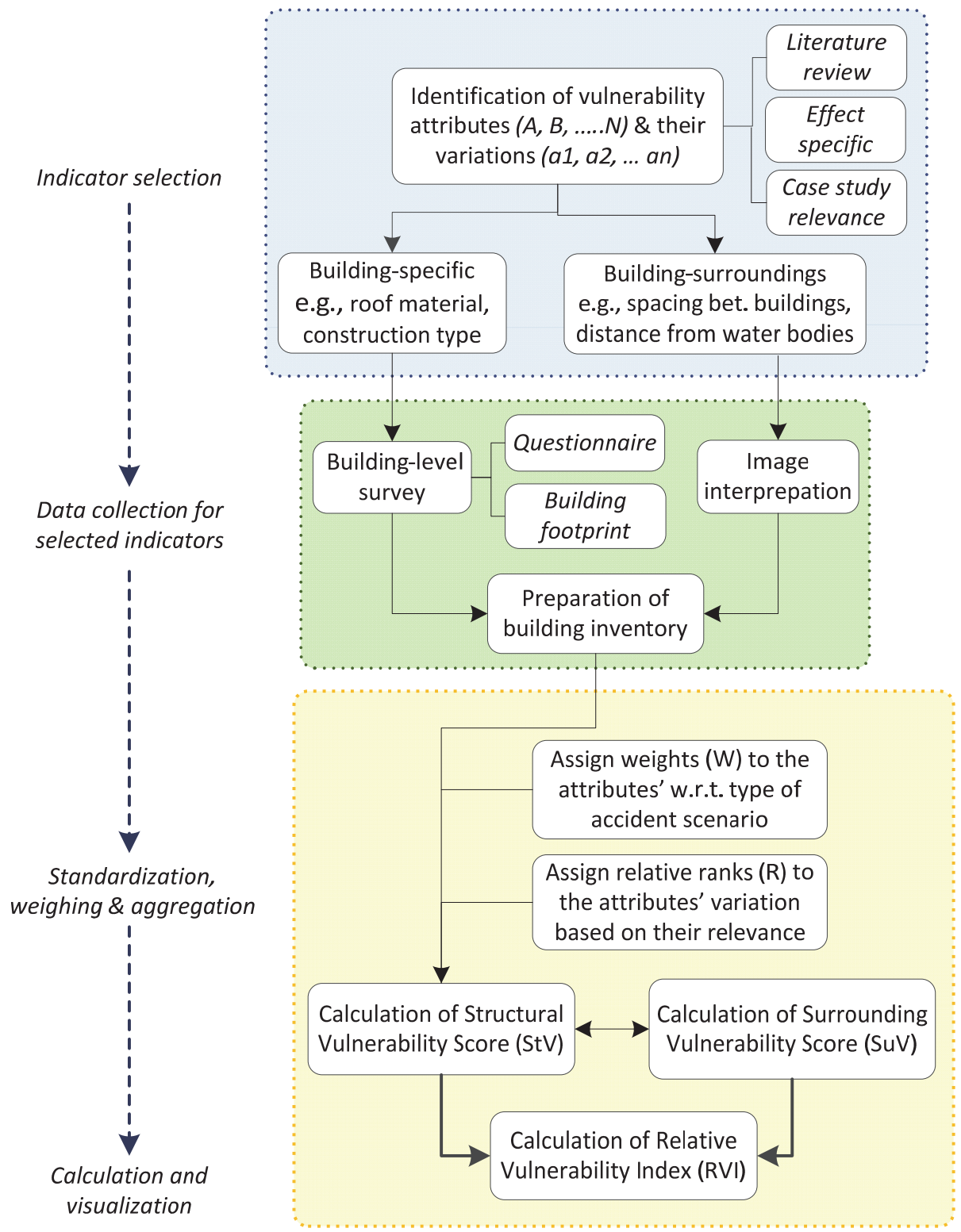

Figure 8-1: Methodology for building vulnerability assessment - SIBVA model 


\subsubsection{Identification and selection of building vulnerability indicators}

Identification of the attributes that influence and change the degree of vulnerability of the building is the first step of the proposed model. A set of indicators representing different building attributes, which can be categorized into two groups (building-specific and building-surrounding), were proposed to assess the vulnerability of individual buildings to industrial accidents (see Table 8-1).The main criteria to select the indicators used for the purpose were: their relevance for a particular physical effect, their predominance in the case study area and data availability, combining both expert and local knowledge (Figure 8-2).

Table 8-1: List of the attributes (indicators) with their variations

\begin{tabular}{|c|c|c|c|}
\hline Category & Attributes & & Variations $^{68}$ \\
\hline \multirow{15}{*}{ Building-specific } & \multirow{4}{*}{\multicolumn{2}{|c|}{ Roof material $\left(R_{f}\right)$}} & Thatched $\left(R_{f 1}\right)$ \\
\hline & & & Tiles $\left(R_{f 2}\right)$ \\
\hline & & & Asbestos $\left(R_{f 3}\right)$ \\
\hline & & & Concrete $\left(\mathrm{R}_{\mathrm{f} 4}\right)$ \\
\hline & \multirow{4}{*}{\multicolumn{2}{|c|}{ Construction type $\left(\mathrm{C}_{\mathrm{t}}\right)$}} & Mud $\left(C_{t 1}\right)$ \\
\hline & & & Thatched $\left(\mathrm{C}_{\mathrm{t} 2}\right)$ \\
\hline & & & Brick $\left(C_{t 3}\right)$ \\
\hline & & & Concrete $\left(\mathrm{C}_{\mathrm{t} 4}\right)$ \\
\hline & \multirow{4}{*}{\multicolumn{2}{|c|}{ Number of floors $\left(F_{n}\right)$}} & Four $\left(F_{n 1}\right)$ \\
\hline & & & Three $\left(F_{n 2}\right)$ \\
\hline & & & Two \\
\hline & & & One $\left(F_{n 3}\right)$ \\
\hline & \multirow{3}{*}{ Infiltration capacity $\left(\mathrm{I}_{\mathrm{c}}\right)$} & $>5$ & High $\left(I_{c 1}\right)$ \\
\hline & & $3-5$ & Medium ( $\left.\mathrm{I}_{\mathrm{c} 2}\right)$ \\
\hline & & $>2$ & Low $\left(\mathrm{I}_{\mathrm{c} 3}\right)$ \\
\hline \multirow{9}{*}{ Building-surroundings } & \multirow{3}{*}{$\begin{array}{l}\text { Space between individual } \\
\text { buildings }\left(\mathrm{S}_{\mathrm{b}}\right)\end{array}$} & $<5 \mathrm{~m}$ & Close $\left(S_{b 1}\right)$ \\
\hline & & $6-10 m$ & Moderate $\left(\mathrm{S}_{\mathrm{b} 2}\right)$ \\
\hline & & $>10 \mathrm{~m}$ & $\operatorname{Far}\left(\mathrm{S}_{\mathrm{b} 3}\right)$ \\
\hline & \multirow{3}{*}{$\begin{array}{l}\text { Distance from highly } \\
\text { vulnerable building }\left(V_{b}\right)\end{array}$} & $<5 \mathrm{~m}$ & Close $\left(V_{b 1}\right)$ \\
\hline & & $6-10 m$ & Moderate $\left(\mathrm{V}_{\mathrm{b} 2}\right)$ \\
\hline & & $>10 \mathrm{~m}$ & Far $\left(\mathrm{V}_{\mathrm{b} 3}\right)$ \\
\hline & \multirow{3}{*}{$\begin{array}{l}\text { Distance from water bodies } \\
\left(\mathrm{W}_{\mathrm{d}}\right)\end{array}$} & $<5 \mathrm{~m}$ & Close $\left(W_{\mathrm{d} 1}\right)$ \\
\hline & & $6-10 m$ & Moderate $\left(\mathrm{W}_{\mathrm{d} 2}\right)$ \\
\hline & & $>10 \mathrm{~m}$ & $\operatorname{Far}\left(\mathrm{W}_{\mathrm{d} 3}\right)$ \\
\hline
\end{tabular}

68 Codes used to denote the variations of each attribute as observed in the case study area 


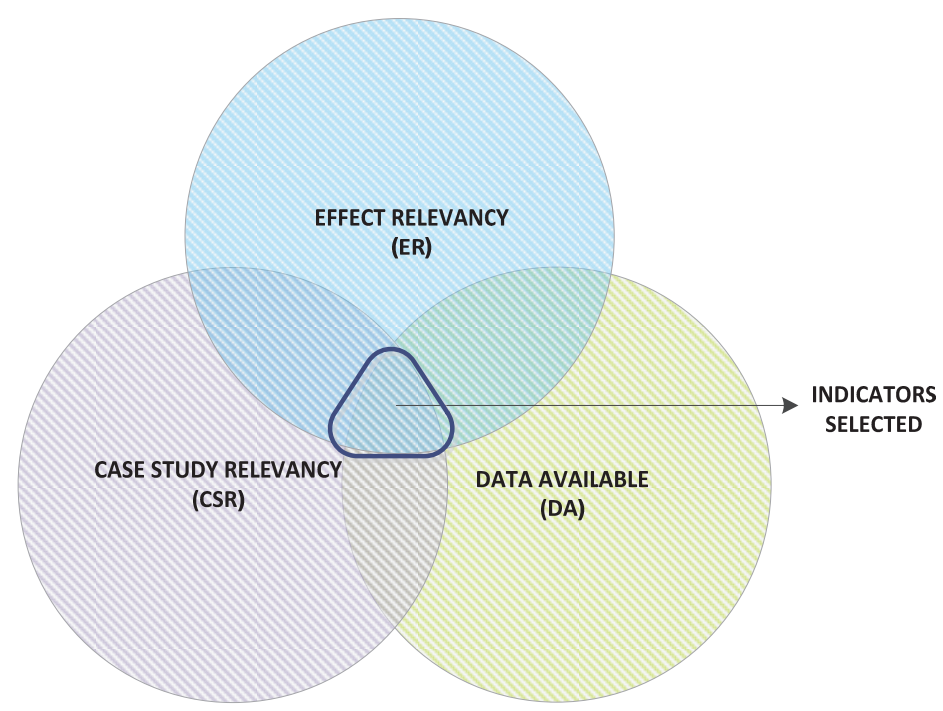

Figure 8-2: Selection of indicators from the whole set of indicators used for vulnerability assessment

\subsubsection{Weighting and ranking of indicators}

The above mentioned attributes are not equally relevant to evaluate the building vulnerability in response to fire, explosion or release of toxic gas events. For example, the number of floors is of more important for toxic release events, whereas roof material is assumed to be the most important factor for an explosion event, because roof collapse is one of the most direct effects of the explosion. Hence, the importance of a particular attribute varies depending on the nature of the physical effect of an accident. On the other hand, irrespective of the nature or type of an event, different variations within an attribute category contribute differently to the overall vulnerability of a building. For instance, the presence of a thatched roof increases the vulnerability of a particular building for any type of accidents rather than other types of roof materials (e.g., tiles, asbestos). Therefore, assessing the vulnerability of a building requires realizing the relevancy and impact of a particular attribute category with respect to different physical effects. A qualitative assessment of the relative importance of each attribute for fire $(F R)$, explosion (EX), and release of toxic events (TR) events is outlined in Table 8-2.

Quantitative information about how these typical construction characteristics influence the overall vulnerability of buildings to various physical effects is difficult to obtain. Alternatively, a semi-quantitative approach was chosen to assign ranks and weights to different attributes and its classes, considering the fact that building vulnerability is not directly measurable. Accordingly, for each attribute category a weight was assigned to quantify the level of 
importance that it has on the overall vulnerability of the buildings (Table 83 ). Each attribute category was assigned with a rank ranging from 1 (low) to 4 (high) (Table 8-4). Ranking of the variation of the attribute is an important aspect of the proposed approach, as it highlights to what degree a particular variable (e.g., thatched, tiles, asbestos, concrete) under a certain attribute category (e.g., roof material) contributes to the vulnerability of a building irrespective of type of accident. The assigned weights and ranks were then further normalized to compute the vulnerability index. The theoretical concept for assigning weights and ranks to different building-specific attributes is graphically presented in Figure 8-3.

Table 8-2: Relevance of the attributes to fire (FR), explosion (EX) and toxic release (TR) $(H=$ high, $M=$ moderate and $L=L o w)$

\begin{tabular}{|c|c|c|c|}
\hline & FR & EX & TR \\
\hline \multicolumn{4}{|l|}{ Building-specific attributes } \\
\hline Roof material $\left(\mathrm{R}_{\mathrm{f}}\right)$ & $\mathrm{H}$ & M & $\mathrm{L}$ \\
\hline Construction type $\left(C_{t}\right)$ & M & $\mathrm{H}$ & L \\
\hline Number of floors $\left(F_{n}\right)$ & $\mathrm{L}$ & M & M \\
\hline Infiltration capacity $\left(\mathrm{I}_{\mathrm{C}}\right)$ & $\mathrm{L}$ & $\mathrm{L}$ & $\mathrm{H}$ \\
\hline \multicolumn{4}{|l|}{ Building-surroundings } \\
\hline Space between individual buildings $\left(\mathrm{S}_{\mathrm{b}}\right)$ & $\mathrm{H}$ & $\mathrm{H}$ & $\mathrm{L}$ \\
\hline Distance from high vulnerable buildings $\left(V_{b}\right)$ & $\mathrm{H}$ & $\mathrm{H}$ & $\mathrm{L}$ \\
\hline Distance from water bodies $\left(\mathrm{W}_{\mathrm{d}}\right)$ & $\mathrm{H}$ & M & $\mathrm{L}$ \\
\hline
\end{tabular}

\begin{tabular}{llll}
\multicolumn{5}{c}{ Table 8-3: Normalized weights of the indicators } \\
\hline Category & Fire & Explosion & Toxic Release \\
\hline Building-specific attributes & & & \\
\hline Roof material $\left(\mathrm{R}_{\mathrm{f}}\right)$ & 0.5 & 0.2 & 0.1 \\
Construction type $\left(\mathrm{C}_{\mathrm{t}}\right)$ & 0.3 & 0.4 & 0.1 \\
Number of floors $\left(\mathrm{F}_{\mathrm{n}}\right)$ & 0.1 & 0.3 & 0.3 \\
Infiltration capacity $\left(\mathrm{I}_{\mathrm{c}}\right)$ & 0.1 & 0.1 & 0.5 \\
\hline Building-surrounding attributes & & & \\
\hline Spacing between individual & 0.5 & 0.4 & 0.1 \\
buildings ( $\mathrm{B}_{\mathrm{d}}$ ) & & & \\
Distance from vulnerable & 0.5 & 0.4 & 0.1 \\
buildings ( $\mathrm{V}_{\mathrm{b}}$ ) & & 0.4 & 0.1 \\
Distance from water bodies $\left(\mathrm{W}_{\mathrm{d}}\right)$ & 0.5 & 0.4 & \\
\hline
\end{tabular}




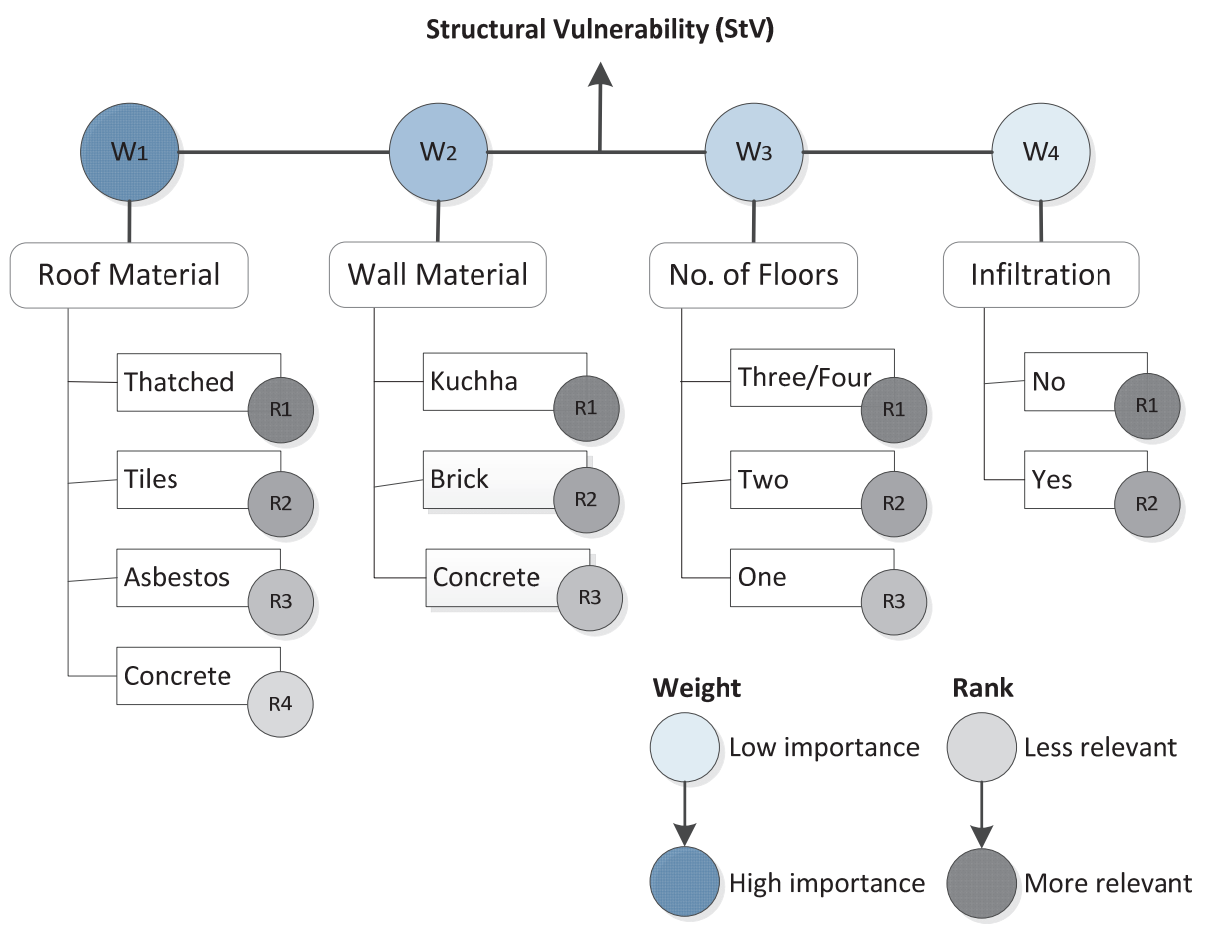

Figure 8-3: Theoretical concept for deriving a building vulnerability index

\subsubsection{Calculation of effect-specific Relative Vulnerability Index (RVI)}

The effect-specific Relative Vulnerability Index (RVI) of individual buildings was calculated as a weighted sum of two independent scores: the Structural vulnerability (StV) and the Surrounding Vulnerability (SuV), as shown in the following Equation:

$\mathrm{RVI}={ }^{2 / 3}(\mathrm{StV})+{ }^{1 / 3}(\mathrm{SuV})$

In particular, the Structural vulnerability (StV) score, depicting the capacity of building to sustain the impact of an accident scenario, was calculated as sum of the ranks and weights assigned to the indicators (Table 8-3 and 8-4) using the Equation 8.2:

$S t V=\operatorname{Rf}[a \times a]+C_{t}[\beta \times b]+F_{n}[Y \times c]+I_{c}[\delta \times d]$

- $a, \beta, Y, \delta$ are the weights of the attributes $R_{f} C_{t} F_{n}$ and $I_{c}$ representing building characteristics (e.g., wall material, number of floors)

- $a, b, c, d$ are the relative normalized ranks of the classes of attributes $\mathrm{R}_{\mathrm{f}}, \mathrm{C}_{\mathrm{t}}, \mathrm{F}_{\mathrm{n}}$ and $\mathrm{I}_{\mathrm{c}}\left(\mathrm{e} . \mathrm{g}_{\text {., }}\right.$ thatched, tiles, asbestos, concrete etc. for wall material). 
Likewise, the Surrounding vulnerability (SuV) score was calculated as the sum factor of the space between two buildings and their distance from water bodies (Equation 8.3):

$\mathrm{SuV}=\mathrm{Sb}_{\mathrm{b}}[\lambda \times \mathrm{p}]+\mathrm{V}_{\mathrm{b}}[\mu \times \mathrm{q}]+\mathrm{W}_{\mathrm{d}}[\mathrm{V} \times \mathrm{r}]$

- $\quad \lambda, \mu, v$ are the weights of the attributes $S_{b}$ and $W_{d}$ representing building characteristics (e.g., wall material, number of floors)

- $\quad p, q, r$ are the relative normalized ranks of the classes of attributes $S_{b}$ and $W_{d}$ (e.g., thatched, tiles, asbestos, concrete etc. for wall material).

Finally, in order to model the spatial distribution of vulnerability of individual buildings in response to different physical effects of accident scenarios, a Multi-criteria Evaluation (MCE) technique was used. It is important to mention that the effect-specific RVI is not dependent on the hazard intensity, rather it expresses a relative vulnerability for each building for different hazards and user defined objectives. 
Table 8-4: Normalized ranks of the indicators

\begin{tabular}{|c|c|c|c|c|}
\hline \multicolumn{3}{|l|}{ Category } & Rank & $\begin{array}{l}\text { Normalized } \\
\text { Rank }^{69}\end{array}$ \\
\hline \multicolumn{5}{|c|}{ Building-specific attributes } \\
\hline \multirow{4}{*}{\multicolumn{2}{|c|}{ Roof material $\left(R_{f}\right)$}} & Thatched $\left(R_{f 1}\right)$ & 4 & 1 \\
\hline & & Tiles $\left(R_{f 2}\right)$ & 3 & 0.75 \\
\hline & & Asbestos $\left(\mathrm{R}_{\mathrm{f} 3}\right)$ & 2 & 0.5 \\
\hline & & Concrete $\left(R_{f 4}\right)$ & 1 & 0.25 \\
\hline \multirow{4}{*}{\multicolumn{2}{|c|}{ Construction type $\left(\mathrm{C}_{\mathrm{t}}\right)$}} & Kuchha $\left(\mathrm{C}_{\mathrm{t} 1}\right)$ & 4 & 1 \\
\hline & & Thatched $\left(\mathrm{C}_{\mathrm{t} 2}\right)$ & 3 & 0.75 \\
\hline & & Brick $\left(\mathrm{C}_{\mathrm{t} 3}\right)$ & 2 & 0.5 \\
\hline & & Concrete $\left(\mathrm{C}_{\mathrm{t} 4}\right)$ & 1 & 0.25 \\
\hline \multirow{4}{*}{\multicolumn{2}{|c|}{ Number of floors $\left(F_{n}\right)$}} & Four $\left(F_{n 1}\right)$ & 4 & 1 \\
\hline & & Three $\left(F_{n 2}\right)$ & 3 & 0.75 \\
\hline & & Two & 2 & 0.5 \\
\hline & & One $\left(F_{n 3}\right)$ & 1 & 0.25 \\
\hline \multirow{3}{*}{$\begin{array}{l}\text { Infiltration capacity } \\
\text { (Ic) }\end{array}$} & $>5$ & High $\left(I_{c 1}\right)$ & 3 & 1 \\
\hline & $3-5$ & Medium $\left(I_{c 2}\right)$ & 2 & 0.66 \\
\hline & $>2$ & Low $\left(\mathrm{I}_{\mathrm{c} 3}\right)$ & 1 & 0.33 \\
\hline \multicolumn{5}{|c|}{ Building-surrounding attributes } \\
\hline \multirow{3}{*}{$\begin{array}{l}\text { Spacing between } \\
\text { individual buildings } \\
\left(\mathrm{S}_{\mathrm{b}}\right)\end{array}$} & $<5 \mathrm{~m}$ & Close $\left(S_{b 1}\right)$ & 3 & 1 \\
\hline & $6-10 m$ & Moderate $\left(\mathrm{S}_{\mathrm{b} 2}\right)$ & 2 & 0.66 \\
\hline & $>10 \mathrm{~m}$ & $\operatorname{Far}\left(\mathrm{S}_{\mathrm{b} 3}\right)$ & 1 & 0.33 \\
\hline \multirow{3}{*}{$\begin{array}{l}\text { Distance from highly } \\
\text { vulnerable building } \\
\left(V_{b}\right)\end{array}$} & $<5 \mathrm{~m}$ & Close $\left(V_{b 1}\right)$ & 3 & 1 \\
\hline & $6-10 m$ & Moderate $\left(\mathrm{V}_{\mathrm{b} 2}\right)$ & 2 & 0.66 \\
\hline & $>10 \mathrm{~m}$ & $\operatorname{Far}\left(\mathrm{V}_{\mathrm{b} 3}\right)$ & 1 & 0.33 \\
\hline \multirow{3}{*}{$\begin{array}{l}\text { Distance from water } \\
\text { bodies }\left(\mathrm{W}_{\mathrm{d}}\right)\end{array}$} & $>10 \mathrm{~m}$ & $\operatorname{Far}\left(\mathrm{W}_{\mathrm{d} 1}\right)$ & 3 & 1 \\
\hline & $6-10 m$ & Moderate $\left(\mathrm{W}_{\mathrm{d} 2}\right)$ & 2 & 0.66 \\
\hline & $<5 \mathrm{~m}$ & Close $\left(\mathrm{W}_{\mathrm{d} 3}\right)$ & 1 & 0.33 \\
\hline
\end{tabular}

\subsection{Building vulnerability assessment of Durgachak area}

The vulnerability of individual buildings located in the Durgachak residential colony of Haldia (as shown in a red box in Figure 8-4) was assessed. This densely populated residential colony with a total population of 12,500 contributes about 10 percent of the total population of Haldia Municipal Area. Being surrounded by many hazardous industries, a significant number of buildings, especially the cluster of buildings located in the southern part of the area, are highly exposed to many potential industrial accidents.

69 Normalized rank I = Raw score I/Maximum raw score (Voogd, 1983) 
Furthermore, in order to avail the employment opportunities from the neighbouring industries, number of residential buildings in this area has increased rapidly in last few decades (Figure 8-5). Buildings within this area differ widely in their occupancy type (e.g., residential, commercial), construction types etc., which results in varying degree of vulnerability.

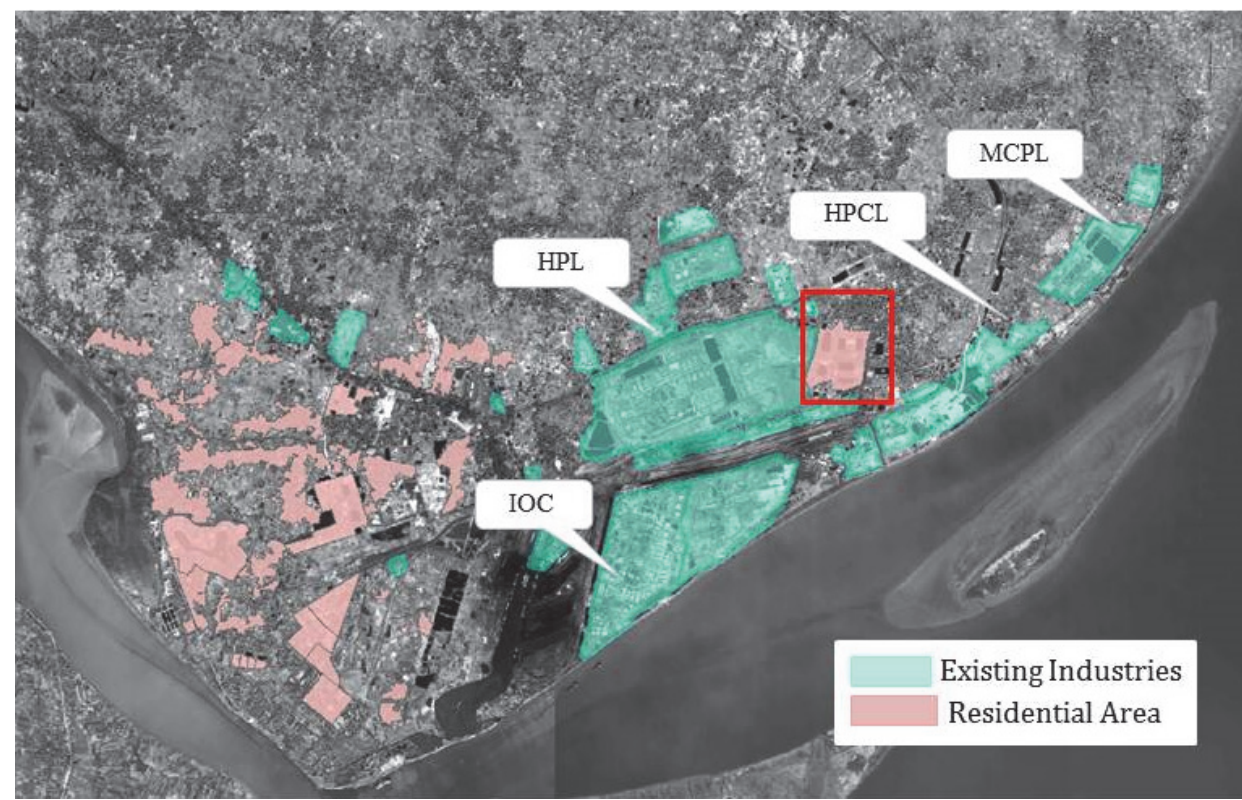

Figure 8-4: Location of hazardous industries in close proximity to Durgachak residential colony, Haldia.

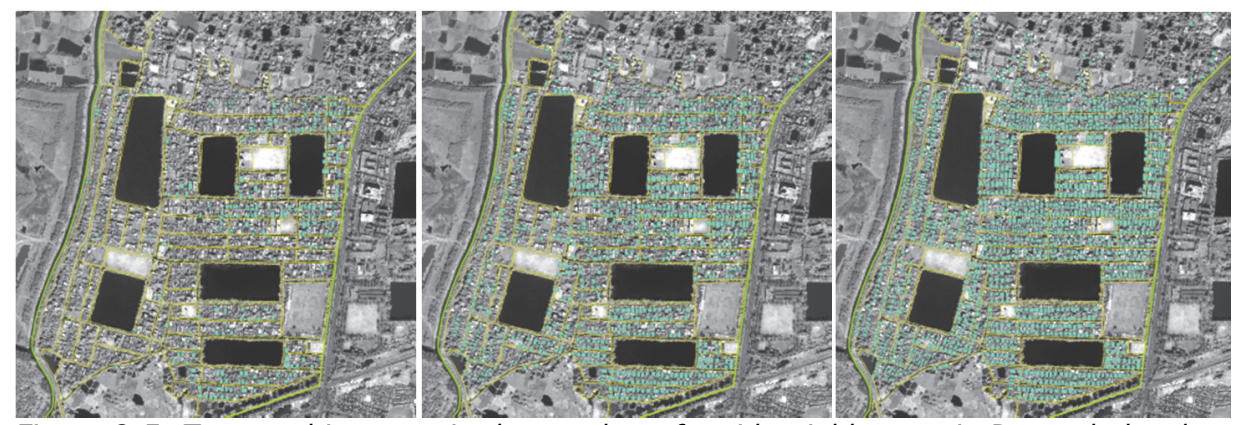

Figure 8-5: Temporal increase in the number of residential houses in Durgachak colony over the last decades, based on survey information.

After having determined the indicators to be used accurate, reliable and accessible data was collected for all indicators as identified in Table 8-1. A house-level survey was conducted to collect the information pertaining to buildings. Based on the survey results, an inventory of 1300 buildings was carried out, as described in chapter 6. 
Using this building inventory, the 'Structural vulnerability score (Sbv)' of each building was calculated and accordingly classified into three different categories. For this purpose, a 'structural vulnerability index' was prepared taking the range of the 'vulnerability score' where values of 1 to 3 represents low category, 4 to 6 represents medium category and 7 to 10 represents high category (Table 8-5).

Table 8-5: No. of buildings in different vulnerable category

\begin{tabular}{llll}
\hline Category & StV score & No. of buildings & Percentage (\%) \\
\hline High & $7-10$ & 93 & 7.15 \\
Moderate & $4-6$ & 477 & 36.69 \\
Low & $1-3$ & 730 & 56.15 \\
Total & & 1300 & 100 \\
\hline
\end{tabular}

After evaluating the structural vulnerability, attributes related to its surroundings were taken into account. In order to do so, three distance maps representing the spacing between individual buildings, distance from highly vulnerable building and distance from water bodies, were generated and overlaid with the building footprint map. Based on their distances, additional ranks were assigned to each building. Later relative weights were assigned to each distance factor according to their importance for different physical effects. Finally using a MCE technique, all attributes were combined to map the spatial distribution of the vulnerable buildings in response to fire (Figure 8-6), explosion (Figure 8-7), and toxic release event (Figure8-8).

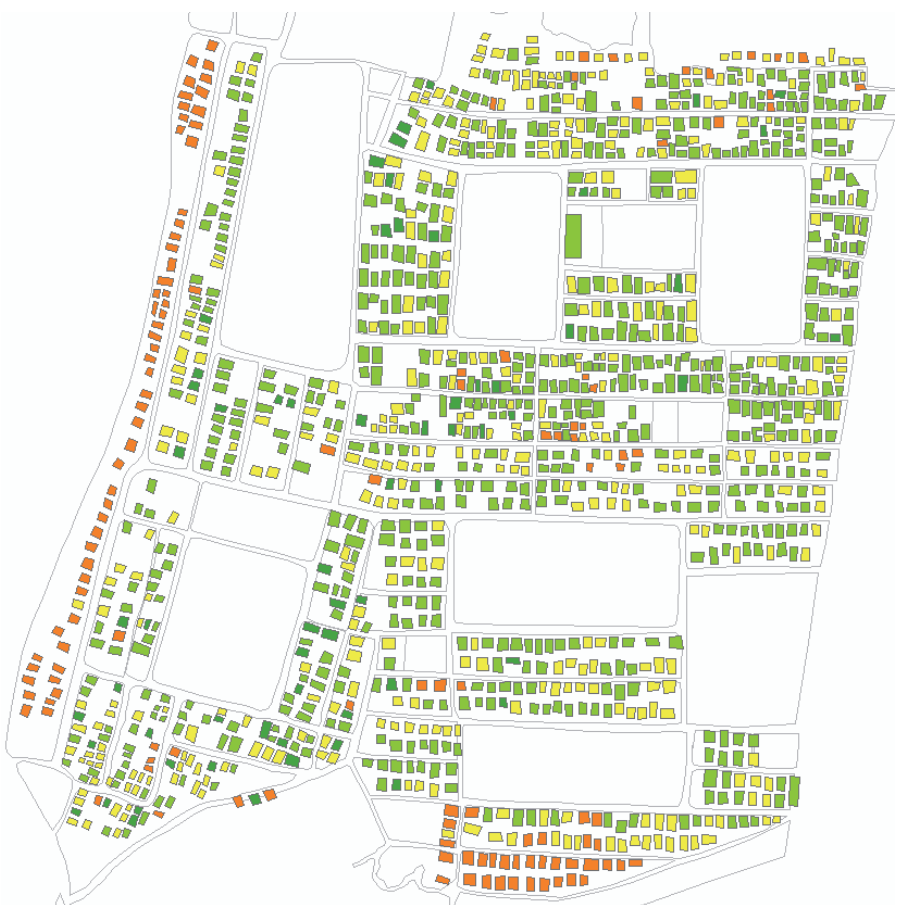

Figure 8-6: Spatial distribution of vulnerable buildings in response to fire 


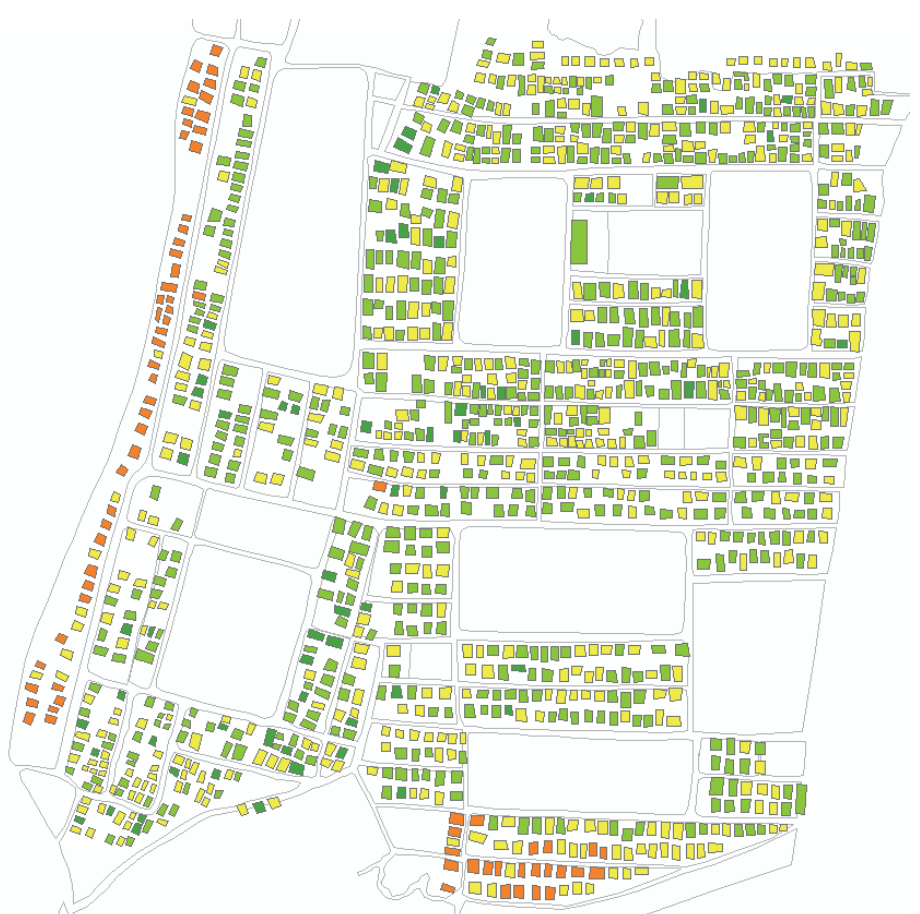

Figure 8-7: Spatial distribution of vulnerable buildings in response to explosion 


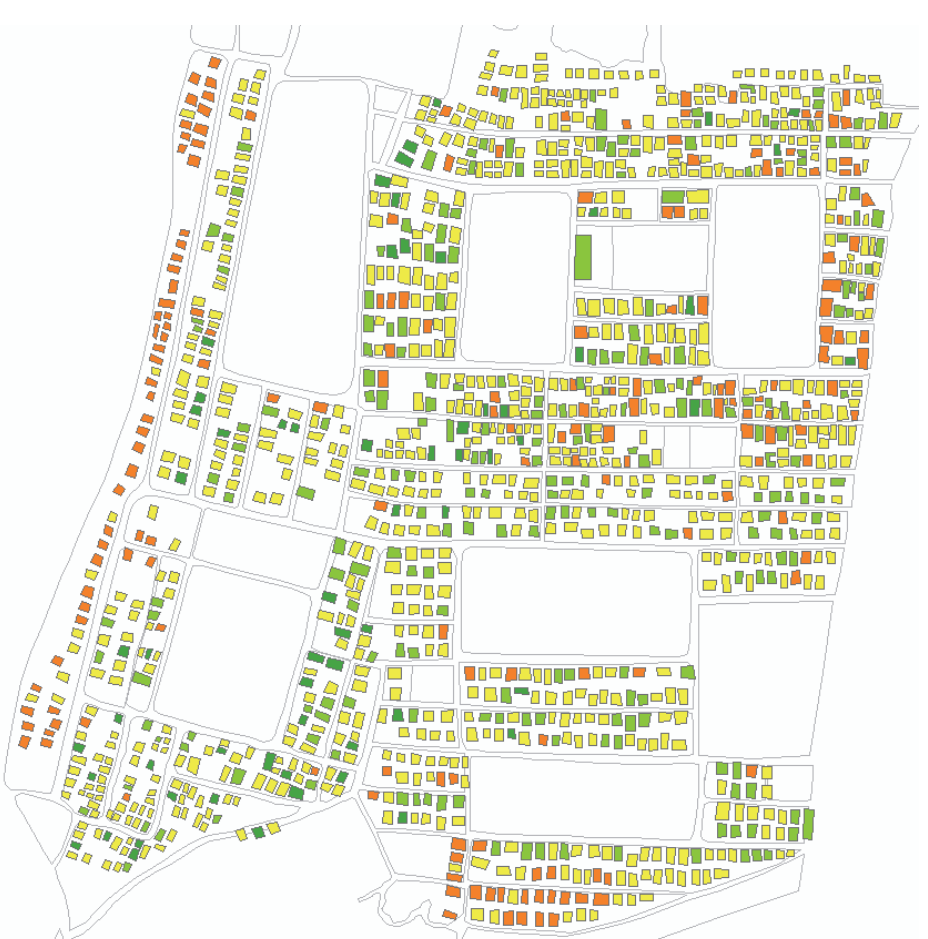

Figure 8-8: Spatial distribution of vulnerable buildings in response to toxic release events

Table 8-6: Number of buildings according to their RVI

\begin{tabular}{lllllll}
\hline \multirow{2}{*}{ Event type } & $\begin{array}{l}\text { Buildings } \\
\text { with Very } \\
\text { Low RVI }\end{array}$ & $\begin{array}{l}\text { Buildings } \\
\text { with Low } \\
\text { RVI }\end{array}$ & $\begin{array}{l}\text { Buildings } \\
\text { with } \\
\text { Average } \\
\text { RVI }\end{array}$ & $\begin{array}{l}\text { Buildings } \\
\text { with High } \\
\text { RVI }\end{array}$ & $\begin{array}{l}\text { Buildings } \\
\text { with Very } \\
\text { High RVI }\end{array}$ \\
\hline Fire & 135 & 40 & 165 & 421 & 567 \\
Explosion & 102 & 249 & 235 & 308 & 435 \\
Toxic release & 178 & 65 & 378 & 273 & 380 \\
\hline
\end{tabular}

\subsection{Discussion}

The results of the study presented here demonstrate the possibility of the proposed methodology to represent the spatial distribution of vulnerable buildings nearby an industrial site in detail. Based on the expert's judgment, the attributes that affect vulnerability were identified and analysed within a GIS.

Application of the proposed methodology would allow the end-users to have a representation of the vulnerable buildings in order to effectively manage the risk. The outcome of the proposed methodology may have important 
implications for emergency planning, and the database can be used by various end-users and stakeholders such as insurance companies, local authorities and the emergency services; therefore supporting the priority setting of different end-users according to their objectives.

The following points can be stated to establish the rationale to carry out such a detailed study concerning the vulnerability of individual buildings exposed to hazardous industries:

a. The industrial hazard and risk in this area without considering the variation in vulnerability may result in an underestimation of the real risk.

b. It would be impossible to relocate every building located within the high exposure zones, due to high costs. It is therefore of vital importance that risk managers and emergency planners are provided with detailed information regarding the location of individual buildings vulnerable to an accident. This would lead to cost-effective mitigation measures and good prioritisation of resources.

c. A GIS-based building database can be updated easily and can be used by various stakeholders according to their needs and priorities.

However, despite of certain advantages, the output of the investigation has revealed several limitations that requiring further research and discussion.

The first important issue is data availability and cost. The proposed approach requires more detailed mapping (i.e. building footprint) and collection of building specific attribute data. Collecting such data concerning the types of housing and detailed population information can be expensive and difficult to acquire. As suggested earlier, this may be overcome by the collection of data either from the local authority and/or through field survey for the characteristics of buildings that are even not available from the local authorities. Nevertheless, the field survey can be time consuming depending on the size of the area under investigation.

A second important issue is related to the weighing of the indicators. Due to the lack of quantitative information about the contribution of a particular attribute for controlling the vulnerability of a building, an expert-based approach has been adopted in the proposed methodology. Apart from the selected attributes, there are several other factors, which are not included in the present framework. For instance the so-called 'shadow effect' where smaller buildings might be protected from the blast of an explosion, because a taller building standing close to it in between the small building and the explosion site, plays an important role in controlling the degree of vulnerability of a building. Therefore it is expected that inclusion of more attributes also changes the weight of individual attributes for a particular effect. In addition to that, the importance hierarchy of the indicators varies 
significantly as it depends on the purpose of the assessment. For example, the height of a building may be important for the emergency management because it enables vertical evacuation, however, when the focus of the study is not the threat to life but the economic loss, the height of the building might be less important than the percentage of the building which is affected. While on the other hand, the vulnerability ranks are supposed to be only effect-specific but not user-specific, whereas the weights are both effect and user-specific. Therefore weighting of the attributes should be chosen by users according to his priorities and the purpose of his assessment.

The third disadvantage is the sensitivity of the results which depend on the weighting of the attributes. For example, according to the present weighting two buildings with different material type are very likely to belong to different vulnerability categories although the rest of their characteristics might be quite similar. On the contrary, buildings made of similar material although they might differ significantly as far as the surroundings is concerned might belong to the same vulnerability class. Although this can be considered as a disadvantage of the approach, it highlights the importance of the fact that in this framework the weighting is flexible and the user can weigh the factors according to their priorities. To overcome this difficulty, it is recommended that a non-linear regression sensitivity analysis needs to undertake in order to determine which attribute within the database has the most significant effect on the overall vulnerability of a building.

Based on these above mentioned observations, it can be concluded that the methodology could further be improved focusing on the acquisition of better quality data, the identification of exposed areas and the modification of the framework to include associated phenomena.

In this study, we consider only the physical or structural vulnerability of buildings. Further improvement could be made to include information on the distribution and characteristics of people to assist the decision makers in effective response strategy or mitigation measures. Also building-level population should be used to model where and how many people are located at different temporal scenarios (i.e. day time, night time). 


\section{Chapter 9 - Synthesis}

The main research question discussed in this thesis examines the relationship between different aspects of industrial risk management in an Indian context and to investigate the challenges which are lying in the way for factoring the risk criteria for planning the uses of land around the hazardous installations. From this strand, the first part of the thesis (chapter 2-4) presents an overview of risk and safety related issues in context of land use planning decisions, and a perspective of the current situation prevailing in India, thereby setting the context for this research. The second part of the thesis (chapter 5-8) deals with application of the proposed methodologies with reference to the case study area, Haldia as introduced in Chapter 5. Chapter 6 focuses on the preparation of the spatial databases for further analysis. Chapter 7 reviews the applicability of a QRA-based approach for risk assessment in an Indian context for estimating the cumulative risk level originating from a cluster of hazardous industries to identify the shortcomings in the existent practice. Thereafter, Chapter 8 demonstrates the application of proposed indicator-based method for vulnerability assessment. This final chapter provides a synthesis of the key issues discussed in the thesis and concludes with a proposal for a risk-based land use planning framework based on these findings.

\subsection{Consolidation of the research framework}

In this section, the research framework as described in the introductory chapter is further consolidated (Figure 9.1) and re-examine its relevance with regard to the research questions and the probable solutions arrived at through this research. Following is a summary and discussion based on the theoretical perspectives, methodological aspects and application context of this research.

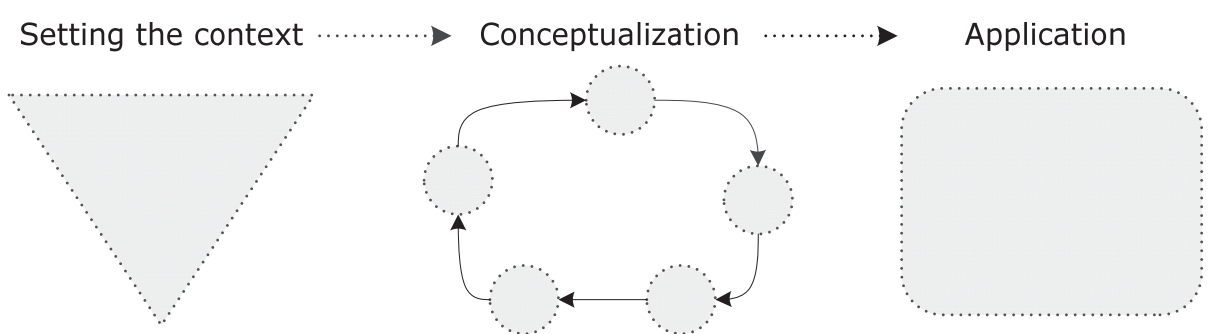

Figure 9-1: Research framework 


\subsection{Setting the context}

\subsubsection{Understanding issues pertaining to governance and management of industrial risk in the Indian context}

Reviews showed that in the post-Bhopal era, considerable progress has happened worldwide and more specifically in India in formulating and implementing regulations and programmes to prevent the recurrence of such incidents. However, even 30 years after the tragic accident, the gravity of aspects related to governance of industrial risk in a densely populated country like India, witnessing fast paced development, still remains crucially important. In brief, there is no overarching policy framework on governance of industrial risk, except certain inter-linkages between other related policy statements like the disaster management policy, environmental policy and the draft land use utilisation policy.

On the regulatory front, there are certain specific provisions of industrial risk regulations focusing on identification of hazards, application of management tools like safety audits and risk assessment etc. However, the scientific basis for these regulations is yet not well established. For example, there is no unified philosophy or principle which governs the risk assessment process that may result in the characterization of risk based on certain acceptable criteria as a benchmark for risk evaluation. More importantly, its little more than 30 years of Bhopal, there is yet no guideline to link properly risk assessment process with land use planning decisions. Even more, no effort has been made so far where the land use planning process around hazardous installations either scientifically examined or thoroughly analysed as a tool for risk reduction. The interactions with the local planning agency carried out as a part of this research revealed that because of the technicalities involved in the process of industrial risk assessment, the planners are ill equipped to factor risk into the planning process. Additionally, there is an absence of a methodology for considering risk factors along with other spatial planning factors in the existent land use planning process at local level. Indeed, dearth of knowledge about in which ways the planning process can be improved and/or on what grounds the planning authorities should make their decisions. All these factors together accounts for inadequate understanding of risk reduction measures, thereby lead towards unplanned and haphazard development of the area. In addition to that, there are weaknesses in the institutional framework to implement any of the above issues. A number of competent authorities both at federal and state level are responsible for regulating risk being present. But the responsibilities of these competent authorities with regard to effective implementation and monitoring of compliance to regulatory provisions are not well laid out in regulations. In view of such existing gaps in policy and regulatory framework, it is expected 
that in continuation with earlier practices, levels of industrial risk will continue to increase in the industrial clusters where development is on-going.

\subsubsection{Rationale to design a methodology for estimating industrial risk - its use as an indicator for guiding land use planning decisions}

Reviews showed that the underlying set of theories and methods on industrial risk assessment, evaluation and its application to planning, as it has been developed and applied in other parts of the world, especially in Europe, are quite different in nature. As well known, Article 12 of Seveso II Directive requires the EU Member States to consider, within their land-use planning policies, the need for defining appropriate safety distances between dangerous establishments and urban, natural and infrastructural developments. In this respect, safety distances are risk acceptability criteria, as they affect the land-use destinations of the surroundings of Seveso sites. Accordingly, different approaches for risk assessment and acceptability or tolerability criteria fulfilling the Seveso II requirements were developed in the Member States in accordance to geographical, regulatory and societal background of the country.

On contrary, an in-depth analysis of the Indian system revealed that there is presently no such systematic framework for industrial risk assessment and risk acceptability criteria which then led to the adoption of suitable risk reduction strategies. In particular, the regulations or associated guidance's do not provide any clarity on methods to be used for consequence estimation, consideration of probability for accidental events, generation of scenarios for probable or worst case accidents, or even for calculation of risk value based on which a consistent evaluation of risk at the industrial cluster or area level can be undertaken. In addition, the lack of risk acceptability criteria stipulated through any regulation is making it difficult for planners or decision makers to achieve a satisfactory goal for safety or to decide a level to which risk has to be reduced through planning interventions. But nonetheless, the outcome of the benchmarking studies as undertaken in the EU Member States, clearly demonstrate that lack of a harmonised or standard methodology can lead to substantial variation in results of risk assessment and may lead to decisions which may not consistent or robust. In addition, the results pinpointed some of the main sources of potential uncertainty in these assessments, confirming at the same time that each phase of the risk assessment process is subjected to a high degree of uncertainty.

In this setting, the existing situation provides considerable opportunity to identify challenges that lie in the way of introducing a standardised approach for risk assessment in an Indian context; hence reinforce the need to conceptualize methodologies for risk and vulnerability assessment, as a likely 
solution for planners. Based on this appreciation and learning from the practices as developed and applied in EU Member States, a simplified methodology adapted from contemporary quantitative risk assessment (QRA), and an indicator-based approach for risk and vulnerability assessment have been conceptualized accordingly. For the ease of application and visualization core of the proposed methodologies is a GIS-based platform.

\subsection{Identification of the information to estimate risk}

Lack of adequate information about the storage and handling of hazardous materials amongst relevant stakeholders, was one of the key factors for causing higher than expected damages, as demonstrated in many historical cases including the Bhopal accident. Learning the lessons from the higher magnitude of this accident and many others, the need for up-to-date information about hazardous facilities, vulnerable communities, population, land use map of the vicinity area, became more relevant so as to provide a more effective situation assessment. Accordingly, many EU Member States put effort to create different databases including industry land use, spatial distribution of population etc. along with geographical dimension. On contrary, reviews showed that no effort has been made so far in Indian this regard, except the ERRIS project. Through this project an effort to consolidate the industry-level information was first made which was implemented in the industrial towns of Haldia and Durgapur in the State of West Bengal in 2006. Moreover, in many cases it has been found that considerable amount of data still remaining in paper format that do not allow for cross disciplinary use by others.

From this standpoint, this research identified the set of data or information need to collect and collate together to carry out industrial risk assessment and further integrated to model a risk-informed land use planning framework. From methodological point of view, any risk-based land use planning framework stands on two main pillars, viz. risk analysis and land use. The applicability such framework therefore relies on availability of information pertaining to industry to map the extent of an accident scenario as well as information relates to land use, population etc. for assessing how certain elements that may be impacted by such an event, hence to compute risk profile of the area under consideration. However, in most cases, such datasets are not readily available in an Indian situation. Consequently, based on the real world objects representing hazards, elements at risk etc., databases related to hazardous industry, cadastre-level land use, building, population prepared for the purpose with reference to the case study area, Haldia.

Industry database 
A significant component of industrial accident risk analysis comprises the data on accident scenario originating either from the fixed or mobile sources; as well as information about facility to understand geographical extent of the facility, the main process the industry is running, the storage conditions, and nature of the hazardous chemical involved, etc. Therefore, identification and characterisation of the hazardous source using a planned exercise in collaboration with the industries, is considered to be an important step in the risk assessment process. Such industry-level information used in this research was primarily developed as a part of the ERRIS Project.

\section{Cadastre-level land use database}

Cadastre information in the form of parcel-level land use map of the area under consideration is another important requisite of the proposed riskinformed land use planning framework in order to understand how certain land uses and the property they characterise, may be impacted by industrial accidents. Accordingly, the planners and the decision makers can adopt policies and plans involving zoning and rehabilitation in order to control or reduce risks associated with a particular land use, e.g., a cluster of hazardous industries, thereby to attain sustainable development of the area. In this regard, internationally there has been a lot of movement to create the Digital Cadastral Database (DCDB) in a referenced spatial framework in the last couple of decades. However, India has remained away from such developments and is yet to reach a position of competence. A few exceptions apart, no significant efforts have been made so far to revise or update the colonial cadastral maps and registers. As a result, the maps and land records available today are mostly outdated and do not always reflect the realities on the ground.Nevertheless, updating of the colonial maps and related registers is anticipated to be very cumbersome for the conventional setup that prevails in India. In this direction, a methodology to construct a seamless cadastral database using the colonial paper-based cadastral maps and VHR satellite imagery, first in its kind in India, is introduced in this research. Usingthis approach, a seamless cadastral land use mapwith acceptable level of accuracywas prepared accordingly for the Haldia planning area.

\section{Building database}

The structural condition of the buildings is one of the indicators to determine the vulnerability of its inhabitants. This aspect is crucially important for a country like India, where urban areas in the close vicinity of the hazardous industries, have wide variability in building types and construction methods from informal hutments to buildings made of concrete. Therefore, a proper understanding of vulnerability of such built environment on an individual basis provides the base for preparedness and mitigation strategies, which in 
turn can reduce the loss of life. In case of an industrial accident, regardless of distance from hazardous industry, not every building within the same exposure zone is equally vulnerable. Depending on structural condition including type of construction, roof material, height, air-infiltration capacity, etc., a particular building either may completely or partially damaged or experience some distortion in response to an accident scenario. In addition, the surroundings of a building like spacing between individual buildings, distance from water body etc., play an important role by offering protection from different physical effects of an accident. With this insight, a building inventory compiling the detailed information about building characteristics and its surroundings was prepared to assess consequence of an accident scenario on a built-environment. For the purpose, a building-level survey was conducted in heterogeneous residential areas within the case study area.

\section{Population database}

An estimate of population size and its spatial distribution is another crucial aspect for risk assessment to calculate societal risk level of an area under concern. In India, Census is the major source for population information. However, the database does not provide information about the spatial distribution of population within a particular census tract; therefore cannot be used for planning or management issues. This aspect is more important for an industrial accident. For instance, in case of a toxic release event, it might need to estimate the number of people for a smaller area within a certain tract, or for an area combining the parts of different tracts, depending on the plume direction. However, currently no dataset is available in India which can provide such information. Accordingly, a database was prepared by areal interpolation of the Census data based on cadastral-level land use map as prepared following the methodology.

\subsection{Application of a simplified QRA-based approach in the case study area}

As mentioned above, at present, there is no standardised and consistent methodology that can be used by regulators, industry or other stakeholders for estimating risks. In view of that, an investigation was carried out to test the applicability of a QRA-based approach for risk assessment in an Indian context. Through the analysis of some reference plants located in the case study area, the study highlighted the current difficulties that an analyst has to face to determine confident risk maps as a basis for land use planning due to lack of guidelines.

The outcome of the study is two-fold: on one side it can lead to backward linkage with harmonization of industrial risk assessment method based on 
standards and criteria as acceptable to the risk management actors; whereas on the other hand there is a scope for using the results in the exploration of forward linkage with the adoption of risk-informed land use planning strategies based on agreed levels of acceptable risk at the societal level as has been developed and applied in the Western European countries.

\subsection{Application of indicator-based approach for vulnerability assessment in the case study area}

The assessment of increasing vulnerability of the communities is of a growing concern; particularly for a country like India where industrial clusters are often co-exist with densely populated areas. As a result, the nearby people are getting exposed to the threats of release of toxic substances, explosions and/or fires. In such cases, the degree of vulnerability of people rises as further industrial development takes place. On top of that, these areas also witness a steady growth of population resulting from in-migration of people to take advantage of jobs and other livelihood opportunities generated by these industries. In order to safeguard such vulnerable communities, it is therefore vitally important to understand the potential impacts of different physical effects of an accident scenario on the built environment.

In this line, an indicator-based approach is introduced that allows coherent assessment of vulnerability in response to fire, explosion and release of toxic gas event. The central idea of this proposed approach is to develop a semiquantitative estimate of risk and vulnerability, taking into account a series of measureable attributes, which are then used as indicators. Using MCE technique, a risk score was then calculated by combining the relative ranks and weights as assigned to the indicators based on expert's judgment. The proposed framework has been tested in the case study area, using the information and dataset prepared for the purpose. Nonetheless, important to mention, the proposed framework is designed in such a way so that it can be applicable for any industrial town in India. Important to mention, the outcome of this approach provides a system for development of vulnerability related indicators, which further can be taken into account for guiding the land use planning decisions at local level.

\subsection{Proposal for a risk-informed land use planning framework}

It is to be noted that land is an economic good. Thus, while there is a need for establishing sufficient separation distances to eliminate intolerable risks at the same time one has to consider that it does not unduly restrict development around the industrial set ups and waste valuable resource like land. Other socio-economic considerations such as contribution of the establishment for the national economy, infrastructure (roads, power, 
communication etc.), employment opportunities, and benefits for the local community from the operation of the plant also constitute additional objectives. Moreover, the stakeholders including industry, authorities, employees, the population and other interest groups may have a conflict of interests and values. For example, the industry may be financially motivated to solve most of the problems, whereas the local population may be concerned more about the environment and the local authorities about employment generation or development of the region.

The trade-off between the increase in socio economic benefits vis-à-vis decrease in human safety due to increase in the risk imposed on the surrounding population by the industrial establishment should be made explicit. The first essential point to note is that unlike most of the European countries with well-defined LUP frameworks and criteria, India is an emerging economy. Therefore, the focus as well as priority on industrial development is relatively high as compared to the developed nations. Development of national industrial zones clearly have shown that setting up of industrial facilities not only increases the money flow in the region and creates jobs but also supports the evolution of infrastructure on the boundaries of the establishments with time. Stricter risk limits for example increases the amount of unused land around the facility and pushes the development of resources farther from the industry. Thus, even though the industrial risks to human population and environment are critical, it is important to address its relevance and weight for an emerging economy.

The next attribute which is equally essential is the diverse nature of Indian state. To start with, the states differ in their land use patterns and resources such as eco-sensitive regions, coastal regions, tribal regions, historical monuments, transportation routes to the facility, safety and security aspects, location of defence establishments, etc. The level of development and priorities differ drastically from one state to another due to variation in the size of industry and priority to growth; need to create jobs, protection of biodiversity areas etc. Thus, there is also a need to for a planning framework which concurs with the above attributes of a country like India.

Human attitudes concerning the plant being set up can vary significantly and may often hinder development. This creates conflicts. The acceptance of a new industrial facility can be made more acceptable to the local population and thus improve the sitting of such facilities by introducing the following:

Joint Fact Finding: Local people may get lost if the siting decision is made on technical grounds that are too complex for the lay man to grasp. Thus, the investigations of facts and probable impacts should be collaborative to make a good decision. 
Reducing Risk: Even if the forecast is done according to the consensus of all stakeholders, they may not all react in the same manner to the information generated. Thus spreading risk or reducing it becomes necessary which can be achieved using insurance schemes. The local people may not resist the setting up of a project if they are guaranteed the current value of their lands or homes plus inflation.

Promising to Mitigate: Stakeholders need conviction that the promises to mitigate unexpected adverse effects will be kept. This can be done by posting a bond or empowering an independent actor through pre-negotiated contracts to hold the parties to their word or phasing a project so that the latter stages proceed only if earlier commitments are honoured. Further, efficient modes of compensation to affected stakeholders, and declaration of shared responsibility of monitoring the facility need to be ensured.

A critical aspect of designing the risk based LUP framework includes setting up of risk tolerability limits for the country. The individual risk limits considered in practice in India are often derived from European countries. However, the risk of living in each country is different owing to difference in health facilities, resource, and economic landscape and so on.

Acceptance of an activity in the society is based on the perceived benefits of the activity vis-à-vis the risk from the activity. To derive the proposed acceptance criteria for India, it would be valuable to calculate several voluntary and involuntary risks borne by an Indian in several day to day activities. Such a basis of risk limit would imply different numbers for risk limit for different countries based on fatalities and risk associated with voluntary activities in that country. Risk limit for India calculated by this method could be argued to be different than that prevalent in Europe given the fact that in developed countries risk borne by a citizen may be less than that in India due to better medical facilities and emergency services.

Even though such a method for devising limit appears logical, it has its own short-comings. Several voluntary and involuntary activities which citizens indulge in have different risks associated with it. The fatality data for all these activities is not readily available to be analysed to form a risk limit. Secondly, the activities which involve voluntary risks differ considerably between citizens depending on their lifestyle. What might be a typical combination of activities in cities may be not be relevant for those in villages where industries are being set up today.

To analyse possible limits for risk in India, Atomic Energy Regulatory Board, Mumbai examined in 2007 the available fatality data due to road accidents (voluntary risk) and lightning striking (involuntary risk). During the years 
1995-2006 the average individual risk of death (no. of deaths/year/total population) due to road accidents was $8.2 \times 10^{-5}$, while for deaths due to lightning the average risk was $1.76 \times 10^{-6}$.

Therefore it may be proposed that no risk greater than that due to road travel in India can be tolerated from an industrial activity, whether existing or new (maximum tolerable risk to a member of public is approximately $10^{-4}$ ) while acceptable risk to an individual from facility should be lower than the probability of death due to lightning (approx. 10-6). The activities with individual risk value below the acceptable risk level can be readily admitted. The activities posing individual risk values beyond the maximum tolerable risk should not be tolerated. However, although such an estimate provides a good estimation for possible risk limit for India, it can be argued that there exist several other voluntary and involuntary activities which can be used as the basis for risk tolerability criteria instead of road accidents and lightning. Once such risk limits are accepted, LUP may be executed on the basis of the principle that land areas peripheral to a process plant (for example) are demarcated as high, medium and low risk zones. The usage of the land may be accordingly fixed so that acceptable risk - individual or societal - to the public is ensured.

Therefore, a rationale Land Use Planning (LUP) framework can help ensuring that the likelihood and the consequences of the potential accidents are taken into consideration during sitting of hazardous installations and extension or modifications of existing installations. Other issues which might be indispensable to address in the process of implementing an improved LUP framework are availability of consolidated data for local factor selection and valuation, rehabilitation of the local community, subjective value-based trade-offs etc. Yet another important consideration is to formulate policies compatible with both old and new developments. With the progress of the economy, the risk tolerability limit should ideally also become more stringent. Time dependent risk limits are complicated to implement though they ensure that the implications of the increased risks are not be paid by the future generations. Finally, since the available land resource of the country is limited, it is also imperative to study the land types and use patterns across country at the central level (beyond the state boundaries) and find out on the basis of set a development goal for the country, the most suitable sites for industrial development which leave maximum utilization of agriculturally fertile land, environmentally bio-diverse area and sustainable forest cover.

Having said this, a proposal for a risk-based land use planning framework should include a number of strategies feasible for addressing the gaps as elaborated in this study. 
One needs to consider the establishment of a contextual, customized risk tolerability criterion. While setting a national limit to the Individual Risk (IR) would ensure that no person is subjected to a very high risk, it does not differentiate whether the number of people exposed to the risk is big or small. This makes it difficult to prioritize and develop a LUP. Thus, prioritizing LUP on the basis of population surrounding the facility may be essential. To consider this aspect, one may need to introduce population density in the tolerability criteria by using Societal Risk or its variant in the overall risk criteria. Integrating individual risk with the societal risk or its variant may mitigate the effects of possible large scale accidents, as, if a population centre is located close to a "safety distance" it is possible that a major accident would claim a large number of victims.

However, societal risk in its nascent form does not include the local priorities of the state. Thus, there is a need to evolve a variant of societal risk which would be more compatible to be used given different state wise priorities in India. Well-structured procedures and robust risk criteria at a national level would ensure that no person is exposed to extremely high-danger situations. It is, however, the local (state) level, where the relevant decisions are going to be made, and it is the local society that is going to confront the implications of these decisions. The criteria established at a national level may be based primarily on safety grounds. However, since development levels are unequal in various Indian states, it may be necessary to keep the risk limits flexible for customization (i.e., rendering them more stringent wherever necessary) at local level so as to include the state-wise priorities.

\subsection{Future research}

Following the 1984 Bhopal disaster, there is an increased activity in the Indian research and academic community, which is evident in terms of publications in science and engineering journals. These articles mainly cover a wide variety of safety topics ranging from clinical studies to estimate toxicity, risk management, design and manufacturing processes, environmental, regulatory issues, etc. On contrary, research on governance and management of industrial risk particularly from the spatial policy and planning context, has been few and far between, if the number of related publications are taken into account. In particular, not many researches have been placed so far for investigating the interaction between related domains of risk mitigation and spatial planning.

With this background, through this research a link has been established to bridge the gap between traditionally two independent domains - industrial risk management and land use planning. It is expected that conceptualization of the risk-based land use planning framework and design of the set of 
information would generate further research interest on how risk policies, regulations and methods can be formulated and applied in practice to make way for a safer society in India. Additionally, investigations to explore the possible implementation of these methodologies at different scale would also result in research on how such framework can be refined and adapted to fulfill the needs of the risk actors. 


\section{Bibliography}

Abbasi, T., \& Abbasi, S.A. (2005). The Expertise and the Practice of Loss Prevention in the Indian Process Industry: Some Pointers for the Third World. Process Safety and Environmental Protection, 83(5), 413-420. doi: http://dx.doi.org/10.1205/psep.04210

AIChE/CCPS. (2000). Guidelines for Chemical Process Quantitative Risk Analysis (2nd Edition): Center for Chemical Process Safety.

Ale, B. J. M. (1991). Risk analysis and risk policy in the Netherlands and the EEC. Journal of Loss Prevention in the Process Industries, 4(1), 58-64. doi: $10.1016 / 0950-4230(91) 80008-i$

Ale, B.J.M. (1993). Dealing with risk of fixed installations in The Netherlands. Cryogenics, 33(8), 762-766. doi: 10.1016/0011-2275(93)90184-p

Ale, B.J.M. (2002a). Risk assessment practices in The Netherlands. Safety Science, 40(1-4), 105-126. doi: http://dx.doi.org/10.1016/S09257535(01)00044-3

Ale, B.J.M. (2002b). Risk assessment practices in The Netherlands. Safety Science, 40(1-4), 105-126. doi: Doi: 10.1016/s0925-7535(01)00044-3

Ale, B.J.M. (2005a). Living with risk: a management question. Reliability Engineering \& System Safety, 90(2-3), 196-205. doi: $10.1016 /$ j.ress.2004.10.015

Ale, B.J.M. (2005b). Tolerable or Acceptable: Comparison of Risk Regulation in UK and NL. Risk Analysis, 25(2), 231 - 241. doi: 10.1111/j.15396924.2005.00585.x

Amendola, A., Contini, S., \& Ziomas, I. (1992). Uncertainties in chemical risk assessment: Results of a European benchmark exercise. Journal of Hazardous Materials, 29(3), 347-363. doi: 10.1016/0304-3894(92)85041$X$

Amendola, A., Egidi, D., Foraboschi, F.P., \& Spadoni, G. (1995). ARIPAR Project: analysis of the major accident risks in the Ravenna area. Reliability Engineering \& System Safety, 49, 75 - 89.

American Industrial Hygiene Association (2008) Emergency Response Planning Guidelines (ERPG) and Workplace Environmental Exposure Levels (WEEL) Handbook: Aiha.

Aven, T. (2007). A unified framework for risk and vulnerability analysis covering both safety and security. Reliability Engineering \& System Safety, 92(6), 745-754. doi: http://dx.doi.org/10.1016/j.ress.2006.03.008

Ayres, R.U., \& Rohatgi, P.K. (1987). Bhopal: Lessons for technological decision-makers. Technology in Society, 9(1), 19-45. doi: 10.1016/0160791x(87)90028-5

Baesi, S., Abdolhamidzadeh, B., Hassan, C.R.C., Hamid, M.D., \& Reniers, G.L.L. (2013). Application of a multi-plant QRA: A case study investigating the risk impact of the construction of a new plant on an existing chemical 
plant's risk levels. Journal of Loss Prevention in the Process Industries, 26(5), 895-903. doi: http://dx.doi.org/10.1016/j.jlp.2012.11.005

Bandyopadhyay, D., \& Paul, N. (2008). ERRIS: A GIS Based Framework for Managing Industrial Risks in India. Paper presented at the Municipalika: Making Cities Work, Mumbai, India.

Bandyopadhyay, D., Sengupta, A., van Westen, C.J., \& van der Veen, A. (2011). Bridging risk management deficits in India using a geo-ICT based tool. ITC Working Paper Series. ITC. Enschede.

Bandyopadhyay, D., Paul, N., Sengupta, A., van Westen, C.J., \& van der Veen, A. (2013). Bridging industrial risk management deficits in India using a Geo - ICT based tool. In: Disaster management and risk reduction: role of environmental knowledge / ed by A.K. Gupta et al. New Delhi: Narosa, 2013. ISBN 978-81-8487-251-4. pp. 99-110.

Bandyopadhyay, D. (2016). Information, Decision And Planning Support For Industrial Risk Management In India. PhD thesis, University of Twente, the Netherlands, $170 \mathrm{pp}$.

Basta, C., Neuvel, J.M.M., Zlatanova, S., \& Ale, B.J.M. (2007). Risk-maps informing land-use planning processes: Netherlands and United Kingdom. Journal of Hazardous Materials, 145(1-2), 241-249. doi: 10.1016/j.jhazmat.2006.11.032

Basta, C., Struckel, M., \& Christou, M.D. (2008). Overview of Roadmaps For LUP (IPSC, Trans.) Technical Report. Italy: JRC.

Bhaduri, B., Bright, E., Coleman, P., \& Urban, M.L. (2007a). Landscan USA: A high-resolution geospatial and temporal modeling approach for population distribution. Geo Journal(69), 103 - 117. doi: 10.1007/s10708-007-91059

Bhaduri, B., Bright, E., Coleman, P., \& Urban, M.L. (2007b). LandScan USA: a high-resolution geospatial and temporal modeling approach for population distribution and dynamics. GeoJournal, 69(1-2), 103-117. doi: 10.1007/s10708-007-9105-9

Birkmann, J. (2006): Measuring Vulnerability to Natural Hazards - Towards Disaster Resilient Societies (Ed.), United University Press, pp 524

Birkmann J (2007) Risk and vulnerability indicators at different scales: Applicability, usefulness and policy implications. Environ Hazards 7:20-31

Bisarya, R.K., \& Puri, S. (2005). The Bhopal gas tragedy-A perspective. Journal of Loss Prevention in the Process Industries, 18(4-6), 209-212. doi: http://dx.doi.org/10.1016/j.jlp.2005.07.006

Blong, R. (2003). A new damage index. Natural Hazards(1), 1-23.

Bottelberghs, P.H. (2000a). Risk analysis and safety policy developments in the Netherlands. J. Hazard Mater., 71(1-3), 59-84. doi: 10.1016/S03043894(99)00072-2

Bottelberghs, P. H. (2000b). Risk analysis and safety policy developments in the Netherlands. Journal of Hazardous Materials, 71(1-3), 59-84. doi: 10.1016/S0304-3894(99)00072-2 
Bowonder, B., \& Miyake, T. (1988). Managing hazardous facilities: Lessons from the Bhopal accident. Journal of Hazardous Materials, 19(3), 237-269. doi: http://dx.doi.org/10.1016/0304-3894(88)80025-6

Boybeyi, Z., Raman, S., \& Zannetti, P. (1995). Numerical investigation of possible role of local meteorology in bhopal gas accident. Atmospheric Environment, 29(4), 479-496. doi: http://dx.doi.org/10.1016/13522310(94)00279-T

Broughton, E. (2005). The Bhopal disaster and its aftermath: a review. Environmental Health: A Global Access Science Source(46), 3-6. doi: doi: 10.1186/1476-069X-4-6

BRZO. (1999). Besluit Risico's Zware Ongevallen 1999. Staatsblad 234.

Büchele, B., Kreibich, H., Kron, A., Thieken, A., Ihringer, J., Oberle, P., Nestmann, F. (2006). Flood-risk mapping: contributions towards an enhanced assessment of extreme events and associated risks. Nat. Hazards Earth Syst. Sci., 6(4), 485-503. doi: 10.5194/nhess-6-485-2006

Cahen, B. (2006). Implementation of new legislative measures on industrial risks prevention and control in urban areas. Journal of Hazardous Materials, 130(3), 293-299. doi: http://dx.doi.org/10.1016/j.jhazmat.2005.07.029

Calvi G.M., Pinho R, Magenes G, Bommer J.J., Restrepo-Velez L, Crowley H (2006) Development of seismic vulnerability assessment methodologies over the past 30 years. ISET J Earthq Technol 43(3):75-104

Carpignano, A., Golia, E., Di Mauro, C., Bouchon, S., \& Nordvik, J. P. (2009). A methodological approach for the definition of multi-risk maps at regional level: first application. Journal of Risk Research, 12(3-4), 513-534. doi: $10.1080 / 13669870903050269$

Casal, J. (2008). Chapter 8 Quantitative risk analysis Evaluation of the Effects and Consequences of Major Accidents in Industrial Plants (Vol. Volume 8, pp. 291-331): Elsevier.

Chatterjee, T. (2009). Reorienting Environment Policy in India towards a local area-based development and management paradigm. Journal of Transdisciplinary Environmental Studies, 8(1), 1-16.

Chouhan, T.R. (2005). The unfolding of Bhopal disaster. Journal of Loss Prevention in the Process Industries, 18(4-6), 205-208. doi: http://dx.doi.org/10.1016/j.jlp.2005.07.025

Christou, M.D., Amendola, A., \& Smeder, M. (1999a). The control of major accident hazards: The land-use planning issue. Journal of Hazardous Materials, 65(1-2), 151-178. doi: 10.1016/S0304-3894(98)00261-1

Christou, M.D., \& Porter, S.E. (1999b). Guidance of Land Use Planning as required by Council Directive 96/82/EC (SEVESO II) European Commission.

Christou, M.D., \& Mattarelli, M. (2000). Land-use planning in the vicinity of chemical sites: Risk-informed decision making at a local community level. 
Journal of Hazardous Materials, 78(1-3), 191-222. doi: 10.1016/s03043894(00)00223-5

Christou, M.D, Struckl, M., \& Biermann, T. (2006a). Land use planning guidelines in the context of article 12 of the Seveso II Directive 96/82/EC as amended by Directive 105/2003/EC: European Commission Joint Research Centre, Institute for the Protection and Security of the Citizen, EUR 22634 EN FR DE.

Christou, M.D., Struckel, M., \& Bieerman, T. (2006b). Land Use Planning Guidelines context of Article 12 of the SEVESO II Directive 96/82/EC as amended by Directive 105/2003/EC (MAHB, Trans.). Ispra: European Commission, Joint Research Centre, Major Accident Hazards Bureau.

Christou, M.D, Gyenes, Z., \& Struckl, M. (2011a). Risk assessment in support to land-use planning in Europe: Towards more consistent decisions? Journal of Loss Prevention in the Process Industries, 24(3), 219-226. doi: http://dx.doi.org/10.1016/j.jlp.2010.10.001

Christou, M.D., Gyenes, Z., \& Struckl, M. (2011b). Risk assessment in support to land-use planning in Europe: Towards more consistent decisions? Journal of Loss Prevention in the Process Industries, 24(3), 219-226. doi: $10.1016 / j$.jlp.2010.10.001

COVO. (1982). Risk analysis of six potentially hazardous industrial objects in the Rijnmond area, a pilot study. Dordrecht, The Netherlands.

Cozzani, V., Bandini, R., Basta, C., \& Christou, M. D. (2006). Application of land-use planning criteria for the control of major accident hazards: A case-study. Journal of Hazardous Materials, 136(2), 170-180. doi: 10.1016/j.jhazmat.2005.12.031

de Freitas, C.M., Porto, M.F.S., de Freitas, N.B.B., Pivetta, F., Arcuri, A.S., Moreira, J.C., \& Machado, J.M.H. (2001). Chemical safety and governance in Brazil. Journal of Hazardous Materials, 86(1-3), 135-151. doi: http://dx.doi.org/10.1016/S0304-3894(01)00251-5

de Souza Porto, M. ., \& de Freitas, C.M. (1996). Major chemical accidents in industrializing countries: the socio-political amplification of risk. Risk Analysis, 16(1), 19-29.

de Souza Porto, M.F., \& de Freitas, C.M. (2003). Vulnerability and industrial hazards in industrializing countries: an integrative approach. Futures, 35(7), 717-736. doi: 10.1016/s0016-3287(03)00024-7

Delvosalle, C., Fiévez, C., Pipart, A., Fabrega, J.C., Planas, E., Christou, M.D., \& Mushtaq, F. (2005). Identification of reference accident scenarios in SEVESO establishments. Reliability Engineering \& System Safety, 90(2-3), 238-246.

Delvosalle, C., Fiévez, C., \& Pipart, A. (2006a). ARAMIS: Reference Accident Scenarios Definition in SEVESO Establishment Journal of Risk Research, 9(July 2006), $583-600$.

Delvosalle, C., Fievez, C., Pipart, A., \& Debray, B. (2006b). ARAMIS: A comprehensive methodology for the identification of reference accident 
scenarios in process industries. Journal of Hazardous Materials, 130(3), 200-219. doi: 10.1016/j.jhazmat.2005.07.005

Eckerman, I. (2005). The Bhopal gas leak: Analyses of causes and consequences by three different models. Journal of Loss Prevention in the Process Industries, 18(4-6), 213-217. doi: http://dx.doi.org/10.1016/j.jlp.2005.07.007

Eckerman, I. (2013). Bhopal Gas Catastrophe 1984: Causes and Consequences is Reference Module in Earth Systems and Environmental Sciences: Elsevier.

Eduljee, G.H. (2000). Trends in risk assessment and risk management. Science of the Total Environment, 249(1-3), 13-23. doi: http://dx.doi.org/10.1016/S0048-9697(99)00507-0

Engineers, I.O.C. (1992). Nomenclature for Hazard and Risk Assessment in Process Industries. Rugby: IChemE.

ERM. (2002). Preparation of Country level Vulnerability Map for Industrial Hazards: MoEF India.

Fabbri, L., \& Contini, S. (2009). Benchmarking on the evaluation of major accident-related risk assessment. Journal of Hazardous Materials, 162(23), 1465-1476. doi: 10.1016/j.jhazmat.2008.06.071

Flowerdew, R., \& Green, M. (1992). Developments in areal interpolation methods and GIS. The Annals of Regional Science, 26(1), 67-78. doi: 10.1007/BF01581481

Fotheringham, A.S., Charlton, M.E., \& Brunsdon, C. (1998). Geographically weighted regression: a natural evolution of the expansion method for spatial data analysis. Environment and Planning A, 30(11), 1905-1927.

Gehlawat, J.K. (2005). Bhopal disaster-a personal experience. Journal of Loss Prevention in the Process Industries, 18(4-6), 261-263. doi: http://dx.doi.org/10.1016/j.jlp.2005.07.002

Gheorghe, A., \& Vamanu, D. (2004). Decision support systems for risk mapping: viewing the risk from the hazards perspective. Journal of Hazardous Materials, 111(1-3), 45-55. doi: http://dx.doi.org/10.1016/j.jhazmat.2004.02.010

GoI:MoRD. (2013). Draft National Land Utilisation Policy. New Delhi.

Gupta, J. P. (2002). The Bhopal gas tragedy: could it have happened in a developed country? Journal of Loss Prevention in the Process Industries, 15(1), 1-4. doi: http://dx.doi.org/10.1016/S0950-4230(01)00025-0

Gupta, J. P. (2006). Land use planning in India. Journal of Hazardous Materials, 130(3), 300-306. doi: 10.1016/j.jhazmat.2005.07.006

Hauptmanns, U. (2005). A risk-based approach to land-use planning. Journal of Hazardous Materials, 125(1-3), 1-9. doi: 10.1016/j.jhazmat.2005.05.015

Havens, J., Walker, H., \& Spicer, T. (2012). Bhopal atmospheric dispersion revisited. Journal of Hazardous Materials, 233-234(0), 33-40. doi: http://dx.doi.org/10.1016/j.jhazmat.2012.06.055 
Heller, S. (2006). Managing industrial risk--Having a tested and proven system to prevent and assess risk. Journal of Hazardous Materials, 130(12), 58-63. doi: 10.1016/j.jhazmat.2005.07.067

Holden, P.L. (1984). Difficulties in formulating risk criteria. Journal of Occupational Accidents, 6(4), 241-251. doi: http://dx.doi.org/10.1016/0376-6349(84)90013-0

Horlick-Jones, T. (1998). Meaning and contextualisation in risk assessment. Reliability Engineering \& System Safety, 59(1), 79-89. doi: 10.1016/s0951-8320(97)00122-1

Factories Act 1948 as amended by the Factory (Amendment) Act 1987 (1987).

IRGC. (2005). White Paper on Risk Governance: Towards an integrative framework. Geneva.

ISDR. (2004). Living with Risk - A global review of disaster reduction initiatives (Vol. Volume - 1). Geneva: United Nations.

ISDR. (2005). Hyogo framework for action 2005-2015: building the resilience of nations and communities to disasters. Paper presented at the World Conference on Disaster Reduction Kobe, Hyogo, Japan.

Jasanoff, S. (1988). The Bhopal disaster and the right to know. Social Science \& Medicine, 27(10), 1113-1123. doi: http://dx.doi.org/10.1016/0277-9536(88)90306-1

Jonkman, S.N., van Gelder, P.H.A.J.M., \& Vrijling, J.K. (2003). An overview of quantitative risk measures for loss of life and economic damage. Journal of Hazardous Materials, 99(1), 1-30. doi: 10.1016/s0304-3894(02)002832

Khan, F.I., \& Abbasi, S.A. (2002). A criterion for developing credible accident scenarios for risk assessment. Journal of Loss Prevention in the Process Industries, 15(6), 467-475. doi: 10.1016/S0950-4230(02)00050-5

Kirchsteiger, C. (2002). Review of International Industrial Safety Management Frameworks. Trans IChemE, 80(5), 235-244. doi: 10.1205/095758202762277597

Kontic, D., \& Kontic, B. (2009). Introduction of threat analysis into the landuse planning process. Journal of Hazardous Materials, 163(2-3), 683-700. doi: 10.1016/j.jhazmat.2008.07.040

Kontic, D., Kontic, B., \& Gerbec, M. (2006). How powerful is ARAMIS methodology in solving land-use issues? Journal of Hazardous Materials, 130(3), 271-275. doi: 10.1016/j.jhazmat.2005.07.012

Laheji, G.M.H., Post, J.G., \& Ale, B.J.M. (2000). Standard methods for landuse planning to determine the effects on societal risk. Journal of Hazardous Materials, 71(1-3), 269-282. doi: 10.1016/S03043894(99)00083-7

Lahr, J., \& Kooistra, L. (2010). Environmental risk mapping of pollutants: State of the art and communication aspects. Science of the Total 
Bibliography

$$
\text { Environment, 408(18), 3899-3907. doi: }
$$

http://dx.doi.org/10.1016/j.scitotenv.2009.10.045

Lees, F. P. (1996). Loss Prevention in the Process Industries: ButterworthHeinemann.

Lenoble, C., \& Durand, C. (2011). Introduction of frequency in France following the AZF accident. Journal of Loss Prevention in the Process Industries, 24(3), 227-236. doi: 10.1016/j.jlp.2010.09.003

Limaye, P. (2014). Bhopal Accident: Release of MIC. In P. Wexler (Ed.), Encyclopedia of Toxicology (Third Edition) (pp. 446-448). Oxford: Academic Press.

Löfstedt, R., \& Boholm, A. (2009). The Earthscan reader on risk: Earthscan.

Mahmoud, M., Liu, Y., Hartmann, H., Stewart, S., Wagener, T., Semmens, D., Winter, L. (2009). A formal framework for scenario development in support of environmental decision-making. Environmental Modelling \& Software, 24(7), 798-808. doi: http://dx.doi.org/10.1016/j.envsoft.2008.11.010

Mannan, M., West, H.H., Krishna, K., Aldeeb, A.A., Keren, N., Saraf, S.R., Gentile, M. (2005). The legacy of Bhopal: The impact over the last 20 years and future direction. Journal of Loss Prevention in the Process Industries, 18(4-6), 218-224. doi: http://dx.doi.org/10.1016/j.jlp.2005.06.037

Marx, J.D., \& Cornwell, J.B. (2009). The importance of weather variations in a quantitative risk analysis. Journal of Loss Prevention in the Process Industries, 22(6), 803-808. doi: 10.1016/j.jlp.2009.08.009

Matthies, M., Giupponi, C., \& Ostendorf, B. (2007). Environmental decision support systems: Current issues, methods and tools. Environmental Modelling \& Software, 22(2), 123-127. doi: http://dx.doi.org/10.1016/j.envsoft.2005.09.005

McDaniels, T., Gregory, R., \& Fields, D. (1999). Democratizing Risk Management: Successful Public Involvement in Local Water Management Decisions. Risk Analysis, 19(3), 497-510. doi: 10.1023/A:1007060931193

McIntosh, B.S., Ascough Ii, J.C., Twery, M., Chew, J., Elmahdi, A., Haase, D., Voinov, A.A. (2011). Environmental decision support systems (EDSS) development - Challenges and best practices. Environmental Modelling \& Software, 26(12), 1389-1402. doi: http://dx.doi.org/10.1016/j.envsoft.2011.09.009

Mitchison, N. (1999). The Seveso II directive: guidance and fine-tuning. Journal of Hazardous Materials, 65(1-2), 23-36. doi: http://dx.doi.org/10.1016/S0304-3894(98)00251-9

Moen, J.E.T., \& Ale, B.J.M. (1998). Risk maps and communication. Journal of Hazardous Materials, 61(1-3), 271-278. doi: 10.1016/S03043894(98)00132-0

MoUAE, G. (1996). Urban Development Plans Formulation \& Implementation (UDPFI) Guidelines New Delhi. 
NDMA. (2007). National Disaster Management Guidelines, Chemical Disaster (Industrial). New Delhi, India: National Disaster Management Authority, Govt. of India.

NIDM. (2009). Paper presented at the Second India Disaster Management Congress, New Delhi, India.

Nye, J. S., \& Donahue, J. D. (2000). Governance in a Globalizing World. Washington DC: Brookings Institutions.

Pasman, H.J. (2000). Risk informed resource allocation policy: safety can save costs. Journal of Hazardous Materials, 71(1-3), 375-394. doi: http://dx.doi.org/10.1016/S0304-3894(99)00088-6

Pasman, H.J. (2011). History of Dutch process equipment failure frequencies and the Purple Book. Journal of Loss Prevention in the Process Industries, 24(3), 208-213. doi: 10.1016/j.jlp.2010.08.012

Pasman, H.J., \& Reniers, G.L.L. (2014). Past, present and future of Quantitative Risk Assessment (QRA) and the incentive it obtained from Land-Use Planning (LUP). Journal of Loss Prevention in the Process Industries, 28(0), 2-9. doi: http://dx.doi.org/10.1016/j.jlp.2013.03.004

Pe, C.S.P.S.M.D. (2005). Hazard assessment. Lees' Loss Prevention in the Process Industries (Third Edition) (pp. 1-123). Burlington: ButterworthHeinemann.

Pey, A., Lerena, P., Suter, G., \& Campos, J. (2009). Main differences on European regulations in the frame of the Seveso Directive. Process Safety \& Environmental Protection, 87(1), 53-58. doi: http://dx.doi.org/10.1016/j.psep.2008.06.001

Porter, S., \& Wettig, J. (1999). Policy issues on the control of major accident hazards and the new Seveso II directive. Journal of Hazardous Materials, 65(1-2), 1-14. doi: 10.1016/s0304-3894(98)00249-0

Porto, d., F.M., \& Freitas, M. C. (1996). Major chemical accidents in industrializing countries: The socio-political amplification of risk. Insurance: Mathematics and Economics, 18(2), 144. doi: http://dx.doi.org/10.1016/0167-6687(96)81426-0

Punihani, H., Ravi, K., Dikshit, O., \& Tiwari, R.S. (2002). Preparation of Zoning Atlas for Siting of Industries Using GIS. Indian Cartographer, MUIP-07, 282-288.

Renn, O. (1999). A Model for an Analytic-Deliberative Process in Risk Management. Environmental Science \& Technology, 33(18), 3049-3055. doi: $10.1021 /$ es $981283 \mathrm{~m}$

Renn, O. (2006). Participatory processes for designing environmental policies. Land Use Policy, 23(1), 34-43. doi: http://dx.doi.org/10.1016/j.landusepol.2004.08.005

Roodbol, H.G. (1984). Risk Assessment studies in Rijnmond J. of Env. International, 10, 441- 453. 
Salvi, O., \& Debray, B. (2006). A global view on ARAMIS, a risk assessment methodology. Journal of Hazardous Materials, 130(3), 187-199. doi: 10.1016/j.jhazmat.2005.07.034

Salvi, O., Merad, M., \& Rodrigues, N. (2005). Toward an integrative approach of the industrial risk management process in France. Journal of Loss Prevention in the Process Industries, 18(4-6), 414-422. doi: 10.1016/j.jlp.2005.06.030

Sebos, I., Progiou, A., Symeonidis, P., \& Ziomas, I. (2010). Land-use planning in the vicinity of major accident hazard installations in Greece. Journal of Hazardous Materials, 179(1-3), 901-910. doi: 10.1016/j.jhazmat.2010.03.091

SEDAC. (2005). Gridded Population of the World (GPW) v3. from http://sedac.ciesin.columbia.edu/data/collection/gpw-v3

Sengupta, A., Bandyopadhyay, D., van Westen, C.J., \& van der Veen, A. (2011). Adapting a Quantitative Risk Assessment based Method to Guide Land use Planning Decisions in India. ITC Working Paper Series ITC, the Netherlands.

Sengupta, A., Bandyopadhyay, D., Lemmen, C.H.J., \& van der Veen, A. (2012). Constructing a cadastral database using colonial cadastral maps and satellite imagery: an Indian perspective: e-book: International Federation of Surveyors (FIG) International Office of Cadastre and Land Records (OICRF).

Sengupta, A., Bandyopadhyay, D., Lemmen, C.H.J., \& van der Veen, A. (2013a). Potential use of LADM in cadastral data management in India. In: Proceedings of the 5th Land Aministration Domain Model workshop, 24-25 September 2013, Kuala Lumpur, Malaysia. pp. 311-328.

Sengupta, A., Bandyopadhyay, D., Paul, N., Nair, S., \& Gupta, A.K. (2013b). Training module: geoinformatics applications in chemical risk management: e-book. New Delhi: National Institute of Disaster Management (NIDM) Deutsche Gesellschaft für Internationale Zusammenarbeit (GIZ).

Sengupta, A. (2014). Land use planning in India. Loss prevention bulletin(240), 17-20.

Sengupta, A., Bandyopadhyay, D., van Westen, C.J., \& van der Veen, A. (2016). An evaluation of risk assessment framework for industrial accidents in India. Journal of Loss Prevention in the Process Industries. doi: http://dx.doi.org/10.1016/j.jlp.2015.12.012

Sengupta, A., Bandyopadhyay, D., Roy, S., van Westen, C.J. and van der Veen, A. (2016) Challenges for introducing risk assessment into land use planning decisions in an Indian context. In: Journal of Loss Prevention in the Process Industries, 42 (2016), pp. 14-26

SFK/TAA. (2011). Recommendation for separation distances between establishments under the Major Accident Ordinance and Areas requiring protection within the Framework of Land use Planning. 
Sharan, M., \& Gopalakrishnan, S.G. (1997). Bhopal gas accident: a numerical simulation of the gas dispersion event. Environmental Modelling \& Software, 12(2-3), 135-141. doi: http://dx.doi.org/10.1016/S13648152(96)00054-0

Sharan, M., Gopalakrishnan, S. G., McNider, R. T., \& Singh, M. P. (2000). A numerical investigation of urban influences on local meteorological conditions during the Bhopal gas accident. Atmospheric Environment, 34(4), 539-552. doi: http://dx.doi.org/10.1016/S1352-2310(99)00262-9

Sharan, M., McNider, R.T., Gopalakrishnan, S.G., \& Singh, M.P. (1995). Bhopal gas leak: A numerical simulation of episodic dispersion. Atmospheric Environment, 29(16), 2061-2074. doi: http://dx.doi.org/10.1016/1352-2310(95)00031-S

Shrivastava, P. (1995). Democratic control of technological risks in developing countries. Ecological Economics, 14(3), 195-208. doi: 10.1016/0921-8009(95)00016-3

Singh, M.P., \& Ghosh, S. (1987). Bhopal gas tragedy: Model simulation of the dispersion scenario. Journal of Hazardous Materials, 17(1), 1-22. doi: http://dx.doi.org/10.1016/0304-3894(87)85039-2

Spadoni, G., Egidi, D., \& Contini, S. (2000). Through ARIPAR-GIS the quantified area risk analysis supports land-use planning activities. J. Hazard Mater., 71(1-3), 423-437. doi: 10.1016/S0304-3894(99)00091-6

Sriramachari, S. (2004). The Bhopal gas tragedy: An environmental disaster. Current Science, 86(7), 905-920.

Sriramachari, S. (2005). Bhopal gas tragedy: scientific challenges and lessons for future. Journal of Loss Prevention in the Process Industries, 18(4-6), 264-267. doi: http://dx.doi.org/10.1016/j.jlp.2005.06.007

Stern, P.C., Fineberg, H.V., Characterization, C.R., \& Council, N.R. (1996). Understanding Risk: Informing Decisions in a Democratic Society: National Academies Press.

Su, M.-D., Lin, M.-C., Hsieh, H.-I., Tsai, B.-W., \& Lin, C.-H. (2010). Multilayer multi-class dasymetric mapping to estimate population distribution. Science of the Total Environment, 408(20), 4807-4816. doi: http://dx.doi.org/10.1016/j.scitotenv.2010.06.032

Tatem, A.J. and Linard, C., (2011), Population mapping of poor countries, Nature, 474, 36.

Taveau, J. (2010). Risk assessment and land-use planning regulations in France following the AZF disaster. Journal of Loss Prevention in the Process Industries, 23(6), 813-823. doi: http://dx.doi.org/10.1016/j.jlp.2010.04.003

Tixier, J., Dandrieux, A., Dusserre, G., Bubbico, R., Mazzarotta, B., Silvetti, B., Salvi, O. (2006). Environmental vulnerability assessment in the vicinity of an industrial site in the frame of ARAMIS European project. Journal of Hazardous Materials, 130(3), 251-264. doi: 10.1016/j.jhazmat.2005.07.020 
Tugnoli, A., Gyenes, Z., van Wijk, L., Christou, M.D., Spadoni, G., \& Cozzani, V. (2013). Reference criteria for the identification of accident scenarios in the framework of land use planning. Journal of Loss Prevention in the Process Industries, 26(4), 614-627. doi: http://dx.doi.org/10.1016/j.jp.2012.12.004

Tyagunov, S., Grünthal, G., Wahlström, R., Stempniewski, L., \& Zschau, J. (2006). Seismic risk mapping for Germany. Nat. Hazards Earth Syst. Sci., 6(4), 573-586. doi: 10.5194/nhess-6-573-2006

Uijt de Haag, P.A.M. (2013). Reference Manual Bevi Risk Assessments. Bilthoven, the Netherlands: National Institute of Public Health and the Environment (RIVM).

Uijt de Haag, P.A.M., \& Ale, B.J.M. (2005a). Guidelines for Quantitative Risk Assessment (Purple Book), CPR18E (First Edition - 1999 ed.). Den Haag, NL: Committee for the Prevention of Disasters.

Uijt de Haag, P.A.M., \& Ale, B.J.M. (2005b). Methods for the calculation of the physical effects resulting from the the releases of hazardous materials (Yellow Book), CPR 14E (First Edition - 1996 ed.). Den Haag: Committee for the Prevention of Disasters.

van Asselt, M.B.A., \& Renn, O. (2011). Risk governance. Journal of Risk Research, 14(4), 431-449. doi: 10.1080/13669877.2011.553730

van Lier, H. (1998). The role of land-use planning in sustainable rural systems. Landscape and Urban Planning, 41, 83-91.

Versluis, E., van Asselt, M., Fox, T., \& Hommels, A. (2010). The EU Seveso regime in practice: From uncertainty blindness to uncertainty tolerance. Journal of Hazardous Materials, 184(1-3), 627-631. doi: 10.1016/j.jhazmat.2010.08.082

Vierendeels, G., Reniers, G.L.L., \& Ale, B.J.M. (2011). Modeling the major accident prevention legislation change process within Europe. Safety Science, 49(3), 513-521. doi: 10.1016/j.ssci.2010.11.011

Walker, G.P. (1995). Land Use Planning, Industrial Hazards and the COMAH Directive. Land Use Policy, 12(3).

Walker, G.P. (2000). Urban Planning, hazardous installations and blight development conflict. J. of Govt. and Policy, 18, 127 - 143.

Walker, G., Mooney, J., \& Pratts, D. (2000a). The people and the hazard: the spatial context of major accident hazard management in Britain. Applied Geography, 20(2), 119-135. doi: http://dx.doi.org/10.1016/S01436228(99)00032-6

Walker, G.P., Mooney, J., \& Pratts, D. (2000b). The people and the hazard: the spatial context of major accident hazard management in Britain. Applied Geography, 20(2), 119-135. doi: Doi: 10.1016/s01436228(99)00032-6

Wettig, J., \& Porter, S. (1998). Seveso Directive: Background, contents and requirements. In M.D.C. Christian Kirchsteiger \& A.P. Georgios (Eds.), Industrial Safety Series (Vol. Volume 6, pp. 27-68): Elsevier. 
Wettig, J., Porter, S., \& Kirchsteiger, C. (1999). Major industrial accidents regulation in the European Union. Journal of Loss Prevention in the Process Industries, 12(1), 19-28. doi: http://dx.doi.org/10.1016/S0950$\underline{4230(98) 00034-5}$ 


\section{Summary}

It is little more than 30 years since the Bhopal accident occurred in India; but then several weaknesses are still there in the industrial risk governance framework. In this regard, though considerable progress has happened worldwide and more specifically in India, in formulating and implementing regulations and programmes to prevent the recurrence of such incidents; however, the gravity of aspects related to governance of industrial risk, for a densely populated country like India, witnessing rapid development still remains crucially important. Except a few discrete regulations, there is a lack of a holistic approach to be followed for assessing and managing risks arising out of hazardous industries.In particular, there is neither a common guideline on risk assessment method, acceptability or tolerability criteria, probability calculation, nor any recommendation on the risk reduction strategy to be followed for the areas where risk level is already high. Above this, there are weaknesses in the institutional framework to implement any of these issues. On the other side, the Bhopal accident was a wakeup call. The immense loss as a result of the incident, created a worldwide awareness that such event can be managed by formulating stringent planning criteria and zoning restrictions around hazardous industries. Consequently, in view of that, many European Member States were galvanized into bringing more elaborate legislation with regard to siting of and spatial planning around hazardous facilities to reduce the level of risk of surrounding population.

All considered, after 30 years of the tragic accident, the practice which was developed in the Europe, is still missing in India.In particular, there is no regulation or guideline to link properly risk assessment process with land use planning decisions. Moreover, the planning agencies are ill equipped to factor risk into the planning process, because of the technicalities involved in industrial risk assessment. As a result, in continuation with earlier practices, significant increase in the risk level can be noted in more than hundred industrial towns or clusters where development is ongoing. The country is yet to join the tradition of employing risk assessment techniques for land use planning decisions around industrial clusters. With this backdrop, this research is focused on identifying the challenges that lie in the way of introducing a risk-based land use planning framework to promote sustainable development of an industrial cluster in India.

This research takes on from the objectives of the Environment Risk Reporting and Information System (ERRIS) project which was set up as one of the first online spatial information system for industrial risk management in India. As an outcome the national-level workshops and meetings organized as a part of this project, the problems being encountered by the decision-makers and stakeholders while seeking information or to arrive at risk-informed decisions 
were initially identified. In addition, a comprehensive review of the policy, regulatory and institutional framework for industrial risk management in India and different approaches for risk-informed land use planning decision as practiced in EU, has been done to identify key gaps in the current system which need to be bridged. Based on these findings it can be concluded that the current practice and legislation in India is far from being effective for national risk reduction policy. In addition, the land use planning process for an industrial town has yet not been scientifically examined or thoroughly analysed as a tool for risk reduction. Indeed, there has been a lack of knowledge in the ways of the planning process can be improved and/or on what grounds the planning authorities should make their decisions. More importantly, absence of an overarching methodology to combine risk assessment into land use planning decisions to support the sustainable development is making the situation worse.

In this setting, an investigation was carried out in the industrial town of Haldia, to test the applicability of a simplified QRA-based approach for risk assessment in an Indian context. By analysing some reference accident scenarios originating from the hazardous industries located in Haldia, the study underlined the current difficulties that an analyst has to face to determine the 'risk maps' as a basis for land use planning due to lack of guidelines. Result of this study is two-fold: on one side it can lead to backward linkage with harmonization of industrial risk assessment method based on standards and criteria as acceptable to the risk actors; whereas on the other hand there is a scope for using the outcomes in investigating the forward linkage for the adoption of risk-informed land use planning strategies based on agreed levels of acceptable risk as developed and applied in the Western European countries.

Based on this appreciation, an indicator-based semi-quantitative approach for risk and vulnerability analysis has been conceptualized which stands on a Multi-criteria Evaluation technique - a likely solution for the planners to estimate and map the cumulative risk level of an industrial area. The choice of indicator-based approach was made because of unavailability of data or information required for risk assessment as well as for generating the composite risk map that portrays a normative view of the distribution of risk in the area. The set of indicators has been designed and developed based on information on hazards, vulnerability and other related aspects that have a role to play in managing industrial risk. The applicability of the proposed framework has been tested in Haldia using the information and dataset prepared for the purpose. Nonetheless, important to mention, the proposed framework is designed in such a way so that it can be applicable for any industrial town in India. 
Finally, through this research a risk-informed land use planning framework has been proposed to support the planners (both at the local and regional level) by establishing a sound basis for their decision making on issues related to location of the hazardous industries, safety distances, restrictions of land use patterns around them etc. The proposed methodology treats land use planning as a problem of 'Multi-Criteria Decision Analysis'. In the land use planning context alternative uses of land around a hazardous site constitute alternative courses of action and hence alternatives in the sense of the MCDA paradigm. On the other hand the use of land around a site could be given and fixed and the alternative causes of action could consist in the location of a new installation or an extension of an existing installation. In both cases, however, the changes in the sources of risk must have a geographical dimension in order to be characterized as a land use planning alternative. Keeping this in view, the proposed methodological framework designed in a structured format through which the planning alternatives can be assessed and compared. For the ease of application and visualization, central to the proposed framework is a GIS-based platform thus allowing the planners to generate alternatives, select the preferred ones and peruse effective solutions both in terms of implied land use patterns and corresponding consequences.

The success in application of the proposed framework would however depend on several factors, including the availability of up-to-date data or information pertaining to hazardous industries, land use pattern, demographic profile of the area under consideration as well as on the agreement of risk assessment methodology, models to be used for consequence assessment, data sharing among various stakeholders etc. For instance, risk analysis should not be a domain of risk analysts, but a decision maker or planner should be able to apply the same after receiving a basic training. For fast growing industrial areas, land use planners can thus easily consider various risk scenarios and spatially overlay them on the present land use in order to allocate land for future industrial and residential development.

It is expected that the proposed methods would undergo further calibration and refinement, when it is put through evaluation exercises by users, for instance through a stakeholder's workshop. Carrying out evaluation of the methods and benchmarking of the criteria for selection of accident scenario, threshold limit for consequence assessment, uses of consequence model, etc. would be an area for further research on the topic. 


\section{Samenvatting}

Na de Bhopal giframp in India, nu ruim 30 jaar geleden, zijn er nog steeds verscheidene zwakke punten te onderkennen in het kader van industriële risicobeheersing. Hoewel wereldwijd en in het bijzonder in India aanzienlijke vooruitgang is geboekt in het formuleren en toepassen van regelingen en programma's om herhaling van dergelijke incidenten te voorkomen, is nog altijd de ernst van diverse aspecten van industriële risicobeheersing in een dichtbevolkt en snel groeiend land als India van cruciaal belang. Uitgezonderd enkele afzonderlijke regelingen ontbreekt het aan een holistische benadering voor het beoordelen en beheersen van risico's voortvloeiend uit gevaarlijke industriële activiteiten. Met name een gemeenschappelijke richtlijn ontbreekt voor een methode van risicoevaluatie, inclusief criteria voor aanvaardbaarheid en tolerantie als ook de wijze van kansberekening, evenals aanbevelingen betreffende een risicoreductie strategie voor gebieden waar het risico niveau reeds hoog is. Bovendien kent het institutionele kader zwaktes om elk van deze onderwerpen aan te pakken. Natuurlijk fungeerde het Bhopal ongeluk als een wake-up call. De immense gevolgen hebben wereldwijd geleid tot een bewustwordingsproces dat gevaarlijke industriële activiteiten onderworpen moeten worden aan stringente planning criteria en zonering. De gebeurtenis heeft vele Europese landen aangezet tot het ontwikkelen van veelomvattende wetgeving met betrekking tot de locatiekeuze en ruimtelijke planning van risicovolle faciliteiten om het risico voor de bevolking in de directe omgeving te reduceren.

Alles in ogenschouw nemend, ontbreekt 30 jaar na het tragische incident de praktijk, die in Europa is ontwikkeld, nog altijd in India. Met name is er geen regeling of richtlijn die risico-evaluatie op een geschikte wijze koppelt aan besluitvorming rond landgebruik en ruimtelijke planning. Bovendien zijn de planning organisaties slecht uitgerust om het onderwerp risico's in het planningsproces op te nemen, vanwege de specialistische technische aspecten rond industriële risico-evaluatie. Als gevolg van voortzetting van eerdere praktijken kan daarom een significante toename in risico niveaus worden vastgesteld in meer dan 100 industriële steden en complexen, waar ontwikkelingen gaande zijn. Het land moet nog de stap maken naar het gebruik van risico-evaluatie technieken binnen het besluitvormingsproces betreffende ruimtelijke ordening rond industriële complexen. Tegen deze achtergrond richt dit onderzoek zich op het identificeren van de uitdagingen die een introductie van een risico-inclusief ruimtelijke ordeningskader gericht op een duurzame ontwikkeling van een industrieel cluster in India in de weg staan. 
Het onderzoek heeft als uitgangspunt genomen de doelstellingen van het Environment Risk Reporting and Information System (ERRIS) project dat is opgezet als een eerste online ruimtelijk informatiesysteem voor industriële risicobeheersing in India. Als onderdeel van dit project zijn op nationaal niveau workshops en bijeenkomsten georganiseerd om te kunnen vaststellen welke problemen besluitvormers en belanghebbenden tegenkomen bij het verzamelen van informatie of het voorbereiden van risico-gerelateerde beslissingen. Daarnaast heeft een uitgebreide verkenning plaatsgevonden van het beleid, het kader van regelingen en instituties voor industriële risicobeheersing in India, afgezet tegen de verschillende benaderingen voor risico-inclusieve ruimtelijke ordening in EU-landen, met het oogmerk om de voornaamste lacunes vast te stellen in het huidige systeem. Op basis hiervan kan worden geconcludeerd dat de huidige praktijk en wetgeving in India verre van doelmatig is voor nationaal beleid gericht op reductie van risico's. Het ruimtelijk planningsproces voor een industriële stad wordt nog niet wetenschappelijk onderzocht en grondig geanalyseerd als een hulpmiddel om te komen tot risico reductie. Het ontbreekt namelijk aan kennis over hoe het planningsproces te verbeteren en/of op welke informatie planning organisaties hun beslissingen zouden moeten baseren. Belangrijker echter nog - en dit is nog zorgwekkender - is het ontbreken van een overkoepelende methodologie om risico-evaluatie te integreren in het ruimtelijke ordeningsproces gericht op duurzame ontwikkeling.

Tegen deze achtergrond is in de industriële stad Haldia een onderzoek uitgevoerd om de toepassing van een vereenvoudigde kwantitatieve benadering van risico-evaluatie te toetsen in de Indiase context. Door middel van een analyse van enkele referentie rampscenario's gerelateerd aan de risicovolle industrieën in Haldia komt in de studie nadrukkelijk naar voren welke moeilijkheden een onderzoeker in de huidige situatie - als gevolg van het ontbreken van richtlijnen - tegenkomt bij het maken van risico-kaarten in het kader van ruimtelijke planning. Het resultaat van de studie is tweeledig: enerzijds kan het leiden tot een terugkoppeling via harmonisatie van een industriële risico-evaluatie methode gebaseerd op voor belanghebbenden acceptabele standaarden en criteria; anderzijds bieden de uitkomsten perspectief om te komen tot een overname van risico-inclusieve ruimtelijke planning strategieën gebaseerd op aanvaardbare risico's zoals ontwikkeld en toegepast in West-Europese landen.

Vervolgens is een semi-kwantitatieve benadering voor een risico- en kwetsbaarheidsanalyse ontworpen onder gebruikmaking van indicatoren en gebaseerd op een Multi-Criteria Evaluatie techniek - een plausibele aanpak voor planners om het cumulatieve risico niveau van een industrieel gebied te schatten en in kaart te brengen. De keuze voor een benadering op basis van indicatoren is ingegeven door het niet voorhanden zijn van benodigde data of 
informatie voor een risico-evaluatie, als ook om het mogelijk te maken een samengestelde risico-kaart te genereren, die op normatieve wijze inzicht verschaft in de verdeling van risico's over het gebied. De verzameling indicatoren is ontworpen en ontwikkeld op basis van informatie over ongevallen, kwetsbaarheid en andere gerelateerde aspecten die een rol dienen te spelen bij de beheersing van industriële risico's. De toepasbaarheid van de voorgestelde methodiek is getoetst in Haldia met gebruik van speciaal voor dit doel verzamelde informatie en data. Desalniettemin is het belangrijk om te op te merken dat de voorgestelde methodiek zodanig is ontworpen dat het generiek toepasbaar is in elke industriële stad in India.

Het onderzoek presenteert een risico-inclusief ruimtelijk ordening kader om planners (zowel op lokaal als regionaal niveau) te ondersteunen in het voorbereiden van deugdelijke informatie op grond waarop beslissingen over onder meer locatiekeuze van gevaarlijke industriële activiteiten, veilige afstanden, en restricties in landgebruik in de directe omgeving kunnen worden gemaakt. De voorgestelde methodiek richt zich op het gebruik van 'Multi-Criteria Decision Analysis' binnen de ruimtelijke ordening. Ten aanzien van landgebruik leiden alternatieve invullingen rond risicovolle locaties tot verschillende aanpakken en dientengevolge tot alternatieven binnen het MCDA paradigma. Anderzijds, als vastgehouden wordt aan bestaand landgebruik rond een locatie, dienen alternatieven te worden beschouwd bij een nieuwe installatie of uitbreiding van een bestaande installatie. In beide gevallen, echter, moeten de veranderingen in de risicobronnen een geografische dimensie hebben om aangemerkt te kunnen worden als een ruimtelijke ordening alternatief. Met deze gedachte in het achterhoofd is binnen de voorgestelde methodiek een gestructureerd format ontwikkeld waarmee planning alternatieven kunnen worden beoordeeld en vergeleken. Voor toepassing en visualisatie staat het gebruik van een GIS platform in de methodiek centraal; hiermee kunnen planners alternatieven genereren, het meest geschikte alternatief kiezen, en effectieve oplossingen onderzoeken voor resulterend landgebruik en daarmee samenhangende effecten.

Het succes bij toepassing van het voorgestelde raamwerk hangt evenwel af van verschillende factoren: de beschikbaarheid van actuele data of informatie betreffende de gevaarlijke industrieën, het landgebruik en de demografische samenstelling in het beschouwde gebied, overeenstemming over de te hanteren risico-evaluatie methode, de te gebruiken modellen voor effectberekening, en de uitwisseling van informatie onder belanghebbenden. Zo dient een risicoanalyse niet alleen het domein te zijn van een risico-analist, maar moet een besluitvormer of planner na een basistraining ook een dergelijke analyse kunnen maken. In geval van snel groeiende industriële gebieden moeten ruimtelijke planners in staat zijn om verschillende risico scenario's te beschouwen en deze ruimtelijk te confronteren met het huidige 
landgebruik om land te kunnen toewijzen voor toekomstige industriële ontwikkeling of voor woonbestemmingen.

De verwachting is dat de voorgestelde methoden een meer uitgebreide kalibratie en verfijning behoeven, wanneer deze worden onderworpen aan evaluaties door gebruikers, bijvoorbeeld via een workshop onder belanghebbenden. Vervolgonderzoek wordt wenselijk geacht ten aanzien van evaluatie van de methoden en het benchmarken van criteria voor de selectie van een ongevalsscenario, drempelwaarden voor effectbeoordelingen, en het gebruik van modellen voor effectberekeningen. 


\section{Author's biography}

Anandita Sengupta received her bachelor's degree in Geography from University of Calcutta in 2002. After that she received her first Masters' degree in Geography from Banaras Hindu University, Varanasi, India in 2004 and second Master's degree in Geohazards from erstwhile International Institute of Geo-information Science and Earth Observation (ITC) jointly with Indian Institute of Remote Sensing (IIRS), Dehradun, India in 2007. During her MSc study, she worked as an intern in European Commission funded project Environmental Risk

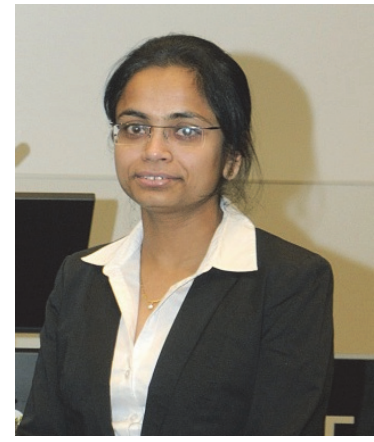
Reporting and Information System (ERRIS) implemented by the Indian Chamber of Commerce Kolkata in collaboration with ITC and Institute for the Protection and Security of the Citizen (IPSC), Joint Research Centre, European Commission Italy.

Prior to her PhD, she worked as a GIS assistant at the Dept. Of Architecture and Regional Planning, Indian Institute of Technology Kharagpur (IITKGP), West Bengal and as a research associate at The AC Nielsen ORG Marg, New Delhi. In 2009, after two years working on various projects for the government and various organizations, she moved to Netherlands for her PhD with the funding received from European Commission under its Erasmus Mundus program. As a part of her PhD, she worked as a research-trainee in the Major Accidents Hazardous Bureau (MAHB) under IPSC of the Joint Research Centre in Italy. In recent times, she was also engaged with the Safety Centre of the Indian Institute of Gandhinagar (IITGN) as a Safety Analyst. Her PhD research aims at conceptualizing different databases and geo-information techniques for assessing industrial risk and vulnerability for guiding a risk-informed decision making in an Indian context. This thesis is the outcome of her research.

\section{Author's publications}

\section{Peer-reviewed journal articles}

Sengupta, A., Bandyopadhyay, D., van Westen, C.J. and van der Veen, A. (2016) An evaluation of risk assessment framework for industrial accidents in India. In: Journal of Loss Prevention in the Process Industries, 41(2016), pp. 295-302.

Sengupta, A., Bandyopadhyay, D., Roy, S., van Westen, C.J. and van der Veen, A. (2016) Challenges for introducing risk assessment into land use 
planning decisions in an Indian context. In: Journal of Loss Prevention in the Process Industries, 42 (2016), pp. 14-26.

Sengupta, A., Lemmen, C.H.J., Devos, W., Bandyopadhyay, D. and van der Veen, A. (2015) Constructing a seamless digital cadastral database using colonial cadastral maps and VHR imagery: an Indian perspective. In: Survey review, (2015) IN PRESS $11 \mathrm{p}$.

Sengupta, A., Bandyopadhyay, D., van Westen, C.J., Krausman, E. and van der Veen, A. An indicator-based framework for building vulnerability assessment to industrial accidents (submitted in International Journal of Disaster and Risk Reduction).

\section{Book chapter}

Sengupta, A., Bandyopadhyay, D., van Westen, C.J. and van der Veen, A. (2014) Is a QRA-based method suitable to guide Land Use Planning decisions in India? in: Safety and reliability: methodology and applications: proceedings of the European safety and reliability conference, ESREL 2014, Wroclaw, Poland, 14-18 September 2014 / edited by T. Nowakowski et al. Boca Raton: CRC Press, 2014. ISBN: 9781-315-73697-6. pp. 1401-1409.

\section{Conference proceedings (full paper)}

Sengupta, A., Bandyopadhyay, D., Lemmen, C.H.J. and van der Veen, A. (2013) Potential use of LADM in cadastral data management in India. In: Proceedings of the 5th Land Administration Domain Model workshop, 2425 September 2013, Kuala Lumpur, Malaysia. pp. 311-328.

\section{$\underline{\text { Scientific and Professional Publications }}$}

Bandyopadhyay, D., Paul, N., Sengupta, A., van Westen, C.J. and van der Veen, A. (2013) Bridging industrial risk management deficits in India using a Geo - ICT based tool. In: Disaster management and risk reduction: role of environmental knowledge / ed. by A.K. Gupta et al. New Delhi: Narosa, 2013. ISBN 978-81-8487-251-4. pp. 99-110.

Sengupta, A., Bandyopadhyay, D., van Westen, C.J. and van der Veen, A. (2011) Adapting a quantitative risk assessment based method to guide land use planning decisions in India. Enschede, ITC, 2011. ITC Working papers series 8, ISBN: 978-90-6164-319-7.

Bandyopadhyay, D., Sengupta, A., van Westen, C.J. and van der Veen, A. (2011) Bridging risk management deficits in India using a geo - ICT based tool. Enschede, ITC, 2011. ITC Working papers series 7, ISBN: 978-906164-318-0. 
Sengupta, A., Bandyopadhyay, D., Lemmen, C.H.J. and van der Veen, A. (2012) Constructing a cadastral database using colonial cadastral maps and satellite imagery: an Indian perspective: e-book. International Federation of Surveyors (FIG), International Office of Cadastre and Land Records (OICRF), 2012. ISBN: 978-87-92853-00-4. 


\section{ITC Dissertation List}

https://www.itc.nl/Pub/research programme/Research-review-andoutput/PhD-Graduates 